\title{
STAC: the Severe Terrain Archaeological Campaign - investigation of stack sites of the Isle of Lewis 2003-2005
}

\author{
Ian McHardy,* Chris Barrowman* and Mary MacLeod ${ }^{I}$ \\ with
}

Ann MacSween, ${ }^{\dagger}$ Jo McKenzie ${ }^{\S}$ Susan Ramsay, ${ }^{\ddagger}$

Catherine Smith ${ }^{\dagger \dagger}$

Compiled and edited by Beverley Ballin Smith*

*Isle of Lewis; 'Western Isles Archaeologist, Comhairle nan Eilean Siar; ${ }^{\dagger}$ Historic Scotland, ${ }^{\ddagger}$ GUARD, University of Glasgow;

§University of Bradford; ${ }^{\dagger}$ Scottish Urban Archaeological Trust

Scottish Archaeological Internet Report 36, 2009 www.sair.org.uk 
Published by the Society of Antiquaries of Scotland, www.socantscot.org.uk with Historic Scotland, www.historic-scotland.gov.uk and the Council for British Archaeology, www.britarch.ac.uk

Editor Helen Bleck

Produced by Archétype Informatique, www.archetype-it.com

ISBN: 9780903903677

ISSN: $1773-3803$

Requests for permission to reproduce material from a SAIR report should be sent to the Director of the Society of Antiquaries of Scotland, as well as to the author, illustrator, photographer or other copyright holder.

Copyright in any of the Scottish Archaeological Internet Reports series rests with the SAIR Consortium and the individual authors.

The maps are reproduced from Ordnance Survey material with the permission of Ordnance Survey on behalf of The Controller of Her Majesty's Stationery Office. (C) Crown copyright 2001. Any unauthorised reproduction infringes Crown copyright and may lead to prosecution or civil proceedings. Historic Scotland Licence No. GD 03032G, 2002.

The consent does not extend to copying for general distribution, advertising or promotional purposes, the creation of new collective works or resale. 


\section{CONTENTS}

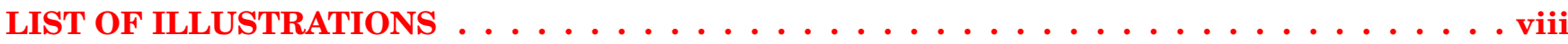

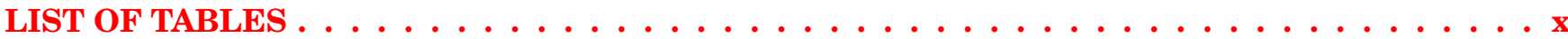

\section{PART I THE STAC PROJECT}

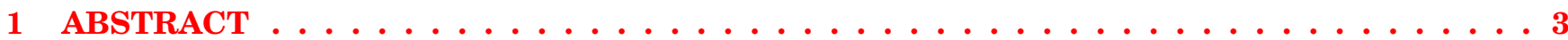

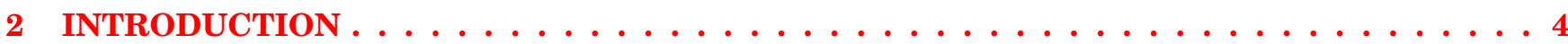

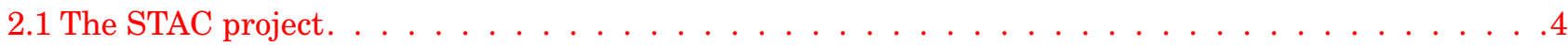

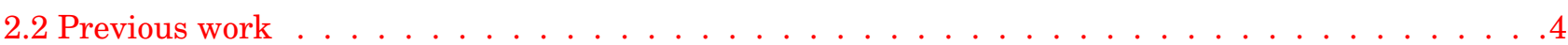

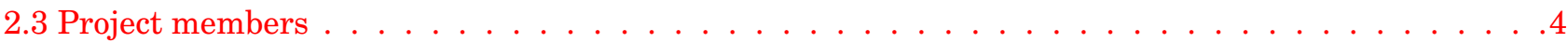

3 THE FORMATION AND LOCATION OF STACKS IN LEWIS . . . . . . . . . . . . . . . . . 5

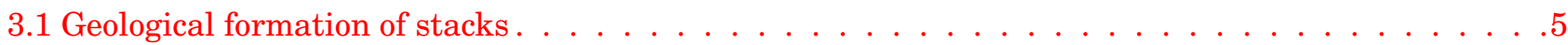

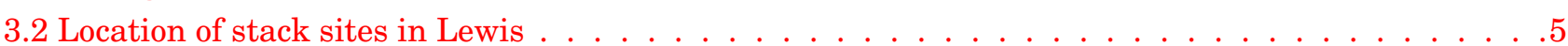

3.3 Sea level rise and erosion . . . . . . . . . . . . . . . . . . . . . . . . . . .

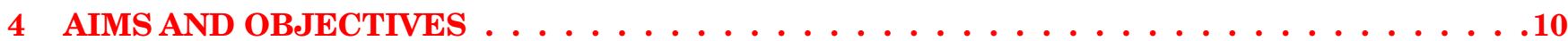

4.1 Research design . . . . . . . . . . . . . . . . . . . . . . . . 10

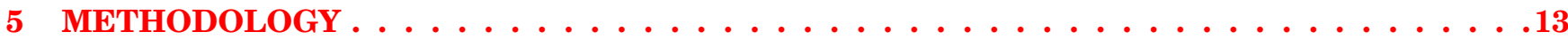

5.1 Rope access methodologies - industrial rope access $\ldots \ldots \ldots \ldots$. . . . . . . . . . 13

5.2 Rope access and the STAC project. . . . . . . . . . . . . . . . . . 13

5.3 Topographic survey methods. . . . . . . . . . . . . . . . . . . . . . . . 13

5.4 Field methodology . . . . . . . . . . . . . . . . . . . . . . . 14

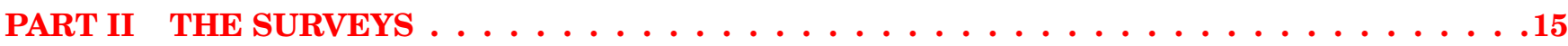

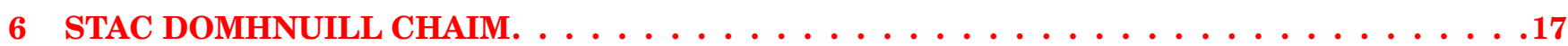

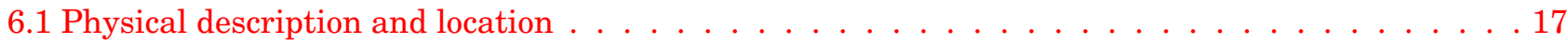

6.2 Erosion . . . . . . . . . . . . . . . . . . . . . . . . . . . 17

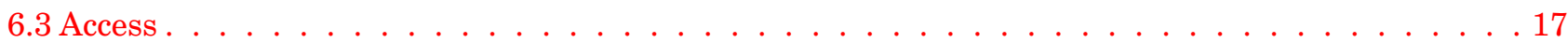

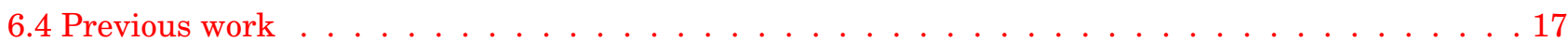

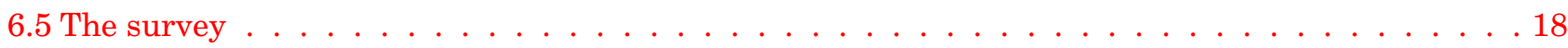

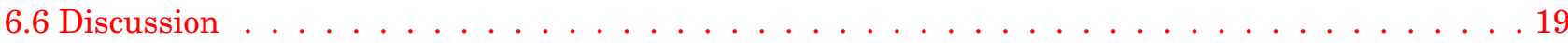

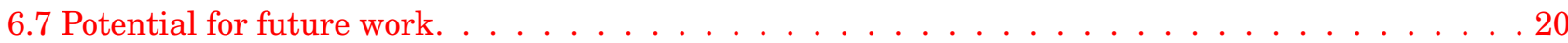




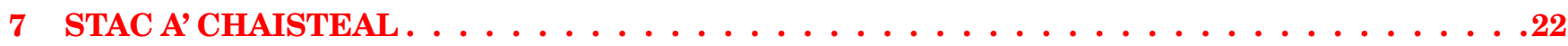

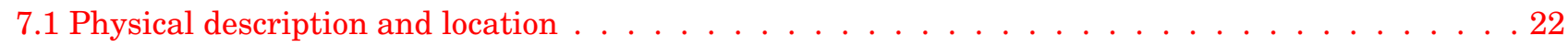

7.2 Erosion . . . . . . . . . . . . . . . . . . . . . . . . . 22

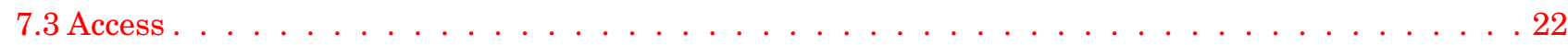

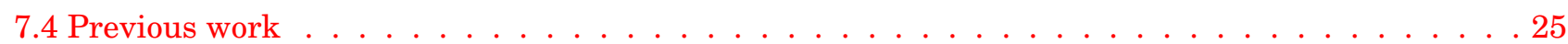

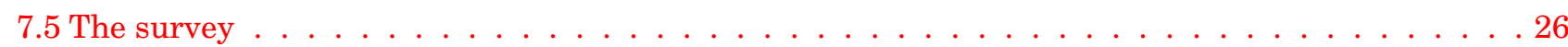

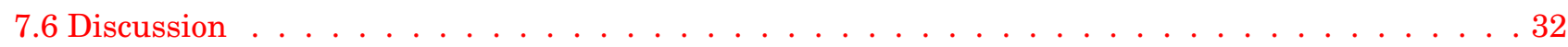

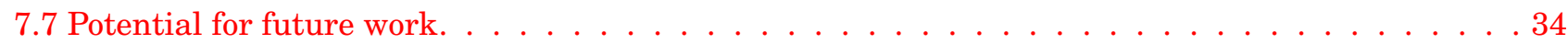

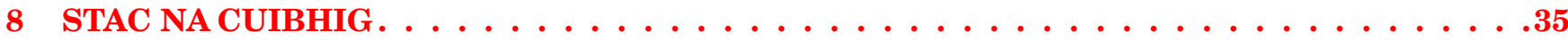

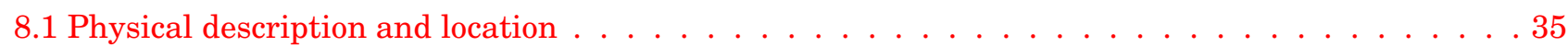

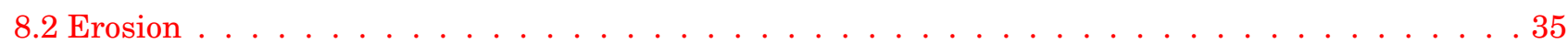

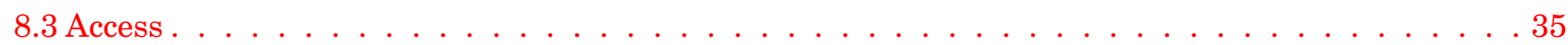

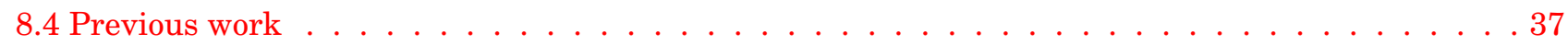

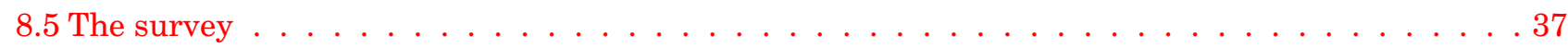

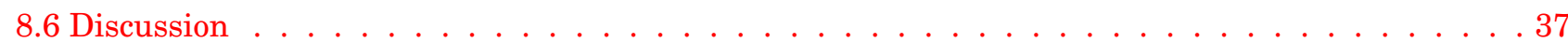

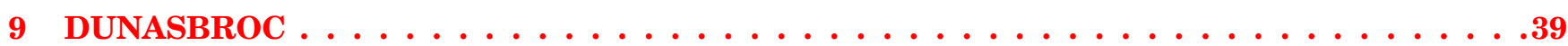

9.1 Physical description and location . . . . . . . . . . . . . . . . . . . . . 39

9.2 Erosion . . . . . . . . . . . . . . . . . . . . . . . . . . . 39

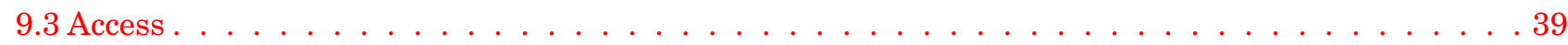

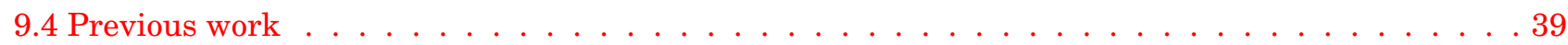

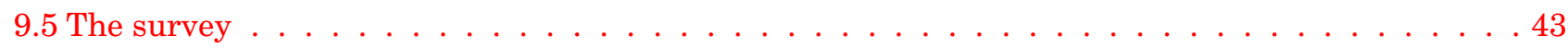

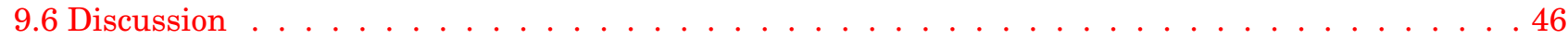

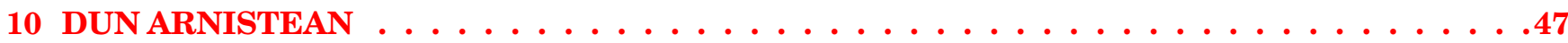

10.1 Physical description and location $\ldots \ldots \ldots \ldots \ldots \ldots \ldots \ldots$

10.2 Erosion . . . . . . . . . . . . . . . . . . . . . . . 48

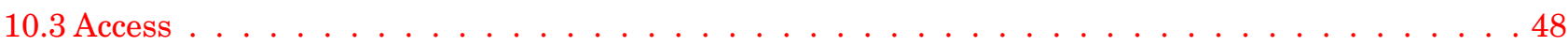

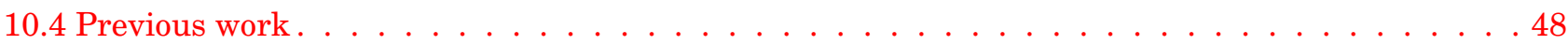

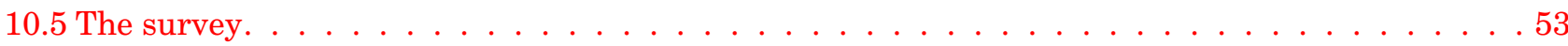

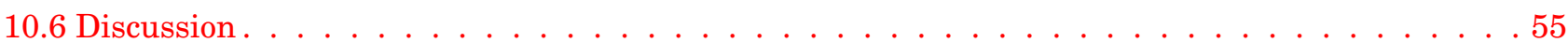

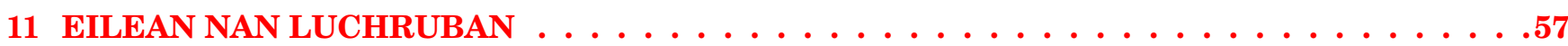

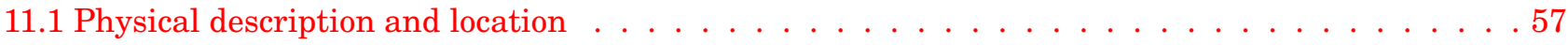

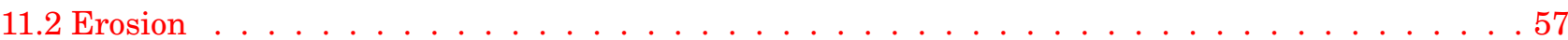

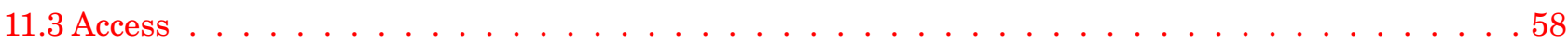

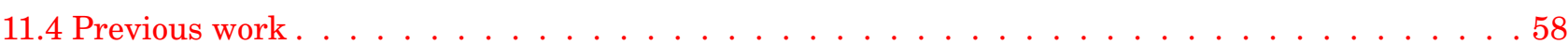

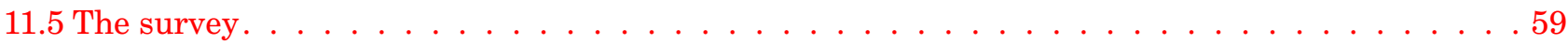

11.6 Discussion . . . . . . . . . . . . . . . . . . . . . . 61

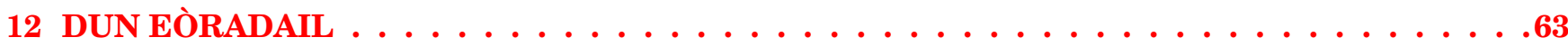

12.1 Physical description and location $\ldots \ldots \ldots \ldots \ldots \ldots \ldots \ldots \ldots \ldots \ldots$

12.2 Erosion . . . . . . . . . . . . . . . . . . . . . . . 63

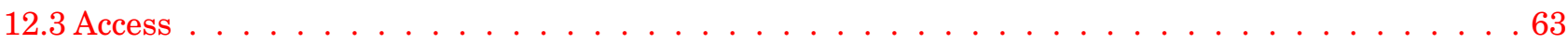

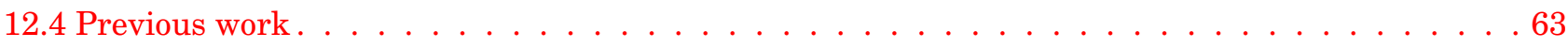

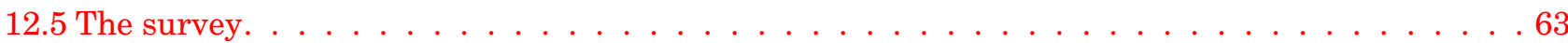




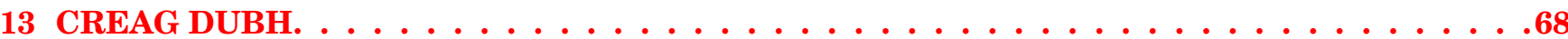

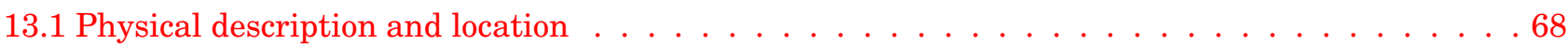

13.2 Erosion . . . . . . . . . . . . . . . . . . . . . . . . . 68

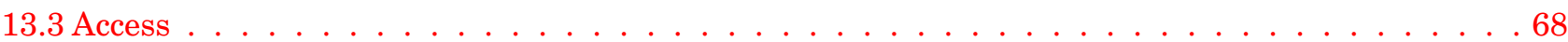

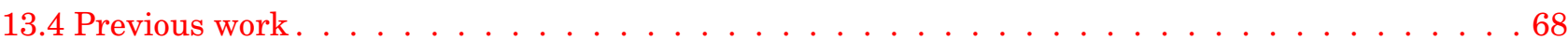

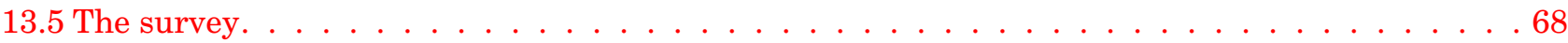

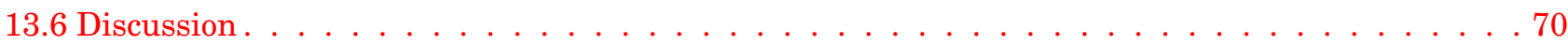

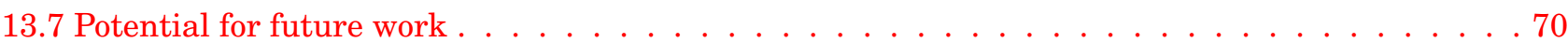

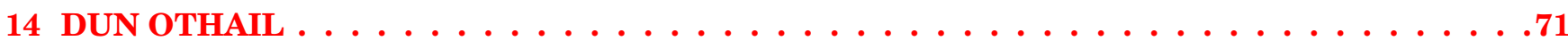

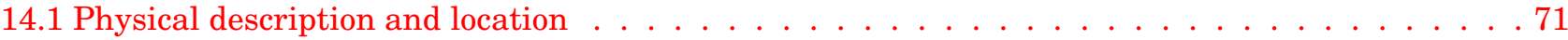

14.2 Access . . . . . . . . . . . . . . . . . . . . . . . . . . 71

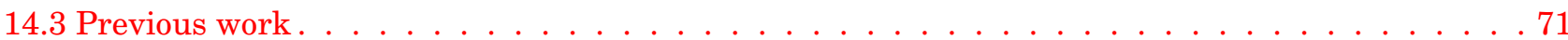

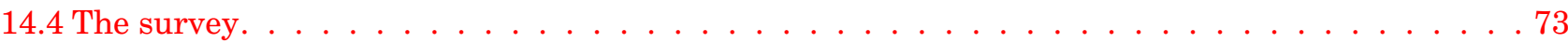

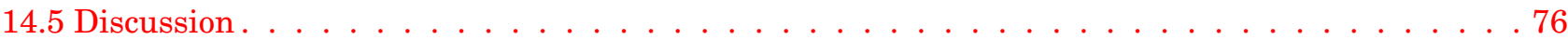

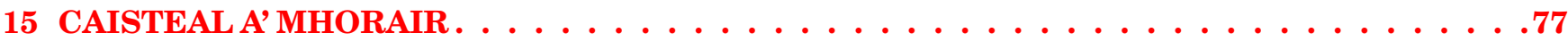

15.1 Physical description and location $\ldots \ldots \ldots \ldots \ldots \ldots \ldots \ldots \ldots$

15.2 Erosion . . . . . . . . . . . . . . . . . . . . . . . . 77

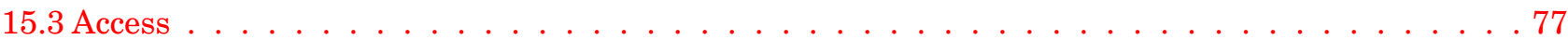

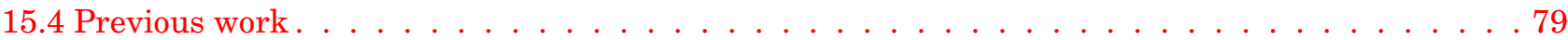

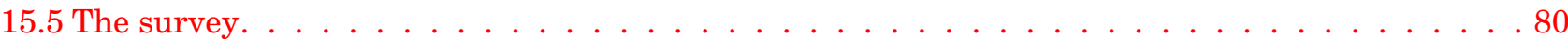

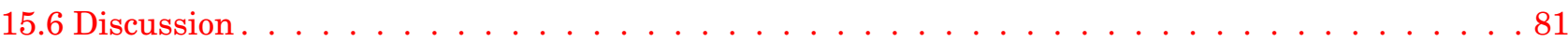

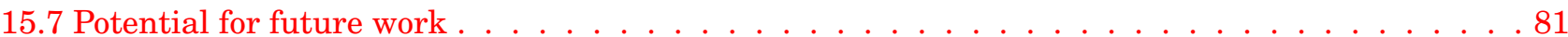

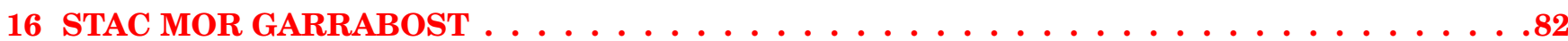

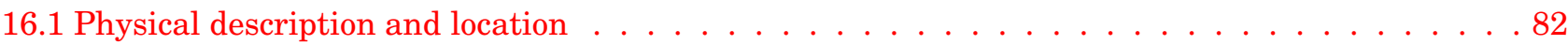

16.2 Erosion . . . . . . . . . . . . . . . . . . . . . . . . . 82

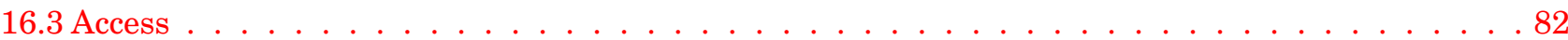

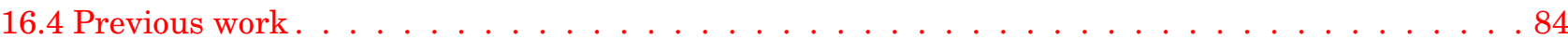

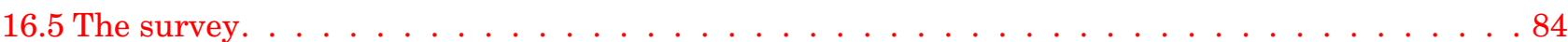

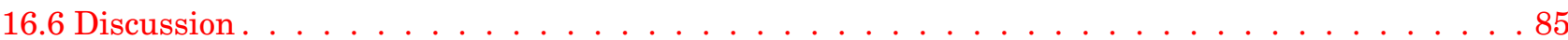

17 GENERAL DISCUSSION AND CONCLUDING COMMENTS $\ldots \ldots \ldots$

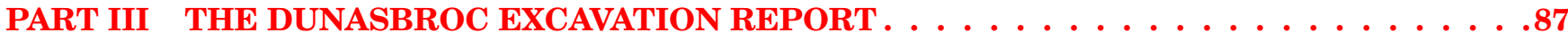

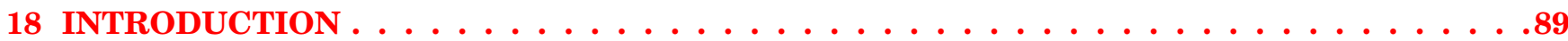

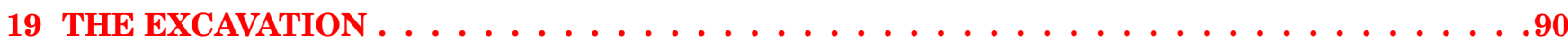

19.1 Trench $1 \ldots \ldots \ldots \ldots \ldots \ldots \ldots$

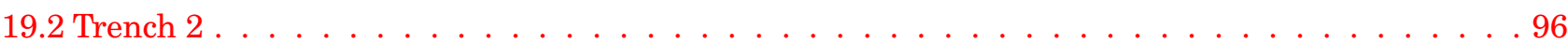




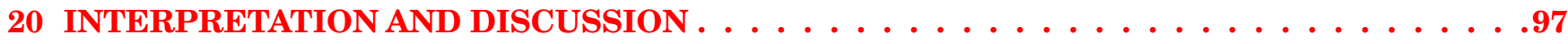

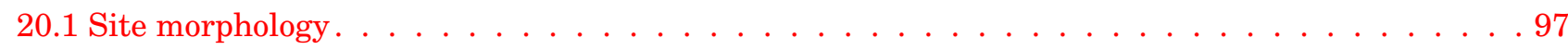

20.2 Neolithic use of the site . . . . . . . . . . . . . . . . . . . . . 97

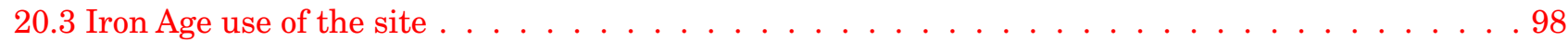

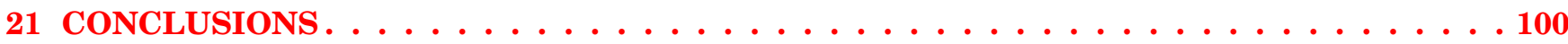

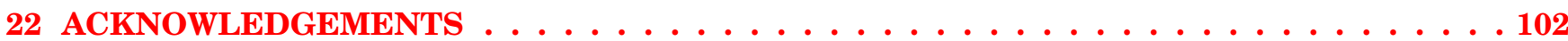

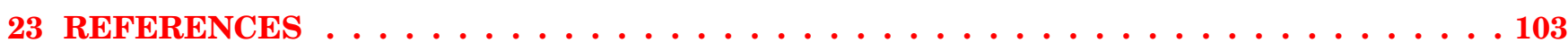

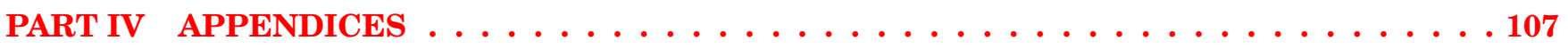

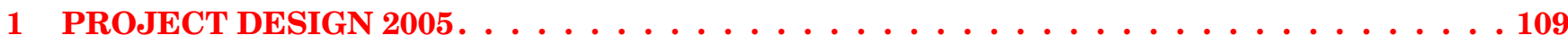

1.1 Summary . . . . . . . . . . . . . . . . . . . . . . . . . 109

1.2 Introduction and previous work . . . . . . . . . . . . . . . . . . 109

1.3 Management of the sea stack sites . . . . . . . . . . . . . . . . . . . . 109

1.4 Fieldwork . . . . . . . . . . . . . . . . . . . . . . . . . 110

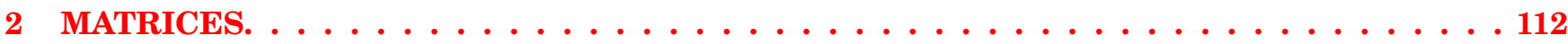

3 REPORT ON THE POTTERY WITH OBSERVATIONS ON NEOLITHIC POTTERY

FROM THE WESTERN ISLES, by Ann MacSween . . . . . . . . . . . . . . . . . 113

3.1 Introduction . . . . . . . . . . . . . . . . . . . . . . . . . . 113

3.2 Composition of the assemblages $\ldots \ldots \ldots \ldots \ldots \ldots \ldots \ldots$

3.3 Evidence from the sites . . . . . . . . . . . . . . . . . . . . . . . 122

4 THE LITHIC ASSEMBLAGE FROM DUNASBROC, by Chris Barrowman . . . . . . . . . . 125

4.1 Introduction . . . . . . . . . . . . . . . . . . . . . . . 125

4.2 Methodology . . . . . . . . . . . . . . . . . . . . 125

4.3 Raw material . . . . . . . . . . . . . . . . . . . . . . . . 125

4.4 Flake analysis . . . . . . . . . . . . . . . . . . . . . . . . . 130

4.5 Modified pieces . . . . . . . . . . . . . . . . . . . . . . . . . . 131

4.6 Contextual analysis . . . . . . . . . . . . . . . . . . . . . . 133

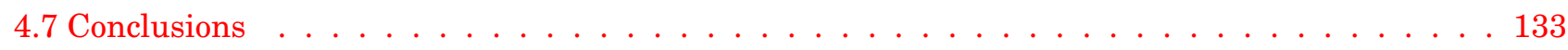

4.8 Flaked lithics from STAC 2004, surface finds . . . . . . . . . . . . . . . . . . 134

5 DUNASBROC 2005: STONE ARTEFACTS REPORT, by Chris Barrowman . . . . . . . . . . 136

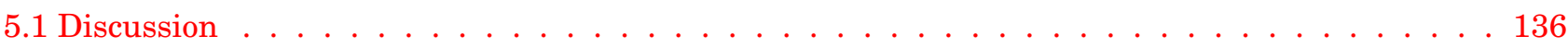

5.2 Contextual analysis . . . . . . . . . . . . . . . . . . . . 137

5.3 Stone from STAC $2003 / 2004 \ldots \ldots \ldots \ldots$

6 BOTANICAL REPORT FROM DUNASBROC, by Susan Ramsay . . . . . . . . . . . . . . 140

6.1 Summary . . . . . . . . . . . . . . . . . . . . . . . . . . 140

6.2 Introduction . . . . . . . . . . . . . . . . . . . . . . . . 140 
6.3 Methodology . . . . . . . . . . . . . . . . . . . . . . . . 140

6.4 Results . . . . . . . . . . . . . . . . . . . . . . . . 140

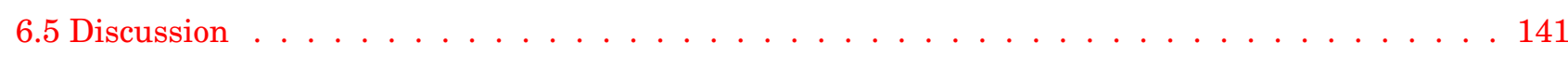

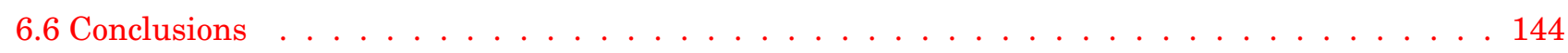

7 ANIMAL BONE REPORT FROM DUNASBROC 2005, by Catherine Smith . . . . . . . . . . 146

7.1 Introduction . . . . . . . . . . . . . . . . . . . . . . . . . . 146

7.2 Method . . . . . . . . . . . . . . . . . . . . . 146

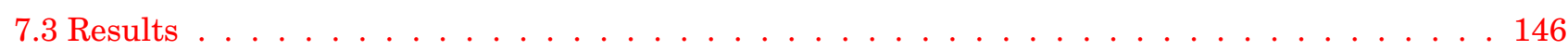

7.4 Discussion . . . . . . . . . . . . . . . . . . . . 146

8 SOIL MICROMORPHOLOGY REPORT FROM DUNASBROC, by Jo McKenzie . . . . . . . . . 148

8.1 Introduction . . . . . . . . . . . . . . . . . . . . . . . . . . . 148

8.2 Methodology . . . . . . . . . . . . . . . . . . . . . . . 148

8.3 Results and discussion $\ldots \ldots \ldots \ldots \ldots \ldots \ldots$

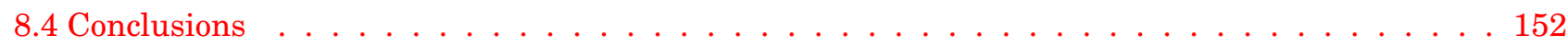




\section{LIST OF ILLUSTRATIONS}

Location map of stack sites investigated on Lewis . . . . . . . . . . . . . . . . . 11

Location map and topographic survey of Stac Domhnuill Chaim . . . . . . . . . . . . . . 16

Stac Domhnuill Chaim, looking south . . . . . . . . . . . . . . . . . . . 18

Stac Domhnuill Chaim from the north, showing structures on top of the stack . . . . . . . . 19

Neolithic pottery from Stac Domhnuill Chaim . . . . . . . . . . . . . . . . . . . . . 20

Location map of Stac a' Chaisteal and topographic survey . . . . . . . . . . . . . . . . . . 21

Stac a' Chaisteal from the south. . . . . . . . . . . . . . . . . . . . . . 22

Access onto Stac a' Chaisteal from the south . . . . . . . . . . . . . . . . . 23

Access onto Stac a' Chaisteal with descending sheep from the south . . . . . . . . . . . . 24

Stac a' Chaisteal structure A from the east. Scale $1.2 \mathrm{~m}$ long . . . . . . . . . . . . . . . . . 25

Stac a' Chaisteal structure B from the south. Scale $1.2 \mathrm{~m}$ long. . . . . . . . . . . . . . . . . . 26

Stac a' Chaisteal structure $\mathrm{C}$ from the west. Scale $1.2 \mathrm{~m}$ long $\ldots \ldots \ldots \ldots \ldots \ldots$

Stac a' Chaisteal structure D from the north-west. Scale $1.2 \mathrm{~m}$ long. . . . . . . . . . . . . . . . 28

Stac a' Chaisteal structure E from the south-east. Scale $1.2 \mathrm{~m}$ long . . . . . . . . . . . . . . . . 29

Stac a' Chaisteal structure F from the east. Scale $1.2 \mathrm{~m}$ long . . . . . . . . . . . . . . . . . 30

Stac a' Chaisteal structure $\mathrm{G}$ from the north-west. Scale $1.2 \mathrm{~m}$ long. . . . . . . . . . . . . . . 31

Stac a' Chaisteal SE corner of structure H from south-east . . . . . . . . . . . . . . . . . . 31

Stac a' Chaisteal NE corner of structure $\mathrm{H}$ from the north. Scale $0.4 \mathrm{~m}$ long . . . . . . . . . . . 32

Stac a' Chaisteal triangular lintel structure $\mathrm{H}$ from the north. Scale $1.2 \mathrm{~m}$ long . . . . . . . . . . 33

Stac a' Chaisteal revetment $\mathrm{M}$ from the north. Scale $1.2 \mathrm{~m}$ long . . . . . . . . . . . . . . . . . 34

Stac na Cuibhig from the WSW . . . . . . . . . . . . . . . . . . . . . . . . 35

Location map and topographic survey of Stac na Cuibhig . . . . . . . . . . . . . . . . 36

Detail of stone bank on Stac na Cuibhig from the north. Scale $1.2 \mathrm{~m}$ long . . . . . . . . . . . 37

Dunasbroc access from the west. . . . . . . . . . . . . . . . . . . . 440

Location map and topographic survey of Dunasbroc . . . . . . . . . . . . . . . . . . . 41

Map of trenches on top of Dunasbroc . . . . . . . . . . . . . . . . . . . . . 42

Erosion scar A, Dunasbroc from the east. Scale $0.3 \mathrm{~m}$ long. . . . . . . . . . . . . . . . . . . . 43

Walling in erosion scar D, Dunasbroc from the east. Scale $0.3 \mathrm{~m}$ long . . . . . . . . . . . . . 44

The level summit of Dunasbroc from the east . . . . . . . . . . . . . . . . . . . . . 45

Dun Arnistean from the east showing access route . . . . . . . . . . . . . . . . . 47

Location map and topographic survey of Dun Arnistean showing erosion scars . . . . . . . . . 49

General view of erosion scars on Dun Arnistean from the south-west . . . . . . . . . . . . . 50

The survey team descending ropes on Dun Arnistean from the east . . . . . . . . . . . . . . .51

The descent of Dun Arnistean from the east . . . . . . . . . . . . . . . . . . . . 52

Erosion scar F on Dun Arnistean from the west. Scale 0.3m long . . . . . . . . . . . . . . . . 53

The ash layer in erosion scar F, Dun Arnistean from the west. Scale $0.3 \mathrm{~m}$ long . . . . . . . . . 54

The erosion scar L, Dun Arnistean from the south-west. Scale $0.3 \mathrm{~m}$ long . . . . . . . . . . . . 55

Eilean nan Luchruban from the south . . . . . . . . . . . . . . . . . . . . . . 57

Mackenzie's plan of Eilean nan Luchruban. . . . . . . . . . . . . . . . . . . . . . . .58

Location map and topographic survey of Eilean nan Luchruban . . . . . . . . . . . . . 60

General view of structure A, Eilean nan Luchruban from the north . . . . . . . . . . . . . 61

Walling of structure A, Eilean nan Luchruban from the south . . . . . . . . . . . . . . . 61

Access to Dun Eòradail from the north . . . . . . . . . . . . . . . . . . . . . . . . 64

Location map and topographic survey of Dun Eòradail . . . . . . . . . . . . . . . 65

The cairn on Creag Dubh from the east. . . . . . . . . . . . . . . . . . . . . . 68

Location map and topographic survey of Creag Dubh . . . . . . . . . . . . . . . . . . 69

Dun Othail from the south . . . . . . . . . . . . . . . . . . . . . 71

Location map and topographic survey Dun Othail . . . . . . . . . . . . . . . . . 72

Accessing summit of Dun Othail from the south-east . . . . . . . . . . . . . . . . . . . . 74

Structure A, Dun Othail from the west. Scale $1.2 \mathrm{~m}$ long. . . . . . . . . . . . . . . . . . . . 75

Structure C, Dun Othail from the north. Scale $1.2 \mathrm{~m}$ long $\ldots \ldots \ldots$. . . . . . . . . . . . . 75

Structures F and G Dun Othail from the south-west. Scale 1.2m long . . . . . . . . . . . . 76

Caisteal a' Mhorair from the south . . . . . . . . . . . . . . . . . . . . . . . . .77

Location map and topographic survey Caisteal a' Mhorair . . . . . . . . . . . . . . . . . 78

Caisteal a' Mhorair structure A from the south. . . . . . . . . . . . . . . . . . . . . 79

Caisteal a' Mhorair structures B and $\mathrm{C}$ from the north . . . . . . . . . . . . . . 80 
Stac Mor Garrabost from the south . . . . . . . . . . . . . . . . . . . . . . 82

Location map and topographic survey Stac Mor Garrabost . . . . . . . . . . . . . . . 83

Wall on Stac Mor Garrabost from the north-west. Scale $0.3 \mathrm{~m}$ long . . . . . . . . . . . . . . . 84

Dunasbroc Trench 1 plan showing wall 025 and Context $002 \ldots$. . . . . . . . . . . . . . 91

Flue/drain feature in Trench 1, Dunasbroc from the north. Scale $0.3 \mathrm{~m}$ long . . . . . . . . . . . 92

Flue/drains beneath wall 025/026, Dunasbroc from the east. Scales $2 \mathrm{~m}$ long. . . . . . . . . . . 93

Sampling using Kubiena tins for micromorphological analysis . . . . . . . . . . . . . . . . . 94

Posthole 015/023 in Trench 1, Dunasbroc from the west. Scale $0.3 \mathrm{~m}$ long . . . . . . . . . . . . 94

Trench 2 plan and section, Dunasbroc . . . . . . . . . . . . . . . . . 95

Hebridean incised wares from Dunasbroc. Vessels 1, 3, 4, 5, 6, 7, 8, 9, 10 and $77 \ldots$. . . . 123

Lithic artefacts from Dunasbroc. SFs $4,5,9,15,33,86$ and $100 \ldots \ldots \ldots 131$

67

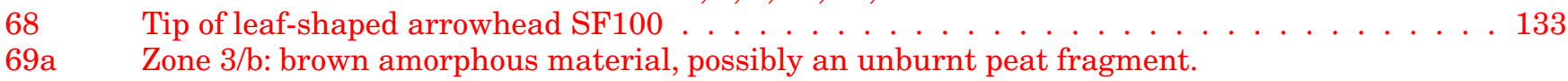

69a Zone $3 / \mathrm{b}$ : brown amorphous material, possibly an unburnt peat fragment. $\ldots \ldots \ldots \ldots \ldots \ldots \ldots \ldots$

69b Zone 3/b: grey crypto-crystalline features possibly representing fuel residue materials. Plane polarised light . . . . . . . . . . . . . . . . . . . . . . . . . . 151

69c Zone 3/b: as above, in oblique incident light. Bright yellow-white colour of possible fuel residue indicates high temperature heating. Note extensive reddening of surrounding soil matrix, indicative of comprehensive heating at $c 400-500^{\circ} \mathrm{C} \ldots \ldots \ldots \ldots \ldots 1 \ldots \ldots \ldots \ldots$ 


\section{LIST OF TABLES}

1

Gazetteer of all stack sites. . . . . . . . . . . . . . . . . . . . . . . . .7

Suitable sites for survey . . . . . . . . . . . . . . . . . . . . . . . . 10

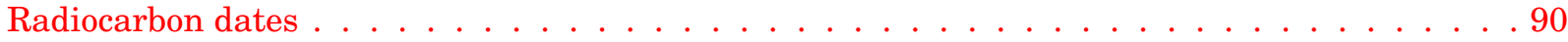

Catalogue of pottery from all sites. . . . . . . . . . . . . . . . . . . . . . . 114

Dunasbroc flaked lithics 2005 . . . . . . . . . . . . . . . . . . . . . . . . . . . 126

Composition of Dunasbroc assemblage . . . . . . . . . . . . . . . . . . . . . . 130

Size variation amongst flakes from Dunasbroc. . . . . . . . . . . . . . . . . . . . 130

Modified and retouched lithics from Dunasbroc . . . . . . . . . . . . . . . . . . . . . 132

Flaked lithics from STAC 2004 surface finds . . . . . . . . . . . . . . . . . . . . . . 135

Dunasbroc 2005 stone artefacts catalogue . . . . . . . . . . . . . . . . . . . . 136

Stone from STAC 2003/2004, surface finds . . . . . . . . . . . . . . . . . . . . . . . 137

Micromorphology of Slide 2 from Dunasbroc . . . . . . . . . . . . . . . . . . . . . . 138

Botanical results from Dunasbroc (bulk samples) . . . . . . . . . . . . . . . . . . . . . . . . . 142

Dunasbroc small find results and charcoal taxa . . . . . . . . . . . . . . . . . . . . . . 144

Catalogue of animal bone from Dunasbroc . . . . . . . . . . . . . . . . . . . . . 147 
PART I: THE STAC PROJECT 



\section{ABSTRACT}

The STAC (Severe Terrain Archaeological Campaign) project conducted topographic and archaeological surveys of sea stacks and other cliff-bound coastal sites around the Isle of Lewis over three annual field seasons from 2003-2005. The project made use of a specialised access system called 'Industrial Rope Access', which proved to be both a safe and a practical way of achieving archaeological research in such places. The first part of this report details the formation and methods of the STAC project, and discusses some relevant geographical issues. The second part presents the results of the eleven site surveys. One of these sites, Dunasbroc, was thought to be particularly vulnerable to erosion and was subject to small-scale excavation, the results of which form the third part of the report. 


\section{INTRODUCTION}

\subsection{The STAC project}

Coastal erosion is an acute problem throughout Scotland, but is most archaeologically damaging in the island groups of Orkney, Shetland and the Hebrides, which have very long and exposed coastlines in proportion to their land area. Since the 1980s, an assessment of the importance of threatened coastal archaeological sites has been undertaken by Historic Scotland (Ashmore 1994; Dawson 2003) throughout Scotland. This has involved several Coastal Assessment Surveys as well as a number of sample excavations on eroding sites (Ashmore 2003, 2). Management of coastal archaeology is an increasing problem and will become more so. There must therefore be further systematic work to catalogue and research coastal sites, to allow appropriate management decisions to be made.

Recent coastal erosion assessments commissioned by Historic Scotland in the Western Isles (eg Burgess $\&$ Church 1997) highlighted the presence of classes of coastal site about which very little is known, in particular, stack and promontory settlements. These sites are typically elevated and exposed, and therefore peculiarly and selectively vulnerable to erosion. In the proceedings of a Historic Scotland seminar on the problem of coastal erosion, Patrick Ashmore emphasised the threat to such sites, finding 'erosion of sites such as promontory enclosures on incised cliffs ... to be of main concern' (Ashmore 2003, 209).

The greatest obstacle to research on these sites has been the risk of access. In the Coastal Erosion Assessment, Lewis (CEAL), Burgess \& Church stated that "The majority of stack sites were inaccessible and hence viewed from the closest available cliff top' (Burgess \& Church 1997). The Severe Terrain Archaeological Campaign (STAC) was established as a pilot project in 2003 to take advantage of the skills and experience of a group of archaeologists with Industrial Rope Access qualifications (see Section 5.1), in order to overcome the risks of accessing such sites and was followed by two further seasons of survey and trial excavation in 2004 and 2005 (see Appendix 1 for the project design).

\subsection{Previous work}

A dedicated study of the promontory forts of Orkney and Caithness was carried out by Raymond Lamb in the 1970s (Lamb 1980). He found that a great many such sites were Iron Age, whether defensive (ibid, 65), concerned with status (ibid, 68), or else early medieval and monastic in function (Lamb 1976 and Lamb 1980, in preface; Lamb 1973, 1976, 1980). He did, however, speculate that the anomalous site of Brough Ness of Garth, Sandness, Shetland (amongst others), is so peculiar that one wonders whether it belongs to some other period than the Early Iron Age' (Lamb 1980, 68). More recent research and evaluation has revealed a wide chronological range for such sites, from the Neolithic to the sixteenth century (Branigan \& Foster 2000, 86; Burgess 1999, 93-104; Barrowman, C S 2002, 2004; forthcoming a \& b; Barrowman \& McHardy 2005; Barrowman R C 2006; and Brady et al 2000), and a similarly wide functional range must probably be assumed.

Rope access techniques have previously been used in Scotland on only two other archaeological sites, both of them coastal sea stacks. In 2000, access to Brei Holm, Papa Stour in Shetland, was established using industrial rope access techniques as part of the Viking and Early Settlement Archaeological Research Project (VESARP; Brady 2002). Similarly, in 2001 and 2002, access to Dun Eistean, off the east coast of Ness, in Lewis was achieved through rope access (Barrowman 2001, 9-10). Both sites were difficult to access although they were above the mean low water mark. The height and severity of the cliffs on the landward sides of the stacks warranted the use of specialist climbing techniques for safe navigation. A combination of industrial rope access techniques was therefore used, employing horizontal Tyrolean traverses and vertical fixed ropes to enable safe access onto the sites at most times.

\subsection{Project members}

In 2003, the STAC project was directed by Mary MacLeod, and staffed by Chris Barrowman, Mark Elliott and Ian McHardy (MacLeod 2003). In 2004, the project was co-directed by Chris Barrowman and Ian McHardy with the help of Mark Elliott in the field. The 2005 season was directed by Ian McHardy, with help from Mark Elliott and Graeme Laidlaw in the field. All members of the team were trained in rope skills prior to work commencing (see Section $5.1)$. 


\section{THE FORMATION AND LOCATION OF STACKS IN LEWIS}

\subsection{Geological formation of stacks}

A study of the coastal sites of Lewis must take into account the geological and geomorphological processes of site formation. The topography of the Lewis coastline is determined in part by the islands' underlying geology. The physical structure of the rocks at the shore determines the formation of stacks and inlets. Although in summary the solid geology of Lewis is relatively uniform, comprising Lewisian gneiss with metasediments and conglomerates in more localised areas, in reality, the more closely it is studied, the more complex it becomes (Angus 1997, 8).

However, the geology is only the medium from which the sculptured shoreline is made. The creation of the stacks, geos (inlets) and reefs of Lewis is also determined by other variables, including the prePleistocene landform, climate, marine variability, sea level rise and the availability of marine and organic sediment (Angus 1997, 84). The erosion of the coasts by the sea is the main influence acting on these variables. During severe winters the west coast of Lewis will be subject to breaking waves exerting a pressure exceeding 24 tonnes $/ \mathrm{m}^{2}$ (ibid, 87).

This continual bombardment of the coastline eventually compromises weak bedding planes and soft rocks, leading to the formation of a variety of different features depending on the geological structure of the bedrock. Where weaker or softer strata lie parallel to the shoreline across a peninsula, sea caves will form and eventually meet, leading to the creation of an arch, and following the collapse of the arch, to an isolated stack. If weaker rocks are perpendicular to the shoreline, geos and inlets will form.

The term 'stack' is difficult to define, but usually refers to an isolated pinnacle of rock entirely surrounded by the sea at high tide (Mellor 2002, 2). If its summit has a larger diameter than its height, then it is an island. Many of the sites included in this project are islands or promontories, despite being described as 'stacks' by their place names. For instance, Stac Domhnuill Chaim (see Section 6), and Stac a'Chaisteal (see Section 7), are both permanently joined to the mainland. The literal translation of the Gaelic stac given by 'Dwelly's dictionary' is 'precipice, steep, high cliff or hill' (Dwelly 1994), and usually applies to any topographic feature which has a pinnacle-like or hay-stack-like shape, including the mountains Stacaiseal, Lewis (NB 3065 3740) and Stac Pollaidh (NC 108 105) and Beinn Stac (NC 270 422) in the north-west Highlands.

\subsection{Location of stack sites in Lewis}

Chris Burgess undertook a large amount of research on promontory enclosures in Lewis throughout the 1990s (Burgess 1999, 2000); a research interest that developed from his work surveying the coastline of Lewis during the Coastal Erosion Assessment (Burgess 1999, 93). He admitted that the "promontory enclosure' description of these sites may well be an inaccurate one: many of the sites are not 'enclosed' but merely 'barred' (ibid), and tidal stack sites are also included in the overall term. He does however divide his general terminology into four sub-categories: promontories, headlands (both barred), coastal enclosures and stacks (which may be linked to or separated from the shore; ibid 96).

The CEAL survey classified 80 sites as promontory enclosures (Burgess 1999, 94). The general distribution of these sites covers much of the Lewis coastline but Burgess divided them into five general areas (ibid, 95-96).

Area 1 - Brenish, Islivig and Camas Uig (17 sites): typified by high eroding sea cliffs with a mixture of high and low promontories and several knife-edge stacks.

Area 2 - Bernera and the Loch Roag complex (12 sites): typified by low eroding edges punctuated by shingle beaches. This area includes Bernera and the Bhaltos Peninsula.

Area 3 - Garenin to Barvas (13 sites): dominated by high Atlantic cliffs with frequent promontories, interspersed with small bays of sand and shingle.

Area 4-North Galson, Ness and Skigersta (16 sites): dominated by machair to the west and high cliffs to the east all backed with flat croft land, this area is the smallest of the five. The coastline has a combination of extensive, low promontories and large eroding stacks on which sites are situated.

Area 5-Tolsta, Broad Bay and the Eye Peninsula (14 sites): this area is the most dispersed and covers the biggest geographic area, with high eroding sea cliffs to the north at Tolsta, and low eroding cliffs formed from soft conglomerate rocks in the Broad Bay area. The Eye Peninsula also has many high sea cliffs punctuated by stacks and promontories, with a change further south as the terrain becomes one of low eroding edges and gentle stacks.

Burgess noted that stacks and promontory enclosures are most common in Area 4, forming $25 \%$ of the 
sites there, with Area 1 having only slightly fewer. When the areas are combined, stacks and promontory enclosures make up 13\% of all sites. As noted on the table of stacks (table 1), five of the sites chosen for study by the STAC project fall into Burgess'Area 4 , which he found to have a very high frequency of stack sites. The rest are distributed evenly across the other areas described above.

\subsection{Sea level rise and erosion}

The relative sea level has an obvious bearing on the interpretation of the types of site being studied, especially as we now know that there was activity in such places as long ago as the Neolithic (see Discussion Section 17, and the report on Dunasbroc Part III Section 18). Were the archaeological structures built upon positions similar to what we now see, or were the structures built upon sites that were subsequently eroded into their present shape? There are two forms of evidence available to help answer this question - the scientific study of sea levels and coastal morphology, and the archaeology remaining on each site itself. Evidence for the latter will be discussed in the section on each site.

Differential isostatic uplift in northern Britain during the Holocene has combined with the general eustatic rise in sea level to create varying coastal effects. In an area encompassing the central belt and much of the Highlands of Scotland, sea level is falling in relation to the land, due to sea level rise being outpaced by the isostatic uplift. This uplift grades out to a zero isobase outside which the sea level is rising relative to the land.

There is consensus that the Western Isles are sinking into the sea. However, the rate at which this is happening seems to be a matter of debate. Professor J. Hansom, in Dawson $(2003,10)$ gives the figure as $0.7 \mathrm{~mm}$ per annum for recent sea level rises in Stornoway (modified after Carter 1988). However, this needs to be added to the figure for isostatic submergence to attain the relative sea level. New research in this field is likely to lead to significant changes to these figures ( $\mathrm{J}$ Hansom pers comm). As a working figure pending these changes, Ritchie (1985) estimates a coastal submergence of between $3 \mathrm{~m}$ and $5 \mathrm{~m}$ since $c 5164$ BP for the Uists, which he translates as an average relative sea level rise of less than $1 \mathrm{~mm}$ per year. There is, as yet, no data relating specifically to the north of Lewis (Professor A Dawson, pers comm).

The average of the above figures is $c 2 \mathrm{~mm}$ per year. From this it is possible to estimate that in the Iron Age the sea was $c 2 \mathrm{~m}$ lower; in the Bronze Age $c 4 \mathrm{~m}$ and in the Neolithic $c 5-7 \mathrm{~m}$. Detailed research into the seabed in each study area, combined with sea-level changes, could demonstrate the differences in coastline plan, for example, at Baile Sear, North Uist (Barber et al 2003). Unfortunately, highdefinition surveys of the inshore waters around Lewis are very rare and it was not possible to find sufficient data to attempt any kind of reconstruction coastal modelling which could have been added to the digital terrain modelling of each stack. However, in most cases (other than Caisteal a' Mhorair and Stac Mor Garrabost, see Sections 15 and 16) the sea bed appears to fall steeply away immediately from the stacks, leading to the working assumption that eight of the eleven sites may not have looked radically different from their present-day appearance, but they were a little taller.

Erosion has had a significant effect, as it would seem likely that the majority of the sites were joined to the mainland in prehistory, and probably started their lives as headlands or promontories, and some may even have had arches. Part of the attraction of such sites in prehistory, as it is today, was likely to have been their height, isolation and liminal placement on the boundary between sea and land. 


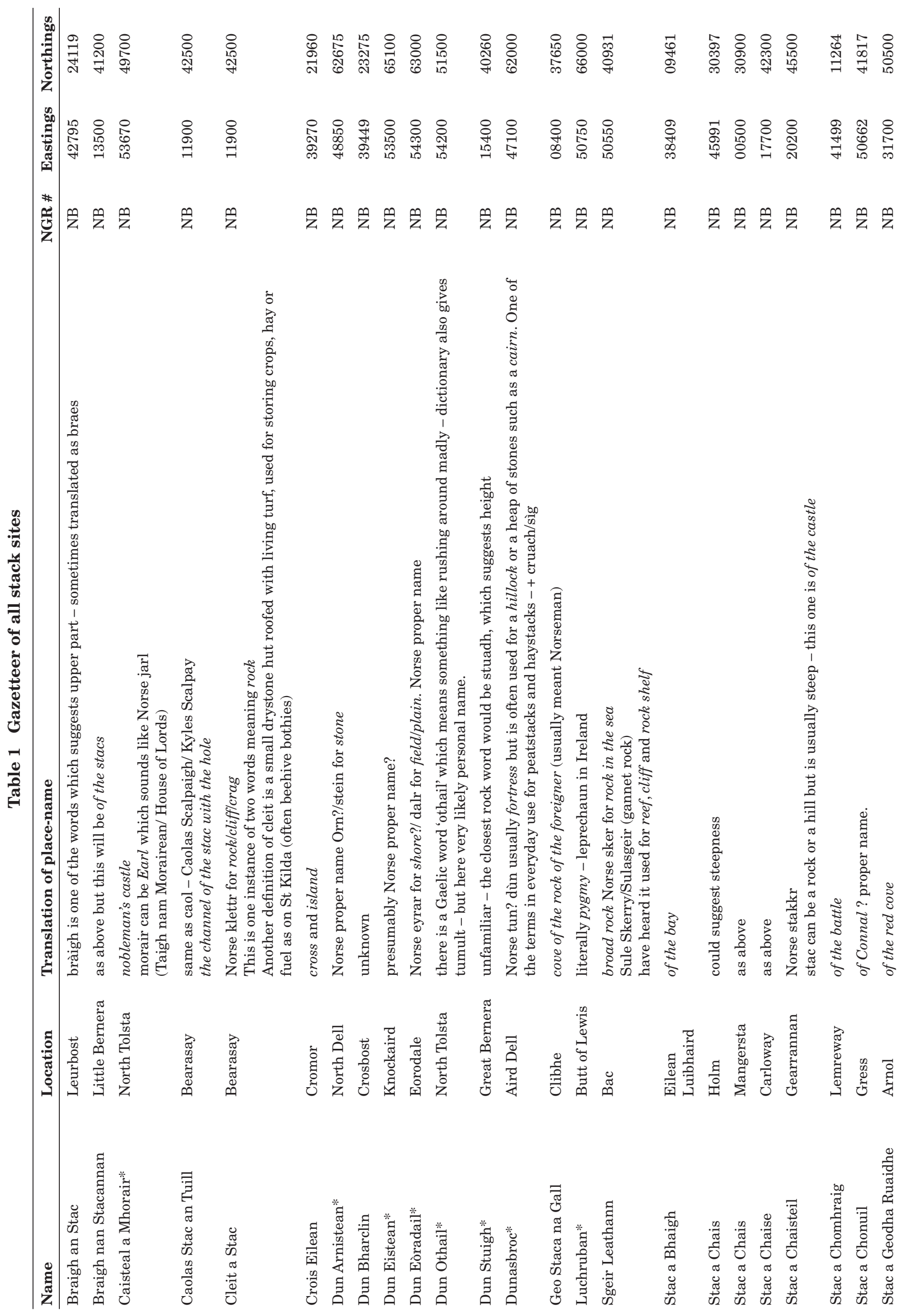




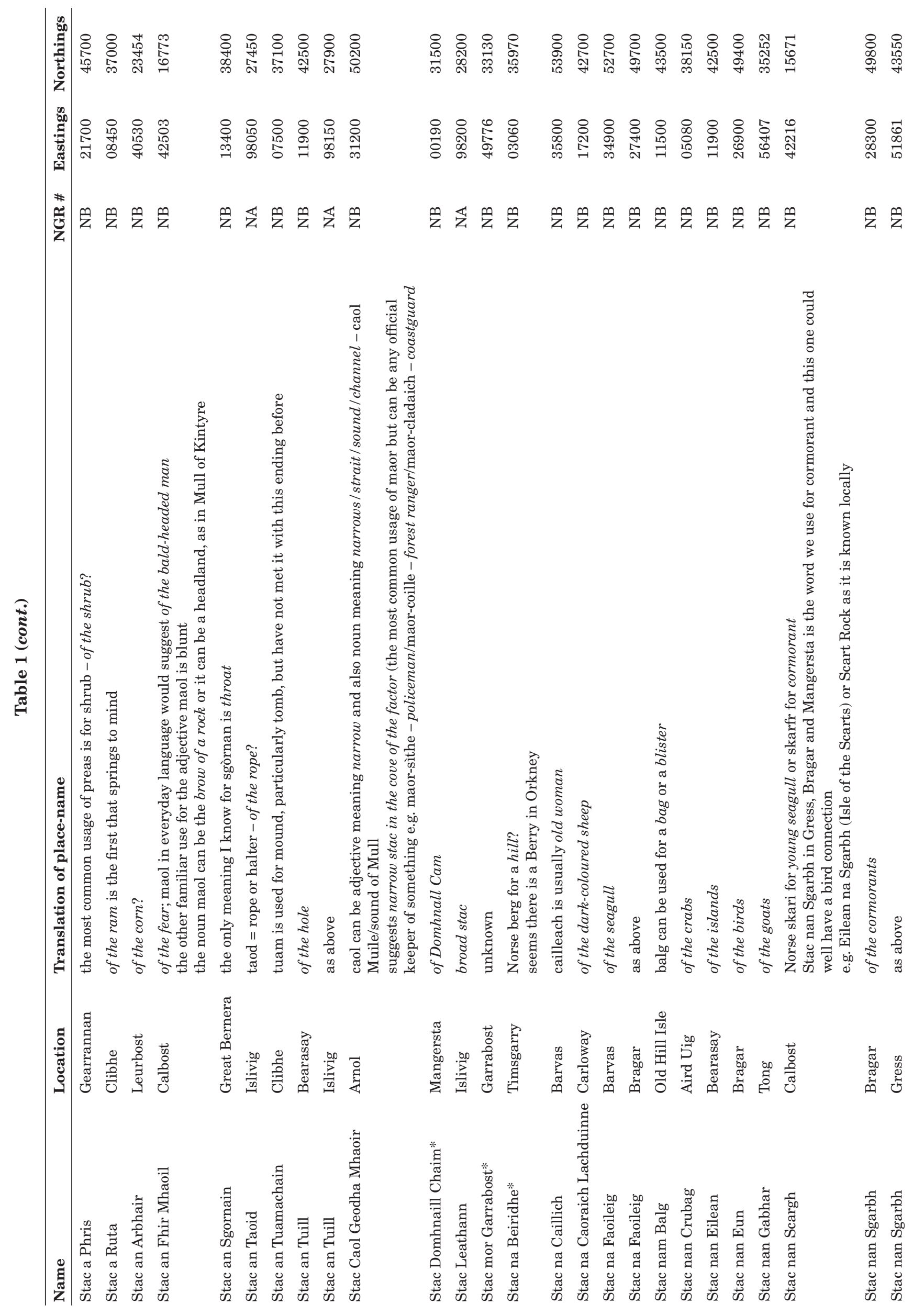




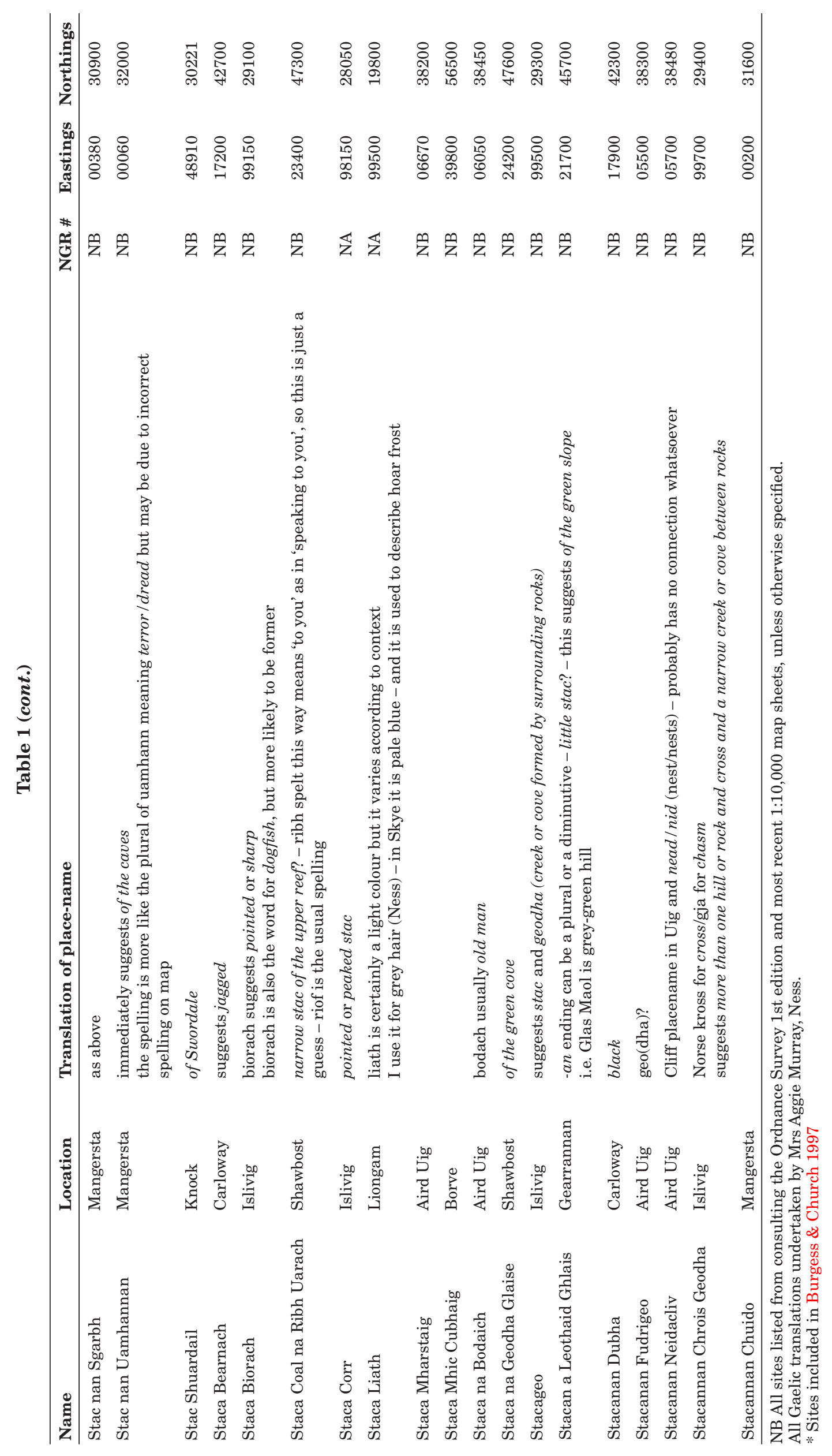




\section{AIMS AND OBJECTIVES}

\subsection{Research design}

The pilot study undertaken in 2003 looked at a variety of different sites including inter-tidal sea stacks, a promontory site and an inland cave site, all requiring ropes for access. An unsurveyed stretch of isolated coast was also walked by the team during the pilot study. Although all of these were valid research avenues, it was decided that the project team's time and experience could be spent more productively if the target sites were more selectively defined.

In order to make full use of the team's experience, it was decided that the project would only survey coastal sites that had access difficulties (Barrowman $\& \mathrm{McHardy} 2005$, 7-8), ie those inter-tidal or promontory sites that could only be accessed safely through the use of ropes. Although many promontory sites may require ropes to enable a safe environment for activities such as survey, they are often easy to access and do not require rope access skills to do so. Conversely, offshore sea stacks or islands have special access difficulties of which the team had little experience, and these were therefore excluded from the study.

However, there are hundreds if not thousands of promontories, tiny peninsulas, rocks and stacks along the coast of Lewis, many of which could possibly qualify for such an investigation. Many of these were named in the past, and a large proportion still retain those names. The majority probably have no structural remains on them, but were used in some way - even just as land/seascape identifiers - attesting to the importance of the coast in people's lives. A compilation of stac place names taken from the Ordnance Survey 1:10,000 scale maps (including the Ordnance Survey 1st edition series) along the $c$ $450 \mathrm{~km}$ stretch of Lewis coast from Uig to Stornoway, which had been surveyed by CEAL (Burgess \& Church 1997) found a total of 70 named stacks (see table 1, including their Gaelic translations). The majority of these had no structural remains on them, but the exercise demonstrated the frequency of the place-name element.

It was therefore decided that only inter-tidal or coastal promontory sites with access difficulties, and known but unsurveyed archaeological structures (whether having a 'stac' name or not), fell within the scope of the STAC project.

Using these criteria, 13 sites in total were suitable for further study (illus 1 and table 2). One of these sites had already been surveyed - Dun Eistean (Barrowman \& Driscoll 2000), and on another the structural evidence was natural rather than anthropogenic (Stac na Beirgh - a potentially significant

Table 2 Suitable sites for survey

\begin{tabular}{|c|c|c|c|c|c|c|c|}
\hline Name & Location & NGR & Eastings & Northings & 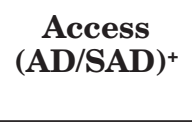 & $\underset{(\mathbf{Y} / \mathbf{N} / \mathbf{U})^{\dagger}}{\operatorname{Archy}}$ & $\begin{array}{l}\text { Erosion assessment } \\
(\% \text { estimate of surface } \\
\left.\text { area eroding }{ }^{\#}\right)\end{array}$ \\
\hline Stac a Chaisteil* & Carloway & NB & 20200 & 45500 & $\mathrm{AD}$ & $\mathrm{Y}$ & $60 \%$ \\
\hline Dun Arnistean* & Ness & NB & 48850 & 62675 & $\mathrm{AD}$ & $\mathrm{Y}$ & $75 \%$ \\
\hline Dun Eistean* & Ness & NB & 53500 & 65100 & $\mathrm{AD}$ & $\mathrm{Y}$ & $30 \%$ \\
\hline Dun Eòradail* & Ness & NB & 54300 & 63000 & $\mathrm{AD}$ & $\mathrm{Y}$ & $10 \%$ \\
\hline Dunasbroc* & Ness & NB & 47100 & 62000 & $\mathrm{AD}$ & $\mathrm{Y}$ & $30 \%$ \\
\hline Luchruban* & Ness & NB & 50750 & 66000 & $\mathrm{AD}$ & $\mathrm{Y}$ & $10 \%$ \\
\hline Caisteal a Mhorair* & North Tolsta & NB & 53670 & 49700 & $\mathrm{AD}$ & $\mathrm{Y}$ & $20 \%$ \\
\hline Dun Othail* & North Tolsta & NB & 54200 & 51500 & $\mathrm{AD}$ & $\mathrm{Y}$ & $5 \%$ \\
\hline Stac mor Garrabost & Point & NB & 49776 & 33130 & $\mathrm{SAD}$ & $\mathrm{Y}$ & $50 \%$ \\
\hline $\begin{array}{l}\text { Stac Domhnuill } \\
\text { Chaim* }\end{array}$ & Uig & NB & 00190 & 31500 & $\mathrm{AD}$ & $\mathrm{Y}$ & $50 \%$ \\
\hline Stac na Beirgh & Uig & NB & 03060 & 35970 & $\mathrm{AD}$ & $\mathrm{Y} ?$ & $60 \%$ \\
\hline Stacan Chuibhig & Dalbeg & NB & 22930 & 46560 & $\mathrm{AD}$ & $\mathrm{Y}$ ? & $40 \%$ \\
\hline
\end{tabular}

* surveyed previously (Barrowman and Driscoll 2000; Barrowman, McHardy and MacLeod 2004)

${ }^{+}$AD Access difficulties/ SAD Special access difficulties; ${ }^{\dagger}$ Y/N/U Yes/No/Uncertain

${ }^{*}$ Percentage based on an average assessment of amount of erosion relative to surface area of stack, $50 \%$ suggesting whole circumference eroding. 


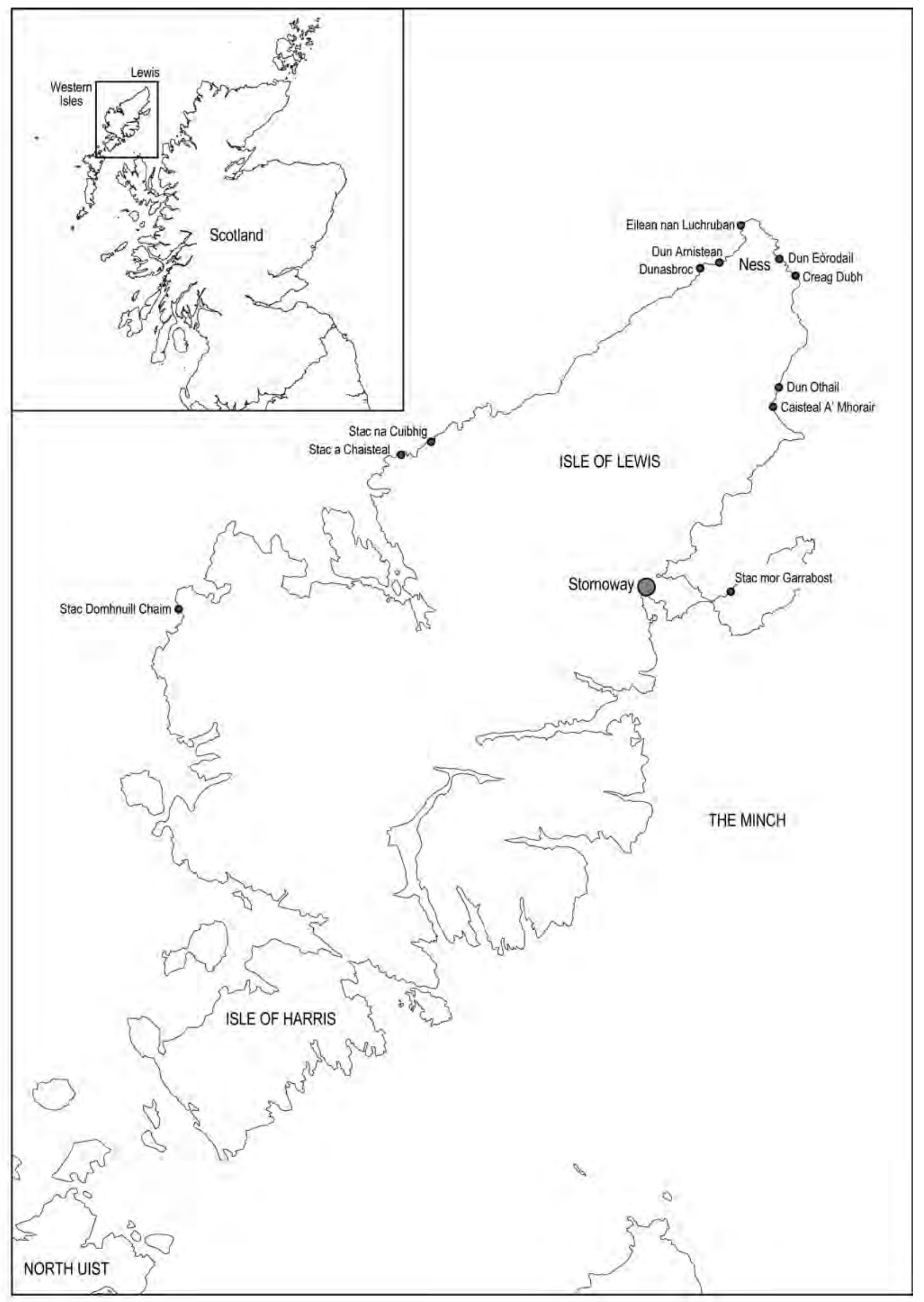

Illus 1 Location map of stack sites investigated on Lewis 
name nonetheless, see Section 6.6 on Stac Domhnuill Chaim). This left eleven stacks to investigate; Stac Domhnuill Chaim, Stac a' Chaisteal, Stac an Cuibhig,
DunArnistean, Dunasbroc, Luchruban, Dun Eòradail, Creag Dubh, Dun Othail, Caisteal a' Mhorair and Stac Mor Garrabost. 


\section{METHODOLOGY}

\subsection{Rope access methodologies - industrial rope access}

Industrial Rope Access is a system of access derived from rock-climbing and caving techniques, which have been adapted to suit industrial situations. Used extensively first on North Sea oil platforms, rope access has spread rapidly across many sectors of industry and throughout the world. Central to its continuing safety has been the formation of IRATA, the Industrial Rope Access Trade Association, a collective of rope access companies in the UK who standardised training and working procedures before any formal legislation. In training, a threelevel system was introduced, where a technician's responsibility increases with his or her knowledge and experience of rope access. A level 1 standard is the basic level, in which a technician can use all rope techniques and equipment safely but does not set up the equipment or bear full responsibility for others' safety, which is the role of the level-3 operative. Two examples of the types of working procedure introduced by IRATA are that every attachment has a back-up (and hence every person is attached to two ropes at all times), and that no one should access an area where they cannot be retrieved by the rest of the team, whether conscious or not.

IRATA has an unrivalled safety record for working at height: there have been no working-at-height fatalities in IRATA companies since IRATA records began in 1989, and greatly reduced incident statistics in general (see www.irata.org or www.hse.gov. $\mathrm{uk} / \mathrm{research} / \mathrm{rrpdf} / \mathrm{rr} 116 . \mathrm{pdf}$ ).

Many of IRATA's tenets are now enforced by law, in the British standards and Working at Height Regulations. This legislation means that it is now illegal to use less safety-conscious practices (such as those used in sport climbing or caving) for professional purposes.

The rope access methods and equipment used in the STAC project adhere to the Working at Height Regulations (WAHR 2005) and the British Standards (BS 8437: 2005) as well as satisfying the procedures and guidelines of the Industrial Rope Access Trade Association (IRATA). All equipment used had the relevant European Norm (EN) and CE marks. All STAC personnel were trained to IRATA level 1 standard, and were under the supervision of an IRATA level 3 supervisor, at all times.

\subsection{Rope access and the STAC project}

Specific access procedures are outlined for each site in the relevant sections of this report. In general, however, access routes for both the landward and the stack cliffs were selected by taking into account a variety of factors, most importantly the security of rock faces above the route, in case of rock fall, and the opportunity for safely fixing ropes. For this reason in some cases an apparently easy approach to the foreshore may not have been used (see Dun Arnistean access discussion, Section 10.3).

The anchoring of ropes in such isolated places was an issue that had to be resolved, and a number of different solutions were used or developed to suit the occasion. The simplest was to drive $1.5 \mathrm{~m}$-long stakes of angle-iron into the ground which were pointed at one end and provided with a hole to clip into at the other. Although very safe, this technique was not ideal for use in archaeologically sensitive areas. Also, the original versions were made from mild steel, which made them very heavy to carry across the moors, especially if using a sledgehammer to drive them in. Aluminium alloy versions were made, which could be driven in with rocks used as hammers found at each site. This technique was most often used on the mainland side of access routes, beyond areas of potential archaeology.

One of the safest ways of anchoring a rope to a rock face is through the use of bolts, stainless steel expansion bolts that lock into pre-drilled holes in the rock. Although these are very versatile and can be used anywhere with solid rock, the technique has the drawback of requiring heavy or inconvenient equipment including a large batterypowered hammer drill, the bolts themselves and an adjustable spanner for installation. Another semipermanent solution was to use 'pitons' or 'pegs'; variously shaped pieces of metal driven into cracks in the rock using a specialised hammer. These also have the drawback of being heavy and potentially awkward. Nevertheless bolts and pegs were used in many cases on the stacks or islands due to overriding safety considerations. Every effort was made to avoid leaving the remains of such equipment on the stacks.

In addition to the above, 'natural protection' was also used, ie various pieces or devices of metal designed to wedge into natural cracks or shapes in the rock, or slings looped over rock protrusions, and removed as the climbing continued. A variety of this type of equipment was used, including rp's, nuts, hexes, cams and friends.

\subsection{Topographic survey methods}

A Leica Electronic Total Station was used for the stack surveys. All data was logged using PENMAP 
4.34b Series 1000:600 software (Strata Software and Consultancy Ltd), and a hand-held Strata field computer.

More than two survey stations were required at many sites in order to attain complete coverage of hidden and seaward slopes. In addition to the archaeological features recorded as strings, a $c$ $1 \mathrm{~m}$ interval or less coverage of spot heights was recorded to allow the creation of a topographical model of the surface of each stack. These surfaces were defined as the area bounded by steep or vertical cliffs. Access routes were also surveyed. The high tide line was clearly visible at all the sites and was therefore used as an approximation for sea level, at Mean High Water Spring. The landward footprint of each site was accurately surveyed. However, the shape of the seaward side of each stack was usually reconstructed from photographs, due to time and safety considerations in all cases except Caisteal a' Mhorair and Dun Othail. Each survey was then tied into fence-lines, summits or other mapped features.

\subsection{Field methodology}

Once each site had been accessed successfully, a description and measured sketch drawing of all the archaeological structures was undertaken, with notes and photographs taken. The top of the stack was then mapped and any archaeological structures were outlined using the digital survey equipment. Progress was often slow, as each team member was required to be attached to a fixed rope at all times on the summit of each stack. 


\section{PART II: THE SURVEYS}

The results of the field surveys are presented clockwise from the south-west (illus 1). All place name spellings are in Gaelic as produced by the Ordnance Survey in the current map edition. 

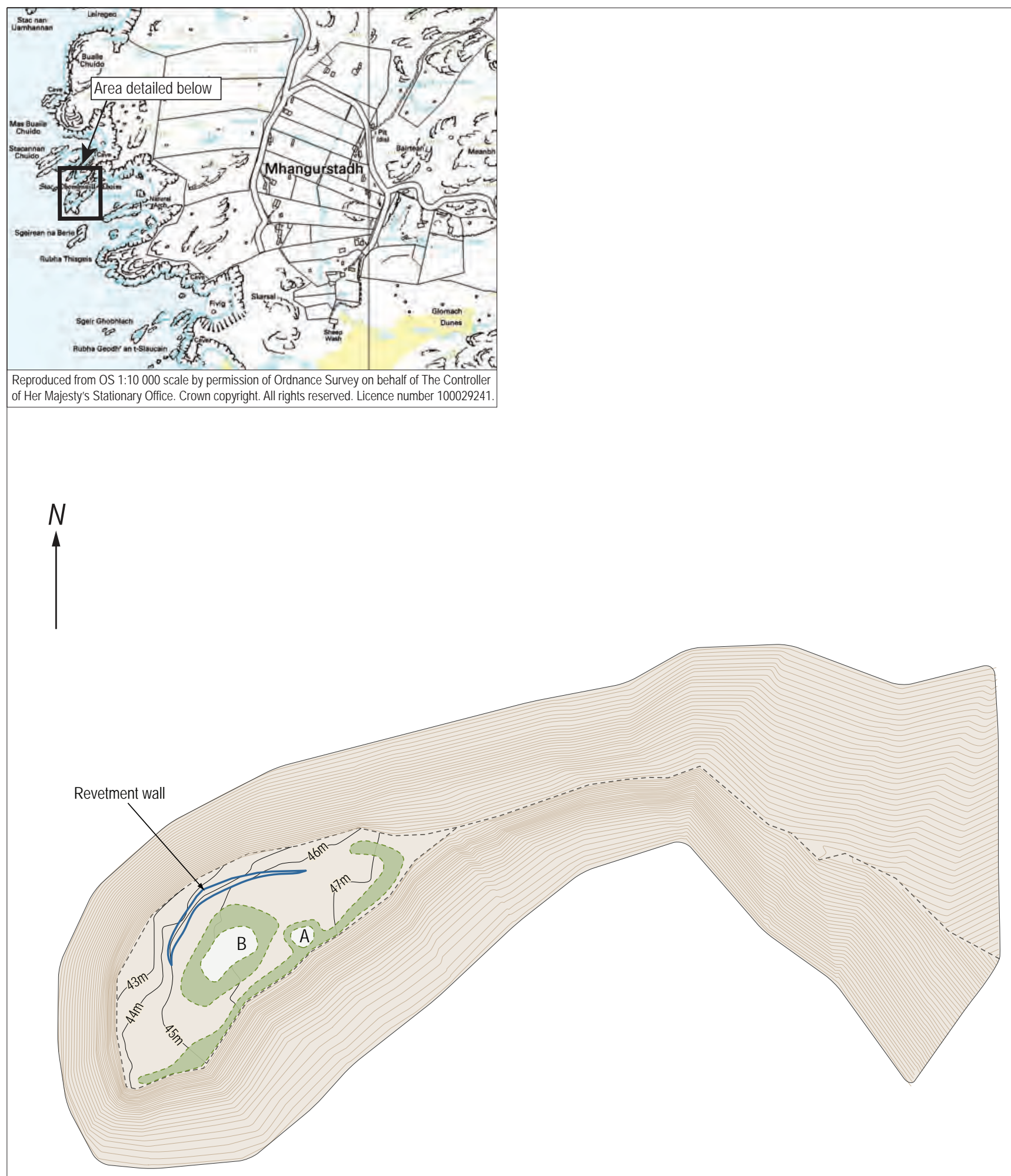

Cliff edge

KEY

Archaeological structure

Archaeological structure, heavily overgrown

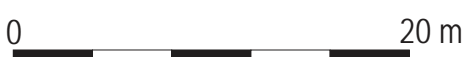




\section{STAC DOMHNUILL CHAIM}

\subsection{Physical description and location}

Stac Domhnuill Chaim is situated in common grazing land, $c 1 \mathrm{~km}$ WNW from the village of Mangersta, in the parish of Uig (NGR: NB 0022 3152; NMRS no. NB03SW1; SAM 5327). Oral tradition suggests that it was once a hideout and fortress. It is a very dramatically shaped stack, nearly $50 \mathrm{~m}$ high, but only $c 20 \mathrm{~m}$ in diameter on top, and is joined to the mainland via a $60 \mathrm{~m}$-long knife-edge or spine of rock (illus 2). The coastline comprises high, incised cliffs of Lewisian gneiss (Burgess \& Church 1997, 69) for many kilometres either side of the site, broken by Mangersta Beach $1 \mathrm{~km}$ to the south and by Camus Uig $6 \mathrm{~km}$ to the north.

\subsection{Erosion}

According to the Coastal Erosion Assessment, Lewis this area of coast is 'actively and rapidly eroding' (Burgess \& Church 1997, 67). This is clear when visiting the site. Local people confirmed that Stac Domhnuill Chaim was disappearing at a dramatic rate, particularly along the spinal ridge and the vertical cliffs at each end, where it seemed that the most active erosion was occurring. Access was made considerably more difficult and dangerous than it had been a mere ten years ago.

The archaeology is also threatened by erosion. Around the southern edge of Structure B, the main structure (illus 2 and below), occupation deposits were exposed in two erosion scars. The building was being undermined by erosion and was open to the full force of prevailing Atlantic conditions. The eastern, landward edge of the stack was also being progressively undercut, eroding a perimeter wall, and directly threatening Structures A and B. Further extensive erosion scars were discovered on the western side of the plateau when revisited in 2006 (see below). However, traces of steps and a pathway could still be made out climbing the landward side of the stack, implying that the overall shape had not changed dramatically since it was last occupied, traditionally in the sixteenth century (MacDonald 1967).

\subsection{Access}

Access to the stack was probably the most difficult of all attempted. A vertical cliff of $c 20 \mathrm{~m}$ was the first obstacle, leading to a thin spine covered in loose, fallen blocks. The spine dropped and then rose to the foot of the stack proper over a distance of $c 60 \mathrm{~m}$. Finally, a $30 \mathrm{~m}$ vertical ascent led to the summit (illus 3).

Two stakes were used to anchor a set of static ropes for the initial descent. Two rock bolts anchored further static ropes along the length of the spine. These ropes were used as protection to traverse the spine, with rock anchors fixed every $5 \mathrm{~m}$. It was necessary to knock off substantial amounts of loose stone blocks during the initial traverse. The final ascent was made using climbing techniques, with a combination of temporary rock anchors, pitons and rock bolts providing protection. One stake was fixed on the summit, which was positioned as far from the visible archaeology as possible. This stake and two rock bolts had to be left in the stack to provide protection for egress.

\subsection{Previous work}

Stac Domhnuill Chaim was amongst the coastal fortifications described by F W L Thomas in 1890 . At that time it was widely known as the refuge of Domhnall Cam MacAulaidh (Donald of the Squint), a 16th-century Uig hero and outlaw. Thomas described the site:

It is about 100 feet high, and on the top is not more than about 20 yards in length. A deep ravine cuts it off from the shore, which, however, remains connected with a rocky isthmus. The rock is otherwise surrounded by the sea, and is quite inaccessible, except on the land side, where a narrow path leads up the steep brae. A wall, from 4-5 feet thick, defends it on the land side, in which, at the south end, there is a gap or gateway, 2 feet wide. The gate would be extremely dangerous to force, as the cliff is close in front of it. There are the ruins of a cottage, $181 / 2$ by 10 feet interiorly, and the walls $4 \frac{1}{2}$ feet thick, on the terre pleine of the rock, as also a sheep-pen attached to the wall. (F W L Thomas 1890, 395)

A plan of the site is produced in the same article, which was presumably drawn by Rev. MacPhail in the $1860 \mathrm{~s}$, as much of the information on the archaeology of these sites was gathered by MacPhail for Thomas (Robson 2004). The original pencil drawing of this plan is held by the National Monuments Record, Edinburgh (Society of Antiquaries of Scotland Collection, DC25533, p 20). 


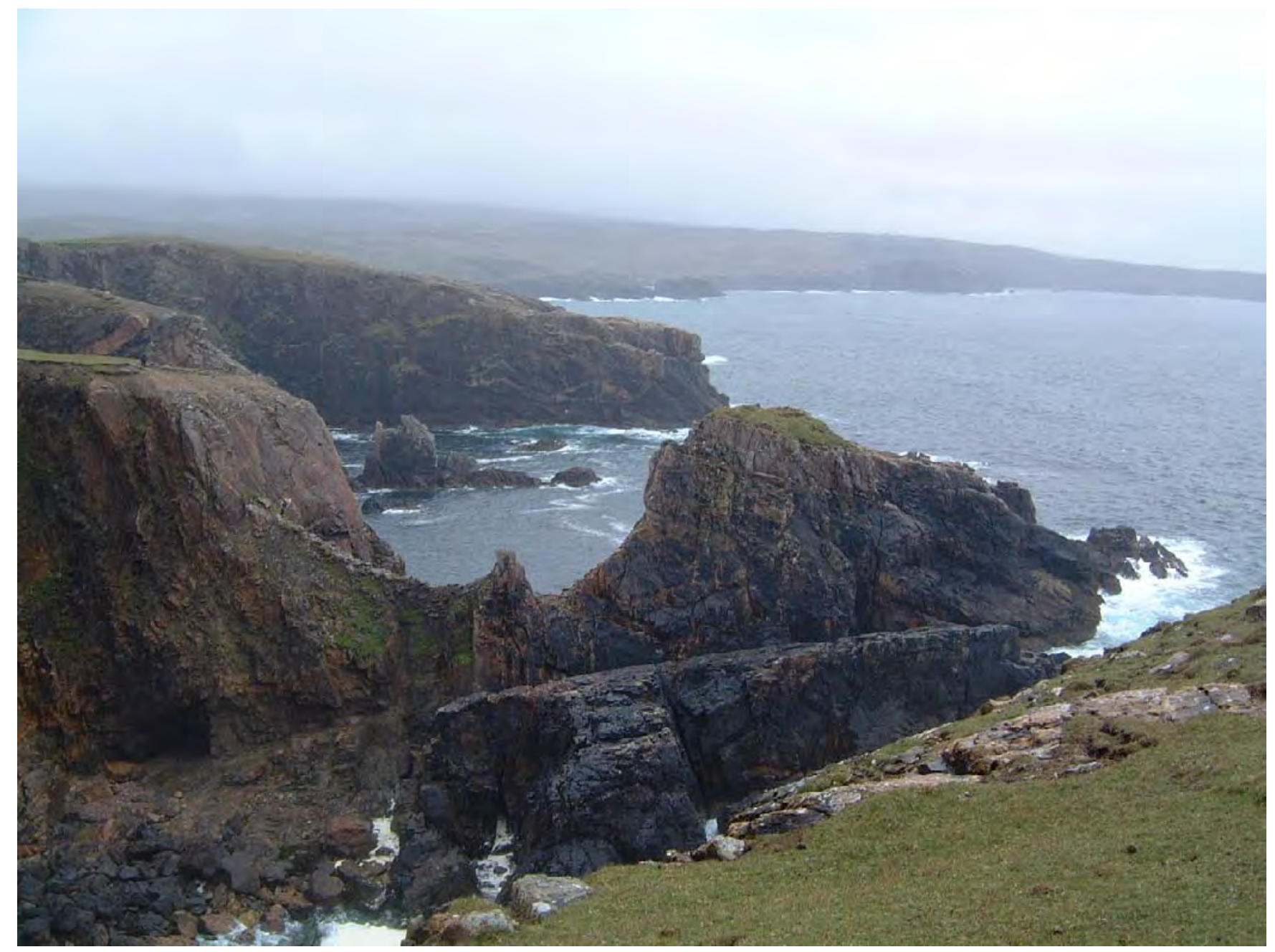

Illus 3 Stac Domhnuill Chaim, looking south

On the first edition of the Ordnance Survey map of the area, surveyed in 1852-3, the stack is shown with a clear access path along the spine joining the site to the mainland. It is given two alternative names, Stac Domhnuill Chaim and Stac na Beirgh (sic).

By 1969, when the site was visited by the Ordnance Survey once again, it was recorded as inaccessible due to cliff falls. However, the site continued to be visited by local people (without ropes) until the late 1980 s or early 1990 s, since which time most have perceived it as too dangerous (Jed Yates, Mangersta, pers comm).

A more recent sketch plan of features on the top of the stack was made by a visiting archaeologist in 1992 (E T Jones, now held in Western Isles SMR).

\subsection{The survey}

The archaeology on the summit was well described by Thomas (above), and little change was seen when visited by STAC. There were two buildings on the summit of the stack, Structures A and B. They were partly enclosed by a perimeter wall (Structure C), which also formed a small, enclosed courtyard at the north end of the site. A possible path led to the lower reaches of the stack on the west side, running from the courtyard, and parallel to Structure B (illus 4).

\section{Structure A}

Structure A was a small, $c 2 \mathrm{~m}$ internal diameter, circular turf and stone building adjoining the perimeter wall (Structure C) on the north-eastern edge of the stack. It had no apparent entrance, although a small break was shown in the middle of the west wall by MacPhail (Thomas 1890).

\section{Structure B}

Structure B was the remains of a sub-rectangular building, of stone and turf, $2 \times 6 \mathrm{~m}$ internally, $c 5$ $\times 10 \mathrm{~m}$ externally. There was no visible entrance, although one was shown to the south of the east wall by MacPhail (Thomas 1890). It occupied the centre of the stack, and was separated from Structure A by a narrow gap, which was likely to have been a wider passage in the past, before the walls of both structures slumped and broadened. The walls survived to a height of between $0.5 \mathrm{~m}$ and $1 \mathrm{~m}$.

Two base sherds of undecorated pottery were discovered outside the western end of the structure 


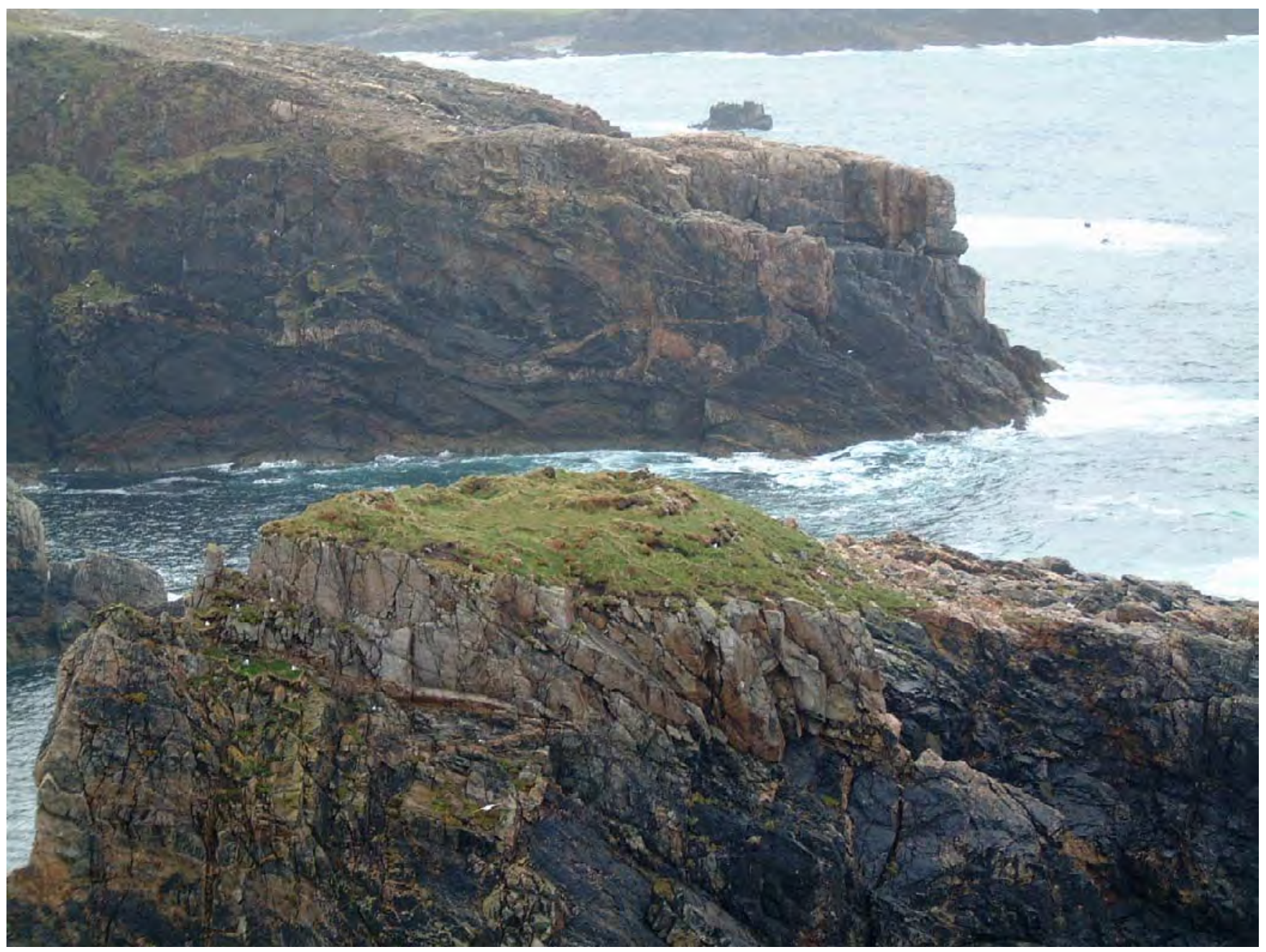

Illus 4 Stac Domhnuill Chaim from the north, showing structures on top of the stack

eroding from one of two open erosion scars. They are considered to be later prehistoric or medieval in date (see Appendix 3).

\section{Structure C}

Structure $\mathrm{C}$ was the perimeter wall. It was constructed of stone and turf, and extended from the northern end of the stack, down the eastern side, to its southern end. At this end the wall became harder to define, but it possibly enclosed two terraces, which occupied the southern end of the stack. Beyond and enclosing these lower terraces, a line of stones may have represented another wall.

A revetment wall, which may have been contemporary with the perimeter wall, appeared to support Structure B around the western edge of the stack. This formed part of a possible path which could be traced to the north-west corner of the site, leading to a small, enclosed area formed by the perimeter wall and the natural rock outcrops at the north end of the site.

\section{Western eroding scar}

A visit in 2006 led to the discovery of a new eroding scar on the western edge of the stack, $5-10 \mathrm{~m}$ west from, and $2-3 \mathrm{~m}$ down slope, of the structures. It measured $c 4 \mathrm{~m}$ long by $1.5 \mathrm{~m}$ high, and had two main deposits, one sealing the other. A pit containing a charcoal-rich soily fill was noticed cut into the lower deposit. The pit was V-shaped in profile, $c 0.3 \mathrm{~m}$ deep and the same in diameter. Some $0.5 \mathrm{~m}$ to the right and $0.2-0.3 \mathrm{~m}$ lower down from this pit a large body sherd of decorated pottery was discovered, which has since been assigned to the early prehistoric, possibly Neolithic period by Trevor Cowie at the National Museum of Scotland (illus 5).

\subsection{Discussion}

The first edition of the Ordnance Survey map for the district gave two alternative names for this site, Stac Domhnuill Chaim and Stac na Beirghe (sic). The latter name may be earlier than the former, as Gaelic beirgh derives from either the Old Norse berg meaning 'rock outcrop' which has been borrowed into Gaelic as beirgh 'coastal promontory (usually with narrow neck or isthmus)' (Cox 2006, 12), or the Old Norse borg, or fort. The name element beirgh is frequently associated with coastal archaeological 


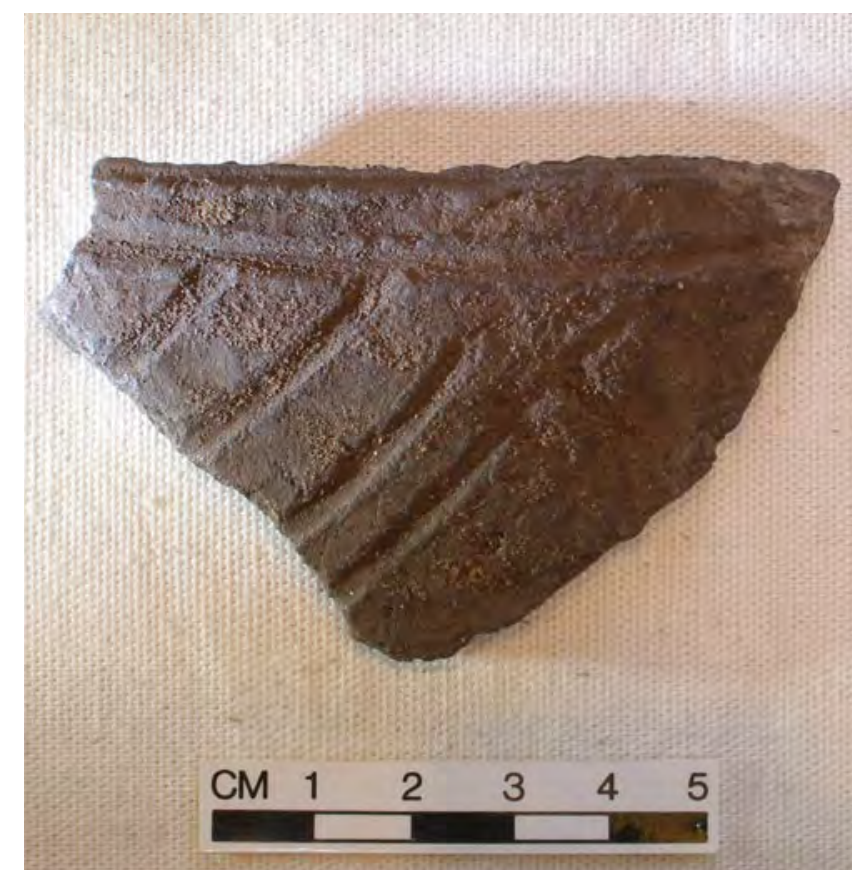

Illus 5 Neolithic pottery from Stac Domhnuill Chaim sites. The nomenclature may therefore suggest the possibility of an earlier occupation of the site prior to its use by the eponymous hero. This possibility seems to have been confirmed by the discovery of prehistoric pottery on the site, which parallels finds from Eilean nan Luchruban (see Section 11 below) and Dunasbroc (Section 9 below).

There was severe and rapid current erosion of both the archaeology and the access route, making future investigation more difficult and dangerous each year.

\subsection{Potential for future work}

Depending on winter storm conditions, it is possible that the next two decades may see the total destruction of this site. Some time before that it will become effectively inaccessible. It would therefore seem sensible that this site be subject to evaluation or small-scale excavation as a matter of some urgency. 


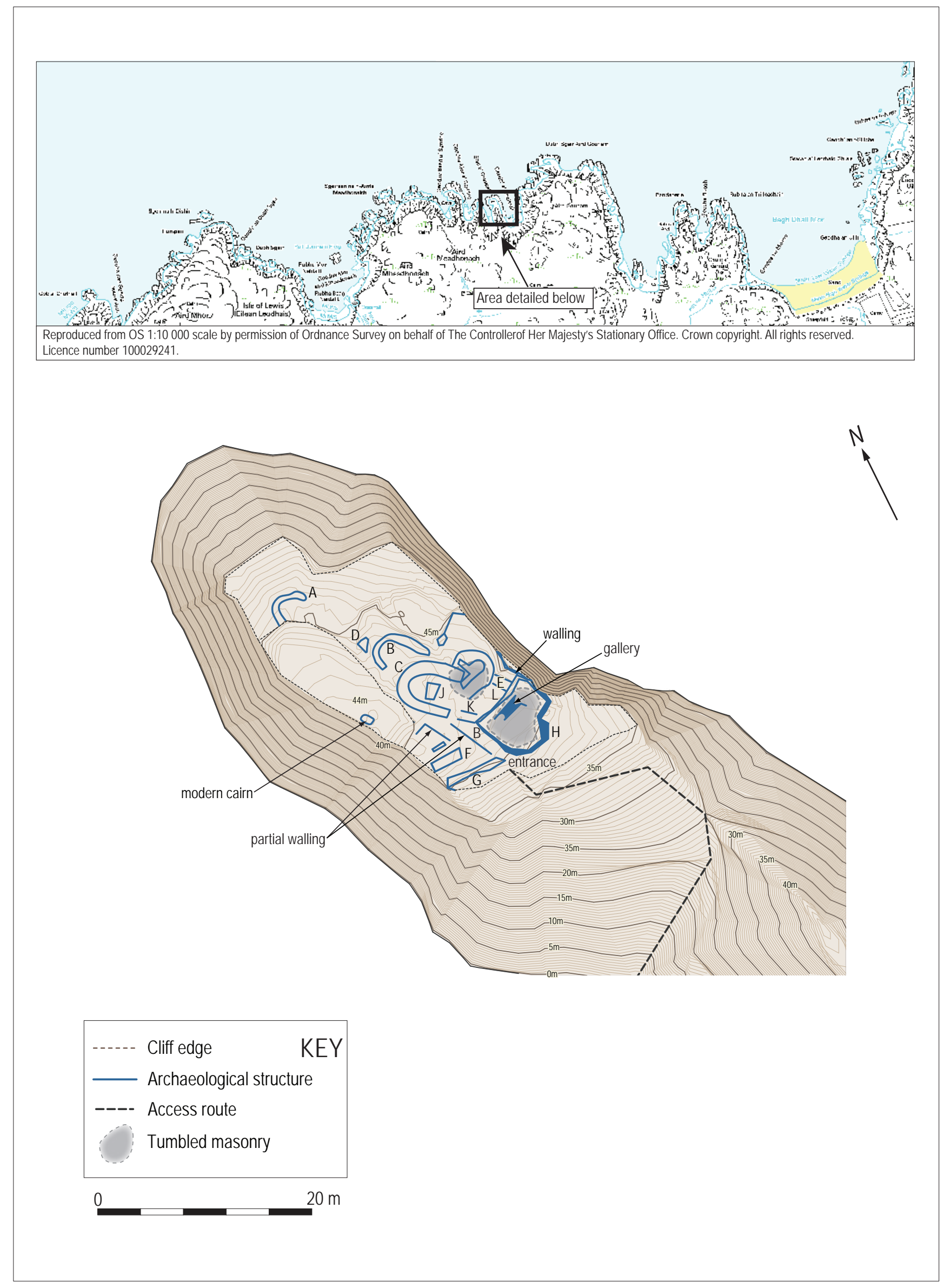

Illus 6 Location map of Stac a' Chaisteal and topographic survey 


\section{$7 \quad$ STAC A' CHAISTEAL}

\subsection{Physical description and location}

Stac a' Chaisteal (NMRS no. NB24NW 5) is located at NGR: NB 2024 4540, almost exactly halfway between the glens of Garenin and Dalmore in the parish of Uig, in the common grazing lands, $c 4 \mathrm{~km}$ from the nearest road end (illus 6). It is a pinnacle shaped stack, over $50 \mathrm{~m}$ high, and joined to the adjacent cliffs by a thin, $35 \mathrm{~m}$ long spine of rock (illus 7 ).

This site can be compared to Stac Domhnuill Chaim in relation to the modern settlement pattern. They both lie on the edge of the township's lands, away from the central focus of settlement, visually and geologically. Both stacks display the collapsed remnants of narrow promontories adjacent to high cliffs. A large natural amphitheatre is formed by the presence of more elevated promontories on the eastern and western sides of Stac a' Chaisteal, with the stack lying in the centre.

The cliffs surrounding the stack comprise basement Lewisian gneiss overlain by glacial till (Burgess \& Church 1997, 207). The bottom two thirds of the stack have rock shelves and sparse areas of vegetation covered in boulders which have

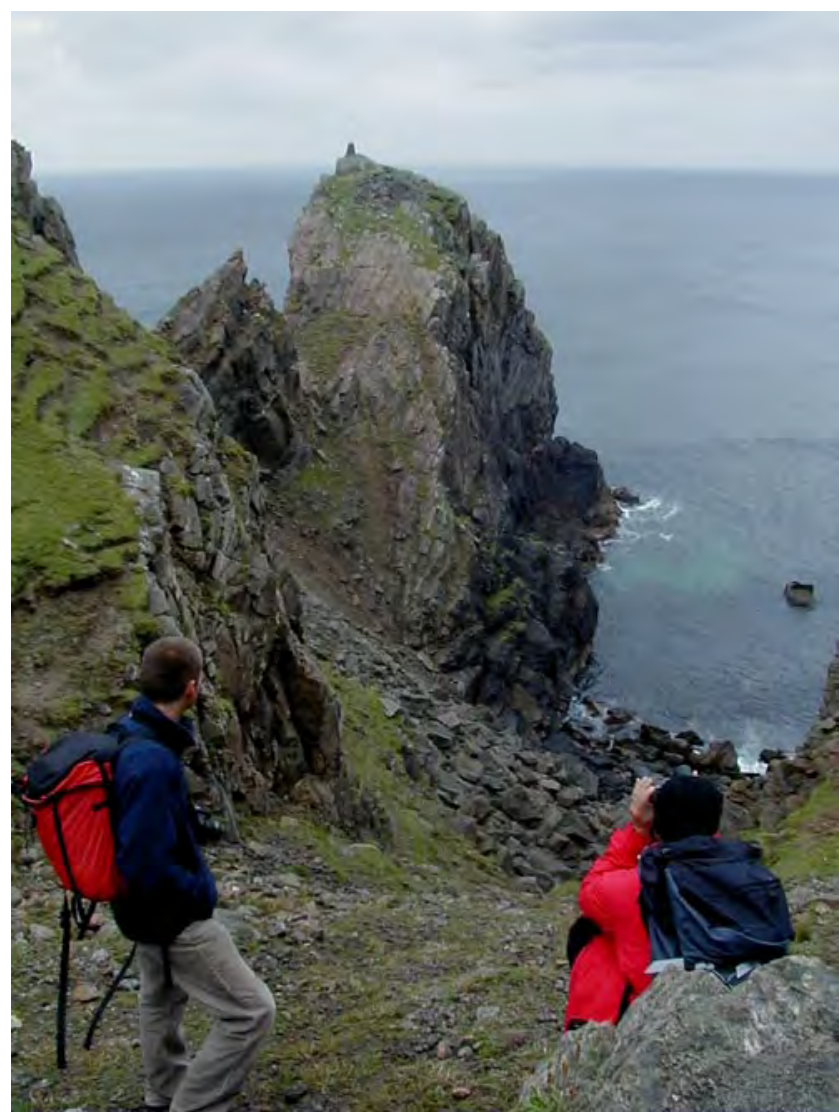

Illus 7 Stac a' Chaisteal from the south fallen from above. The top third comprises a rock slab or ramp which represents an entire bedding plane of Lewisian gneiss, as the strata along this length of coast lean out from the vertical, creating an acute angle to the sea. The seaward side of the stack forms a near-vertical cliff with a jagged crosssection through all the geological strata, punctuated by eroding ledges and grassy terraces. The east and west sides of the stack are also vertical.

\subsection{Erosion}

This area of coastline is actively eroding. There are obvious signs of rock falls and large block slippage of the bedrock, as well as erosion of the topsoil at cliff edges. The incised coastline gives rise to many promontories and stacks, and was specifically highlighted in the CEAL project as requiring regular monitoring (Burgess \& Church 1997, 204).

Erosion of the stack itself is of particular concern. At the time of the survey archaeological structures were noted to be collapsing down the landwardfacing cliff-edge. Evidence for the speed of this erosion was described by Mr D R MacLeod of Gearrannan, who used to climb the stack in his youth. Mr MacLeod informed us that about 35 years ago it was still possible to pass along the ridge connecting the stack to the land, which is now a treacherously loose knife-edge of rock. The Ordnance Survey team of 1969 presumably also managed to access the stack at that time, given the detail of their description (see below).

\subsection{Access}

Access to Stac a' Chaisteal was difficult and timeconsuming, given its distance from the road and its physical shape. All equipment had to be carried over moorland to the site, which involved a walk of 45 minutes. A safe route had then to be found onto the stack: the spine was too dangerous and unstable to traverse, and there was the danger of loose and eroding rock falling onto the foreshore.

The access route was therefore chosen to avoid these loose areas as far as possible. It commenced with a $30 \mathrm{~m}$ abseil down a steep grassy ramp on the stable, southern headland to gain the shoreline. Two stake anchors driven into the top of the landward cliff secured the ropes for this end. From the small and boulder-strewn beach, the stack was scaled directly up its landward face. A fixed rope was then secured up the route for the rest of the fieldwork. The route was protected using climbing techniques to fix rock 


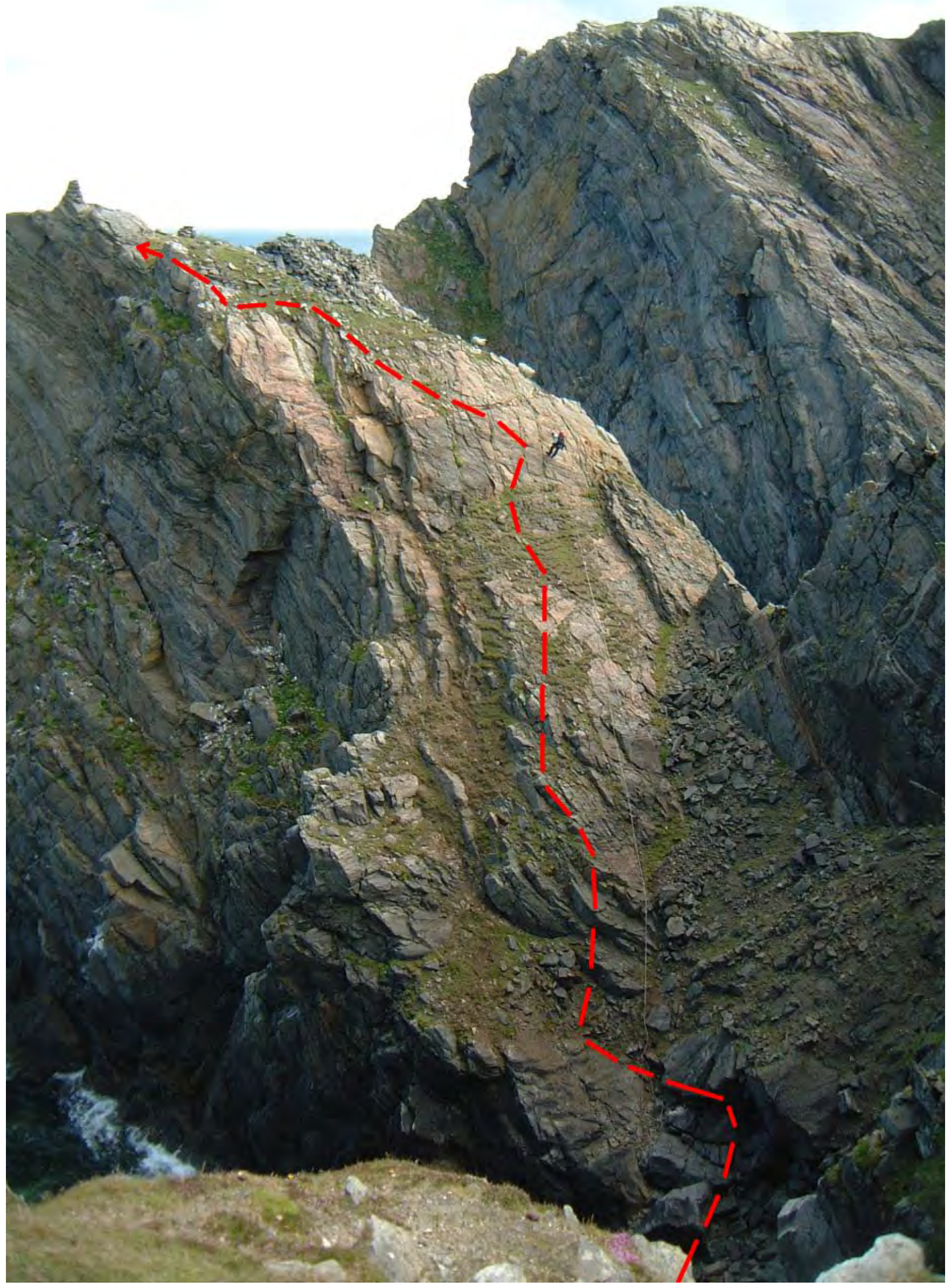

Illus 8 Access onto Stac a' Chaisteal from the south 


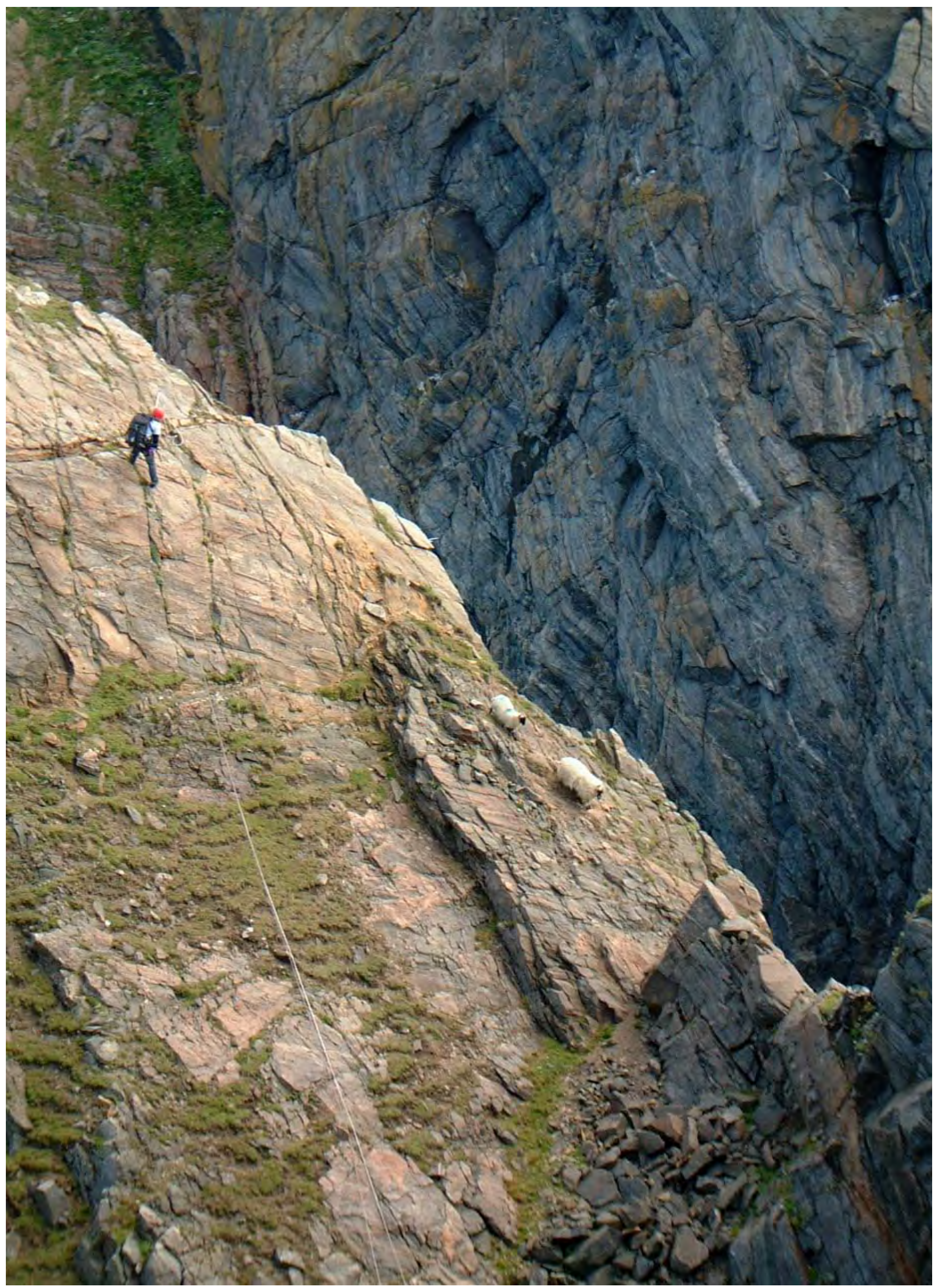

Illus 9 Access onto Stac a' Chaisteal with descending sheep from the south 
anchors and pitons into appropriate cracks in the rock (illus 8 and 9).

The success of the access was dependent upon finding solid rock to provide safe anchors and had this not been discovered the stack would not have been climbed. Any loose rock encountered on or around the route had to be dislodged to ensure continuing safety.

\subsection{Previous work}

The earliest documentary evidence for Stac a' Chaisteal comes from the Ordnance Survey Name Book of 1852, which described it as: 'A small ruin, said to be the remains of a castle, with a considerable portion of the wall still standing.' (Ordnance Survey Name Book 1852.)

The next mention in the NMRS is again from the Ordnance Survey, this time in 1969 during the course of their 1:10,000 map survey. It is obvious the team managed to access the stack because of the detail recorded:

On Stac a' Chaisteal there is the much reduced and overgrown remains of a galleried dun or semi-broch. It consists of a substantial stone wall measuring $c 13 \mathrm{~m}$ in length and $c 4.5 \mathrm{~m}$ in width, and pierced by a central entrance passage $1.1 \mathrm{~m}$ in width, placed on the lip of a cliff across the eroded ridge joining the promontory to the mainland.

The west half of the wall has fallen into the sea, but the footings of the outer wall face and entrance-passage survive. The outer wall face of the $\mathrm{E}$ half has a considerable batter, and reaches a maximum height of $1.8 \mathrm{~m}$. at the $\mathrm{SE}$ corner.

The inner wall face is vertical, $0.9 \mathrm{~m}$ in height, and pierced by a lintelled entrance, $0.8 \mathrm{~m}$ in width, which leads into the remains of a cell too ruinous to be properly examined.

Within the enclosed area, measuring $c 13 \mathrm{~m} \mathrm{~N} /$ $\mathrm{S}$ by $10 \mathrm{~m}$ transversely, there are traces of other structures, of which only one can be recognised as an oval corbelled chamber, about $3.3 \mathrm{~m} \mathrm{E} / \mathrm{W}$ by $2.3 \mathrm{~m}$ transversely, with a lintelled entrance in its $\mathrm{N}$ wall. [Surveyed at 1:10,000, visited by Ordnance Survey (AA) 20 June 1969.]

The site was also described by the Coastal Erosion Assessment, Lewis (Burgess \& Church 1997) and was considered in subsequent and related work

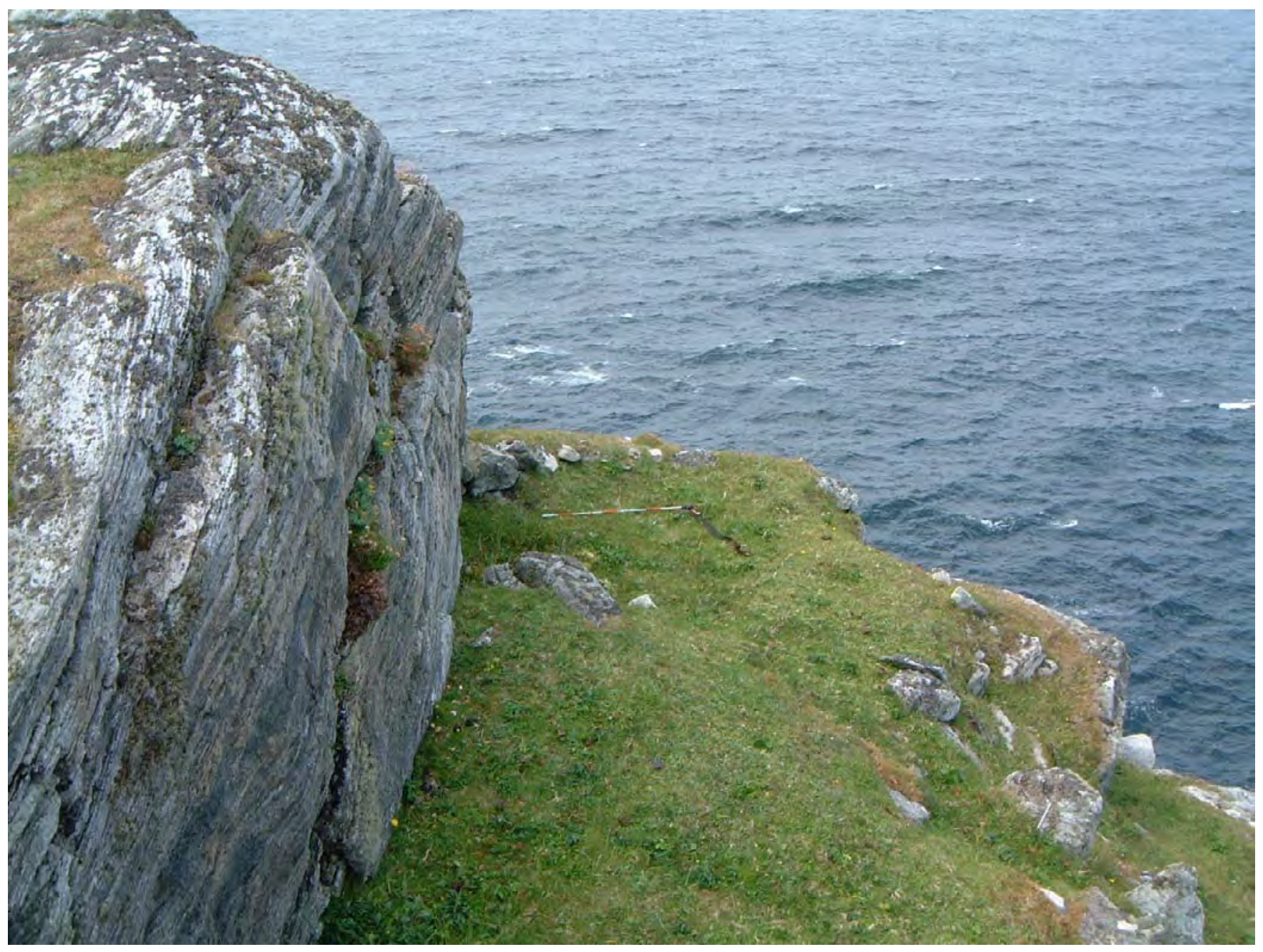

Illus 10 Stac a' Chaisteal Structure A from the east. Scale $1.2 \mathrm{~m}$ long. 


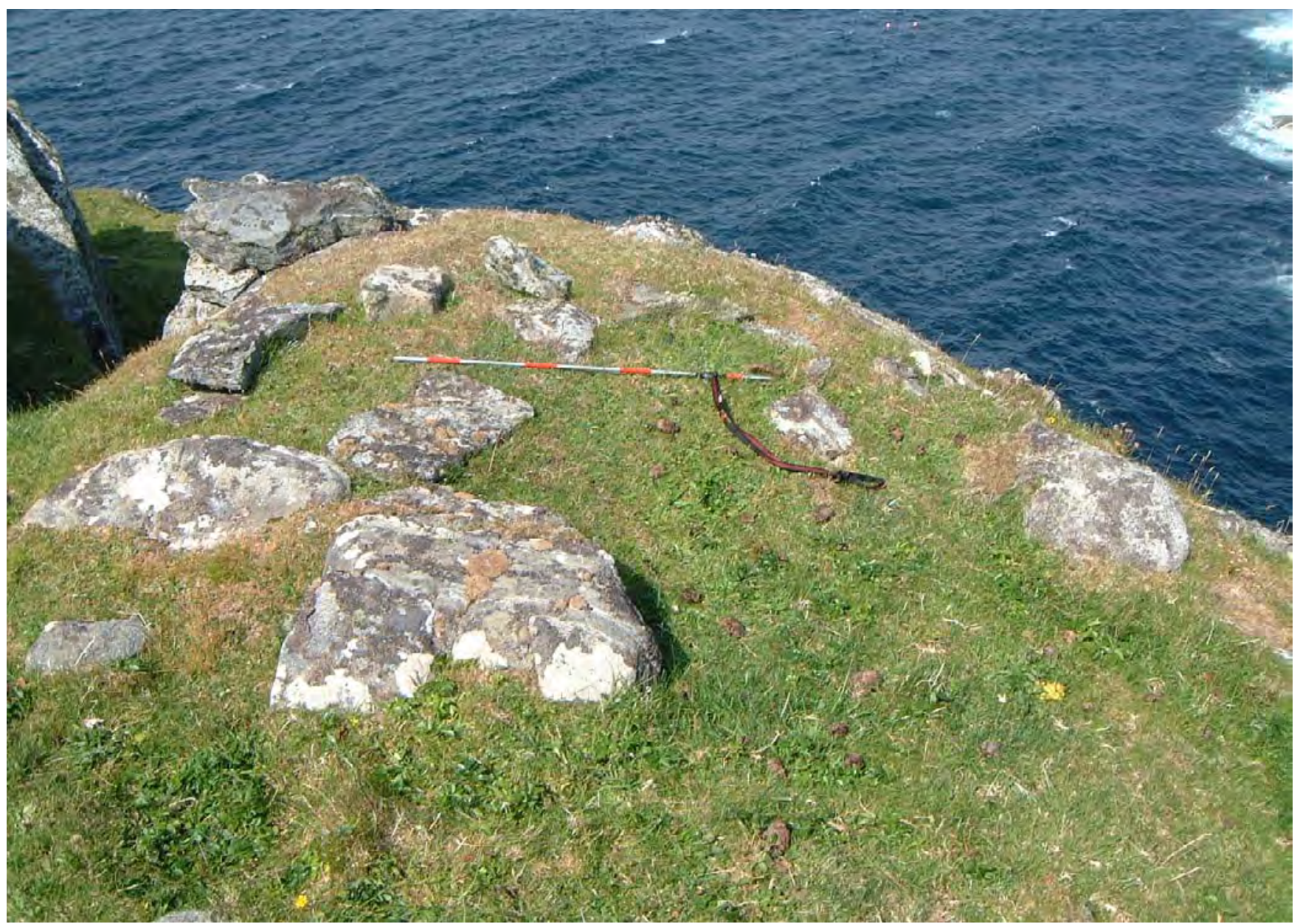

Illus 11 Stac a' Chaisteal Structure B from the south. Scale $1.2 \mathrm{~m}$ long.

(Burgess 2000; Burgess 1999). Burgess described the construction of the site in his $\mathrm{PhD}$ :

... one promontory enclosure, Stac a' Chaisteal, appears to be constructed using techniques similar to that seen in complex Atlantic round houses, using flat slabs of stone to produce a blockhouse structure, apparently with an intra-mural space. While the structural similarities may be a result of no more than the use of the same building materials, the final effect at Stac a' Chaisteal must have been monumental, visually similar to the large complex Atlantic round houses, presenting a large featureless surface punctuated only by a small entrance. (Burgess 2000, 130)

Although the site was not accessed during this work, he noted that it was examined closely with binoculars from all sides, and appeared to be of linear rather than circular construction, and having '. . . either rooms, cells or an intra-mural space within the thickness of its wall' (ibid, 250).

\subsection{The survey}

The structure described by Burgess above formed a linear and large dry-stone rectangular wall or blockhouse running along the southern extremities of the site. This enclosed at least six other structures on top of the stack, within a small oval area measuring $c 30 \times 15 \mathrm{~m}$, about two thirds of the summit. These structures consisted of curving lines of turf-covered wall footings, supported by revetment walls at the cliff edge. The remaining third of the summit was an outcrop of bedrock running along the western side of the summit, a couple of metres higher than the archaeological structures (illus 6).

The structures are described here from north to south, with their phasing discussed at the end.

\section{Structure A}

On the seaward or northern face of the stack, the turf and stone footings of a curved, double-skinned, drystone wall abutted an outcrop of rock and then ran along the top of a north-facing cliff for $c 3 \mathrm{~m}$ before terminating at the easy angled grassy slope of a natural terrace (illus 10). The wall was $c 0.4 \mathrm{~m}$ thick and is constructed of blocks of Lewisian gneiss, which measure on average $c 200 \mathrm{~mm}$ long $\times 200 \mathrm{~mm}$ wide.

A small but regular break of slope immediately uphill of Structure A may have represented a further wall or revetment built into the slope. 


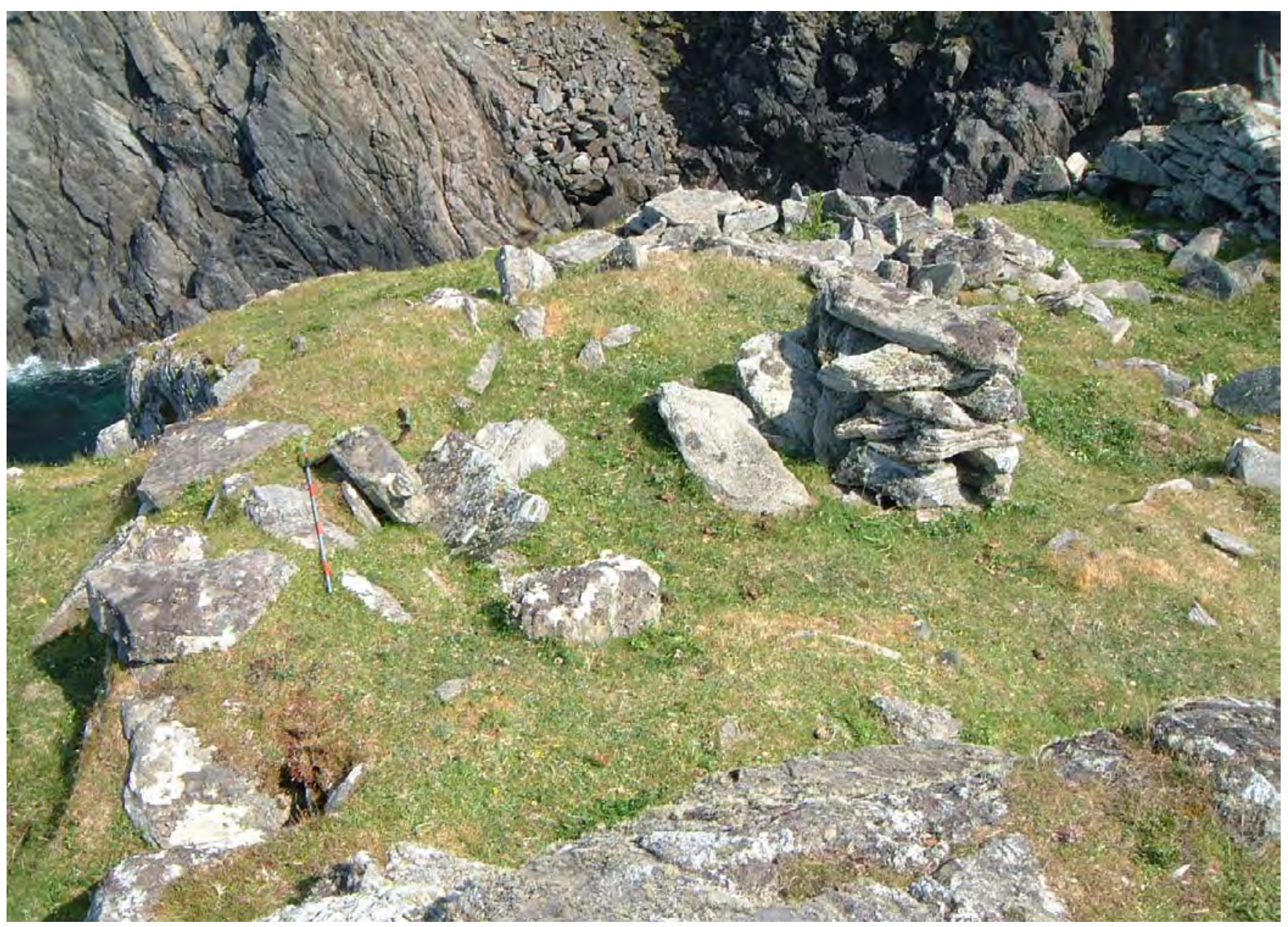

Illus 12 Stac a'Chaisteal Structure C from the west. Scale $1.2 \mathrm{~m}$ long.

\section{Structure B}

Approximately $8 \mathrm{~m}$ upslope and to the south-west of Structure A, resting upon another outcrop of rock, were the horseshoe-shaped foundations of another double-skinned, drystone-walled enclosure (Structure B), which opened to the south. This was slightly more substantial than Structure A. It measured roughly 4 $\times 4 \mathrm{~m}$ in plan, with walls $0.5 \mathrm{~m}$ thick (illus 11 ).

\section{Structure $C$}

Structure C was also horseshoe-shaped and opened to the south. It measured $5 \mathrm{~m} \mathrm{~N} / \mathrm{S}$ by $4 \mathrm{~m}$ E/W internally. The wall rested upon and covered the whole of an outcrop of rock (illus 12).

The foundations of the structure were constructed of large slabs of gneiss measuring up to $1 \times$ $0.2-0.7 \mathrm{~m}$, with a wall thickness of $c 1 \mathrm{~m}$. The walls were more heavily built than the two structures previously described, and belonged to a more substantial building. Only one course of walling was visible along its length, but the south-east wall end to the structure revealed at least three courses of stonework, which showed signs of corbelling.

The west wall of this building continued further to the south than the east wall, and ended squarely with two courses of large gneiss blocks, which may have been one side of a doorway. The opposing wall may have been represented by Structure K, a linear grassy bank with the same alignment that lay $1 \mathrm{~m}$ beyond the wall termination.

\section{Structure D}

To the north of Structure $\mathrm{C}$ and running along the west side of Structure B was a short pathway set into a natural fissure between two rock outcrops. This measured $c 1 \mathrm{~m}$ wide, was orientated N/S, with the outcrop to the west $1.5 \mathrm{~m}$ high. Although the outcrop to the east was lower, it had been accentuated by the construction of a roughly built section of drystone walling (illus 13). This formed a natural passage, and may have been used to gain access to the site from the seaward side of the stack.

The section of walling was perched on the edge of the outcrop and was right-angled, with faces to the north and east. It was constructed of large gneiss slabs, measured $c 0.5 \times 0.5 \mathrm{~m}$, and survived to a height of $0.7 \mathrm{~m}$. This may have been the east jamb of a doorway, and could have held a lintel, although there were no obvious marks or signs of quarrying of the rock face to the west.

A similar passageway accentuated by drystone walling running parallel to the east of Structure B was also noted, but this was not as convincing as Structure D. 


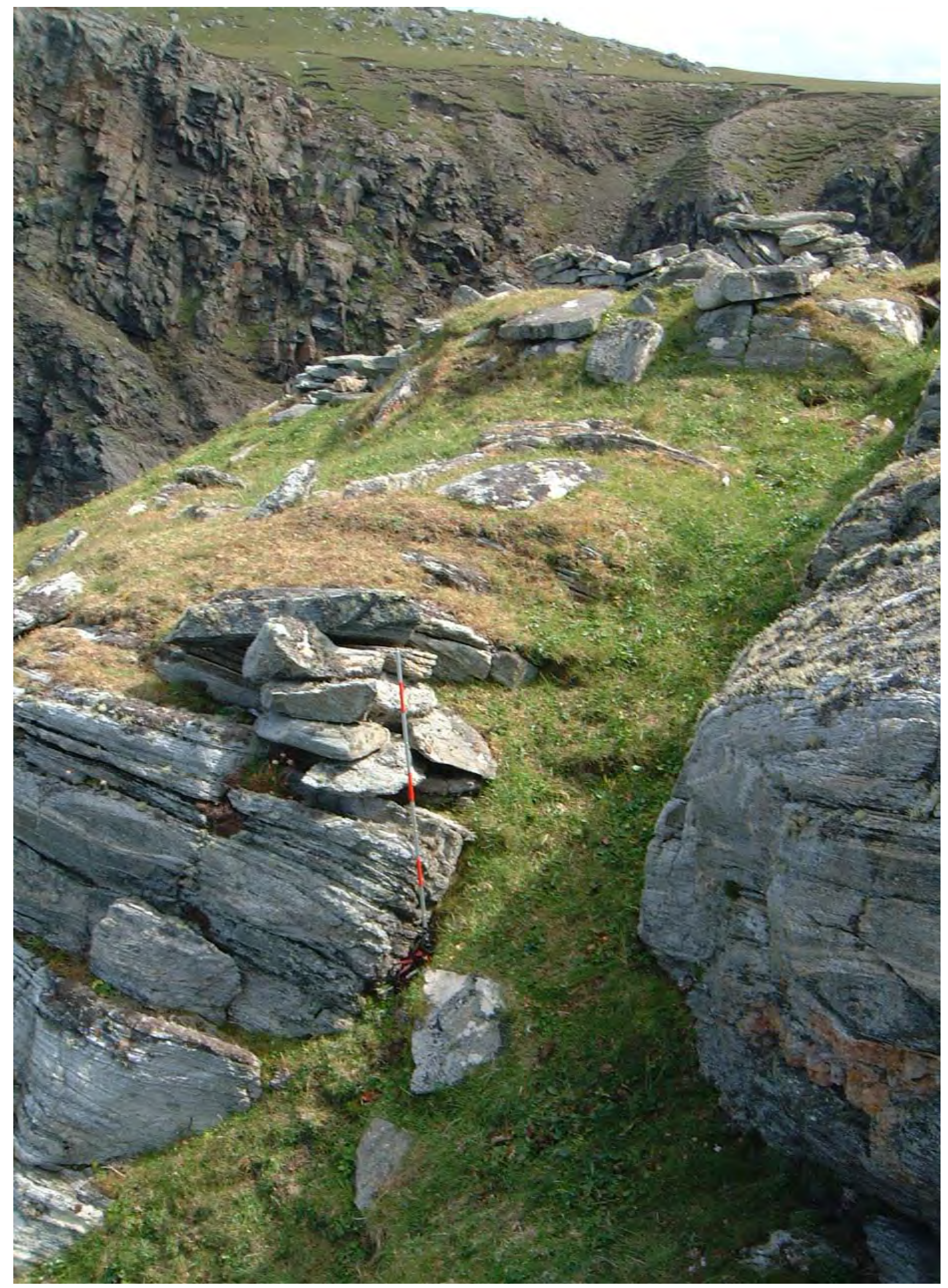

Illus 13 Stac a' Chaisteal Structure D from the north-west. Scale $1.2 \mathrm{~m}$ long. 


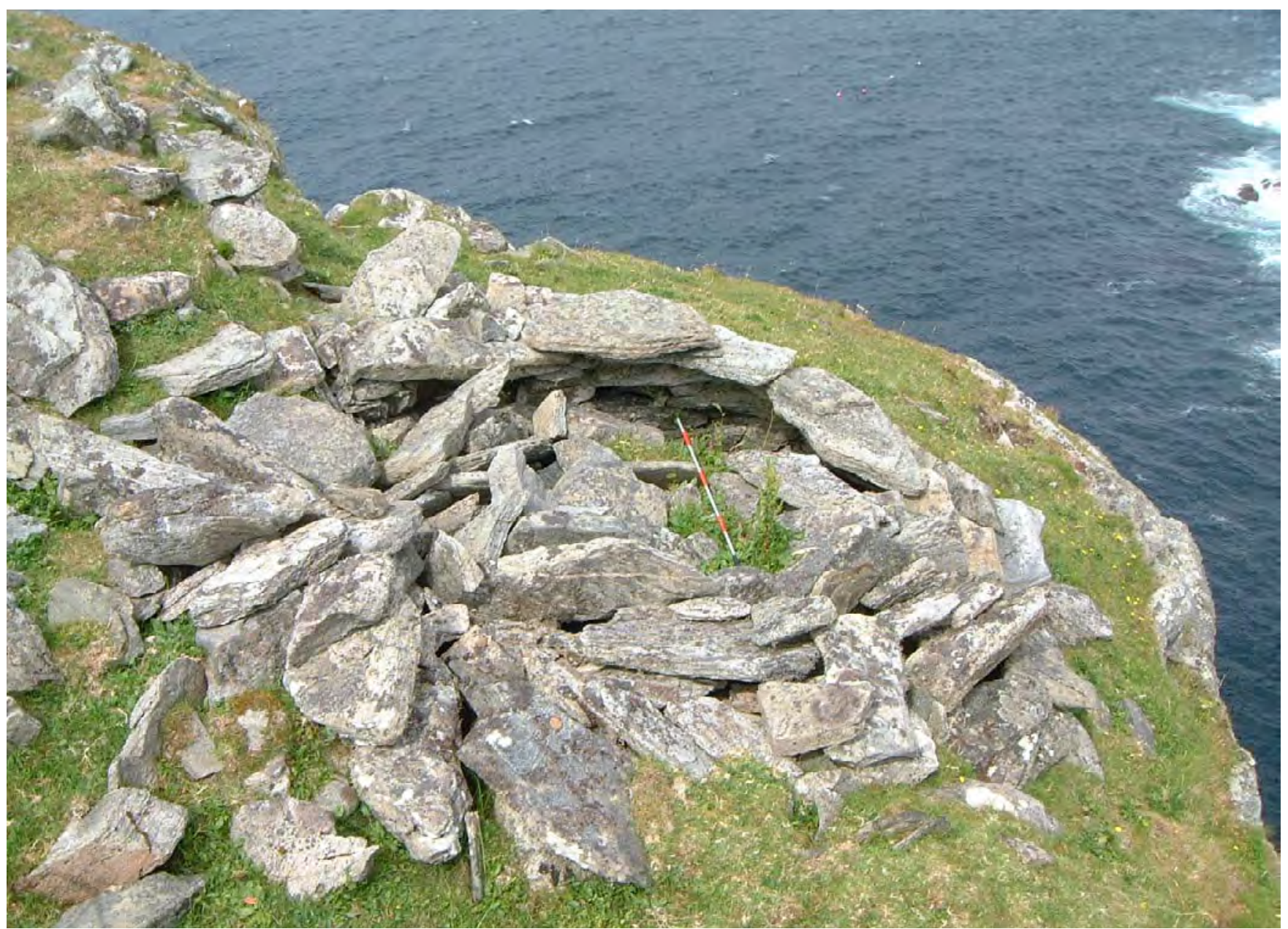

Illus 14 Stac a' Chaisteal Structure $E$ from the south-east. Scale $1.2 \mathrm{~m}$ long.

\section{Structure E}

Structure E is a drystone, beehive-shaped, corbelled cell, which measured $c 4 \times 4 \mathrm{~m}$. It was constructed of a single face of large gneiss slabs attaining over $1 \mathrm{~m}$ in length and, although the wall had large gaps throughout, it has survived to a height of $0.5 \mathrm{~m}$ or four courses above present ground level (illus 14). The cell vaulted sharply inward over these four courses from an inside diameter of $c 3.6-1.4 \mathrm{~m}$ at its full height.

The cell had two openings. One entrance was on the west side and was well-constructed but partially collapsed, including its lintel. It was $0.3 \mathrm{~m}$ high and $0.6 \mathrm{~m}$ wide. A passage leading to the entrance was formed by the eastern wall end of Structure C and an opposing wall at right angles to this.

The second entrance was in the north of the cell, where a $0.5 \mathrm{~m}$ wide by $0.4 \mathrm{~m}$ high opening led into a $1 \mathrm{~m}$ long passage flanked by stone orthostats. This passage is in a derelict state but would have been roofed, judging by the amount of masonry tumble present.

\section{Structure F}

Structure F consisted of three separate, but possibly related, features described as $\mathrm{F}(\mathrm{a})$, (b) and (c). The first, Structure F(a), comprised two courses of a drystone, double-skinned wall, of large $c 0.6 \times 0.3$ $\times 0.3 \mathrm{~m}$ rectangular blocks, partially turfed over. It was $c 0.8 \mathrm{~m}$ wide and stretched $3 \mathrm{~m} \mathrm{E} / \mathrm{W}$ on the south-west of the stack (illus 15). The western end was partially collapsed and had fallen over the edge of the stack.

Structure $F(b)$ was a short length of turfed-over stone walling, running parallel and $2 \mathrm{~m}$ to the north of $\mathrm{F}(\mathrm{a})$. A $2 \mathrm{~m}$ long stone slab, possibly a lintel, lay along this wall. An ephemeral turf- and stone-line joined the north-east end of $\mathrm{F}(\mathrm{b})$, and $\operatorname{ran} \mathrm{N} / \mathrm{S}$, parallel to the west end of Structure G. F(b) and (c) together enclosed a small area to the west of the stack, with the north side formed by a rock outcrop.

\section{Structure $G$}

Structure G is described in two parts. G(a) was a substantial wall and footing of up to 4 courses high, surviving $5.5 \mathrm{~m}$ long and at least $0.9 \mathrm{~m}$ thick, running NW/SE, to the south of, and slightly out of alignment, with Structure F. The wall was of drystone construction and consisted of massive 1 $\times 0.5 \mathrm{~m}$ rectangular blocks of stone. It may have been of double-faced construction, given its width, but only the outer face was visible. A batter was 


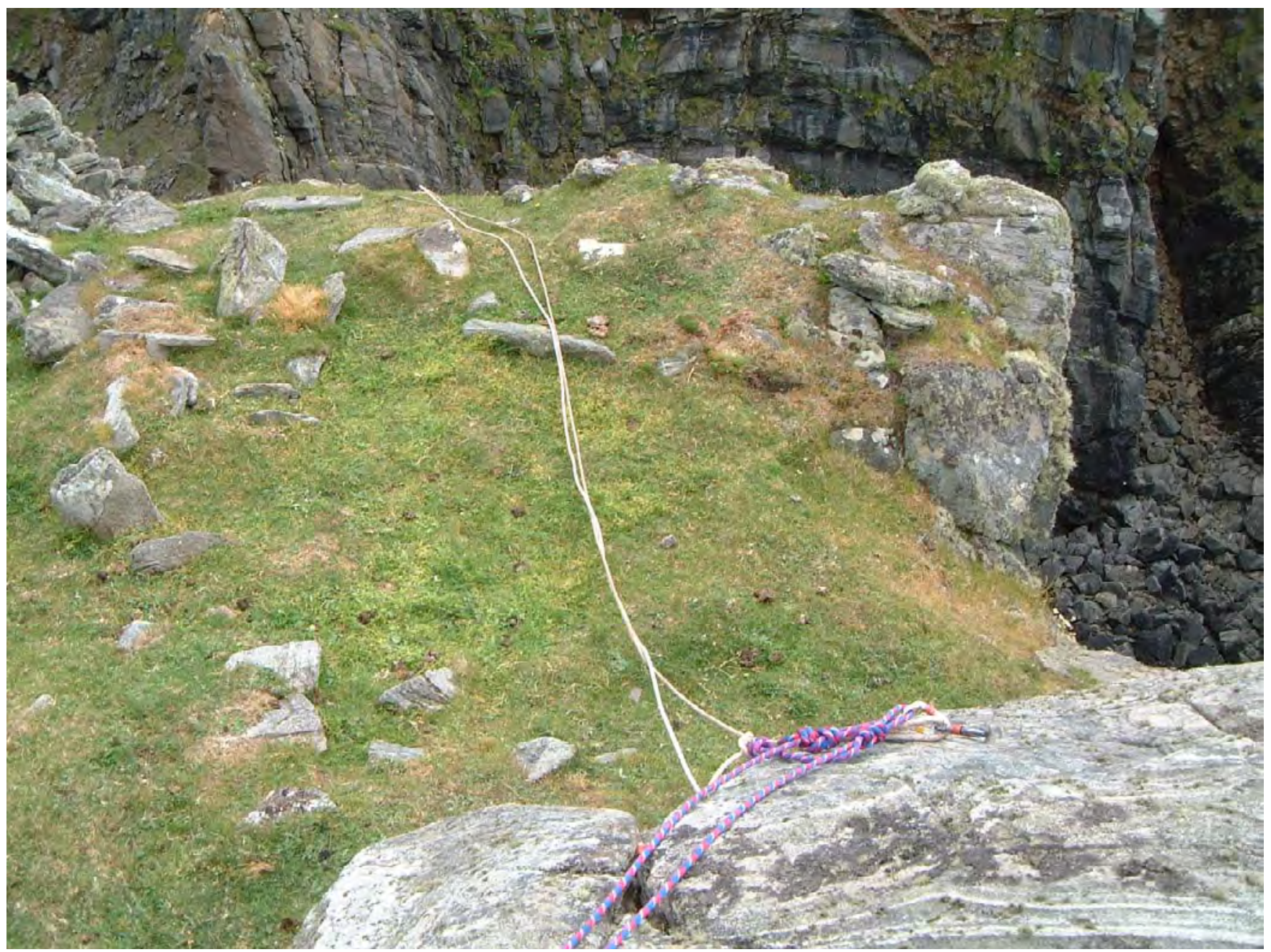

Illus 15 Stac a' Chaisteal Structure F from the east

apparent over its height, similar to that seen in Structure H (see below).

Both Structure F and Structure G(a) have jagged western ends where it is clear that they are falling into the sea; some of their courses overhung the cliff face.

At its eastern end, Structure G(b) may have been the same as the foundations of a wall running N/S, parallel to the west wall of Structure H (illus 16). The structure ran for approximately $5 \mathrm{~m}$, and was constructed of blocks of the same size and character as Structure G(a), but other dimensions were unclear due to vegetation cover.

\section{Structure $H$}

Structure $\mathrm{H}$ was the most substantial and best preserved building on the stack, surviving in places up to eight courses or $2 \mathrm{~m}$ in height. It was sub-rectangular in plan and measured $6 \times 4 \mathrm{~m}$. A substantial batter was apparent on what remains of the south, landward-facing wall. The building stood across the south-eastern neck of the stack, blocking access to its interior. Most of its southern and western wall sections were collapsing into the sea, but the eastern wall and the south-eastern corner were well preserved and remained perched on the edge of a 40m-high cliff (illus 17 and 18)

The north wall survived intact to a height of $1.5 \mathrm{~m}$ to its roof stones. It formed an internal gallery which possibly turned south to follow the east wall of the structure. An entrance, $0.8 \mathrm{~m}$ wide with a triangular lintel (illus 19), and a mere $0.3 \mathrm{~m}$ higher than the present ground surface, was present in its outer wall. It opened directly onto the internal gallery. No other entrance was visible.

An obvious passage was formed between Structure $\mathrm{H}$ to the east, and Structures F and G to the west (illus 16 above). This was described by the Ordnance Survey as the entrance passage to a massive structure spanning the whole width of the stack, an interpretation that was supported by this survey.

The passage measured $1.1 \mathrm{~m}$ in width and extended along the entire width of Structure H. Unfortunately, the outward threshold of the passage had collapsed to the east $(\mathrm{H})$ and is no longer present to the west (G) so it is not known what kind of doorway might have existed. An eroded beach pebble hammerstone was found in the tumble from the wall to the east of this passage (SF1). 


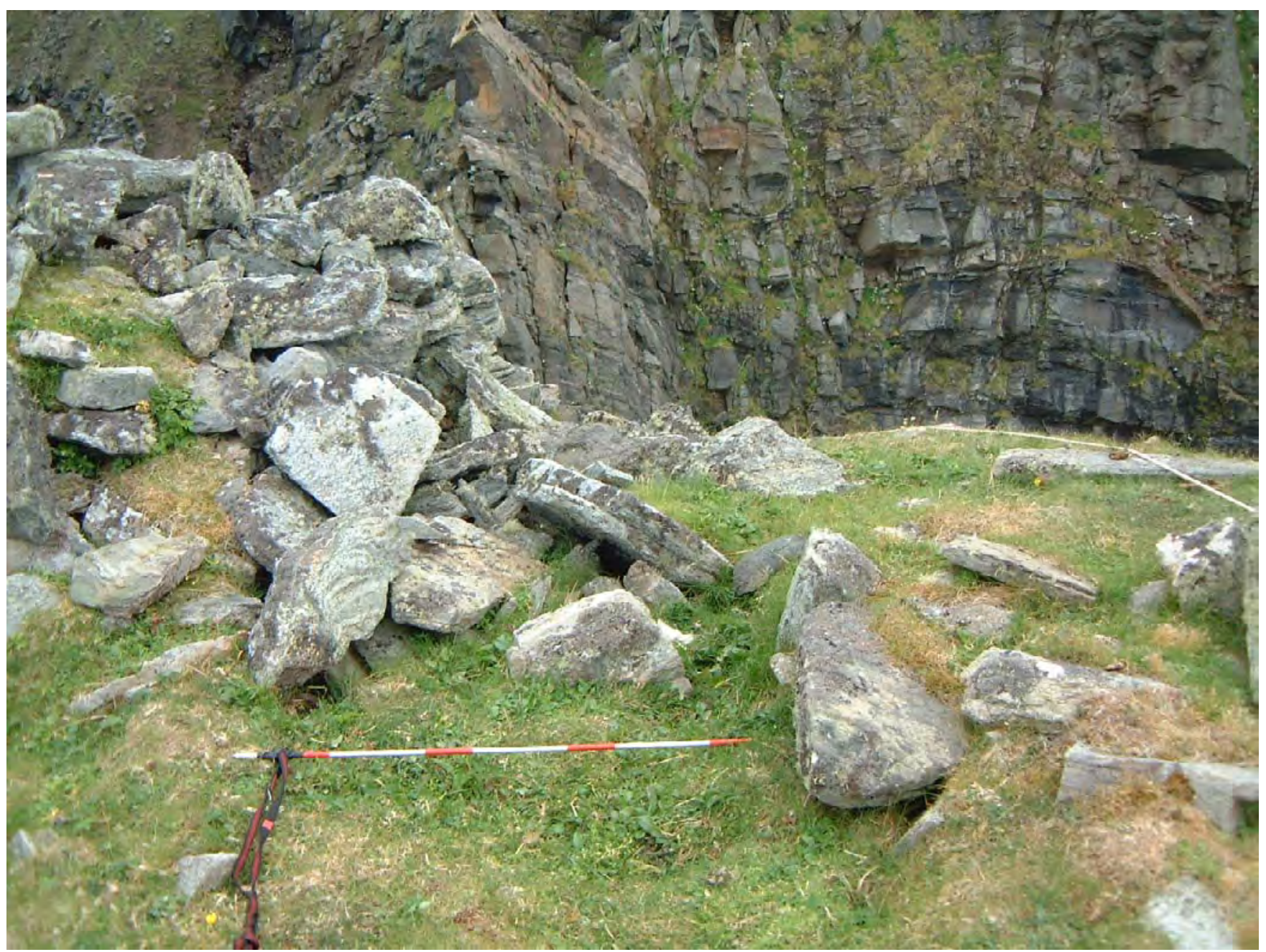

Illus 16 Stac a' Chaisteal Structure G from the north-west. Scale $1.2 \mathrm{~m}$ long.

\section{Structure I}

Structure I was the large modern cairn situated upon the highest point of the stack. Cairns like these are found all over the coast of Lewis as navigation aids to fishermen. It is not known when this one was constructed.

\section{Structure $J$}

In the middle of Structure $\mathrm{C}$ was a stone construction $c 1.5 \mathrm{~m}$ high by $1 \mathrm{~m}$ long and $0.5 \mathrm{~m}$. wide. It consisted of two rough piles of stone slabs with a larger, flat slab on top (to the right in illus 12 above). The construction was so poor that it gave the impression of being very recent in origin, and did not seem to relate to the other structures. It is known that within living memory young men would challenge each other to ascend this and other stacks (D R MacLeod, Gearrannan, pers comm) and would build something to prove their exploit. This may be one such construction.

\section{Structure K}

A grassed-over linear mound that could be the remains of a wall measuring $0.9 \mathrm{~m}$ wide ran $1.7 \mathrm{~m}$ N/S from the southern end of Structure E (illus 6).

\section{Structure L}

Running between Structure E and the north-eastern corner of $\mathrm{H}$ were the ephemeral remains of another possible wall, $c 1 \mathrm{~m}$ wide by $1.7 \mathrm{~m}$ long. This may have been a continuation to the south of the eastern

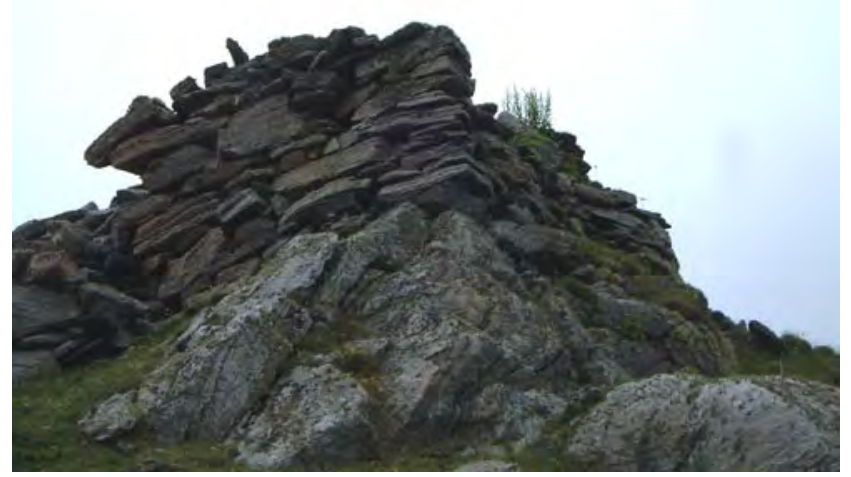

Illus 17 Stac a' Chaisteal SE corner of Structure H from south-east 


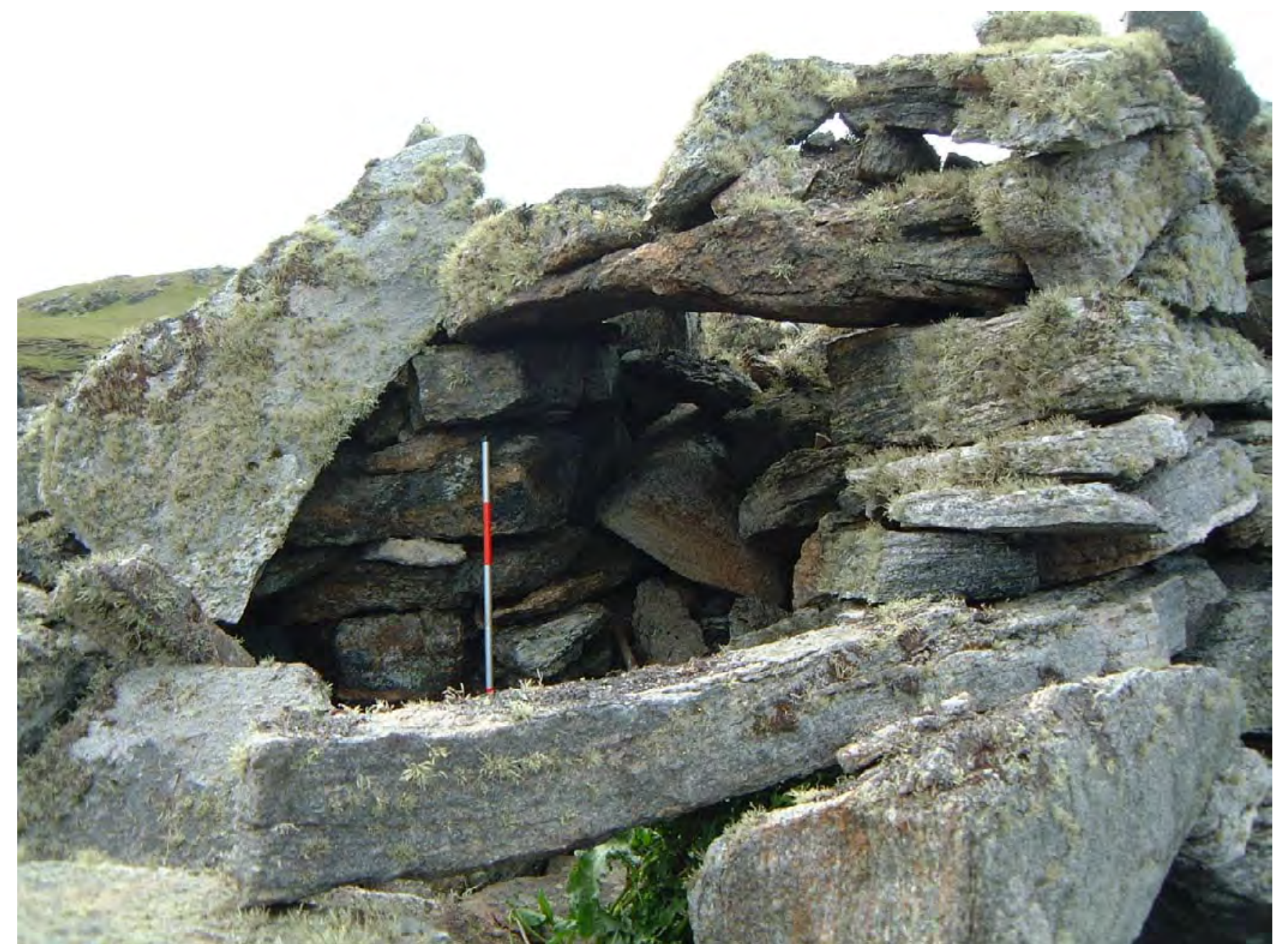

Illus 18 Stac a' Chaisteal NE corner of Structure H from the north. Scale $0.4 \mathrm{~m}$ long.

wall of Structure C, subsequently obscured by the construction of Structure E.

\section{Structure $M$}

A substantial revetment wall measuring $2 \mathrm{~m}$ high and $c 6 \mathrm{~m}$ long underlay and supported structures $\mathrm{E}$, $\mathrm{L}$ and $\mathrm{H}$. It was built along the south-eastern flank of the stack (illus 20). This may have related to the earliest phase of construction on the stack. It sealed a steep gully draining water away from the summit plateau onto its eastern face. It was well preserved, with no evidence of subsidence or collapse.

\subsection{Discussion}

The buildings on Stac a' Chaisteal fell into three distinct groups. The first group includes the curvilinear, double-faced foundations of structures A, $\mathrm{B}$ and $\mathrm{C}$, which closely followed and respected the shape of the stack. Structure D may also have been contemporary with these structures as it was positioned along a natural path leading from one structure to another. These buildings were protected from the prevailing south-west weather by the rock outcrop forming the summit of the stack.

Structure A may have represented no more than an open-ended section of walling, similar to that found in Structure D, rather than the remains of a building. The relationship of this to the alteration or enhancement of natural passageways by the construction of drystone walling (Structure D) implied the importance of movement between the top of the stack and the seaward face. The seaward face was actually more easily angled for access than the rocky and exposed landward one and contained many little grassy terraces. Time and logistical problems did not allow a fuller survey of these terraces, but they may have been an integral part of the site as a whole.

Structures B and C were closely related, with B interpreted as an extension to the larger building $\mathrm{C}$. They were very similar in construction.

Structure C may have been a large, 12m-long oval building, incorporating isolated walls at its southern end (Structures K and L), and pre-dating 


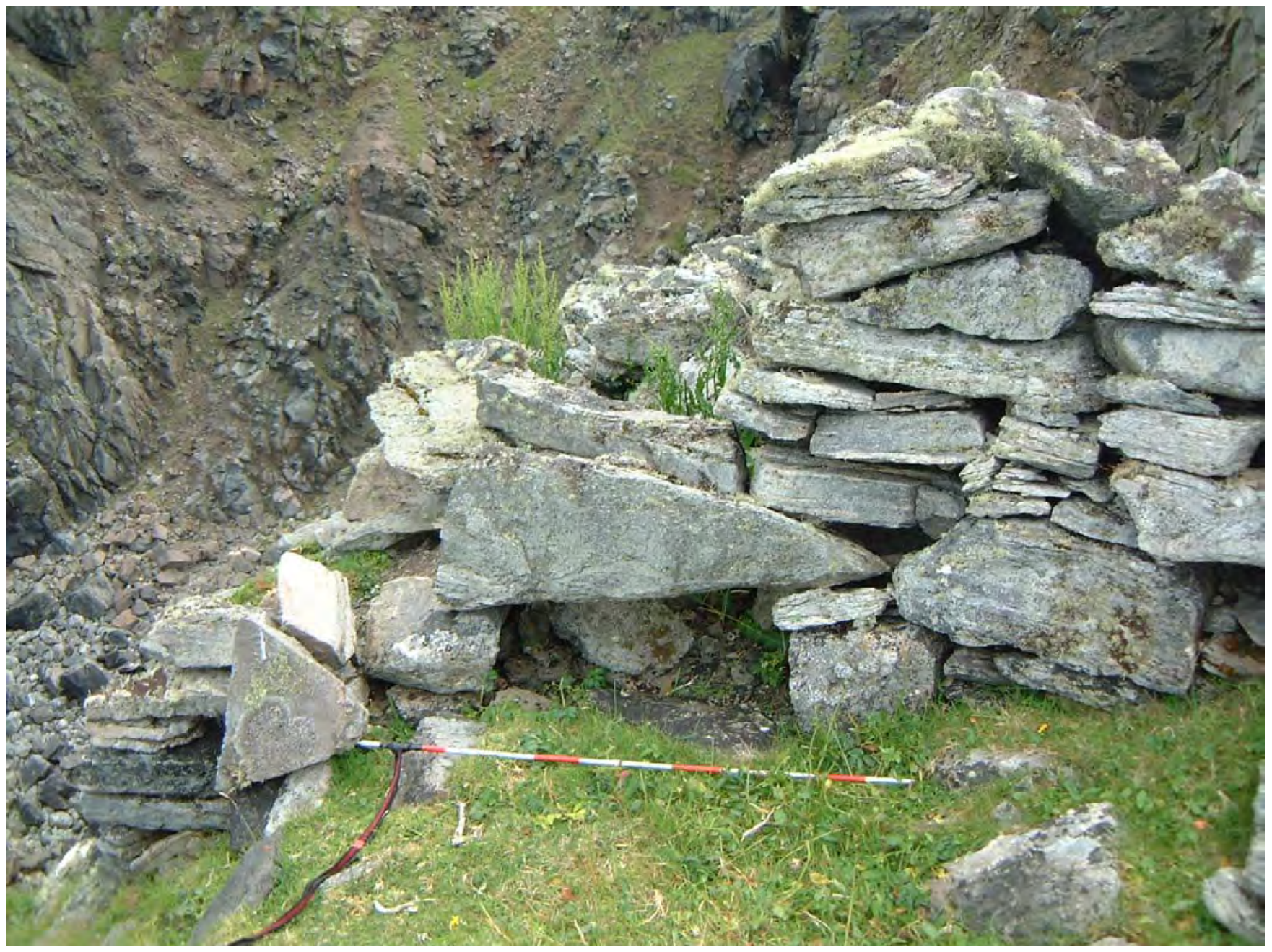

Illus 19 Stac a' Chaisteal triangular lintel Structure H from the north. Scale $1.2 \mathrm{~m}$ long.

the standing building to the south (Structure $\mathrm{H}$ ). Certainly Structures $\mathrm{K}$ and $\mathrm{L}$ continued on the same alignment as $\mathrm{C}$, and appeared to run underneath Structure $\mathrm{H}$.

The second group of buildings was represented by Structure E. It had a completely different style of construction from the previously described buildings, having a single face of long, thin slabs corbelled inwards to form a roof. The large holes throughout its construction implied that the building was probably covered in turf, as it certainly could not have provided shelter otherwise. It also had two entrances, one of which was blocked.

These architectural components are found in the ubiquitous Hebridean beehive-shaped shielings (eg Thomas 1859), and although they are predominantly found in inland, upland locations, there are some found on maritime island locations (Loch Roag, J Crawford pers comm). These shielings have a lengthy period of use. Structure E was assumed to be the latest phase of building on the site.

The third distinct group of buildings was characterised by that of Structure H, which was presumably part of a larger building incorporating the wall footings of Structures G and F. It contrasted with the other buildings by dominating the stack, and using the powerfully physical nature of the rock pinnacle. The intention of its construction would not only have been for defence, but to impress.

This structure has been identified previously as being a blockhouse (Burgess 1999), being almost identical to the blockhouses described by Lamb on Shetland (Lamb 1980, Mowbray 1936). If Structures $\mathrm{F}, \mathrm{G}$ and $\mathrm{H}$ were all part of the same original building, then Structure G(b) would have been half of the central entrance passage and Structures F(a) and $F(b)$ could have been part of a corresponding intra-mural gallery to match that in Structure H. The substantial foundation wall of Structure G(a) was angled acutely to Structure F, almost mirroring the shape of Structure H. The building would in effect be a massive cordon-wall stretching across the neck of rock.

Lamb (1980) discussed other sites with evidence of habitation immediately behind the blockhouse, possibly similar to Stac a' Chaisteal. He also 


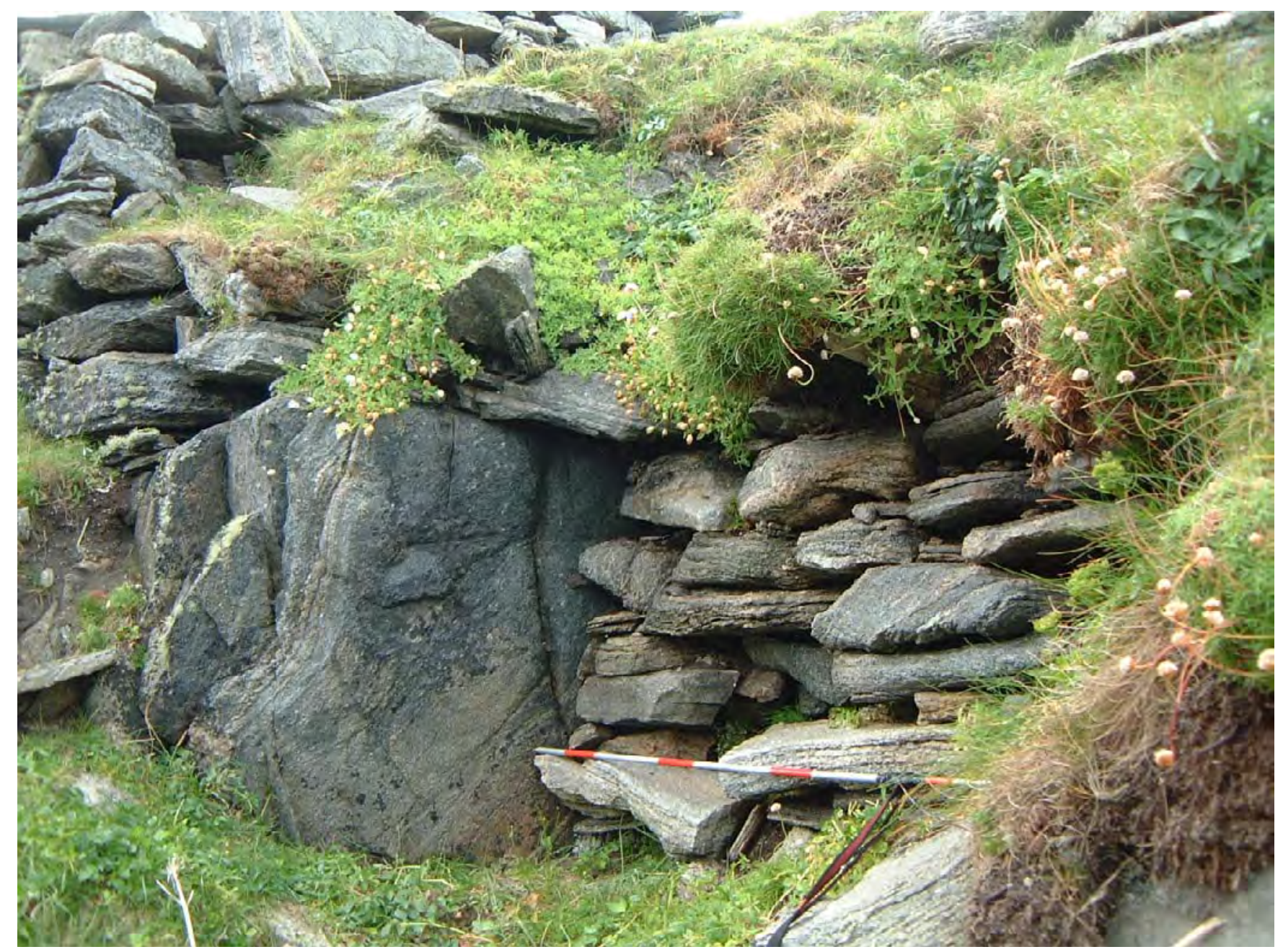

Illus 20 Stac a' Chaisteal revetment $M$ from the north. Scale $1.2 \mathrm{~m}$ long.

noted that some Shetland blockhouses (eg Burgi Geos on the island of Yell) are located amid large expanses of unproductive blanket bog, in contrast to the Lewis sites, which appear to be located on the margins of coastal settlement areas. However, many more of the Shetland sites are inaccessible from the sea, or positioned in areas of treacherous seaward approach, as at Stac a' Chaisteal. Lamb saw no strategic value in the Shetland blockhouse at all (Lamb 1980,69), and certainly these marginal sitings indicate that these were not conventional farming settlements, but must have been dependent upon agricultural production from other areas. In Shetland a further problem concerning defence is that many of the blockhouses appear not to have blocked the whole promontory, leaving a gap for easy access. In contrast, Structure $\mathrm{H}$ appeared to block the whole neck of land, but changes due to erosion may have altered its relationship to the area of the promontory. Although some structures on Stac a' Chaisteal may have been defensive they may also have had status.

\subsection{Potential for future work}

This site had many complex and well-preserved structural remains on it. The main problem encountered there in terms of erosion and collapse was different from other stack sites. On Stac a' Chaisteal there are no exposed and eroding soil layers as its plateau is above the reach of most wave action. The deterioration to the archaeological remains is caused by the undermining of structural remains, which collapse as the underlying rock gives way. Structures G, H and M are threatened in this way as they are perched on the very edge of the stack. Any future work on this site should concentrate on recording as much of these structures as possible, by standing building survey, including drawn elevations and detailed photographs of all aspects of the buildings.

Possible trial trenching over the other structures may be possible in order to assess the quality and depth of deposits, and recover suitable samples for environmental and dating analysis. 


\section{STAC NA CUIBHIG}

\subsection{Physical description and location}

Stac na Cuibhig (NGR: NB 2293 4656) is a strangely shaped, tidal island, some $30-40 \mathrm{~m}$ in diameter and $15-20 \mathrm{~m}$ tall, located just north of Dalbeg on the west coast of Lewis (illus 1, 21, 22). There is a large cairn-like pile of stones on its summit, which the CEAL project (Burgess \& Church 1997, 213) lists as a settlement mound. The surrounding cliffs are of basement Lewisian gneiss, with overlying glacial tills, and are actively eroding (ibid, 214-5).

There was a curving stone-faced bank and a pile of stones on the summit of the stack (illus 23); the stone bank has eroded severely due to the collapse of the cliff edge.

\subsection{Erosion}

The active erosion recorded in 1996-7 (Burgess
\& Church 1997, 214) is continuing, with scars of recent falls and fallen blocks visible in the area. The summit itself is also actively threatened, with the main structure on the stack being progressively destroyed.

\subsection{Access}

Access to Stac na Cuibhig required some difficult but well-protected climbing. A steep but easy path on the landward side led down to the foreshore, from which at low tide it was possible to scramble over to the natural arch, which formed the edge of the stack. This feature formed the only dry access to the summit, which was achieved safely through the use of climbing techniqes using very regular rock anchors. There were also abundant rock anchors on top of the island.

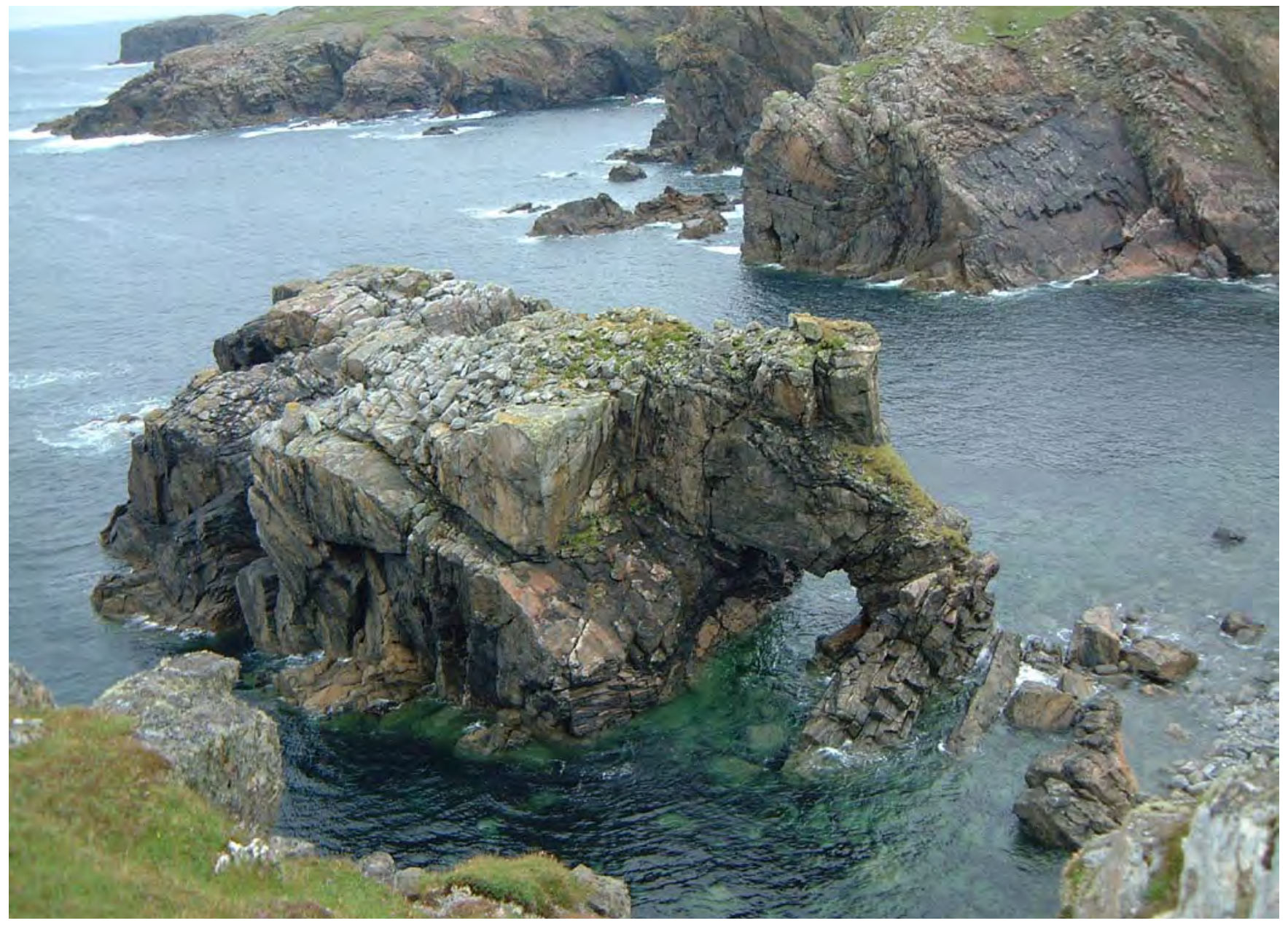

Illus 21 Stac na Cuibhig from the WSW 

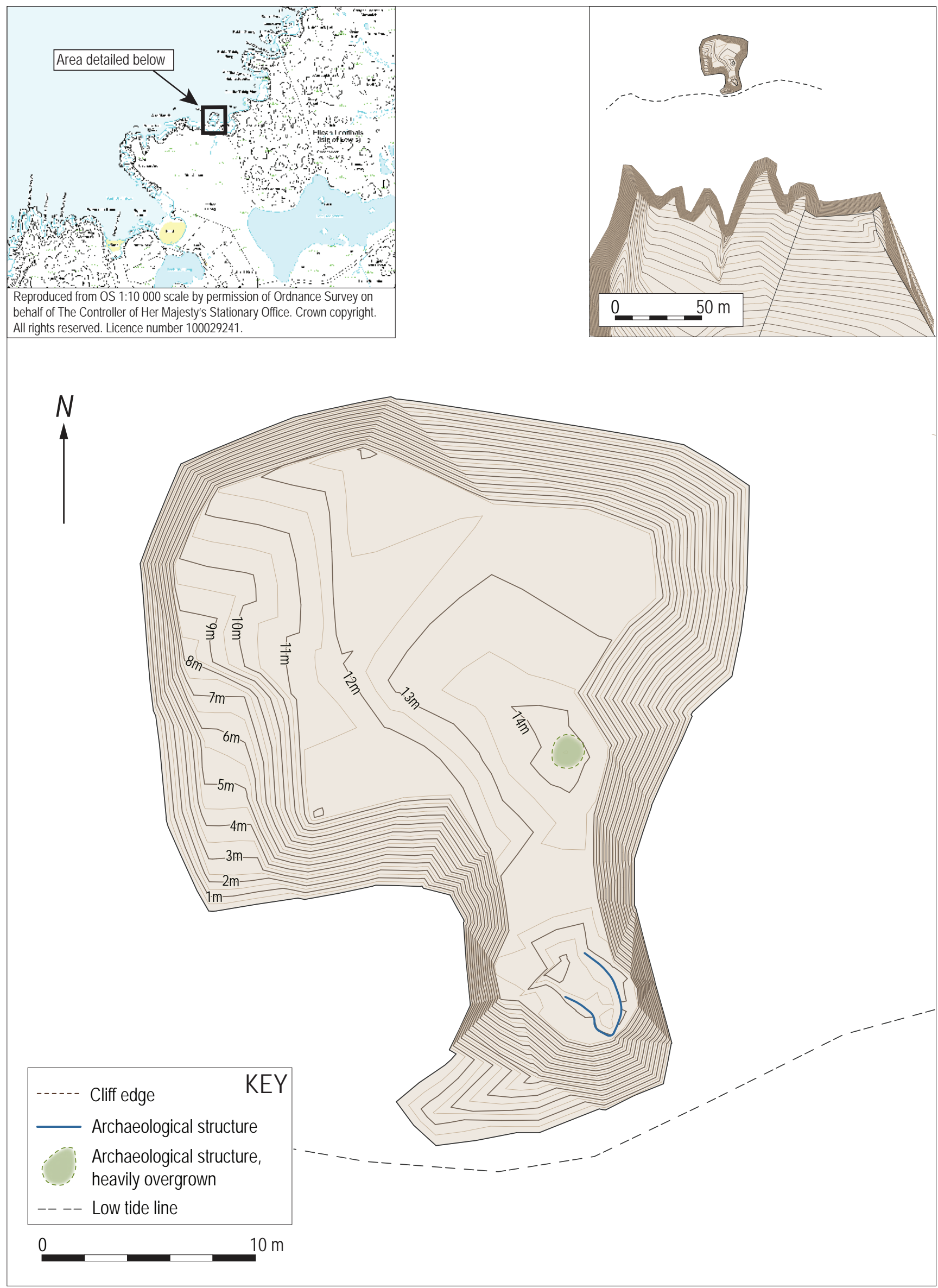

Illus 22 Location map and topographic survey of Stac na Cuibhig 


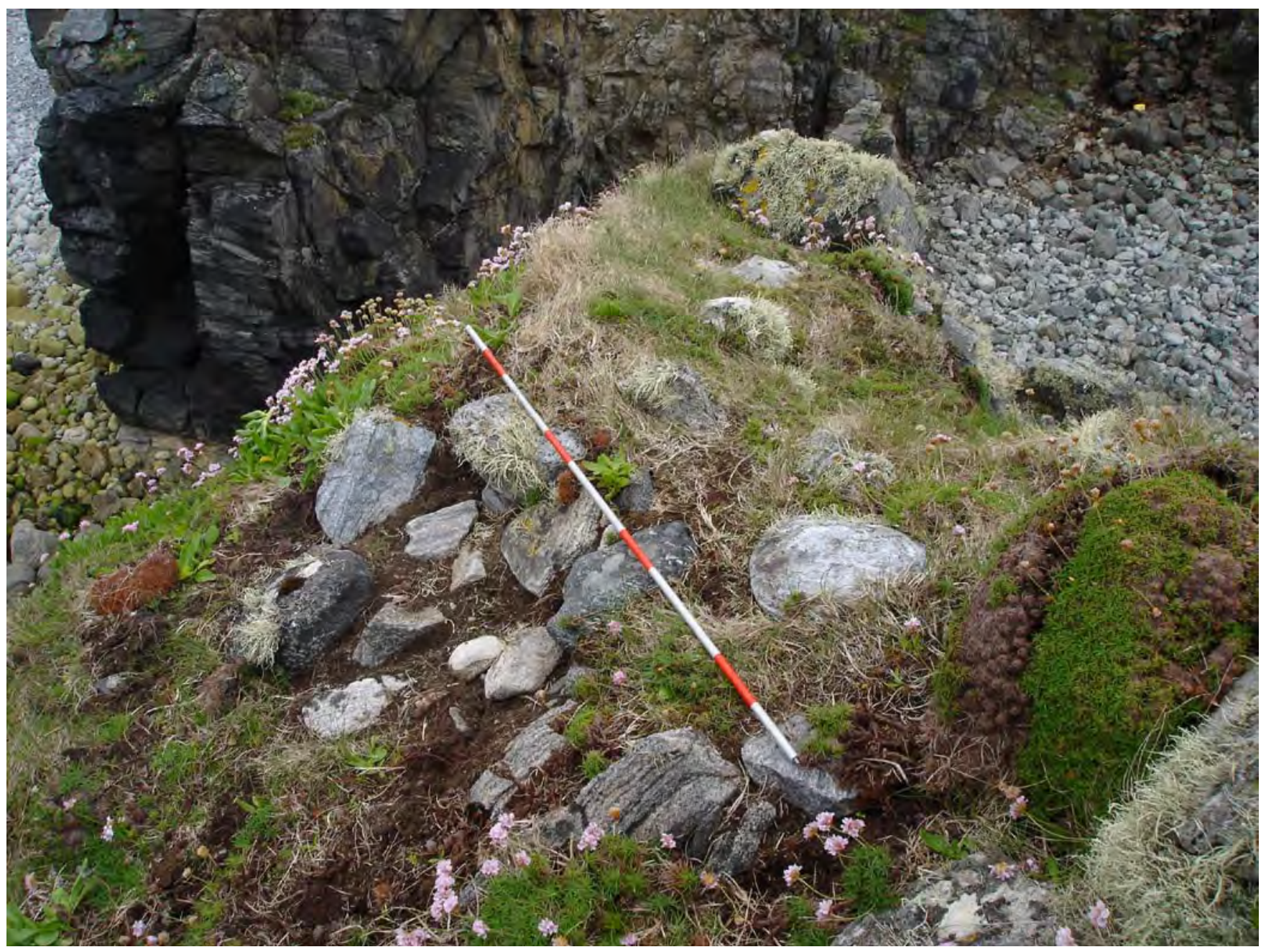

Illus 23 Detail of stone bank on Stac na Cuibhig from the north. Scale $1.2 \mathrm{~m}$ long.

\subsection{Previous work}

This site was identified as a stack with a settlement mound, by the Coastal Erosion Assessment, Lewis (Burgess \& Church 1997, 213) but they were unable to gain access to the site. No other work has been undertaken on the site.

\subsection{The survey (illus 22)}

The top of the island is dominated by a large pile of stone blocks, similar to the underlying geology. Close inspection of this material determined that it is possibly entirely natural in origin. Most blocks measured over $2 \mathrm{~m}$ in length and formed no discernible structure. However, a small hammerstone of a red metamorphic rock quite unlike the gneiss was discovered amongst this material (SF51).

Directly above the natural arch on the landward side of the summit plateau, a stone- faced bank (illus 23) arced for approximately a third of a full circle, the remainder having been destroyed by erosion. It was impossible to determine the original length of this wall, as both ends had been lost to erosion.
The bank was regular in cross section along its length, regular in its arc and maintained a height of $0.5 \mathrm{~m}$. The soil between the stones in the bank was a good quality topsoil of organic silty clay, possibly indicating that the bank was originally a turf and stone wall which had slumped over time. This soil was not present anywhere else on the island. The stones of the bank included many beach cobbles of c $300 \mathrm{~mm}$ diameter, which again were not present elsewhere on the summit. These seem all the more unusual given that the plateau was covered in large, naturally rectangular blocks, suitable for building. However, one of these large blocks was used as one of two courses at what may have been a wall termination or one half of an entrance, at the end of the arc, on the edge of the landward cliff. The bank deposits of the arc are eroding quickly and there is no evidence of archaeological deposits.

\subsection{Discussion}

Although Stac na Cuibhig has been the site of human activity culminating in a structure, there is not enough evidence to adequately support any 
further interpretation. It is possible that the low bank may have originally been part of a circular shieling-type structure, possibly with turf walls, which it resembles. There is, however, no surviving evidence as to its age or what alternative functions the bank might have had, as it has been largely destroyed by erosion. 


\section{DUNASBROC}

\subsection{Physical description and location}

Dunasbroc (NGR: NB 4713 6215, NMRS no. NB46SE 19) is located near Aird Dell in the township of South Dell, parish of Barvas, on the west coast of Ness, Isle of Lewis (illus 1).

It is a small, steep-sided, conical stack situated close to shore and linked to it via a low ramp of rock even at high tide. It is $c 20 \mathrm{~m}$ tall and $c 40 \mathrm{~m}$ in diameter at its base, with a flat summit platform measuring $c 6 \times 15 \mathrm{~m}$. The landward south-westfacing side of the stack is the only area to retain soil and vegetation, the side exposed to the sea being scoured to bare rock. There are no obvious structures at first inspection, but sections of well-made yet slight drystone walling are exposed in many places (Burgess \& Church 1997, 266-7).

The adjacent coastline is characterised by high, impassable cliffs, although immediately opposite Dunasbroc a large concave grassy slope makes access to the shore easy and creates a natural amphitheatre setting for the stack. To the south of the site, the cliff-line becomes lower lying and is punctuated by sandy beaches. The hinterland is a mixture of improved moorland and moor; the coastal areas are currently grazed. There are larger areas of peat moorland a few hundred metres from the coast to the south-east towards Aird Dell, and to the south along Dibidale Burn.

This moorland preserves a relict multi-period landscape, with sub-peat enclosure walls and stone structures appearing through peat cutting (Barrowman, C S 2006, 19; Barrowman, C S 2007, 33). Numerous artefacts dating from the Neolithic, Bronze Age, Iron Age and Norse periods have been recovered in the area over the past 100 years, indicating that the area was once populated and the land worked before the formation of the peat. The Dell River, slightly over $1 \mathrm{~km}$ to the north, is the largest river north of Barvas and would have been a major fishing resource. It also provides easy access to the interior loch fishing and summer grazing areas.

The local geology is a rock platform of Lewisian gneiss supporting low cliffs of till, glacial sands and gravels with marine deposits (Burgess \& Church 1997, 273-4). Behind the site is a raised beach (Angus 1997, 274).

\subsection{Erosion}

Dunasbroc is situated in a 'generally eroding' coastal erosion cell (Burgess \& Church 1997, 270). The CEAL survey concluded that periodic monitoring of this zone is recommended.
The landward side of the platform on the top of the stack retains topsoil and archaeological features, but is actively eroding through many open scars, whilst the seaward side has been completely scoured down to bare rock.

The rock itself is not eroding quickly, as no loose angular blocks or cliff scars were noted. All of the fallen boulders on the nearby shore are rounded and weathered, indicating a long presence there. It is therefore specifically erosion of the vegetation, soils and archaeological deposits that is of primary concern rather than the underlying geology or access to the stack.

\subsection{Access}

Safe access to Dunasbroc (illus 24) was relatively straightforward compared with other sites in the project. It was possible to walk down the grassy landward slope to the rock ramp situated at the foot of the stack. This ramp is approximately $5 \mathrm{~m}$ above sea level, and so is accessible even at high tide.

Adifficult and exposed ledge then wound clockwise from the base of the stack following a natural line of weakness in the rock created by quartz-rich veins. This path included a $0.4 \mathrm{~m}$ wide ledge, which had to be traversed for $3-4 \mathrm{~m}$ before gaining an easier angled ridge which could be followed back anticlockwise to gain the summit platform area.

From the ramp, climbing techniques and rock anchors enabled safe access along the ledge and up the ridge. Once on the summit, permanent bolt type anchors were used to fix ropes for the rest of the team for the duration of the excavation.

Final egress took place using pull-through abseiling techniques whereby each rope can be retrieved from the base of the abseil by using a double rope length.

\subsection{Previous work}

Dunasbroc was wrongly positioned on the 1852 1st edition Ordnance Survey map, an error which has subsequently been copied onto every edition except the most recent, when the place-name was correctly moved south by $150 \mathrm{~m}$. The NMRS entry reads:

Dunasbroc, pointed out at NB 4713 6200, and wrongly positioned on O.S. 6" 1965 , is a conical stack, on which a fragment of low walling can be seen, apparently constructed of quite small, poor quality stones, unlike the wall footing of a dun. [Ordnance Survey (NKB), 16 June 1969] 


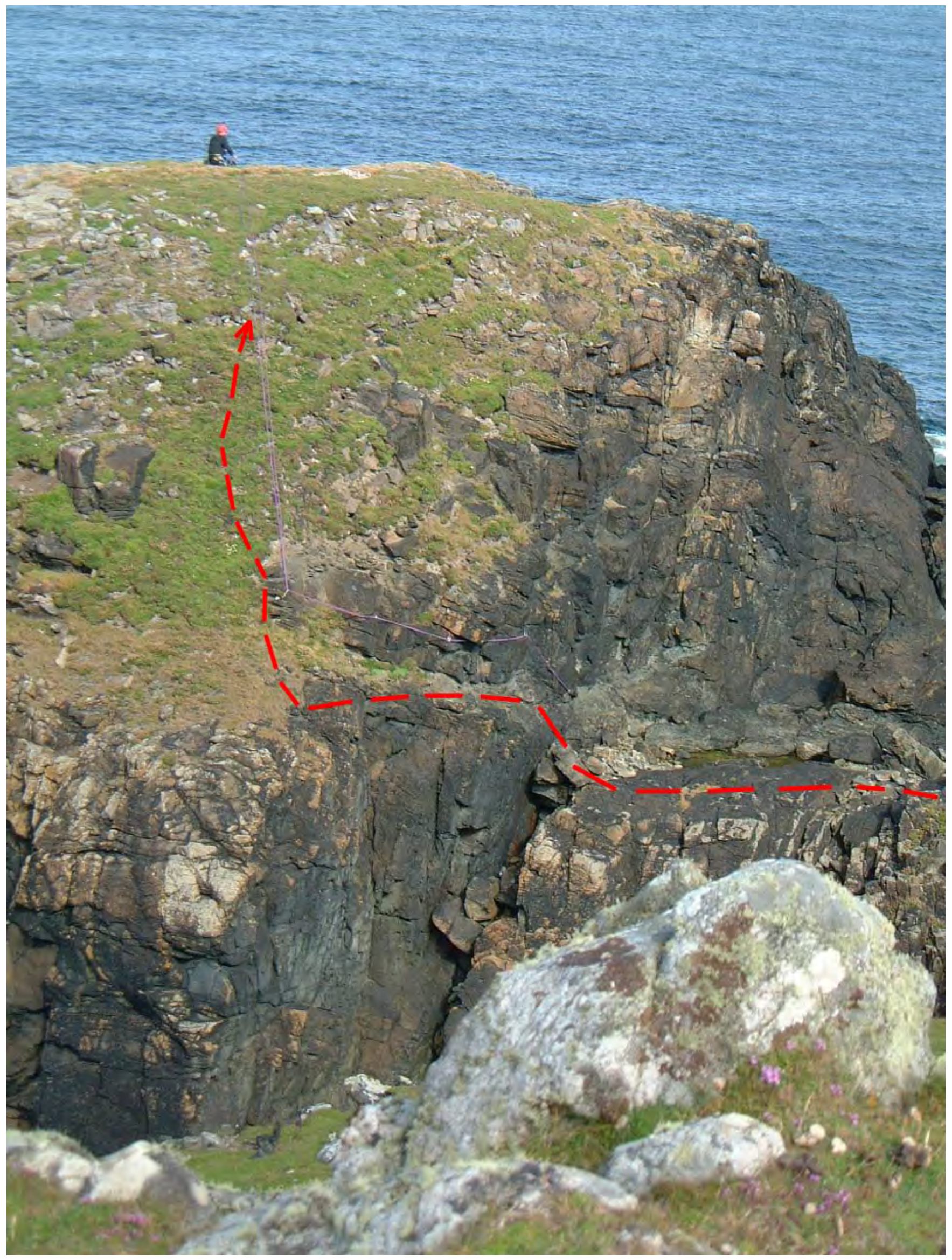

Illus 24 Dunasbroc access from the west 


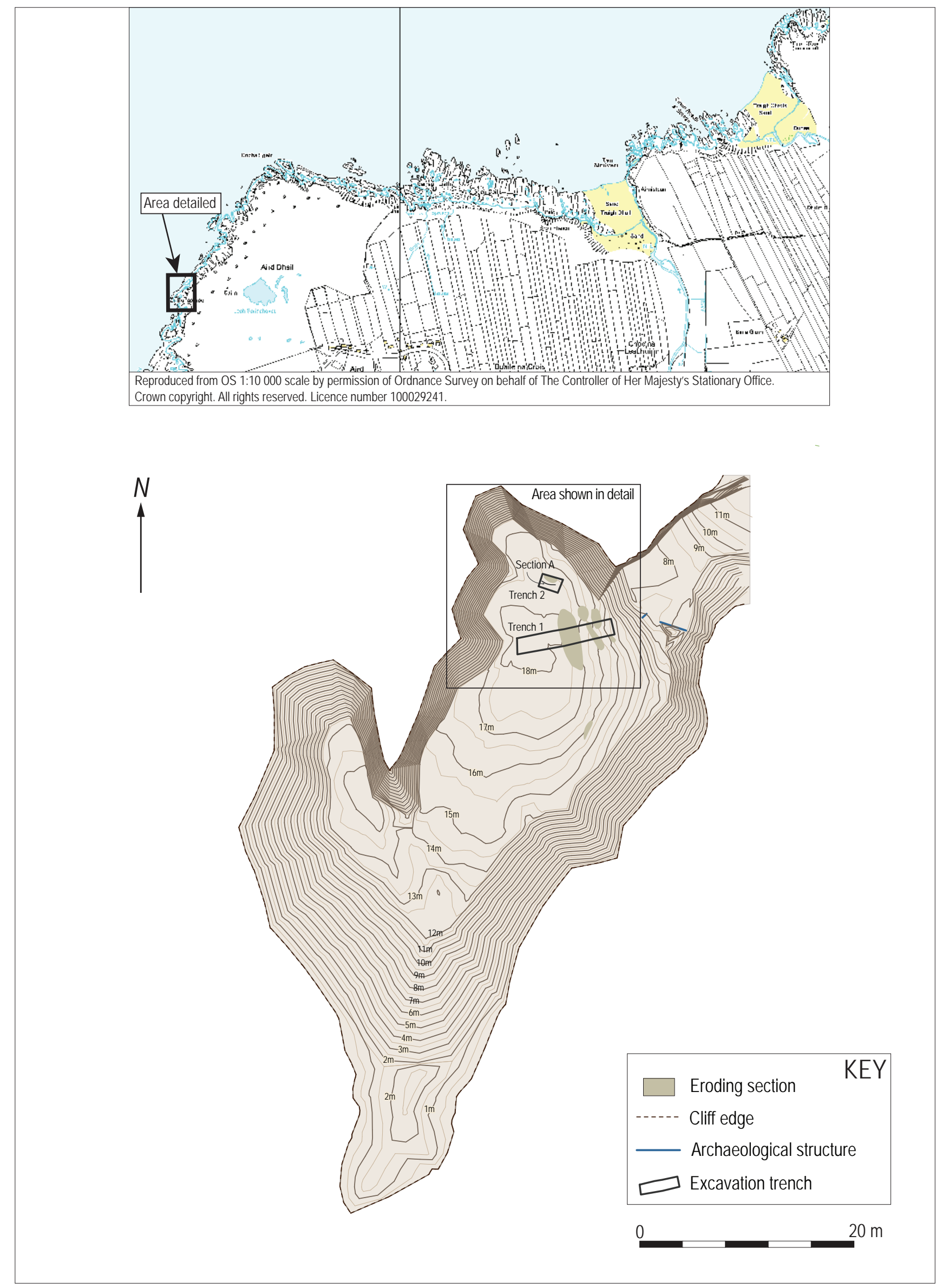

Illus 25 Location map and topographic survey of Dunasbroc 

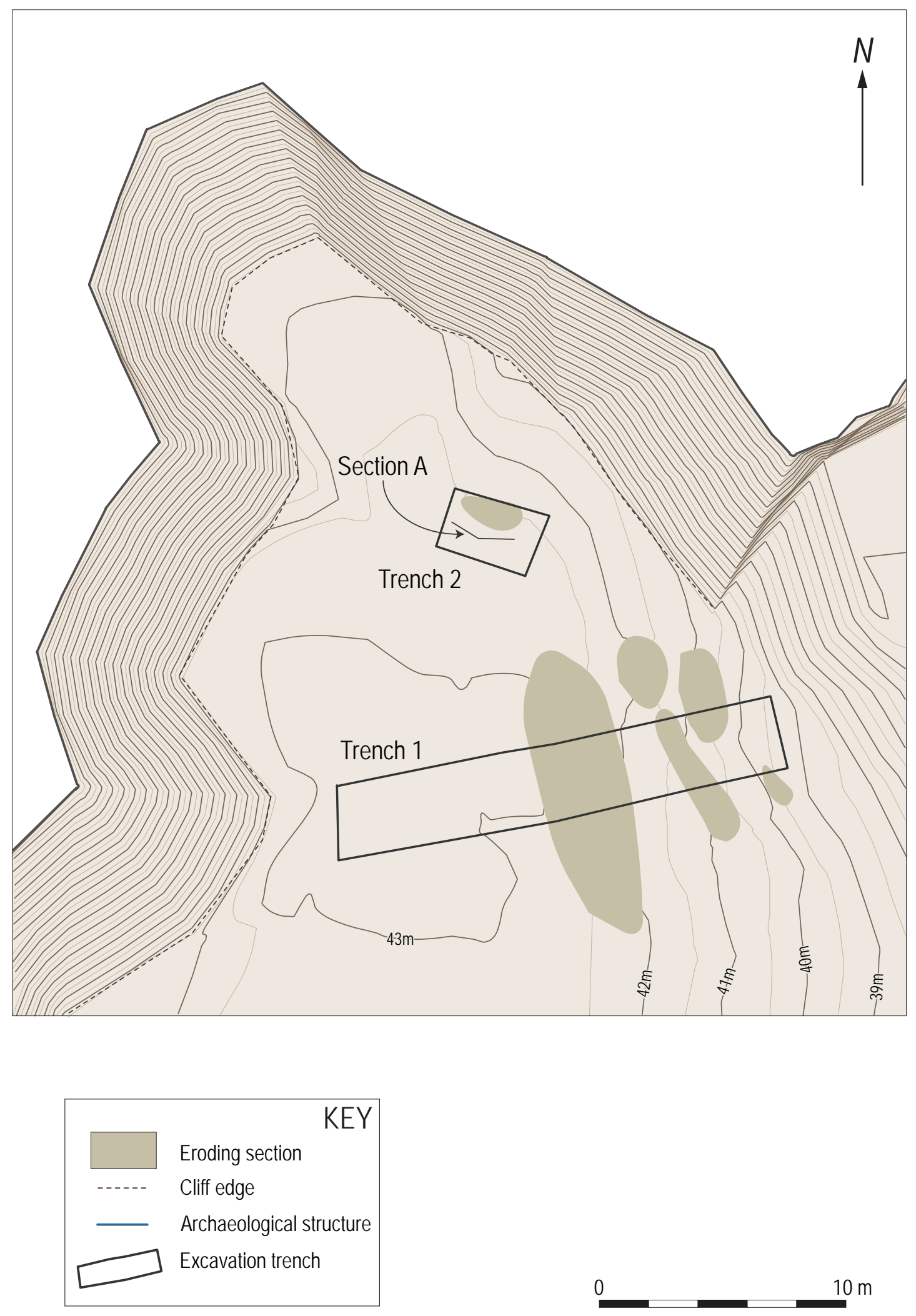


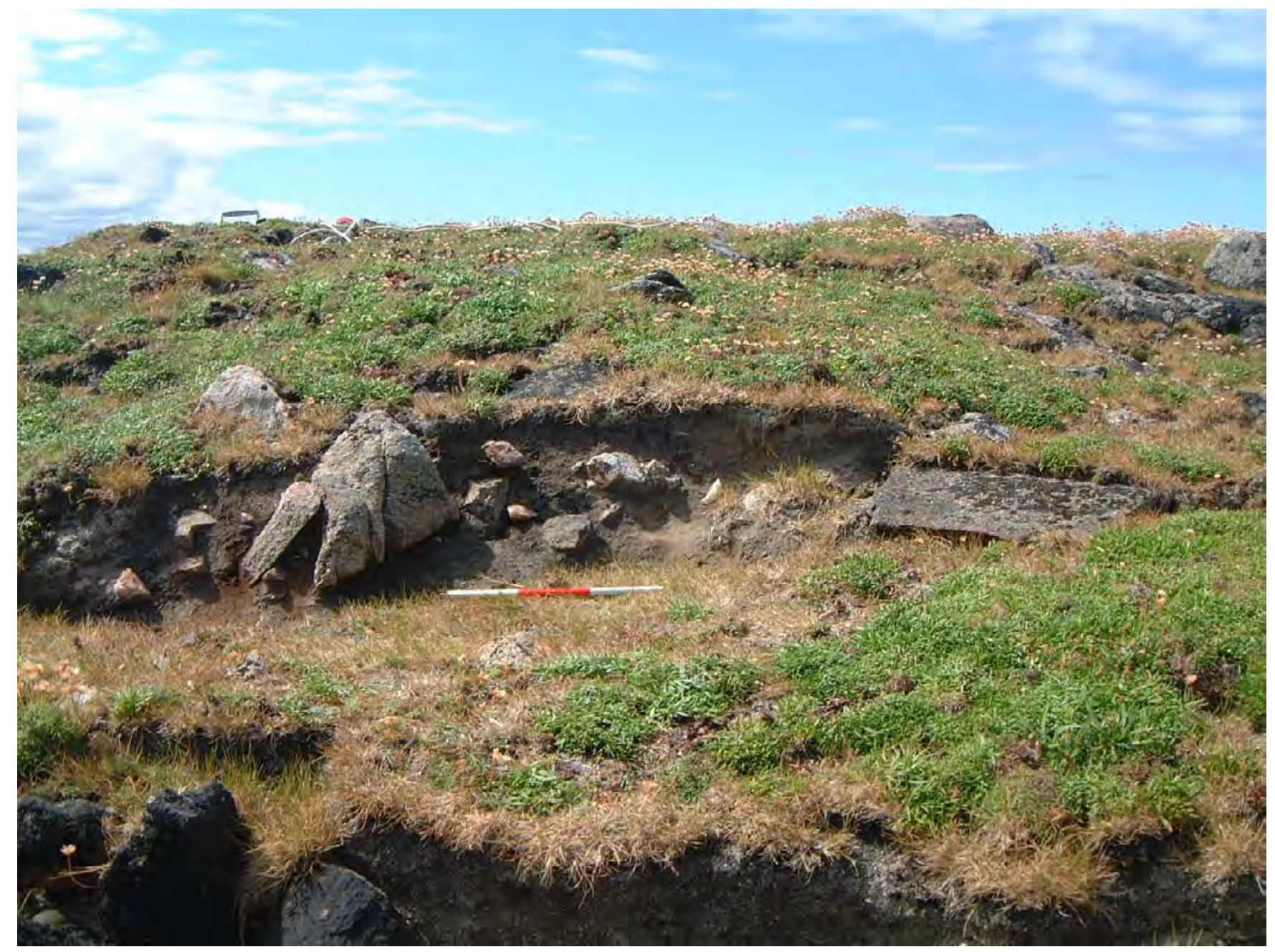

Illus 27 Erosion scar A, Dunasbroc from the east. Scale $0.3 \mathrm{~m}$ long.

The site was also noted during the coastal survey undertaken by the Central Excavation Unit in 1978 (Cowie 1995), and by the more recent coastal survey in 1996 (Burgess \& Church 1997, 266), where it is described as being a stack with an enclosure wall.

\subsection{The survey}

There were no obvious structures on the stack, but archaeological deposits were visible in a series of eroding scars. These scars were scattered through many little ramps and terraces on the steepest, landward face (illus 25). Close examination showed the terraces to be supported by walls and revetments, often running along the contours of the stack and making use of natural outcrops.

Each eroding scar has been identified by a letter, beginning from the north. Their locations are marked on illus 26 .

\section{Erosion Scar A}

A small, $0.3 \times 1 \mathrm{~m}$, east-facing section yielded ceramic sherds, unworked quartz chips and pebbles, small flecks of charcoal and two rough $300 \mathrm{~mm}$-long slabs of gneiss (illus 27). The soil consisted of very compact, almost concreted silty sand, varying from light grey and shell-rich at the top to darker brown organic-rich lower down, without any distinct context change and with charcoal flecks throughout. Sherds of pottery were also found throughout.

Approximately $100 \mathrm{~mm}$ below the top of the scar, within the lighter coloured sediments and towards the south end, two large decorated body sherds of carinated pottery and one rim sherd were discovered, lying laterally and very close to each other as if smashed in situ (SF8, discussed below).

\section{Erosion Scar B}

This large scar on the south-east face of the stack measured $c 6 \mathrm{~m}$ in length by $c 2 \mathrm{~m}$ high. It consisted mostly of a mixture of bedrock and tumbled stone slabs, measuring on average $c 300 \times 500 \mathrm{~mm}$. There were two distinct soil layers, the uppermost being similar to that of section A. The lower was a greybrown, compact silt, which contained occasional pottery sherds, charcoal lumps and broken shells throughout, and was damaged significantly by 


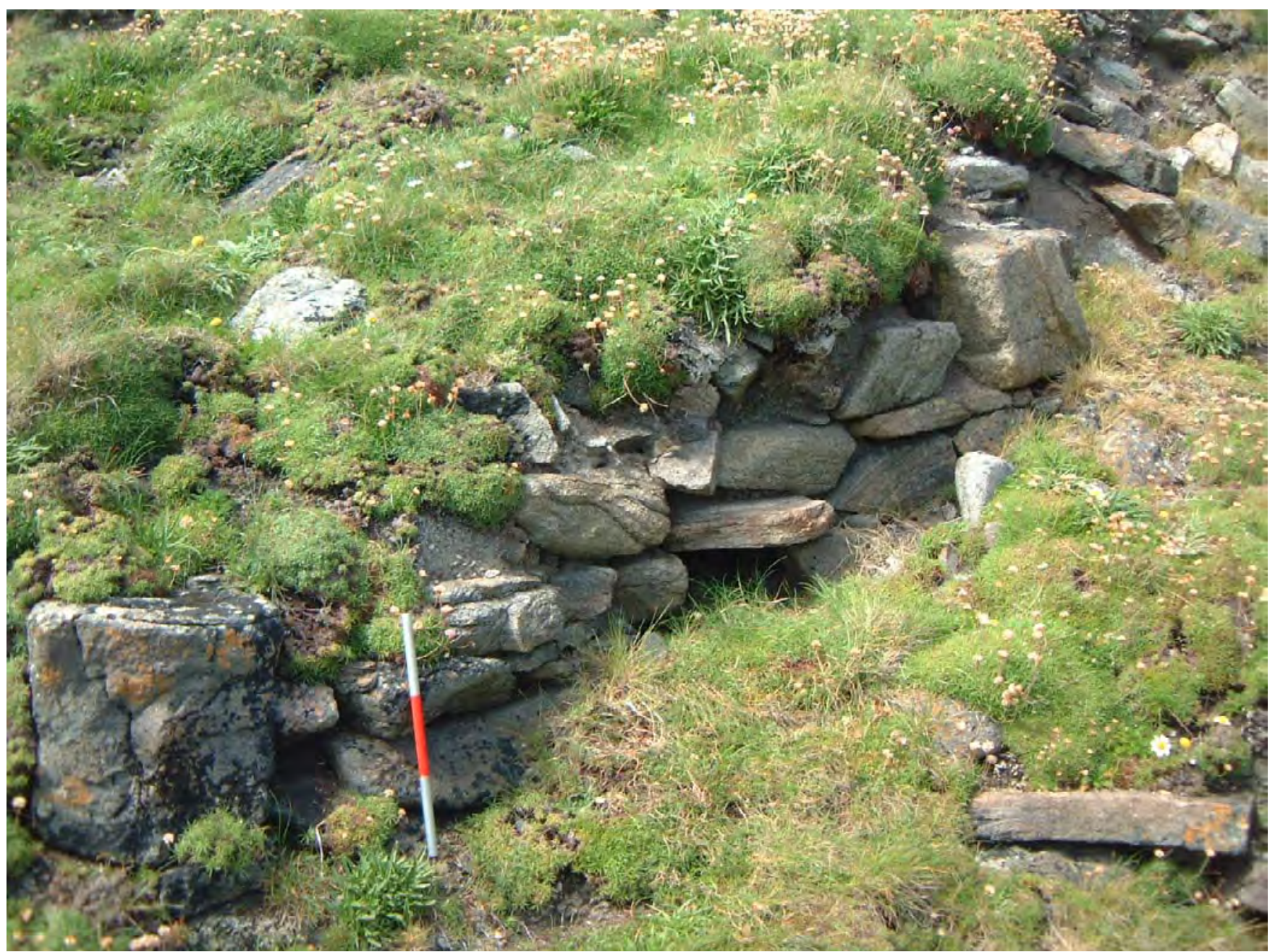

Illus 28 Walling in erosion scar D, Dunasbroc from the east. Scale $0.3 \mathrm{~m}$ long.

rabbit burrows. It also contained lumps of quartz measuring $c$ 20-30mm and a stone burnisher (SF13).

\section{Erosion Scar C}

This eroding scar measured approximately $1.5 \times$ $1.5 \mathrm{~m}$ and is situated down-slope from scar B, forming the eastern side of scar D. Again, bedrock outcropped towards the base of this feature and many tumbled blocks and slabs of gneiss were present throughout. Two large slabs to the south end could possibly have been structural and related to scar D (see below and illus 26).

The uppermost soils here were very similar to those in erosion scar A and the top of scar B, although lacking pottery. A further context of fine, light-brown silty loam with no finds or inclusions was visible towards the bottom $0.5 \mathrm{~m}$ of the section.

\section{Erosion Scar D}

This was the most distinct structural element encountered on the survey. A drystone wall of at least four courses, and measuring $c 0.5 \mathrm{~m}$ long, ran parallel with the contours of the stack for $4 \mathrm{~m}$, on the landward face (illus 28).

The size of the wall stones was in general more substantial than those in the other walls found on the stack, measuring $c 400 \times 200 \mathrm{~mm}$ on average. Two larger blocks, each $c 400 \times 400 \mathrm{~mm}$, lay at either end of this wall, although it is not thought that these were terminals. To the south, the wall disappeared under vegetation and to the north it had probably fallen away, leaving the exposed soil layers in scar C. The soil matrix around the stones was very similar to that of scar C, with a ground stone tool (SF11), and fire-cracked stones found in the upper layers. A dark-brown organic-rich loam, with charcoal flecks throughout, was recorded below those already described.

\section{Erosion Scar E}

This scar contained four courses of dressed drystone wall covering an area $c 1 \mathrm{~m}$ long by $0.5 \mathrm{~m}$ high, resting on bedrock. It may have originally continued to the north but has since collapsed. This section was only 


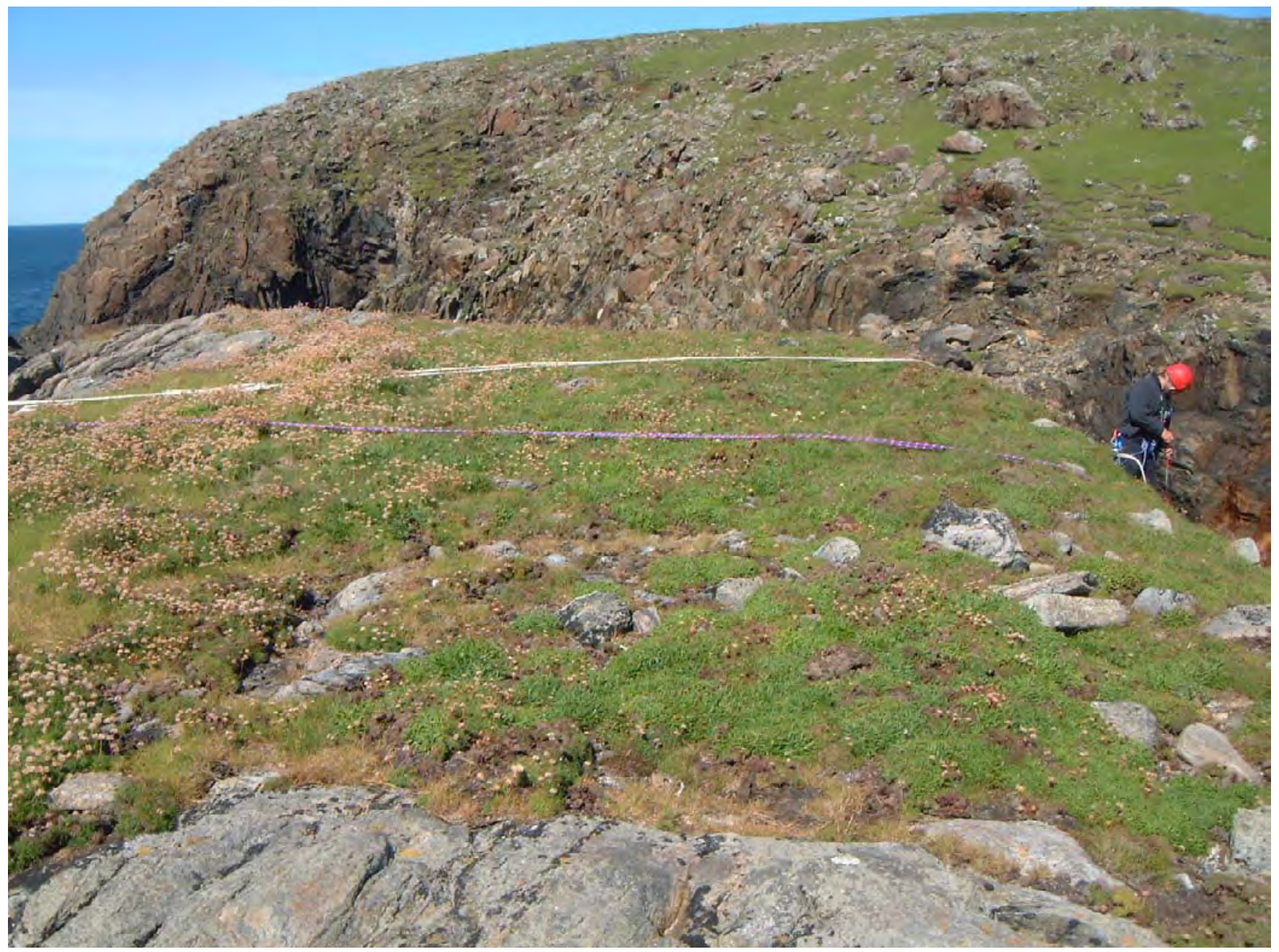

Illus 29 The level summit of Dunasbroc from the east

$1 \mathrm{~m}$ lower than scar $\mathrm{D}$, and could have been related to the wall there, although the blocks were smaller here, being $200 \times 100 \mathrm{~mm}$ in size. The surrounding soil deposits were very similar to the lower deposit in scar D, above.

\section{Area F (illus 25)}

This refers to the $c 3 \mathrm{~m}$-wide ramp that formed the present access route to the site, just above the traverse. It was not clear whether this ramp would have been present in antiquity, and it may have been an outcome of the slumping and erosion of whatever structures were originally present. Again occupation debris such as animal bone, shell and charcoal flecks could be seen within soils very similar to those uppermost in scar A. Stone tools were also retrieved from the surface here (SF4, illus 29).

Erosion Scar G (illus 25)

A small drystone wall, three courses high, covering an area $c 1.2 \mathrm{~m}$ long by $0.5 \mathrm{~m}$ high was constructed of stone slabs measuring $c 400 \times 150 \mathrm{~mm}$. It was sur- rounded above, below and to the sides by bedrock outcrops.

Area $H$

This was the flat area on the top of the stack (illus 26 ). Measuring roughly $15 \times 6 \mathrm{~m}$, the platform was formed of bedrock except on its eastern edge, where vegetation and soils, the latter probably anthropogenic, were noted (see Part III, Section 18).

\section{Erosion Scar I}

Another short length of drystone walling consisted of at least three visible courses of stone slabs measuring $c 400 \times 150 \mathrm{~mm}$. This wall was not very well constructed, with running vertical joints and badly fitting slabs. Like the walling in section $\mathrm{G}$, it was built into a fissure between bedrock outcrops, and did not appear to be structural.

\section{Artefacts}

A total of 48 pottery sherds, five of which were decorated, and five stone tools were collected during the survey of this site. In addition, 
samples of butchered bone and charcoal were also retrieved.

Two large, decorated body sherds and one rim sherd (all joining) were recovered from section A. The pottery is part of a Neolithic assemblage from the site (see Appendix 3, MacSween, below), and has marked similarities with the sherd found at Luchruban (see Section 11).

\subsection{Discussion}

The evidence suggests (see Section 9.2 above) that the landward side of Dunasbroc is relatively stable at present, and may not have suffered active erosion for some time, but it is difficult to assess the degree of change to the access to the site. It is unclear whether there might have been a land bridge present at the time of its earliest use or not. However, the presence of walling on the landward descending edge of the stack suggests that it was, in the past as now, detached from the mainland to a greater or lesser degree.

These small sections of drystone walling (described above in Section 9.5) seem to have been constructed with relatively small, often rounded stones and built with no defensive function. They have a close association with the outcropping bedrock and may have been built for less prosaic, even cosmetic, reasons - in order to blur the distinction between the natural stack and the structure. It is clear that they could not have formed part of a massive defensive structure such as a broch or dun.

Charcoal is present in almost every eroding context on this site, as are shell and bone (including butchered bone). The large number of artefacts recovered indicates that there was extensive activity on this site. This site was examined in more detail by trial excavation, the results of which are described in Part III and Appendix 2 (Matrices), with further discussion in the concluding sections of this report. 


\section{DUN ARNISTEAN}

\subsection{Physical description and location}

Dun Arnistean (NGR: NB 4886 6266; NMRS no. NB46SE 6) is a small, inter-tidal stack lying just to the north of Traigh Dhail (Dell beach) in South Dell, on the north-west coast of Lewis (illus 1). A steepsided and eroding gully separates the stack from the mainland, although it is accessible at low tide by traversing a rocky foreshore a few metres to the north of the gully (illus 30).

The underlying rock changes from Lewisian gneiss to metasediments of the Lewisian complex at this point (Burgess \& Church 1997, 273). These vertical or steeply dipping rocks have promoted the formation of stacks and rocky outcrops such as Dun Arnistean.

The scant foundations of a possible small rec- tangular building lie in the lee of a rock outcrop that forms the summit of the stack. This area was partially excavated in 1970 and periodically during the early 1980s by the late Professor Murray Campbell, and several highly decorated Iron Age pottery sherds were recovered. Approximately 35 sherds were donated to the NMS, and some others to the Comunn Eachdraidh Nis. Miscellaneous stone tools and pot lids were also recorded. The excavation trench from 1970 is still visible.

Numerous sections of walling and masonry are now exposed as a consequence of natural weathering, although it is difficult to interpret the exact shape of any structures. Approximately 80 further sherds of pottery, several pebble tools including small hammerstones and rubbers, two chips of flint, and several pieces of animal bone were recovered and surveyed

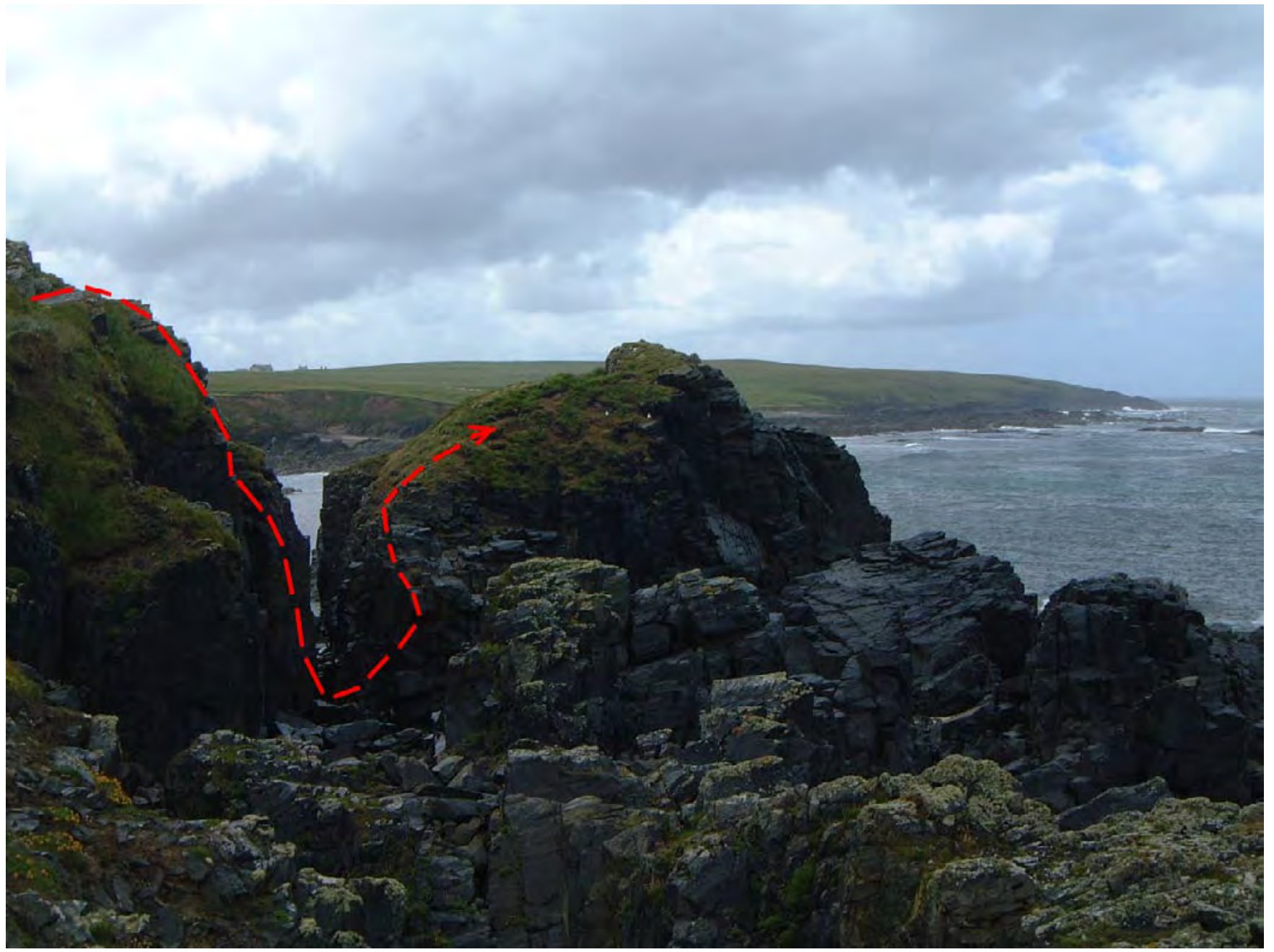

Illus 30 Dun Arnistean from the east showing access route 
in situ. This material lies in a series of bands across the site in relation to the eroding scars.

\subsection{Erosion}

Today the stack is the result of progressive erosion of weaker or softer rock between the stack and the mainland. In the past, the site would presumably have been joined to the foreshore at its closest point, and an eroding rock stack is still apparent on the landward side of the gully. It is impossible to tell when this assumed peninsula would have eroded, and whether it would have preceded any occupation of the stack.

The archaeological structures on Dun Arnistean were relatively sheltered from marine erosion, being sited to the south and east in the lee of the highest point of the stack. A rocky foreshore takes the brunt of the Atlantic swell and extends down to the sea to the north. A rock outcrop caps the top of the site, and extends as an outcropping arm to the southwest corner. The remainder of the stack is covered in grass and turf, and this is where the archaeological structures were concentrated.

There was a high level of surface erosion on the archaeologically sensitive areas of the site. This erosion covered approximately $30 \%$ of the total surface area, and took the form of linear scars, open to the south and running from west to east in a series of shallow terraces to the south-west of the stack. The worst-affected area measured $c 12$ $\times 4 \mathrm{~m}$ in plan (illus 31 and 32 ). What appeared to be wall ends were exposed in many of these scars, and slumped walls and occupation soils (including midden material) were apparent in plan over this area of the site (illus 31). A large number of artefacts (see below and Appendices 3 and 4) were recovered from almost all these areas. There were also some eroding scars on the top of the east-facing slopes.

\subsection{Access}

Although the foreshore below the stack could be reached by walking along a narrow and rocky track a few metres to the east of the site, this was extremely slippery when wet, and would have been overly complicated to protect with safety equipment. It was therefore considered safer and easier to attach a fixed rope from the highest point of the landward cliff edge (illus 30,33 and 34), and abseil down this to the foreshore. From here a relatively easy scramble up the south-east corner of the stack was required, with a fixed rope maintaining security. The rope on the landward side was anchored at two points into a secure rock outcrop using pitons placed into cracks, and on the stack side the rope was anchored by placing an aluminium stake into the soil to a safe depth, with a series of further anchors placed at intervals on the steeper sections of the route. Where stakes were used, they were placed in an area beyond obvious archaeological deposits.

\subsection{Previous work}

\section{The Ordnance Survey in 1852:}

The ruin of what is supposed to have been an old castle, on a small island on the coast at Arnistean. There is no part of it visible at present, except about half a dozen large stones in its foundation. [Ordnance Survey Name Book 1852]

No local traditions describing the use of the supposed dun were recorded at the time, although there is a tradition today that the occupants of the site had a family dispute and some left to go and live at Cnocan Glas (NGR: NB 5013 5971), sited on the flood plain of Dell River (Angus Smith, pers comm; Robson 2004, 12). Cnocan Glas is cited in the NMR as being 'shieling huts (possible), mounds', NB55NW 44. Similar pottery was recovered from both sites by Professor Murray Campbell during his investigations of them in the 1970s (see below). Recent geophysical survey of this site has identified a circular stone structure, possibly the remains of a prehistoric roundhouse, lying beneath one of the mounds (Barrowman, C S 2007b), 46-56). Pottery and round clay beads from these mounds have also recently come to light (Barrowman, C S 2007b, 54).

The Royal Commission described the site as having been a 'circular tower' (RCAHMS 1928). The Ordnance Survey record for 1969 describes the conical stack as being 'of difficult access' with no traces of walling being visible, and no certainty whether the site was ever a fortification.

In 1970 the late Professor Murray Campbell undertook an investigation of the site. There are no available site records from this work, and only personal recollections from local people who were involved with the project.

The NMR entry states:

Considerable quantities of Iron Age pottery found during the summer of 1970 , together with traces of walling exposed by howking. Some of the pottery sherds are in the National Museum of Antiquities of Scotland, and in the possession of Dr Campbell, the finder. (M Campbell, Dept of Chemistry, Heriot-Watt University.)

(Information from Audrey S Henshall, 15 June 1969)

In correspondence with staff of the National Museum, the trench section showed three levels: a top ash level, a central sandy loam layer 9-10 inches $(0.26-0.28 \mathrm{~m})$ thick, with a basal ash layer. Numerous 


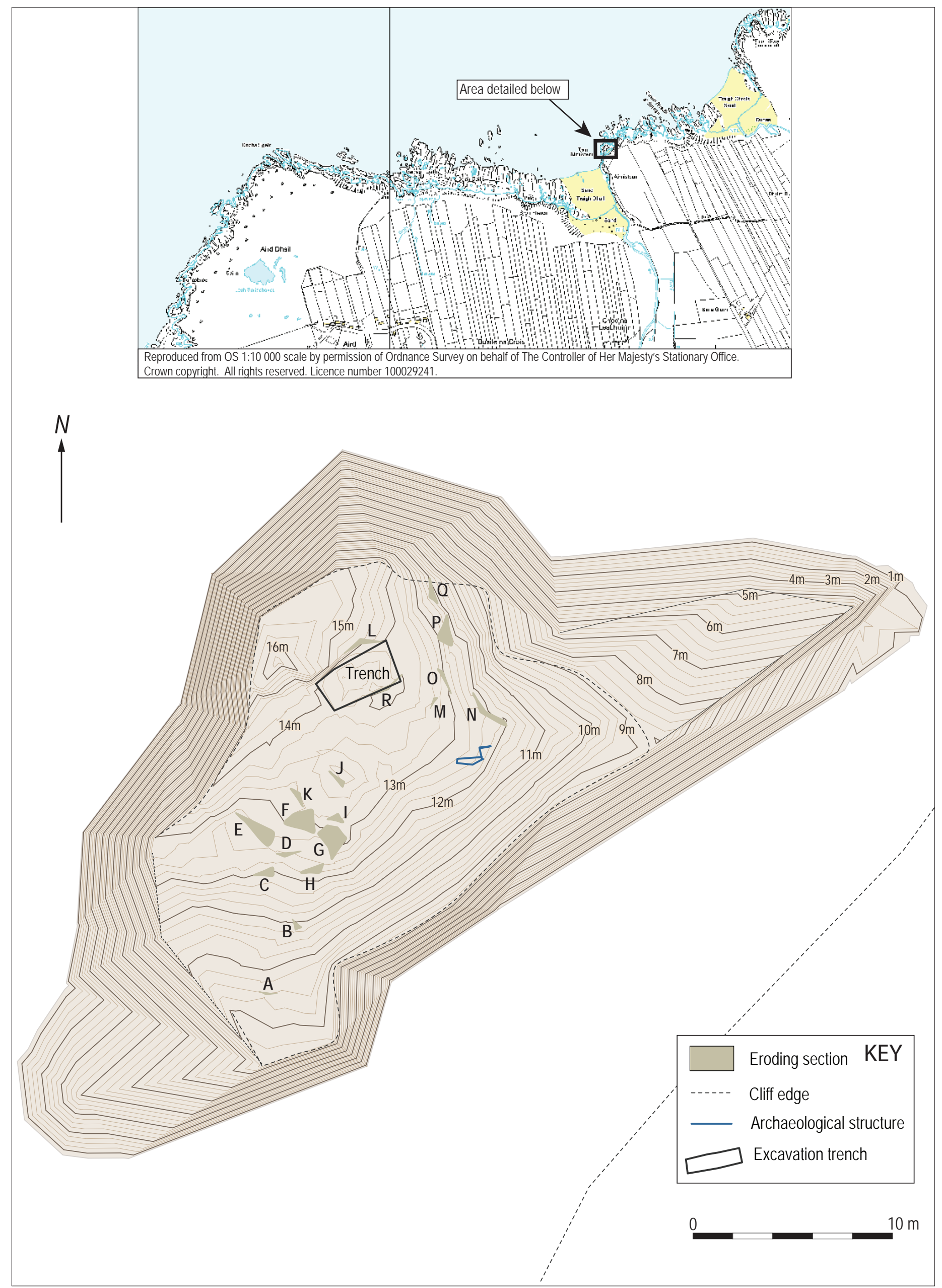




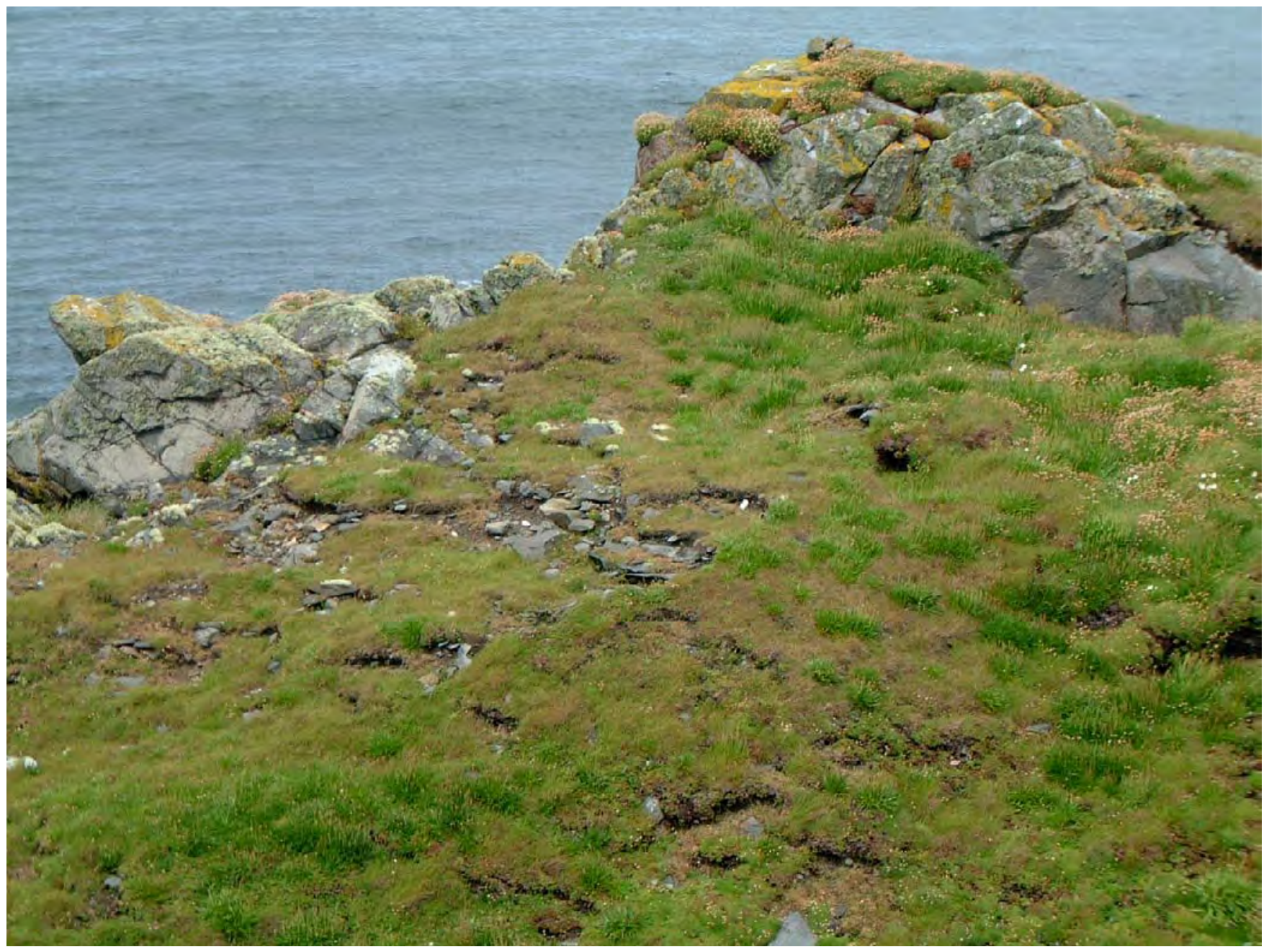

Illus 32 General view of erosion scars on Dun Arnistean from the south-west

stone pounders, whetstones and stone discs were discarded; there was also said to have been much bone present (Cowie 1995, 15). Several highly decorated Iron Age pottery sherds were recovered. Approximately 35 sherds were donated to the NMS, and some others to the Comunn Eachdraidh Nis (Ann MacSween pers comm). A pottery disc bead, 0.8 " (20mm) diameter was also donated to the NMS, along with two stone discs, assumed to be pot lids. More pottery was also recovered in August 1971.

The site was visited and recorded again in 1978 as part of a coastal survey concentrating on prehistoric sites in Lewis undertaken by the then Central Excavation Unit (CEU). This work was commissioned by the Scottish Development Department, Historic Building and Monuments Board (the predecessor of Historic Scotland), and led by Trevor Cowie (Cowie 1995). They recorded:

The traces of the 'excavation' area were still clearly visible (even from the coast edge) in 1978. Despite the exposed location, erosion was limited to the exposed faces of the trench from which sherds (with a total weight of $964 \mathrm{~g}$ ) were recovered. As a result of further erosion and/or disturbance of the site, further pottery, including a complete vessel, was recovered in 1983 (in private possession). (Cowie 1995, 15-16)

The pottery recovered by the 1978 survey was subsequently analysed by Alan Lane (Lane 1995). He classified the sherds as being from the Late Iron Age/ Dark Age, with diagnostic 'zigzag cordons appearing on what may be flaring rim vessels' (ibid, 4). Further vessels are described from the Dark Ages (the Late Iron Age pre-Norse period), with ' . . . two flaring rims and two bases with tongue-and-groove construction ...' although 'there are also cordons in the same collection and the whole group could belong to the Late Iron Age style'. A possible Norse bowl form was also recovered from this assemblage (ibid, 5).

Mention was also made of the discovery in 1983 of a complete pottery vessel from the site. This was excavated by Mr Vaughan and Mrs M Ponting (now Mrs M Curtis), and is now in the possession of $\mathrm{Mr}$ Vaughan, who moved away from the island in the 1980 s. This is the most recent record of any investigation on the site, although it is known that other individuals have discovered and removed pottery from the site (M Robson pers comm). A broken rotary quern 


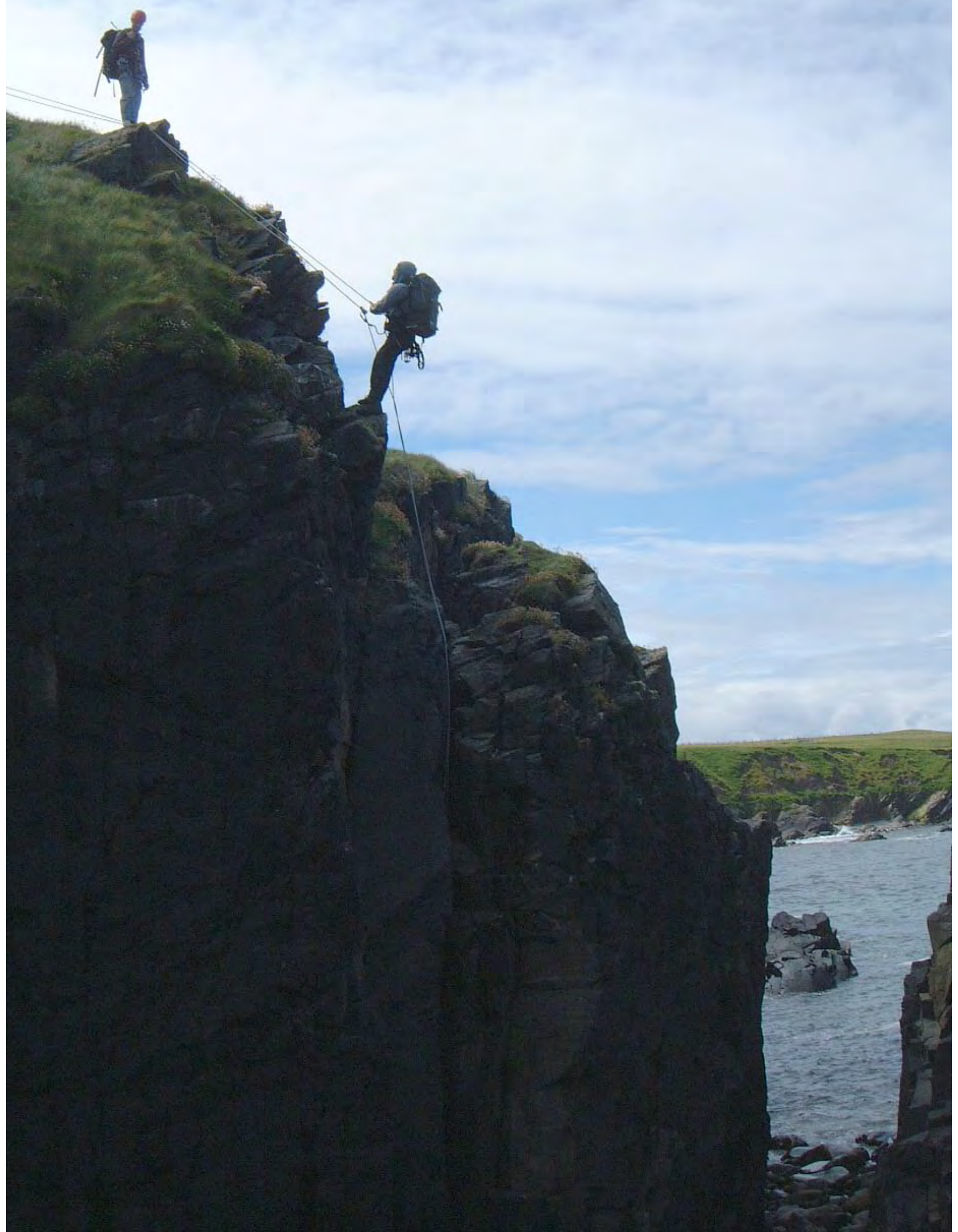

Illus 33 The survey team descending ropes on Dun Arnistean from the east 


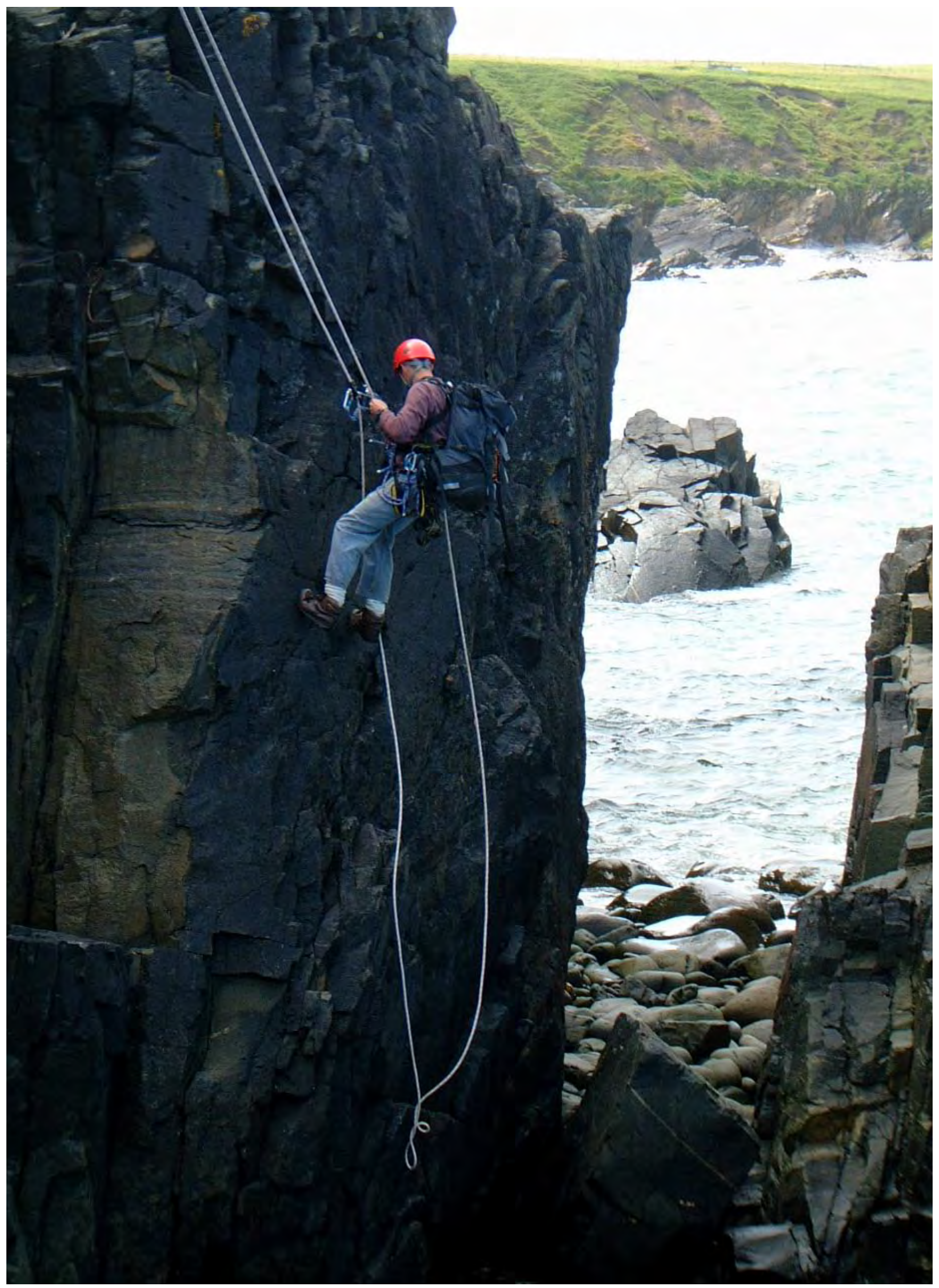

Illus 34 The descent of Dun Arnistean from the east. 


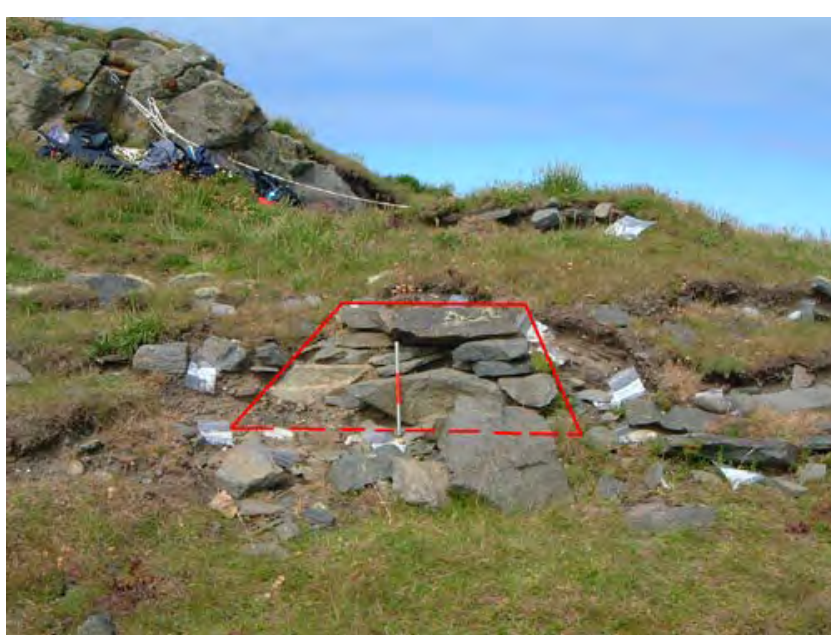

Illus 35 Erosion scar F on Dun Arnistean from the west. Scale 0.3m long.

from the site is in the possession of Mrs M Curtis, and this has been examined and photographed.

\subsection{The survey (illus 31)}

As mentioned above, the southern area of the stack was mainly turfed over. A level plateau sat below the rock outcrop on the centre of the site measuring c $9 \times 6 \mathrm{~m}$, and eroding grassy slopes fell away to the south-west, south and south-east of this for approximately $5 \mathrm{~m}$ before they levelled out slightly, and then fell away more steeply to bare, vertical cliff faces. A small rectangular sunken area was located against the vertical face of a rock outcrop in the centre of the stack. This measured $c 5 \times 2 \mathrm{~m}$ internally, and c $7 \times 3 \mathrm{~m}$ externally. The rock face measured $c 6 \mathrm{~m}$ at its longest, and $2.5 \mathrm{~m}$ high. This feature may relate to Campbell's excavation trench, although a local informant who helped during the excavations suggested the trench was much smaller and that the feature is the remains of a building (A Murray, North Dell pers comm). There is certainly walling visible in the south-east corner of this sunken area, but it lies at right-angles to the exposed section.

Possible turfed-over footings remain of two lengths of wall, one running parallel to the vertical face of the rock outcrop forming the longest side, and one to the east that abuts the rock face to the north, and joins the side wall to the south, forming an end. A near-vertical grassy slope falls away immediately to the east of this end. No stonework is visible within this feature, although the internal faces of the walls described above are actively eroding. A shallow 'spade-hole' measuring $0.3 \times 0.3 \times 0.3 \mathrm{~m}$ was noted in the north-west corner of the structure.

Another short section of turf-covered wall standing to no more than $c 0.3 \mathrm{~m}$ lies south-west of this building, and may represent a separate structure. Halfway down the south-eastern slope, three large boulders sit on a level contour approximately $5 \mathrm{~m}$ below the higher plateau. Scant turf footings of a small section of wall lie $c 1 \mathrm{~m}$ to the east of these. This feature is in line with the most obvious landward access route to the main part of the site.

The remainder of the archaeological features are represented by a series of short and exposed lengths of walling and scatters of artefacts, all eroding from scars to the south-west of the main building.

There are 18 significant eroding scars, described below as A-R (illus 31 for location).

$A$ - The lowest point of the stack in the south-west corner. This curvilinear area of erosion was southfacing and measured $c 0.5 \mathrm{~m}$ in length and $c 0.1 \mathrm{~m}$ deep. The soil matrix was silty sand with pottery sherds and shell throughout, possibly a midden deposit. Two unworked beach pebbles were also present.

$B$-A small scar facing south which measured $c 0.2 \mathrm{~m}$ long by $c 0.1 \mathrm{~m}$ deep. The eroding soil is the same as in scar A above.

$C$-A curvilinear south-facing scar, which measured $c 0.2 \mathrm{~m}$ in length and $c 0.2 \mathrm{~m}$ deep. A section of drystone walling, three courses high, was noticed protruding and slumping from the west side of this scar. The flat stone used in the wall was Lewisian gneiss and each stone measured on average $400 \mathrm{~mm}$ wide by $100 \mathrm{~mm}$ thick. Undecorated pottery sherds were recovered from this scar.

$D$ - Two courses of walling were visible with stones of similar dimensions to $\mathrm{C}$ above, which might have related to the walling in erosion scar C. Pottery and burnt animal bone were also present.

$E$ - Bedrock was exposed in the west of this scar which extended $c 1.5 \mathrm{~m}$ to the east and was on average c $0.2 \mathrm{~m}$ in depth (including scars $\mathrm{F}$ and $\mathrm{G}$ ). It was divided into three due to its erratic shape. It faced south for $c 0.2 \mathrm{~m}$, then curving to the north-east as scar F, and finally swung south to face west (scar G) There was a large amount of tumbled masonry and collapsed walling protruding from these combined scars, along with distinctive occupation deposits and ash layers (illus 35).

$F$ - The middle part of this scar ran as a deep curvilinear scar. As can be seen on illus 35 the wall section had at least four courses and large foundation stones. It may have represented a revetment to the more level plateau at the top of the site (see below).

There were many natural beach pebbles and some worked stone tools from this scar, along with pottery. The distinctive ash layer appeared to be slumped to the eastern side of the wall, and contained distinctive separate layers and charcoal (illus 36). This feature may have represented redeposited hearth material rather than in situ deposits. 


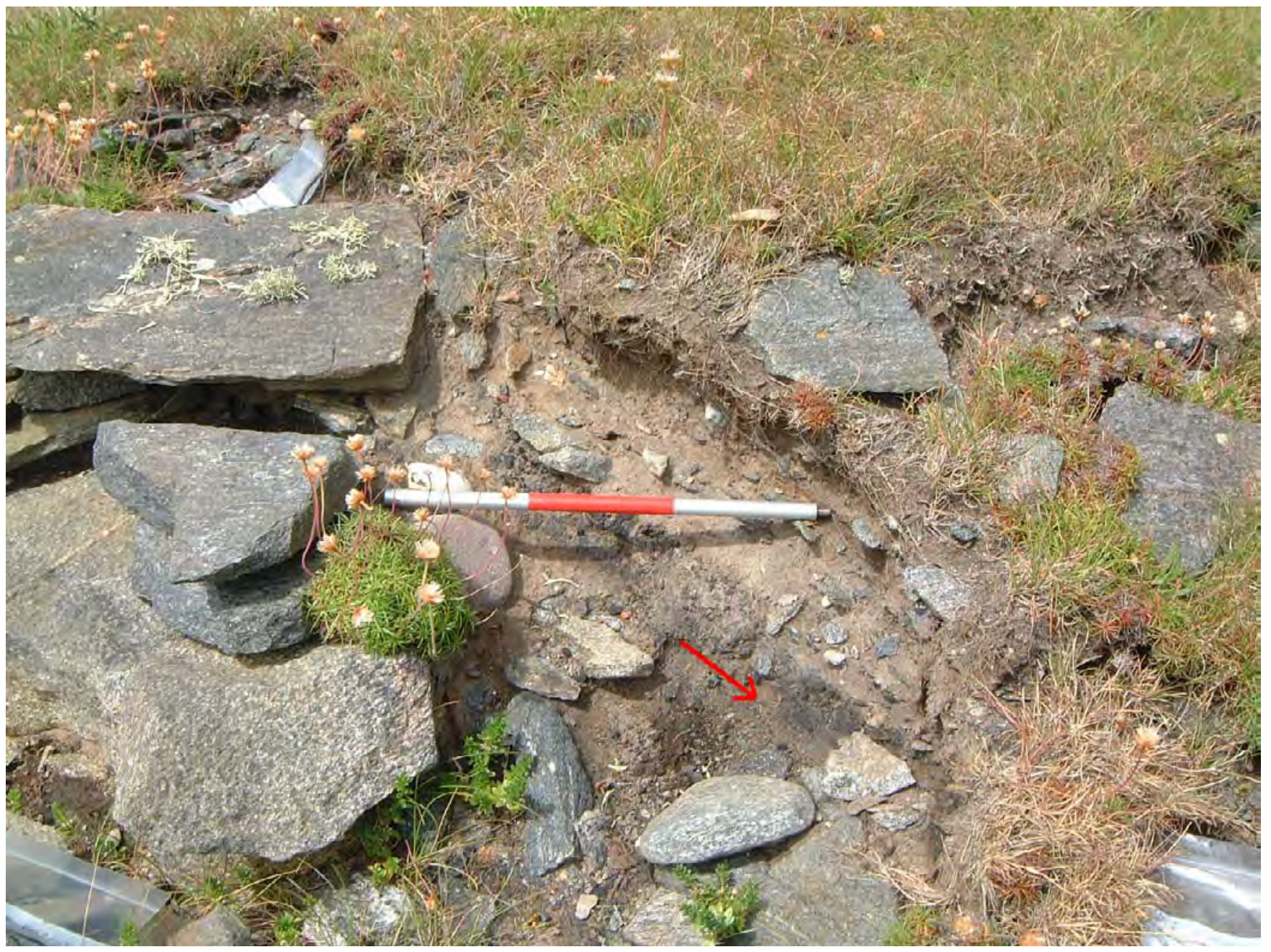

Illus 36 The ash layer in erosion scar F, Dun Arnistean from the west. Scale 0.3m long.

$G$ - The eastern third of the scar ran almost north to south and faced west. More slumped walling was noted to the west of this, and pottery and carbonised material was present within occupational deposits.

$H$ - A small semi-circular scar facing south-west, just to the south of scar G. This measured $c 0.3 \mathrm{~m}$ in overall length, by $c 0.1 \mathrm{~m}$ deep. Some pottery and small stones representing masonry were present.

$I$ - This was a short and shallow scar to the northeast of $\mathrm{G}$, which measured $c 0.4 \times 0.1 \mathrm{~m}$. Pottery was again recovered, with masonry appearing in the scar. The soil matrix was silty sand and similar to that noted previously.

$J$ - This scar was on the more level plateau of the site, and appeared to be cut into what looked like the turf-covered footings of a wall. The scar ran $\mathrm{NW} / \mathrm{SE}$ and faced south-west. It measured $c 0.6 \mathrm{~m}$ in length and $0.2 \mathrm{~m}$ deep. There were five large stones lying side by side along its length, indicating a wall, with a possible second course below. Pottery was recovered from amongst the stones. In plan, the wall was aligned NW/SE and was about $2 \mathrm{~m}$ long and $1 \mathrm{~m}$ wide. It ended abruptly to the south-east.

$K$ - A very shallow west-facing scar, less than $0.1 \mathrm{~m}$ high and $c 0.5 \mathrm{~m}$ long. Pottery sherds were noted throughout its silty sandy matrix.

$L$ - This scar lay to the north of the sunken area, and was south-facing (illus 37). It exposed the soil lying over the rock outcrop, and ran from the top of the stack to the top of the east wall of the building. It measured $c 1.3 \mathrm{~m}$ long by $0.3-0.4 \mathrm{~m}$ deep.

The soil matrix in this scar was fine silt and may have included ash or decomposed turf. Pottery and a possible pebble smoother were recovered from this deposit, which may have been dumped spoil from previous excavations.

$M$-A small scar that measured $c 0.2 \times 0.1 \mathrm{~m}$ to the south of the main structure which faced south. A sheep scapula was present eroding from this. The soil matrix was silty sand.

$N$ - This scar lay to the south-east corner of the contour running $c 5 \mathrm{~m}$ below the level plateau. A large 


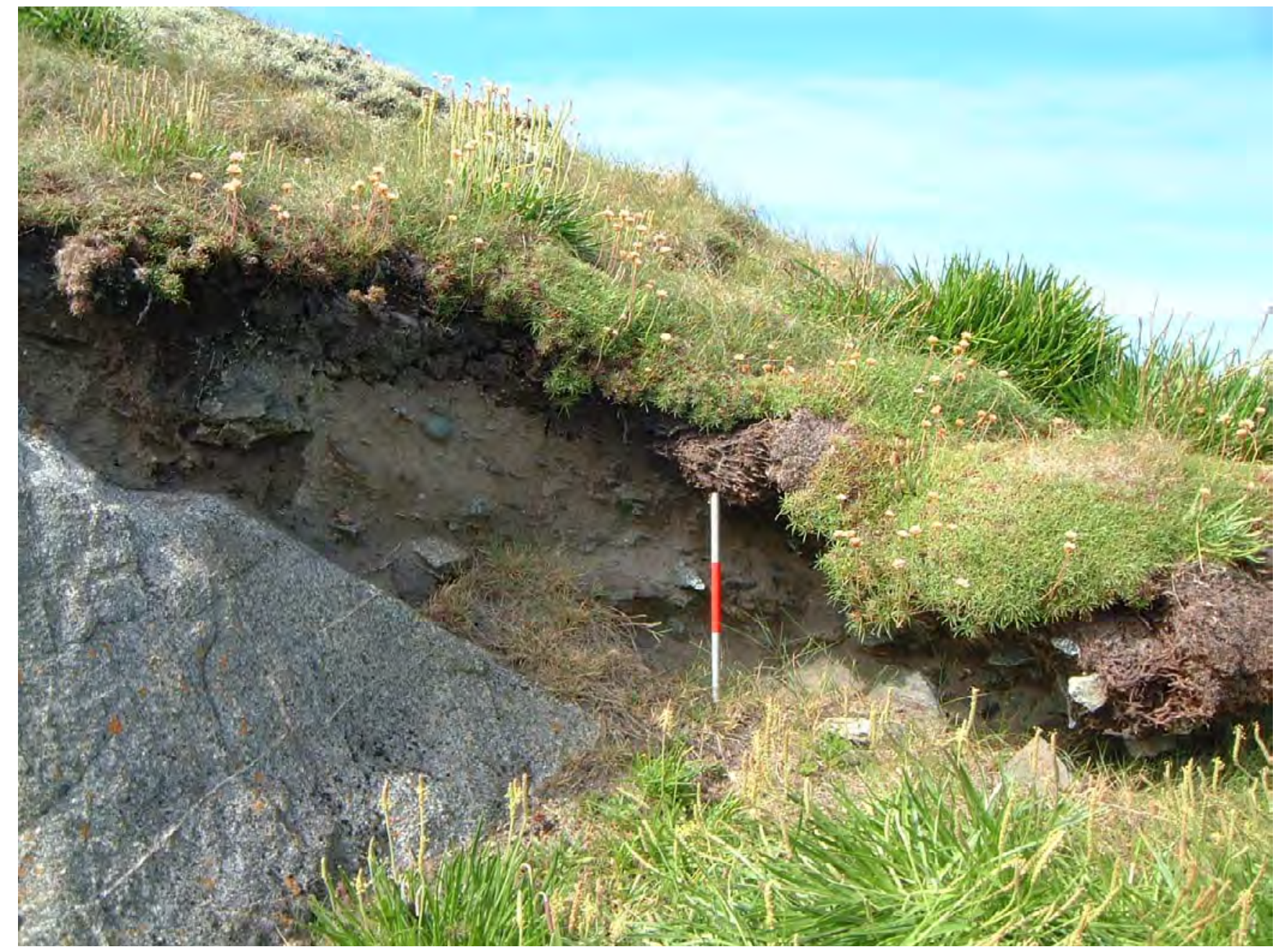

Illus 37 The erosion scar L, Dun Arnistean from the south-west. Scale 0.3m long.

stone $c 0.5 \times 0.4 \mathrm{~m}$ sat at the south end of this scar, and may have formed the end of a wall (described above) running N/S along the extreme east side of the stack.

$O, P$ and $Q$ - Three eroding scars on the east-facing steep grassy slope. These all consisted of eastwardslanting, tumbled walling with no discernible coursework and masonry blocks measuring $c 0.5 \times$ $0.2 \mathrm{~m}$. The soil matrix was fine silty sand, with occasional charcoal flecks throughout. These scars suffered from both marine and animal erosion, including nesting fulmar. Measurements of these scars were on average $0.4-0.6 \mathrm{~m}$ long by $0.3 \mathrm{~m}$ deep. The soil exposed in scar Q lay directly over a rock outcrop.

$R$ - An exposed scar along the internal north-facing wall of the building, which measured $c 2 \times c 0.4 \mathrm{~m}$. There were five courses of stonework visible on the eastern end of the scar, relating to the end wall of a building truncated by excavation. The soil matrix was very fine silt, similar to the deposit in scar L, and it contained pottery sherds. Occasional stones that may have related to the structure of the wall appeared across the scar.
Approximately 80 sherds of pottery, 10 pebble tools (including small hammerstones and rubbers), 2 chips of flint and several pieces of animal bone were recovered and surveyed in situ. The distribution of artefacts was fairly uniformly spread around the eroding scars.

\subsection{Discussion}

This site is of great interest and importance to the settlement record of Ness. The fact that it has been examined in some detail by many others over the past 40 years adds historical significance to the site. The recovery of such a large amount of material demonstrated that there are archaeological remains still worthy of investigation on the site.

Information given about the past activities on the site raises a variety of questions about the interpretation of the structures as seen today. Mr Alec Dan Murray (North Dell) pointed out where Professor Murray Campbell had excavated in the 1970s, within the sunken area on the level plateau of the site. He stated that the small 'spade-hole' in the north-west corner of the structure was the remains 
of Campbell's investigations, the full extent of the excavations. However, it seems more likely that the edges of the sunken area are the edges of Campbell's trench, rather than the eroding internal faces of walls.

There is no surviving evidence on Dun Arnistean for the substantial monumental structures often associated with Iron Age occupation, despite the presence of Iron Age pottery. This negative evidence is supported by the dating of the ceramics (see Appendix 3) to the latter part of the Iron Age, $c$ 4th to 6 th century $\mathrm{AD}$, a period during which architectural forms seem to have become rather less monumental (Armit 1996, 162-78).

Examination of the site through more intensive survey and possible trial excavation is proposed in the future. It is suggested that further recording and recovery of artefacts is undertaken within the next five years, as surface erosion of structures and exposed occupational layers will continue at a steady pace.

It seems likely that a Late Iron Age/Norse building is present at Dun Arnistean. Further analysis should be undertaken on not only the most recently recovered artefacts, but on the collections in the NMAS and in private hands. Attempts should also be made to obtain copies of any notes or drawings that may survive from Professor Campbell's excavations.

Catastrophic erosion and collapse of structures is not likely to occur, due to the nature of the site. 


\section{EILEAN NAN LUCHRUBAN}

\subsection{Physical description and location (illus 38)}

The stack or small island of Eilean nan Luchruban or Pygmies Isle (NGR: NB 5078 6600; NMRS no. NB56NW 4; SAM 5878) lies approximately $1 \mathrm{~km}$ south-west of the Butt of Lewis. The area is characterised by high, incised cliffs of Lewisian metasediment (Burgess \& Church 1997, 283).

The stack itself is a cliff-bound island, separated from the mainland by a chasm $c 30 \mathrm{~m}$ high and $50 \mathrm{~m}$ wide. The slightly rounded surface of the island is heavily overgrown with turf and Armeria maritima which, ungrazed, forms cushions and tussocks varying in height from $c 0.2-0.5 \mathrm{~m}$, masking the surface of the stack and the contours of the structural remains. The plants are not strongly rooted and are vulnerable to damage from walking. The edges of the stack are used by nesting sea birds, but in 2003 there were a few nests on the upper surface of the stack.

In the seventeenth century there was a narrow neck of land joining the island to the mainland of Lewis (Dymes 1630). A structure was visible sunk into the north-eastern corner of the island, at the point of access. This was the structure excavated in the nineteenth century (see Section 11.4), which at the time of the survey was suffering from indirect erosion as a result of collapse of the edges of the open hollow.

\subsection{Erosion}

The coastline from Traigh Sanda around the Butt of Lewis to Port of Ness is considered to be actively eroding in the Coastal Erosion Assessment, Lewis (Burgess \& Church, 1997, 283-4). There is active erosion on the landward edge of the stack and particularly on the adjacent mainland cliffs by the access point to the stack. Here large rock falls are evidence of recent erosion. The seaward side of the island appeared to be stable.

The Ordnance Survey noted a general deterioration of the exposed structure on the top of the stack when they surveyed the site in 1969 . They considered that the structures were 'much less visible' when compared to an earlier RCAHMS plan of 1928 (RCAHMS 1928, 9). Evaluation of these two surveys suggests that the deterioration has occurred to the internal structure of the building, perhaps by

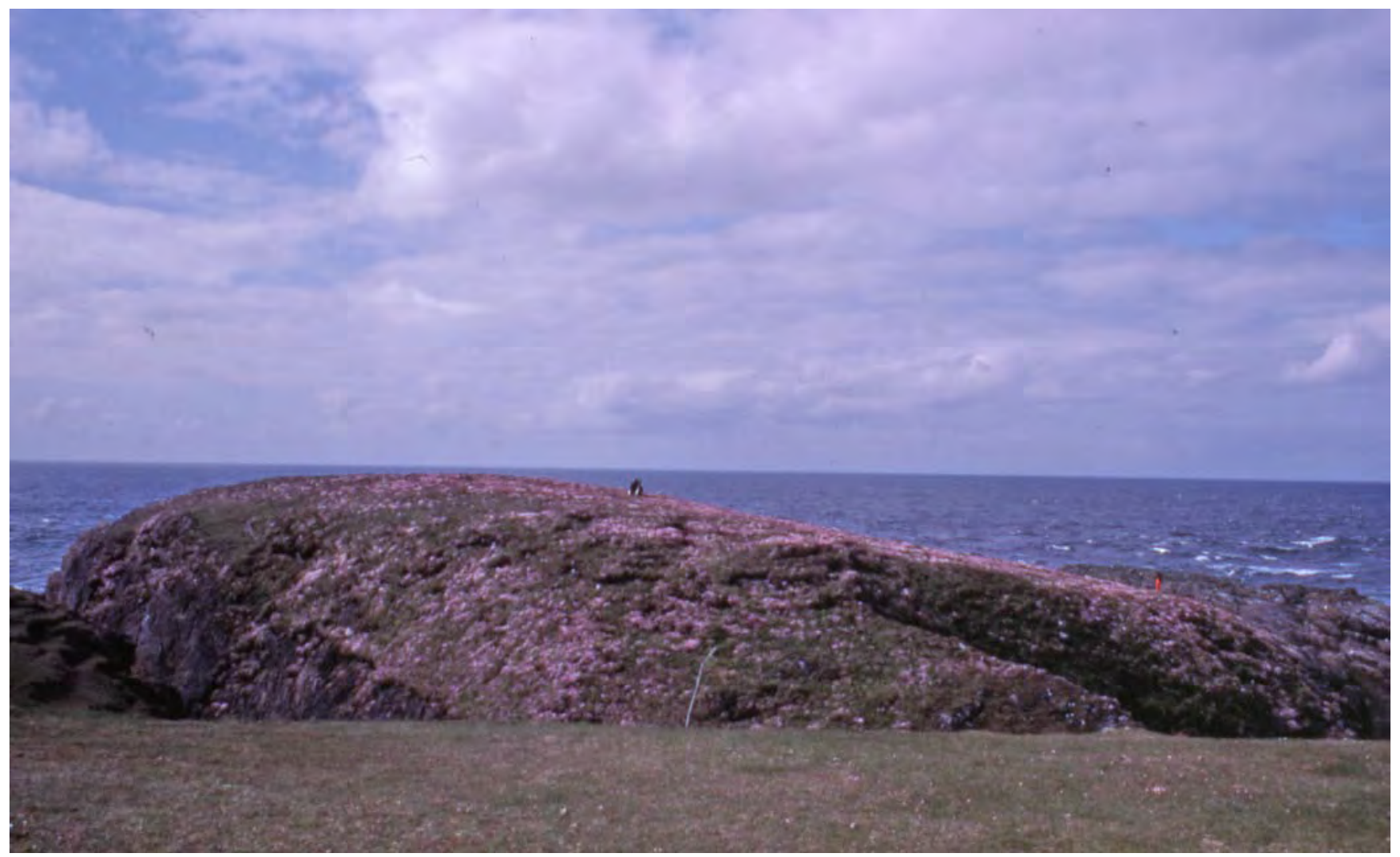

Illus 38 Eilean nan Luchruban from the south 


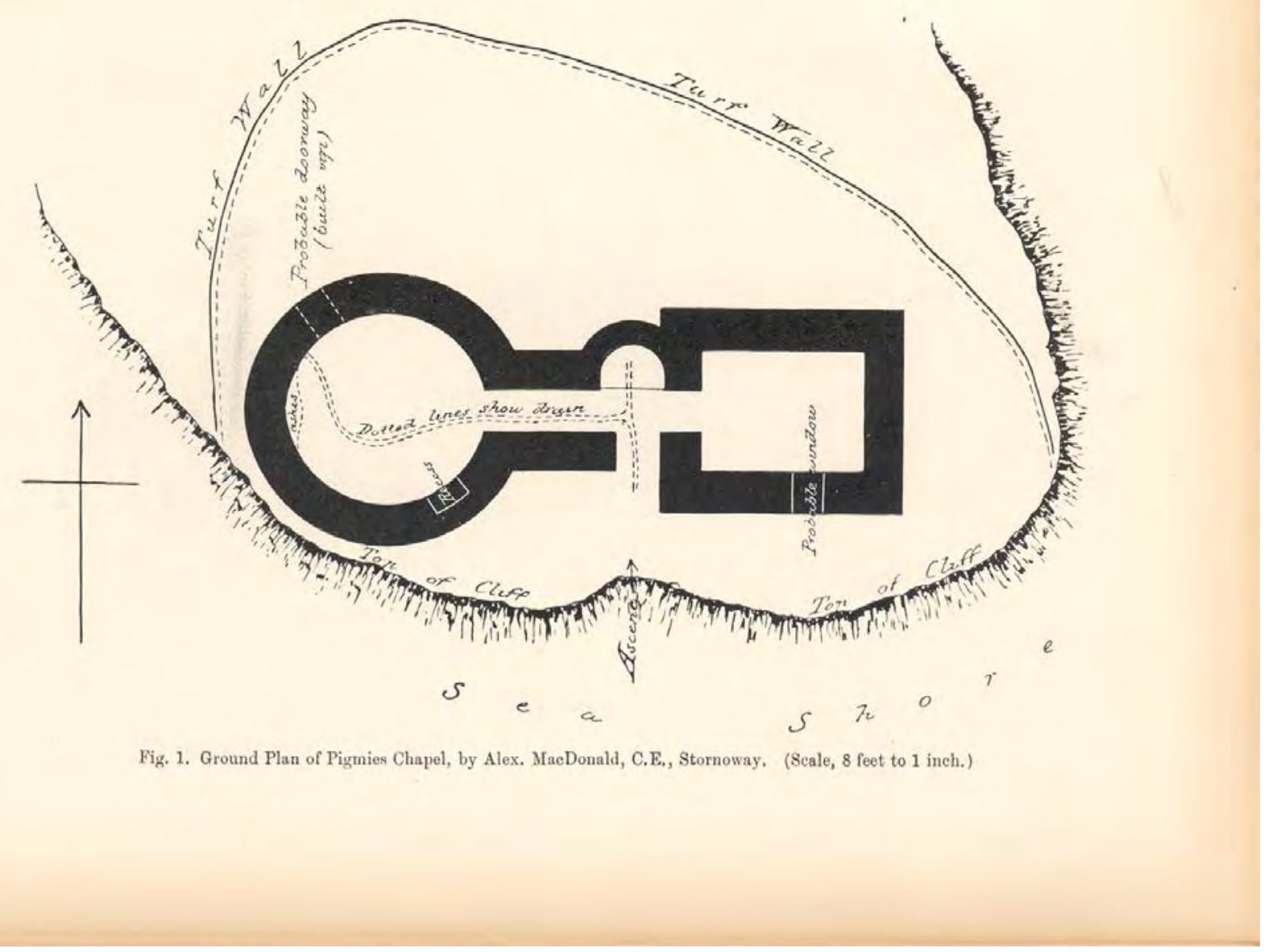

Illus 39 Mackenzie's plan of Eilean nan Luchruban

animal or human agency, rather than to the outer edge adjacent to the cliff line.

The nature and severity of this erosion is, however, not of immediate concern. The main structures are on the sheltered, landward side of the stack, away from the full force of the Atlantic Ocean, and it is unlikely that large parts of the site would be lost in the near future, although slow decay will continue.

\subsection{Access}

Access entailed an initial $1 \mathrm{~km}$ walk, followed by an easy, angled $30 \mathrm{~m}$ descent on fixed ropes attached to stakes driven into the ground. The base of the chasm between the mainland and stack is above most high water levels, so it was possible to walk across to the foot of the stack. From here a $20 \mathrm{~m}$ ascent gained access to the summit. The initial ascent was made using climbing techniques with natural rock anchors. Two stakes were then fixed as far from the visible archaeology as was possible and static ropes anchored from these. On the final retreat, the stakes were lifted and the last descent made, again using climbing techniques with natural rock anchors.

The main risk at Luchruban was from loose blocks of stone around or above the descent route on the landward side, which were potentially very dangerous. This risk was controlled by choosing the most solid route down, and then dislodging all loose rock from above and around this route.

\subsection{Previous work}

Eilean nan Luchruban (the Pygmies Isle) was first mentioned by Dean Munro in about 1549 . He was made aware of the site from the reports made by earlier investigators, although no references are known for these (Mackenzie 1905, 248). He described the site as being a 'kirk' where pygmies were buried. There are several references to the island throughout the following centuries. Captain Dymes investigated the remains in the 1630s, and John Morrison of 
South Bragar mentions the site in 1680 (MacGregor 1967, 178; Robson 2004, 19). Martin Martin also notes the place in his accounts at the end of the 17th century, although it is doubtful whether he visited the site. A full description of these visits and reports has been undertaken elsewhere (MacGregor 1967; Robson 2004). It is important to note, however, that the site appears to have become infamous due to its association with the local tradition that it was once inhabited by 'pygmies'.

William Cook Mackenzie commented upon various excavations carried out on the site, and published a detailed account of those undertaken by his brother and his cousin (Mackenzie 1905, 248-58). He describes a semi-subterranean rectangular building visible on the surface of the stack, and attached by a passage to a circular structure, the interior length of the whole complex being $24^{\prime} 9^{\prime \prime}$ ( $c 8 \mathrm{~m}$; ibid, 253). A stone-lined drain ran under the structure of the buildings. The whole complex was surrounded by an enclosure wall (illus 39).

The Mackenzie excavations yielded five sherds of pottery; a base, three body sherds and a rim (ibid, 252), the latter four of which were identified by R B K Stevenson $(1946,141)$ as Neolithic in date. The base was interpreted as being of more recent date. There is scant stratigraphic evidence for the location of the material, which came from the interface between a dark loam and a layer of sea sand within the rectangular building (Mackenzie 1905, 252).

A plan of the site was published in the RCAHMS Inventory of 1928 (site 22, 9), and was resurveyed at a scale of 1:2500 by the Ordnance Survey in 1969. It was also included in the coastal surveys conducted in 1978 and 1996 (Cowie 1995; Burgess \& Church 1996).

Recent survey work around the site has uncovered the possible remains of several standing stones, which may be associated with the prehistoric activities on the island, and which are to be investigated in more detail in forthcoming work (Barrowman, C S 2007, 29-32; Barrowman, C S forthcoming a) and b)).

\subsection{The survey (illus 40)}

There is a stone-built structure partly dug into the south-east corner of the island, immediately adjacent to the access route used by the survey. An enclosure wall runs around this structure, and there are two slight hollows to the north of this, which may represent further remains below the thick vegetation. Because of the vegetation growth, referred structural measurements below are approximate.

\section{Structure A}

Structure A was the building identified in the past by Dean Munro as a chapel, and it formed the eastern part of the whole structure. This rectangular but much collapsed and overgrown building was orientated $\mathrm{E} / \mathrm{W}$ and was semi-subterranean (illus 41).
Its internal measurements were approximately $2 \times$ $2.5 \mathrm{~m}$. One clearly defined drystone wallface survived a maximum of six courses on the SW-facing side (illus 42). The opposing wall formed a curve of loose, irregular stone and was partially obscured by vegetation. This appeared to have been rebuilt recently, and may have been the result of reconstruction of the building after excavation in the early 1900s. There was no sign of the passage exit connecting this structure to Structure B.

Three plain sherds of pottery were recovered from this building, two body sherds and one base sherd. They came from an eroding scar north of the internal wall and are late prehistoric or later in date (see Appendix 3). A hammerstone was also recovered from a further eroding scar in the northern wall, although at a higher point, and it is possible that this came from the backfill of Mackenzie's excavations. Three probable struck quartz flakes were also found.

\section{Structure B}

Structure B was the circular building described by Mackenzie $(1905,252)$. Its form appeared to be slightly oval, with a long axis orientated N/S, but the structure was much overgrown and collapsed. On the north-eastern edge of Structure B, a wall corner was visible, presumably the north-western edge of the passage which joined Structures A and B. There was no longer any sign of the drain described by Mackenzie (ibid, 253).

\section{Structure C}

Structure C lay to the west of A and B, and consisted of a slight, oval concavity, which may have been structural, in the terracing of the island surface. It measured $3 \times 4 \mathrm{~m}$.

\section{Structure D}

Structure D was another slight, circular concavity to the north-east of Structure C, with traces of a possible retaining drystone wall around its northern edge and a large stone slab along its eastern edge. It measured $c 4 \mathrm{~m}$ in diameter and was heavily overgrown.

\section{Structure E}

The enclosing wall shown on Mackenzie's plan (illus 39) was a circular wall, running around the northwest side of Structures A and B, and to the north-east of Structure A before reaching the cliff edge, and curving around to the south-east. There was a small break of $c 2 \mathrm{~m}$ in the wall at this point which was used by Mackenzie and STAC as the access route. The wall began again to the south of Structure B, and curved round the south-west and west sides of this before joining its northern extent (illus 40).

The wall seemed to form an external wall to Structures A and B where it abutted them to the north-east, east, south and south-west, and enclosed an overgrown but slightly concave area to the north and north-west. The entire wall was circular in plan, 


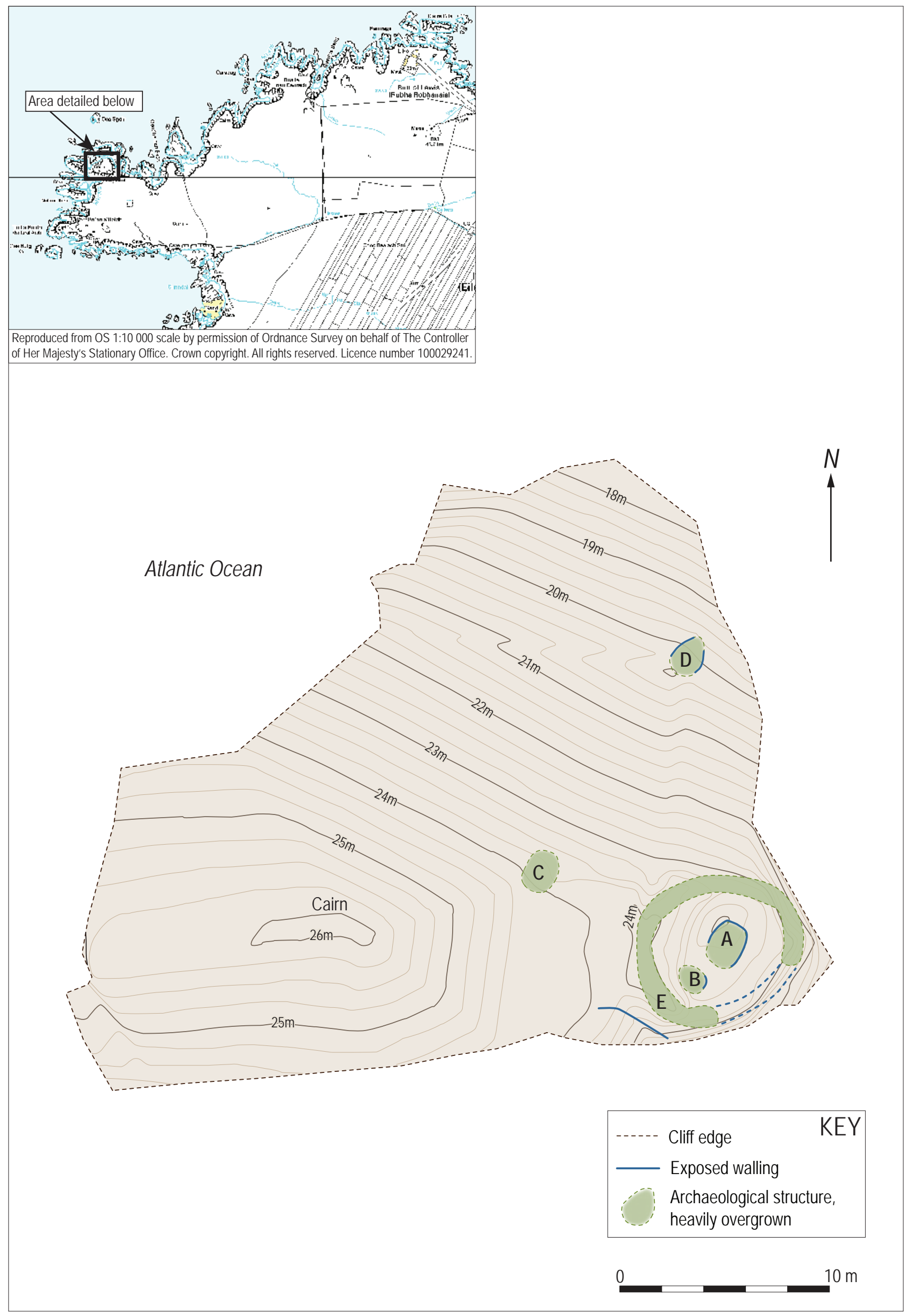




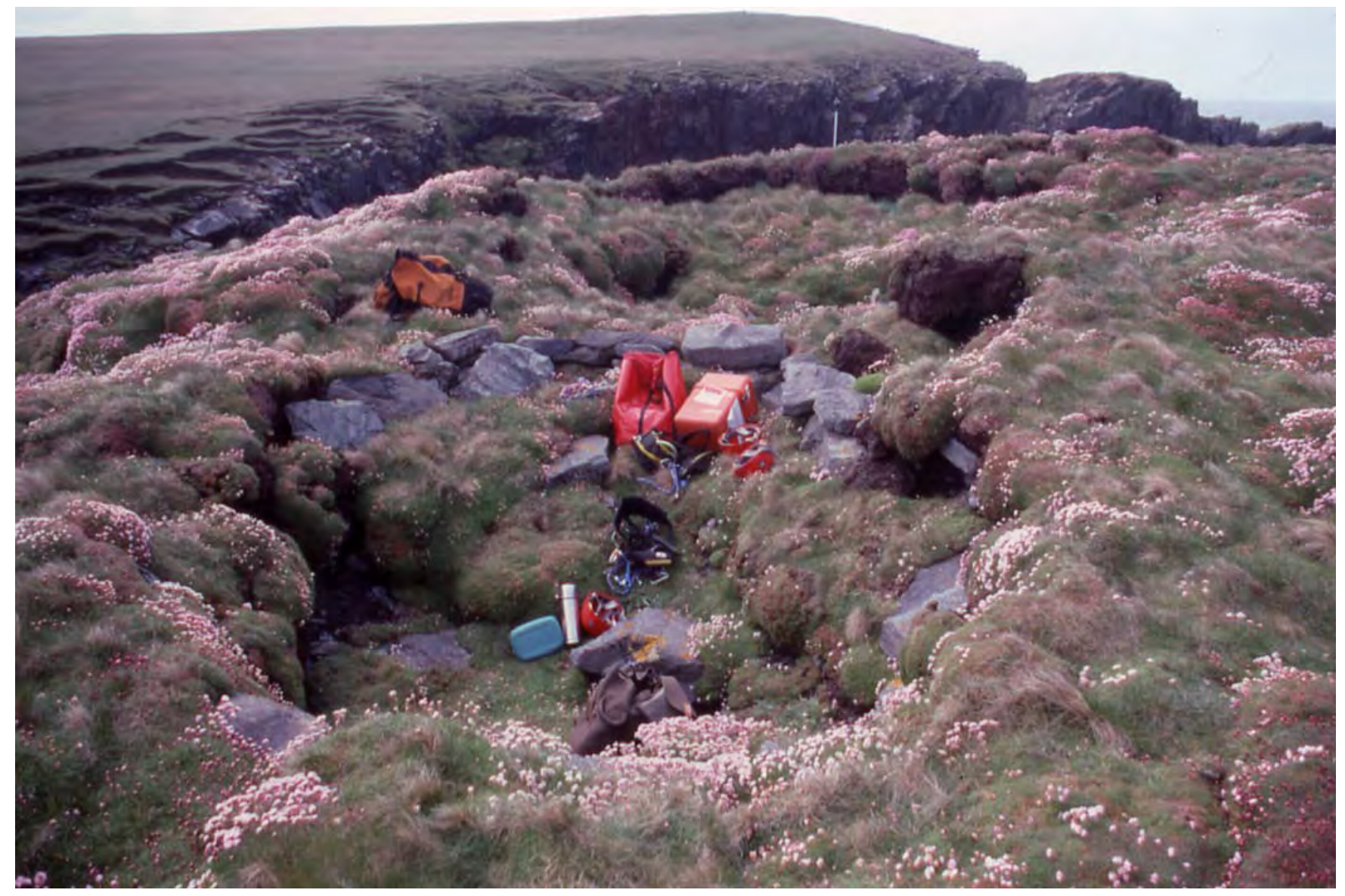

Illus 41 (above) General view of Structure A, Eilean nan Luchruban from the north

Illus 42 (right) Walling of Structure A, Eilean nan Luchruban from the south

and measured $c 12 \mathrm{~m}$ in diameter, and was $1.5 \mathrm{~m}$ broad on average. No stone work was visible, given the thick vegetation cover, although there were some eroding faces to the south and south-west, outside and downslope of the wall, which showed coursed stonework. This indicated the extent of the archaeology to be at least $4 \mathrm{~m}$ from Structure A.

\subsection{Discussion}

On the basis of an early tradition of a chapel referred to by Dean Munro in 1549, this stack has been identified for many years as an early Christian oratory or hermitage (eg Thomas 1971, 85-6). There is, however, no place name evidence for such an attribution, which may have derived

Illus 40 (opposite) Location map and topographic survey of Eilean nan Luchruban

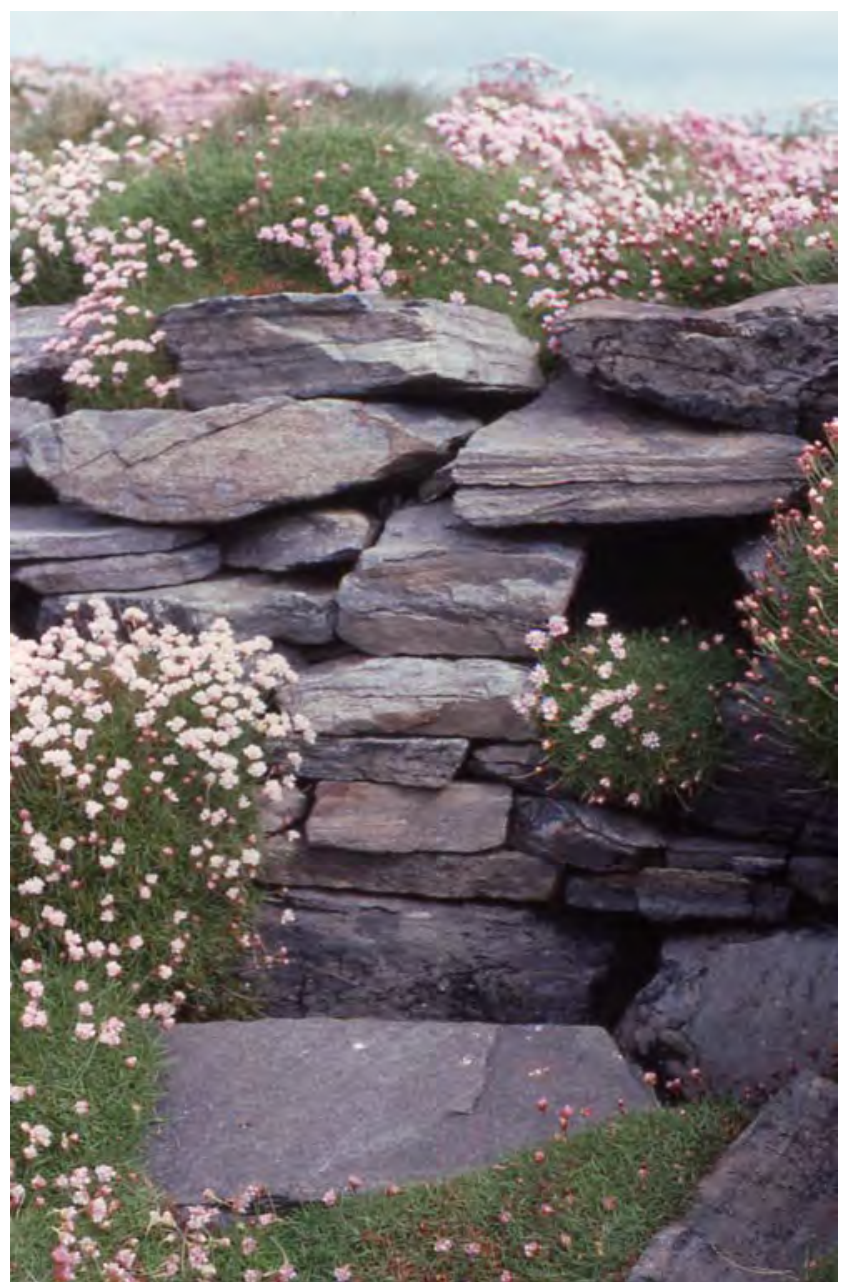


from the finding of bones on the site (Mackenzie 1905, 248-9). There is also no supporting archaeological evidence for an ecclesiastical function, and the presence of Neolithic pottery provides a very positive prehistoric dating. Whilst an earlier occupation does not preclude an early Christian presence, the lack of evidence for the latter means that the traditional interpretation of the site should be reassessed.

There is also a major difference between the survey produced in this report, and that published by Mackenzie (1905, illus 39). Where the original plan shows two compartments joined by a passage, orientated $\mathrm{E} / \mathrm{W}$, and enclosed by a turf wall, the
STAC survey shows that the enclosure wall is more substantial and circular, enclosing the building formed by Structures A and B. Although the shape of the internal structures is hard to discern, and there is only one visible wall face, the rectangular structure it represents is aligned $\mathrm{NE} / \mathrm{SW}$, and runs parallel to the enclosing wall at its south-east side. Indeed, the one visible internal face may correspond to the internal face of the enclosure wall, and when this is considered along with the circular form of the outer wall, the whole structure gives the impression of a roundhouse. Perhaps the passage described by MacKenzie was part of a gallery, now either hidden or destroyed. 


\section{DUN EÒRADAIL}

\subsection{Physical location and description}

Dun Eòradail (NGR: NB 5426 6297, NMRS no. NB56SW 13) is an inter-tidal stack or small island located less than $500 \mathrm{~m}$ from the Eorodale road end at Ness, and roughly $4 \mathrm{~km} \mathrm{SE}$ of the Butt of Lewis. The coastline is characterised by high cliffs of Lewisian complex anorthosite and metasediments (Burgess \& Church 1997, 291). The stack itself is cliff-bound on its eastern, southern and western sides, with a steep rocky promontory running towards Port of Ness to the north. It has a diameter of $c 200 \mathrm{~m}$ and is slightly rounded on top. It is covered in grass and has been used to graze sheep until very recently. The grasscovered footings of a number of buildings are visible on the south-eastern edge of the island.

\subsection{Erosion}

The site and the coastline around it are actively eroding (Burgess \& Church 1997, 289). There is evidence of recent rock falls at the landward side of the northern extremity of the site, where the traditional access has been. The erosion of the access route was confirmed by the occupier of the croft adjacent to the site, who informed the project that a substantial amount of rock had fallen off the landward side of the stack within the last 30 years, making access to the stack much more difficult (Calum MacKenzie, Eorodale, pers comm). This erosion potentially threatens part of the enclosure wall (Structure P, below)

\subsection{Access (illus 43)}

The access involved an easy walk through croft land to a rocky beach. It was only possible to reach the base of the island at low tide. A $10 \mathrm{~m}$ ascent up a near-vertical rock face, using climbing techniques, led to the top. Temporary rock anchors were used to secure the ascent route, while two stakes were fixed on the summit in order to anchor two static ropes for the remainder of the visit.

Due to the tidal restrictions, three members of the team camped on the island for one night so that the survey could be completed. Work on the site was timetabled to fit in with a forecast of a two-day spell of fine weather and suitable tides.

\subsection{Previous work}

Martin Martin was the first to describe 'Dun-coradil' as a natural fort in 1695. Despite the discrepancy of name, he was probably referring to Dun Eòradail, as it was clearly a known site when, in the nineteenth century, it was described by the Ordnance Survey in 1852 as 'A small but high island, which is isolated only at high water. There is the site of an old building on its summit, more like the site of a shieling than a castle.' (Ordnance Survey Name Book 1852). In his article on the Duns of the Outer Hebrides, Captain Thomas noted it as 'a small tidal island joined at low water to the main[land] by an Eyrr or Ore, ie beach, and which has apparently been fortified by a wall (Thomas 1890, 369).

The site was surveyed at a scale of 1:2500 in 1969 by the Ordnance Survey, who identified 'ten small rectangular stone-built huts with rounded corners, now heavily turfed. There are slight traces of a wall along the north-east side of the island but this does not seem to have been defensive, and was probably a turf wall reinforced with stones to keep animals off the cliff' (Ordnance Survey, 18 June 1969). They interpreted the site as a medieval settlement, on the basis of its similarity to Dun Eistean (Barrowman \& Driscoll 2000; Barrowman, C S 2001), which lies $c$ $2 \mathrm{~km}$ to the north.

\subsection{The survey (illus 44)}

The surface of the stack was covered in grass that had been grazed in recent years, and was therefore not particularly overgrown.

There were a total of 13 structures, concentrated on the highest area of the island to the north-east. Most of these were small, oval hollows or depressions in the ground, with only the faint traces of walling remaining. The largest structure was a rectangular stone building, which is located in the centre of the island. A stone and turf perimeter wall could be followed around the south, south-east and north sides of the island.

The archaeological remains were clearly visible, but it was often not evident whether the structures were constructed of turf and/or stone. Because many of the structures appeared as hollows or concavities with no clear standing walls, only internal faces were recorded.

\section{Structure A}

Structure A was a roughly circular hollow, $c 5 \mathrm{~m}$ in diameter, on the south-eastern edge of the island, just beyond the southern end of the perimeter wall (Structure P).

\section{Structure B}

Structure B was a rectangular building, $2.5 \times 4.5 \mathrm{~m}$ 


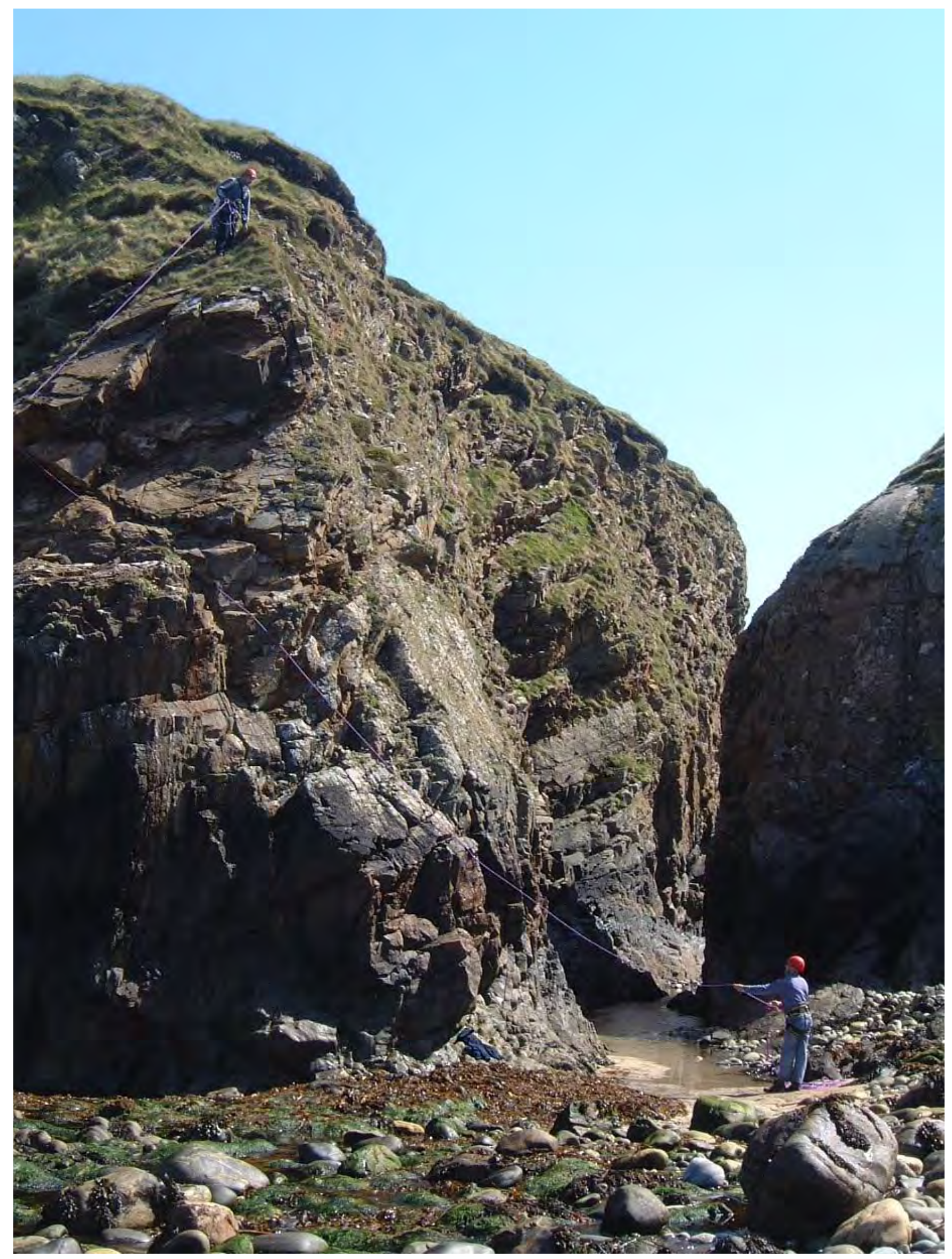

Illus 43 (above) Access to Dun Eòradail from the north

Illus 44 (opposite) Location map and topographic survey of Dun Eòradail 

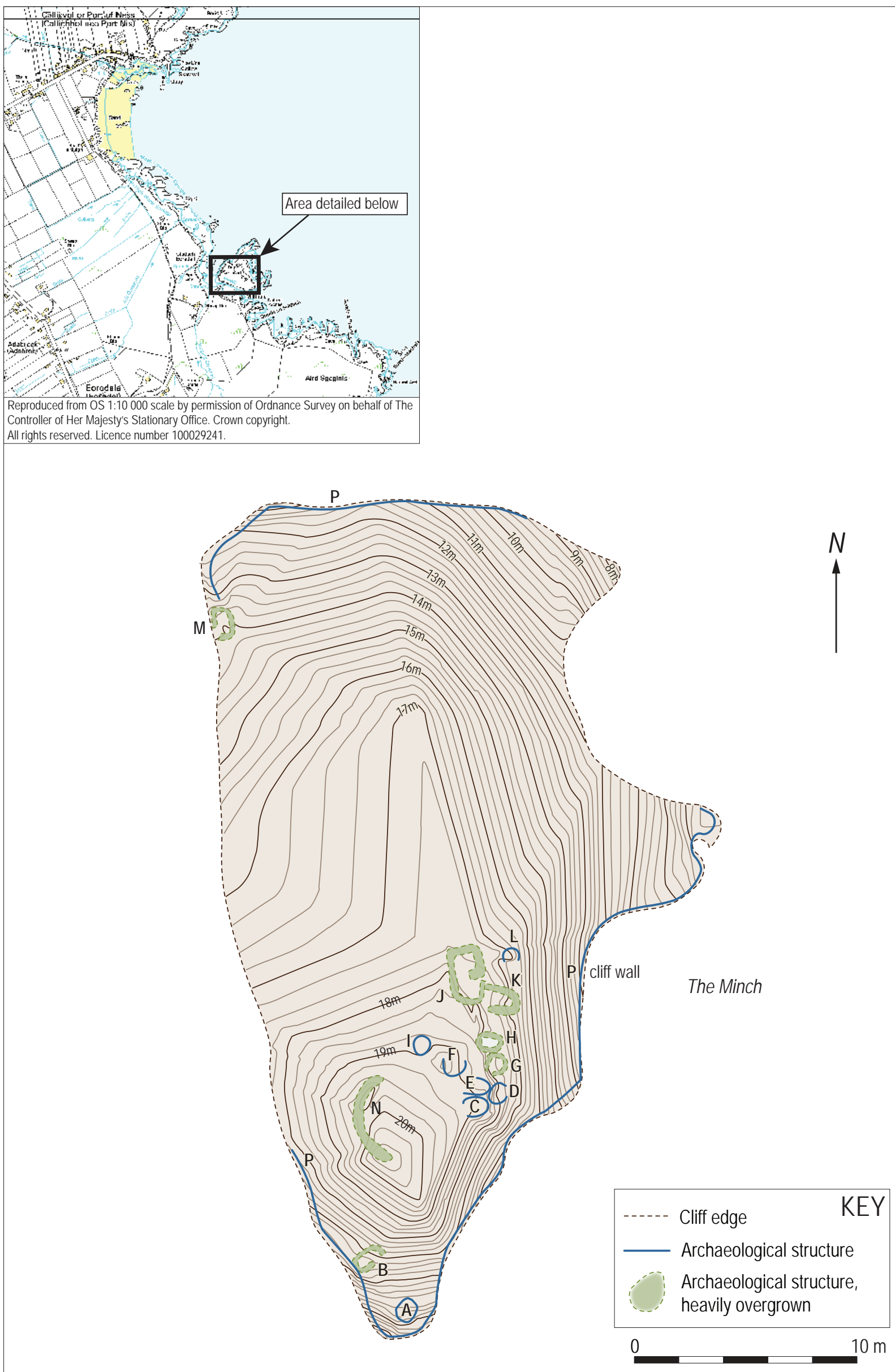
internally, orientated N/S, built into the southern part of the perimeter wall (Structure P). It had an entrance in its north-eastern corner.

\section{Structure C}

Structure C was a small, U-shaped hollow, backed against Structures D and E. It opened to the southwest, and measured $3 \times 6 \mathrm{~m}$ internally.

\section{Structure D}

Structure D was a small, U-shaped hollow, abutting Structures $\mathrm{C}$ and $\mathrm{E}$. It opened to the north-east and measured $3 \times 4 \mathrm{~m}$ internally.

\section{Structure E}

Structure E was a small, U-shaped hollow, abutting structures $\mathrm{C}$ and $\mathrm{D}$. It opened to the west, and measured $3 \times 3 \mathrm{~m}$ internally.

\section{Structure $F$}

Structure F was a small, U-shaped hollow, opening to the north, and measuring $3 \times 3 \mathrm{~m}$ internally.

\section{Structure G}

Structure G was a circular structure, with an entrance to the south-west. It abutted Structure $\mathrm{H}$, and measured $4 \times 4 \mathrm{~m}$ internally. The floor was lower than the surrounding ground surface, giving an impression of being partly subterranean.

\section{Structure $H$}

Structure H was a sub-rectangular building orientated $\mathrm{E} / \mathrm{W}$, without a visible entrance. It adjoined Structure G, and measured $5 \times 2.5 \mathrm{~m}$ internally.

\section{Structure I}

Structure I was a very small, circular hollow without a visible entrance. It measured $2 \times 2 \mathrm{~m}$ internally.

\section{Structure J}

Structure J was the largest structure on the stack. It was a sub-rectangular building, orientated $\mathrm{E} / \mathrm{W}$, and measured $4 \times 9 \mathrm{~m}$ internally, and $7 \times 11 \mathrm{~m}$ externally. On the northern long wall, a small, probably secondary wall, curved south and west to form a small compartment against the inside of the north wall.

\section{Structure K}

Structure K was a sub-rectangular building at rightangles to the north-eastern end of Structure J. It measured $3.5 \times 6 \mathrm{~m}$ internally, and may have related to the entrance of Structure J, possibly acting as an annexe. A gap between the north-eastern corner of Structure $J$ and the beginning of the eastern wall of Structure K appears to have formed an entrance, facing east.

\section{Structure L}

Structure L was a faint, amorphous, C-shaped hollow, opening to the east. It measured $c 3 \mathrm{~m}$ in diameter.

\section{Structure $M$}

Structure $M$ was a rectangular building, measuring $5 \times 3 \mathrm{~m}$ internally and $6 \times 4 \mathrm{~m}$ externally. It was built into the western perimeter wall (Structure P), away from the other buildings. There appeared to have been an entrance in the south-western corner of the building, but this may have been caused by erosion.

\section{Structure N}

Structure N was a very ephemeral, long, curved bank, which formed a shallow C-shape opening to the east. It was $c 15 \mathrm{~m}$ in diameter, and sat on the top of the island. It was possibly natural.

\section{Structure $P$}

Structure P was an intermittent perimeter wall, following the edge of the island around the southern and northern sides, with gaps at the north-east, the north-west, and along the western edge. The eastern and western ends of the northern wall appeared to be real, rather than being caused by erosion. The western end of the southern part of the wall was similar, although this may be due to erosion that also caused the deterioration to the access route.

At the western end of the north wall, a strongly marked in-curve was noticed just above a rock outcrop overhanging a freshwater pool, which is fed by drainage from a small boggy area at the centre of the site.

\subsection{Discussion}

Little is known about the function or date of this site, even after survey. There is no excavated evidence from it, and no known oral tradition concerning it. The remains, although more ephemeral, are not dissimilar from those on Dun Eistean, as suggested by the Ordnance Survey in the 1960s. The large rectangular building (Structure J), may have been an occupied house of medieval or post-medieval date, with the other forms representing smaller storage huts or earlier buildings. The perimeter wall suggests a defended or enclosed site.

The location of the archaeological features on the east coast of the island, south of Dun Eistean (NGR: NB 5355 6501), and north of the promontory forts of Dun Bhilascleitir (NGR: NB 5602 5762), Dun Othail (NGR: NB 5420 5150) and the stack Caisteal a' Mhorair (NGR: NB 5368 4969) suggests a function in overlooking the seaway of the Minch, which was of so much strategic importance in the Norse and medieval periods. The presence of a managed freshwater source on the island suggests that it could have been occupied for extended periods of time, though the lack of other resources emphasises the dependence of the settlement on its immediate hinterland for support.

Overall the structures are in a relatively stable condition and there is little direct threat to the 
buildings from coastal erosion. The only main threat to the site is from the erosion of the access route and consequently part of the perimeter wall, around the landward edge of the site. 


\section{CREAG DUBH}

\subsection{Physical description and location}

The site (NGR: NB 55706148 ) is a $1 \mathrm{~km}$ walk ESE from the township of Sgiogarstaigh, Ness. It is located in an area of high cliffs composed of Lewisian complex anorthosite and metasediments (Burgess \& Church 1997, 291), which stretch from Port of Ness in the north to Tolsta in the south, some $15 \mathrm{~km}$. The east coast south of Sgiogarstaigh is very ragged, and almost entirely made up of geos and promontories, one of which is the site itself. The site is a very small promontory, $40 \mathrm{~m}$ long and only $5 \mathrm{~m}$ wide. All that is left of the archaeology is a small cairn of $c 3 \mathrm{~m}$ diameter at the extremity of this promontory (illus $46 \mathrm{~B}$ ), a small section of wall on an offshore stack, with two turf walls and a circular structure on the mainland.

\subsection{Erosion}

The site is rapidly disappearing, with the cliff edges being undermined by marine erosion. The area is considered to be actively eroding by the Coastal
Erosion Assessment, Lewis (Burgess \& Church 1996, 289).

\subsection{Access}

Access was gained to the cairn at the end of the promontory by fixing stakes and rock anchors along the length of the promontory, and using climbing techniques with dynamic rope. A small stack that survives to the north of the promontory was not accessed.

\subsection{Previous work}

There has been no previous work on this site.

\subsection{The survey (illus 46)}

\section{Structure A}

Structure A was the slight remains of what seems to be a turf-built circular building $c 10 \mathrm{~m}$ in external

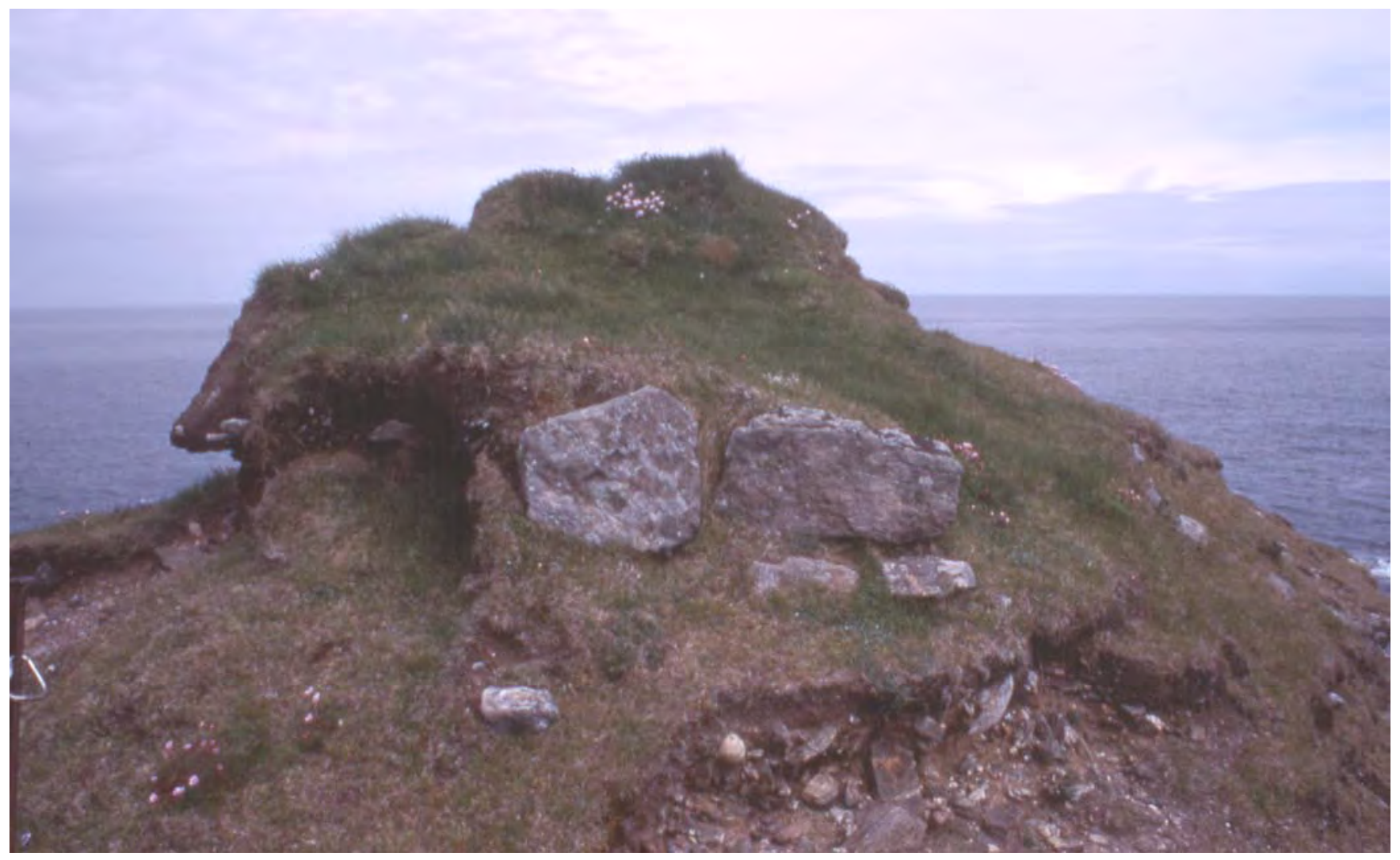

Illus 45 (above) The cairn on Creag Dubh from the east

Illus 46 (opposite) Location map and topographic survey of Creag Dubh 


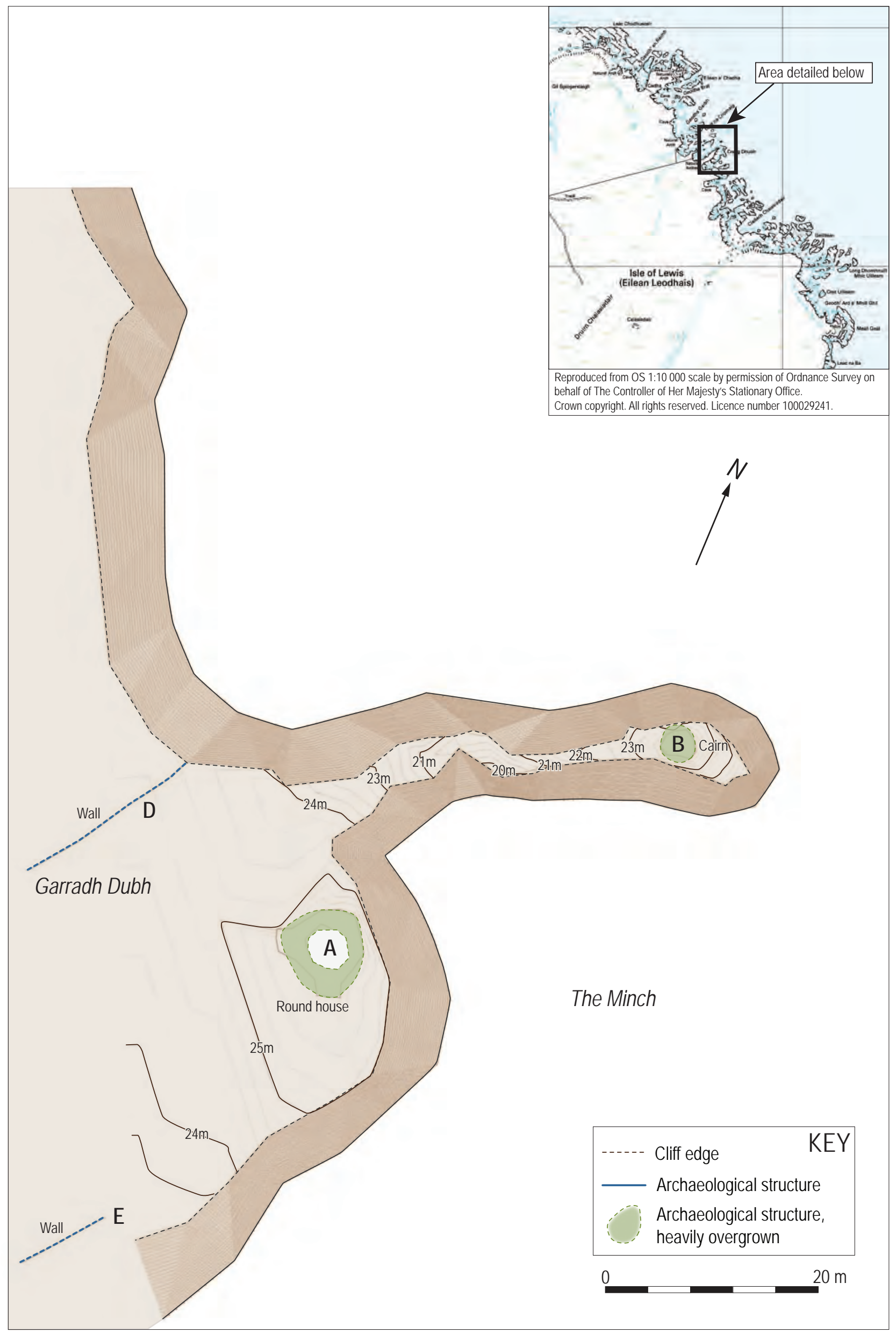


diameter, with walls $c 0.4 \mathrm{~m}$ thick. It was located on the mainland adjacent to the site.

\section{Structure B}

Structure B was the rapidly eroding remains of a stone, turf-covered cairn on the extreme eastern, seaward end of the peninsula. The surviving remains were $c 3 \mathrm{~m}$ diameter, but the eastern edge of the structure was heavily damaged by erosion. Two probable kerb stones lie on the south-western edge of the cairn (illus 45).

\section{Structure $C$}

Structure C was a stone wall fragment on the southern edge of a stack lying north of the peninsula. It was not possible to gain access to the stack without a boat, and this feature was therefore not surveyed.

\section{Structure D}

Structure D was a turf wall on the mainland to the west of the other archaeological features. It was damaged at its western end by peat cutting, but may originally have abutted wall Structure E, with which it formed an enclosure around the archaeological features. There is a ditch on the south side of the wall, and further inland, a second wall runs parallel to this ditch.

\section{Structure E}

The eastern end of a massive turf or turf and stone wall of varying width and construction, which extended well outwith the survey area. The wall had slumped heavily, and had been damaged by peat cutting and modern fencing. This was the northeastern end of the Garadh Dubh (see discussion below).

\subsection{Discussion}

Creag Dubh (the black crag) is at the northern end of the Garadh Dubh (the black enclosure wall), which forms the outfield head dyke of all the west coast townships. It runs parallel with the west coast of Lewis to Carloway in the south. As such it is one of the largest and potentially most important landscape features on the island, and is helpful in understanding the development of the island's settlement patterns.

The Garadh Dubh is of unknown antiquity, but as the major boundary feature of the west side of Lewis, it may belong to the earliest phase of coastal settlement on the west side of the island. Present evidence suggests the possibility that the coastal settlement pattern was established by the Iron Age, which may provide a possible date for the original line of the Garadh Dubh.

This has interesting implications for the roundhouse and cairn on the Creag Dubh. Both would fit with the known archaeological and architectural patterns of the later Bronze Age or earlier Iron Age in the islands (for example, the round houses at Cladh Hallan in South Uist, Parker Pearson forthcoming; and the burial cairn at Cnip, Uig, Close-Brooks 1995). Creag Dubh is rapidly eroding and the cairn is already partially destroyed and separated from any relationships which it may or may not have had with other features in the vicinity such as the wall on the adjacent stack, which is also imminently threatened, or indeed the boundary wall, Structures $\mathrm{D}$ and $\mathrm{E}$, with which it has the obvious place name connection.

\subsection{Potential for future work}

This site may well be destroyed in the next decade, depending upon the winter storm patterns. The cairn would benefit from immediate, total excavation, with trial trenching to investigate the mainland features, particularly the Garadh Dubh, the adjacent wall (Structures D and E) and the circular Structure A. 


\section{DUN OTHAIL}

\subsection{Physical description and location (illus 47)}

Dun Othail(NGR:NB 5420 5144, NMRS no. NB55SW 01, SAM5455) is situated on the east side of Lewis and is a striking pinnacle of rock with a vertical cliff face on its landward side. The base of this pinnacle can be accessed by traversing a steep path from the south, which runs north-east to a promontory below the pinnacle. On the seaward side of this promontory at least five structures sit on a series of small terraces, and are protected by a defensive wall.

The site is within an area of high cliffs of basement Lewisian gneiss and is considered to be eroding but stable (Burgess \& Church 1997, 307).

\subsection{Access}

Access to the main terrace on Dun Othail was via a straightforward but steep descent and traverse, with no need for ropes. However, ropes and climbing techniques were required to explore further small terraces and the top of the pinnacle itself.

\subsection{Previous work}

The first brief mention of the site as 'Dun-owle', a natural fort, was by Martin Martin in 1696. The next reference is from the Ordnance Survey:

A large and prominent rock almost perpendicular. Its top is covered with a thin surface that produces scanty grass through which portions of rock appear. At the SE base of this rock above the level of the sea are the ruins of a house said to have been erected and inhabited by an outlaw ... (Ordnance Survey Name Book, 1852)

T S Muir described the site in 1861 as 'an architectural remain - of an early chapel, probably' (Muir 1861, 168; MacLeod 1997, 37). It is not known where Muir got this information from, but it differs from the earlier description by the Ordnance Survey.

MacGibbon and Ross continued Muir's assertion that the building was a chapel when they included the site in their gazetteer of ecclesiastical sites (MacGibbon \& Ross 1896-7), and Captain Thomas also mentioned this reference (Thomas 1890). He

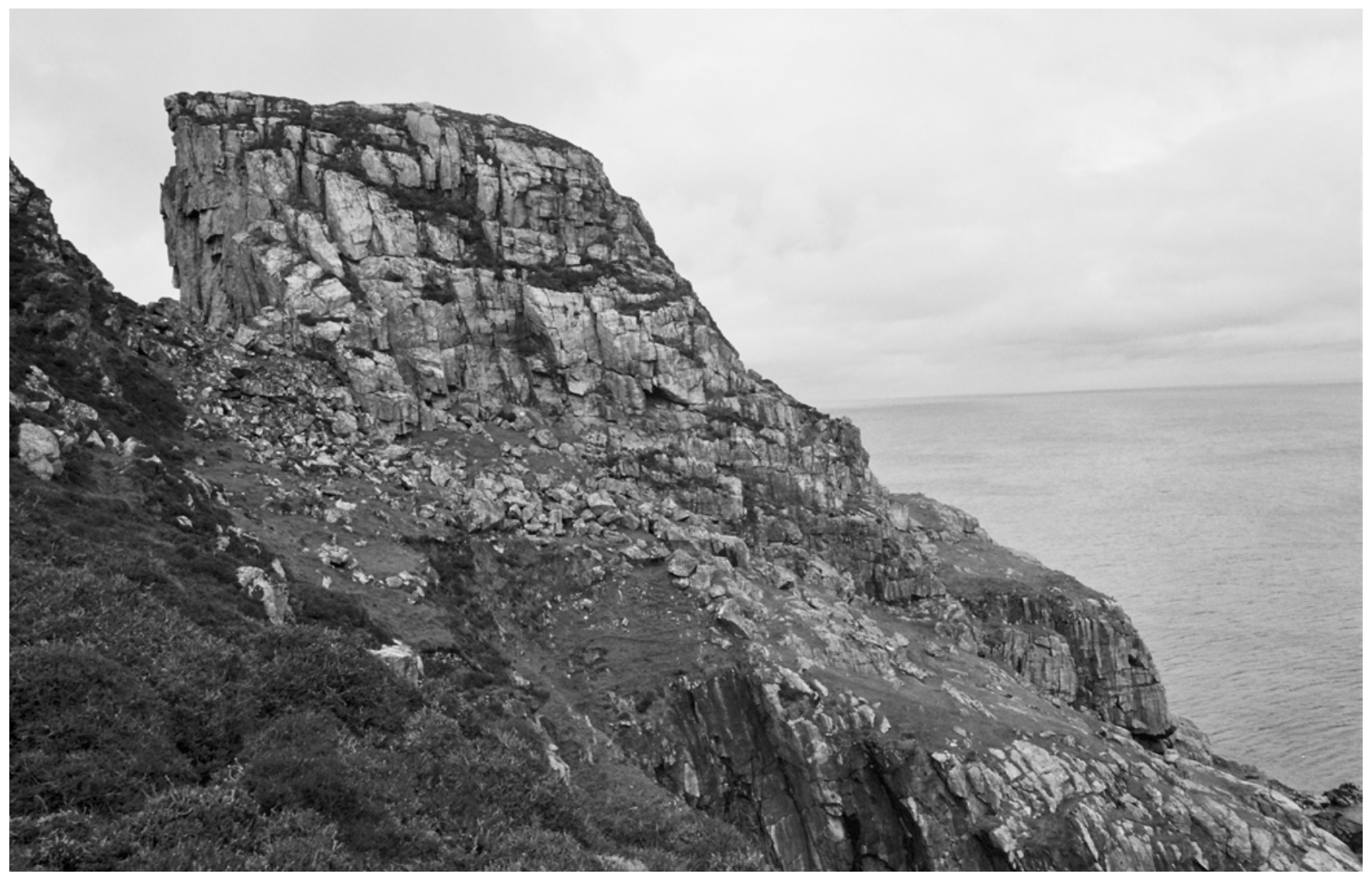

Illus 47 Dun Othail from the south 


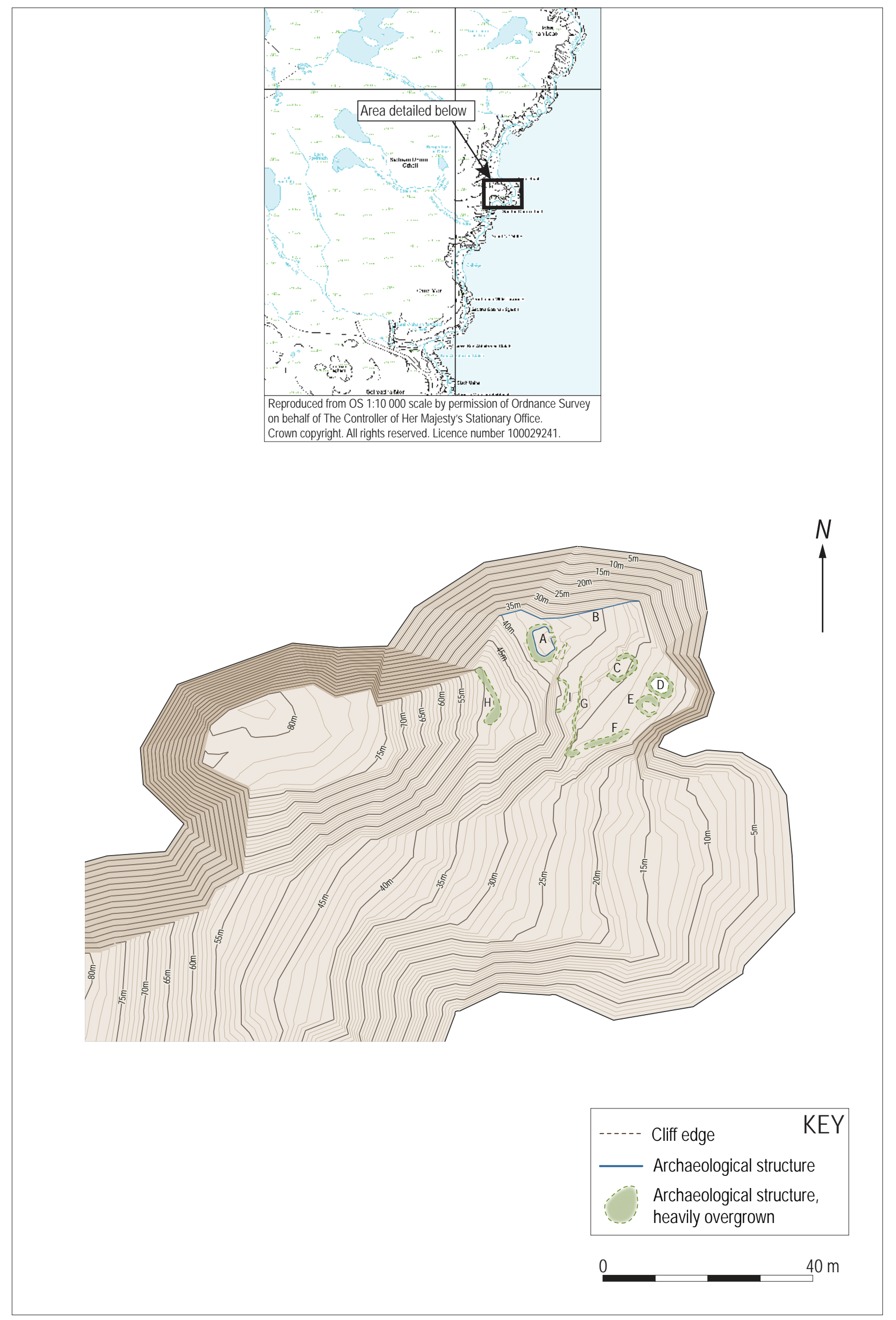


recounted notes taken by the Rev. MacPhail from his visit in the $1860 \mathrm{~s}$, 'although there is no defensive masonry upon the rock a single person could defend the path. An oblong ruin upon its extreme point is supposed to have been a chapel' (cited in Robson 2004, 22).

MacPhail's notes on the site are quoted at length by Robson (2004, 21-23), and these also refer to two local traditions associated with the site. The first account describes how 'Oighre MhicLeod' (Heir of the MacLeod or Torquil Heir, the son of MacLeod) was imprisoned at Dun Othail by a MacNicol, in revenge for serious injuries inflicted on him by MacLeod. The tale is also described at length elsewhere (MacDonald 1967, 241; MacGregor 1933, 207; Thomas 1890, 371), but suffice it to say that the MacNicol jumped off the top of Dun Othail with the heir, and they were both dashed on the rocks below. The gorge and dun were henceforth called 'MacNicol's Leap'.

The second tradition recounted a prophecy by the Coinneach Othair (the Brahan Seer), who foretold that the whole of Lewis would be depopulated by the sword, but that 'there shall come out of Dun Othail one who will render them aid' (MacGregor 1933, 206; Robson 2004, 22). The site was also linked to the Morrison clan and a further tradition which stated that Alan Morrison, famous for his daring leap across the chasm at Dun Eistean, was buried in a small hollow above Dun Othail with his two brothers (MacGregor 1933, 211).

In 1928 the RCAHMS failed to note any buildings on the dun, although in 1969 the Ordnance Survey located the so-called chapel building and described it as orientated NNE/SSW, defined by turf-covered footings $c 0.5 \mathrm{~m}$ high, and measuring $5 \times 3 \mathrm{~m}$ internally. It had an entrance near the north end of the south-east wall but the Ordnance Survey stated, 'There is nothing to support its classification as a chapel' (Ordnance Survey 1969).

\subsection{The survey (illus 48)}

The dun did not have any structures on its summit, but there were a series of structures on the lower grassy slopes to the east or seaward side of the site. The turf-covered footings of a perimeter wall enclosed a series of terraces over an area of approximately $20 \times 20 \mathrm{~m}$ on the lowest slopes of the eastern part of the dun. The area within the perimeter wall was also enclosed to the north, east and south by steep cliffs to the sea, and by a steep, grass-covered hill sloping upwards to the summit of Dun Othail to the west.

The approach to this enclosure was via a series of terraces on the south side to a narrow ledge. The ledge, $c 2 \mathrm{~m}$ wide and $10 \mathrm{~m}$ long, created a strong natural fortification, which only a few people could pass at a time. This opened onto the lowest and largest terrace. A natural path wound upwards between rock outcrops to a middle terrace, and then continued uphill to a third terrace, all of which had structures upon them. The summit plateau was gained and surveyed, but it contained no structural features (illus 49). A deepwater inlet immediately below the lower terrace could possibly have been a landing place.

\section{Structure A}

Structure A (illus 50) on the middle terrace was referred to as a chapel in many previous descriptions of the site. It measured $5 \times 3 \mathrm{~m}$ internally, with walls flattened and collapsed, measuring a maximum of $c 0.5 \mathrm{~m}$ high, and $1 \mathrm{~m}$ in width. Visible stone walling formed the internal face of the building, surviving up to two courses high at the north corner. There was no visible external face. A narrow entrance, $0.75 \mathrm{~m}$ wide, perforated the north end of the east wall, and was flanked by large square boulders. Rock outcrops sheltered the west and south sides of the building.

\section{Structure B}

The only other structure on this terrace was a revetted wall visible to the north. The revetting contained soils above a narrow path, which was cut into the steep slope at the base of the dun. The path led to the highest terrace and another rectangular building.

\section{Structure $C$}

Structure C (illus 51), lay in the lee of a rock outcrop, on the lower terrace, and was sub-rectangular, measuring $6 \times 3 \mathrm{~m}$ externally. There were only three walls; the side wall to the north was formed by the rock outcrop. The west wall did not abut the rock face, but created a gap that may have been the entrance. The walls were at most $0.4 \mathrm{~m}$ high, and no more than $0.75 \mathrm{~m}$ in width, and were turf-covered.

\section{Structure D}

Structure D was a sub-rectangular building, measuring $3 \times 2 \mathrm{~m}$ externally, with no visible entrance. Its turf-covered walls were at most $0.4 \mathrm{~m}$ high and no more than $1 \mathrm{~m}$ in width. It was adjacent to, but not connected with, Structure E.

\section{Structure E}

Structure E was also sub-rectangular and measured $4 \times 2 \mathrm{~m}$ externally. It may have had an entrance in the eastern wall, and appeared to have been built into the perimeter wall of Structures F and G. The remains of its walls were $c 0.4 \mathrm{~m}$ high and $0.75 \mathrm{~m}$ wide. It was separated by only $1 \mathrm{~m}$ from Structure D.

\section{Structure F}

The turf-covered footings of the perimeter wall enclosed the terraces on the lowest slopes of the eastern part of the site. The wall was in two 


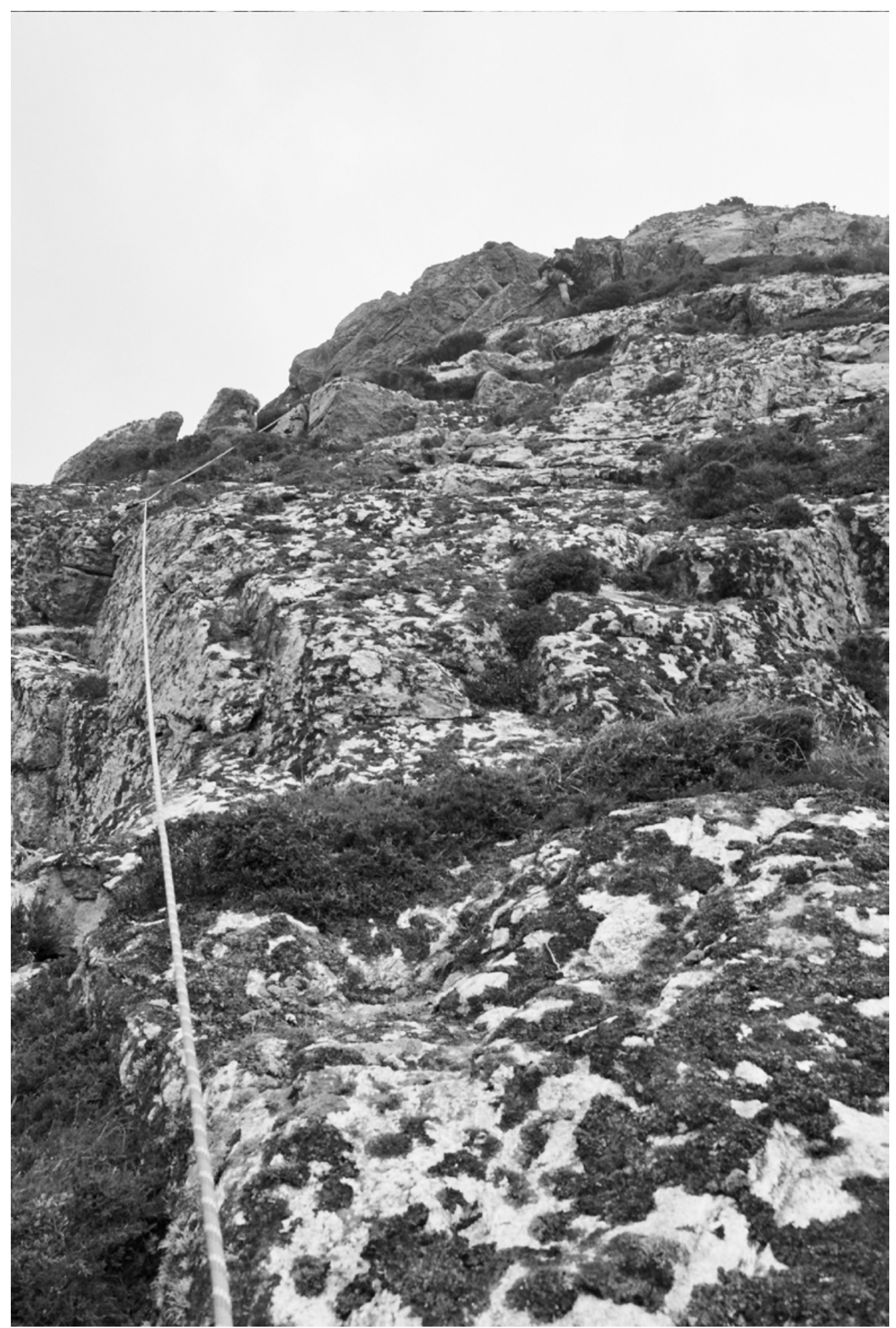

Illus 49 Accessing summit of Dun Othail from the south-east

parts, Structure F and Structure G, divided by an entrance. Structure F ran along the eastern cliff top that skirted the terrace. The wall was revetted, to bring it up to the same level as the plateau, and to support it where the cliff had no well-defined edge. It enclosed the lowest and largest terrace. Two small fragments of undiagnostic pottery were recovered from amongst the revetting stones outcrops.
Structure G

This part of the perimeter wall abutted a nearvertical cliff face at its western end, and an entrance was positioned about $2 \mathrm{~m}$ to the east of this. The wall to the west of the entrance was Structure G (illus 52 ). It was up to $1.5 \mathrm{~m}$ thick. The break between the two parts of the wall appeared to have been enlarged by erosion in recent years. 


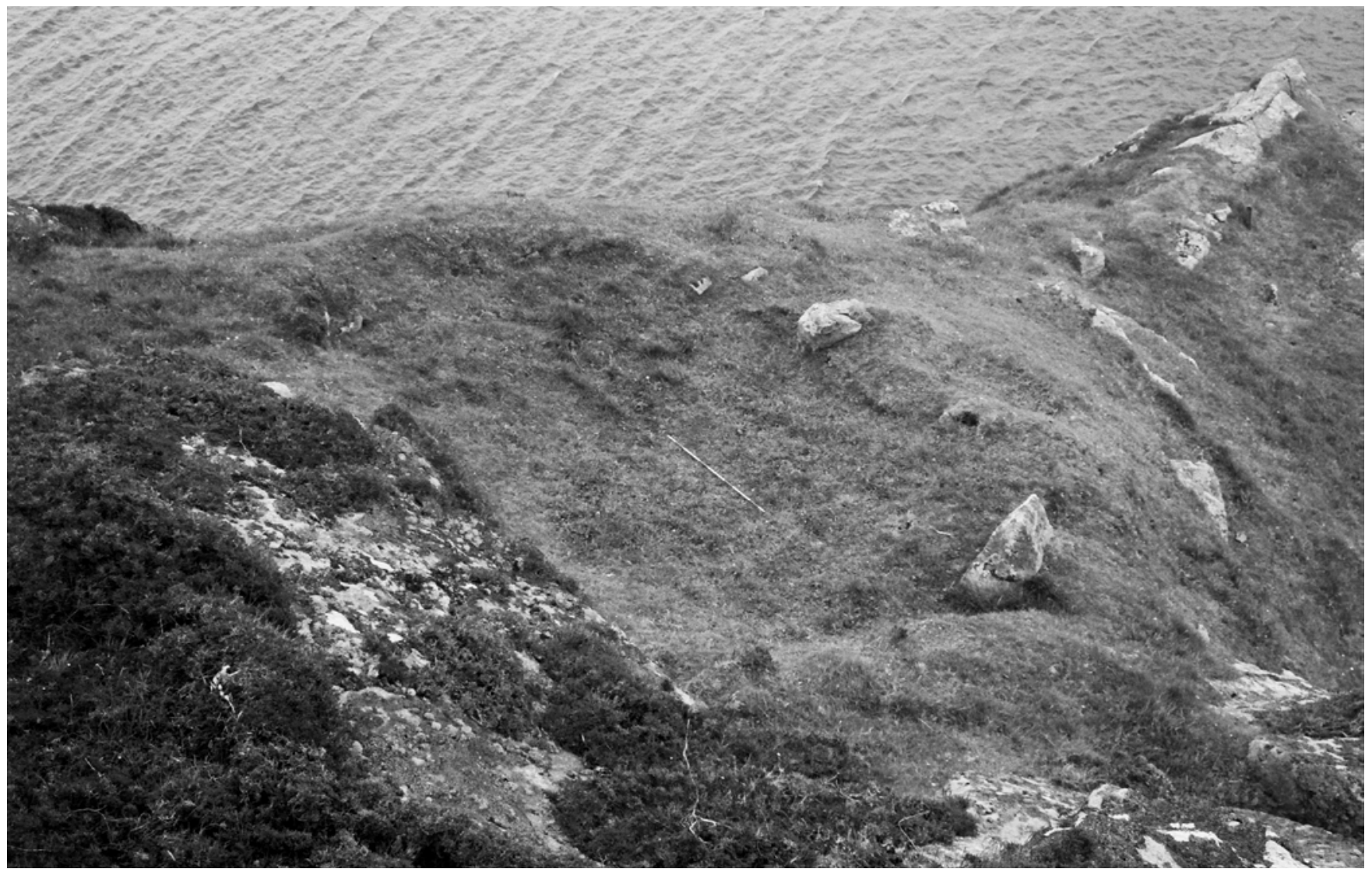

Illus 50 Structure A, Dun Othail from the west. Scale $1.2 \mathrm{~m}$ long.

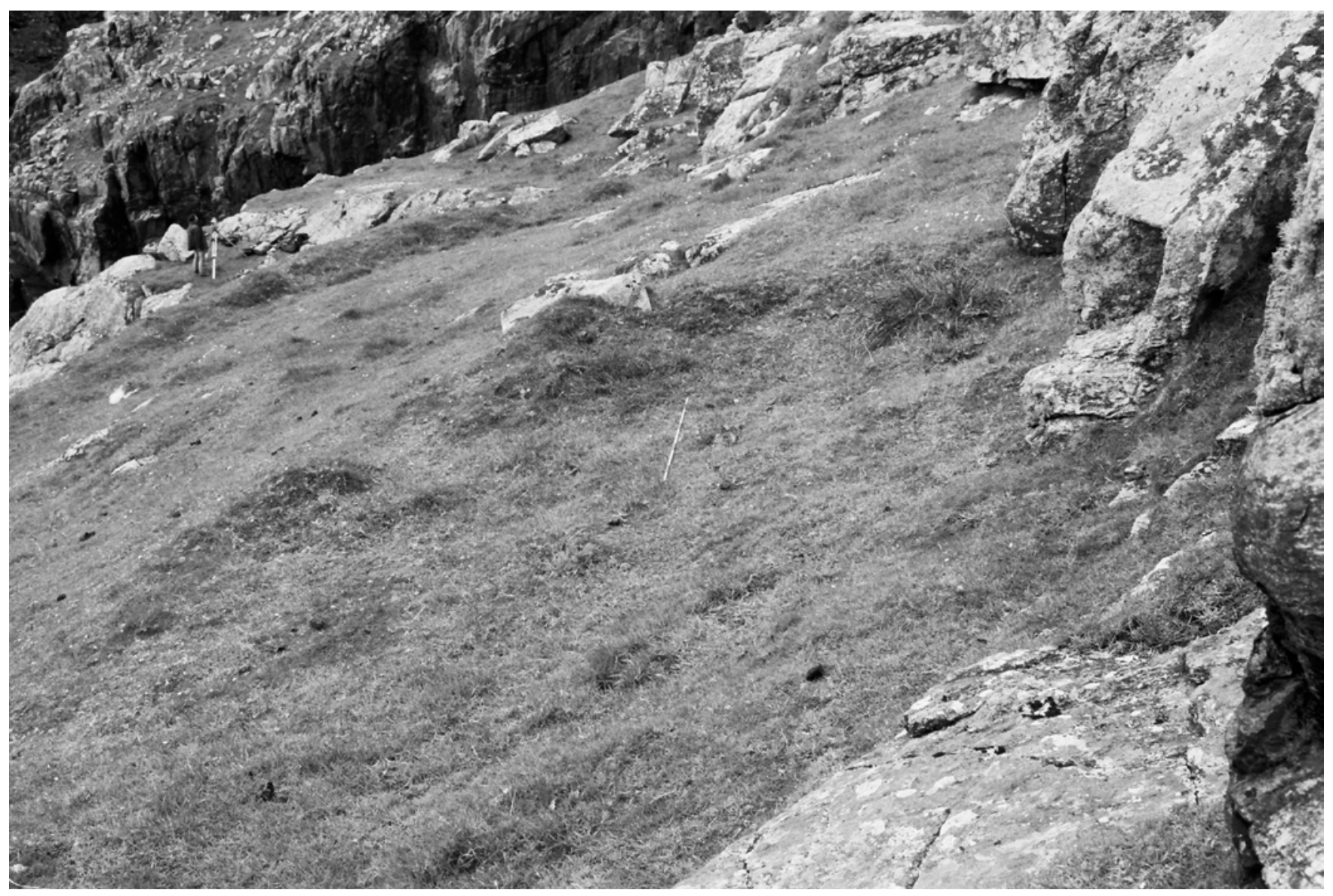

Illus 51 Structure C, Dun Othail from the north. Scale $1.2 \mathrm{~m}$ long. 


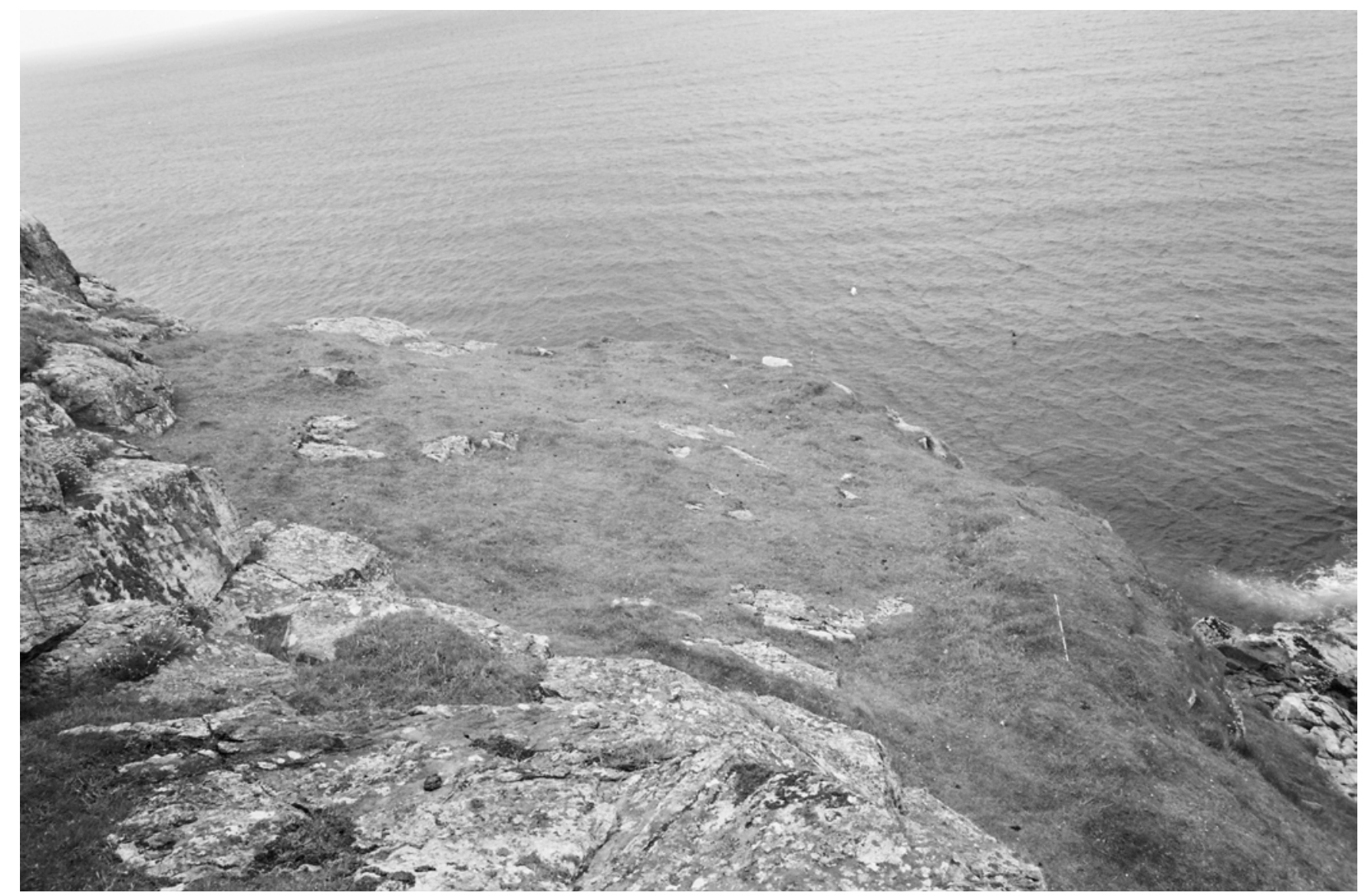

Illus 52 Structures $F$ and $G$, Dun Othail from the south-west. Scale $1.2 \mathrm{~m}$ long.

\section{Structure $H$}

Structure $\mathrm{H}$ was the remains of a wall roughly $0.4 \mathrm{~m}$ wide, which could be discerned tracing most of the edge of a small, higher terrace, $c 15 \times 5 \mathrm{~m}$ large, some $20-30 \mathrm{~m}$ above the main terraces.

\section{Structure I}

A natural access ramp led to the top of the outcrop behind Structure C, and to the middle terrace. The low remains of another semi-circular wall abutted a rock outcrop at the western edge of this terrace, in a similar way to Structure C, but without any visible gap for an entrance. Structure I measured $7 \times 3 \mathrm{~m}$, with walls $c 0.5 \mathrm{~m}$ wide and $c 0.3 \mathrm{~m}$ high.

\subsection{Discussion}

Only the Ordnance Survey surveyors of 1852 noted the presence of ' 3 ruins, one above the other at different levels' on the lower terraces of Dun Othail. The other writers were possibly preoccupied by the apparent existence of a chapel (Structure A) since its description by Muir in the 1860s. Malcolm MacPhail mentioned the access path, defensive wall and chapel, but there was no mention of the other buildings, despite his almost certainly having visited the site and usually being detailed in his note-taking.

The Ordnance Survey, in 1969, located the 'chapel' and confirmed the description given by Muir (later reiterated by MacGibbon \& Ross); but they did not identify the other buildings on this occasion.

The possibility of there having been a chapel on the site stems from a misidentification by Muir in the 1860s of Structure A. This affected subsequent descriptions of the remains despite the accuracy of the original description taken by the Ordnance Survey ten years earlier, which referred to the main structure as having been built by an outlaw. This description would have been taken from a local informant and had strong associations with the various local traditions that linked the site to clan histories. The physical remains today would fit this interpretation, when compared with the form of buildings on known clan sites such as Dun Eistean. Dun Othail would be easily defended from the land and the sea, and affords excellent views of the Minch. However, it is impossible to interpret the site further from these traditions alone. 


\section{CAISTEAL A' MHORAIR}

\subsection{Physical description and location}

Caisteal a' Mhorair (NGR: NB 5368 4970; NMRS no. NB54NW 1; SAM 5250) lies at the south end of Traigh Ghearadha. The stack on which it sits is only $c 23 \mathrm{~m}$ high but is a thin, near-vertical finger of rock rising to a plateau $8-9 \mathrm{~m}$ wide at maximum (illus 53). It is the tallest and most substantial of three such rock pillars rising from the intertidal zone of Traigh Ghearadha (Garry Beach). High cliffs frame the relatively small beach to the north and south, which is at the intersection of an eroding sandy geomorphic cell and stable Lewisian gneiss rock platform (Burgess \& Church 1997, 309).

\subsection{Erosion}

The previous surveys and descriptions are largely accurate, and there is little sign of erosion on either the access to the site, or the stack itself. Burgess \& Church agree that the area is 'stable' (ibid, 307).

\subsection{Access}

Access onto the stack involved climbing directly from the beach approximately $10 \mathrm{~m}$ up a steep grassy path flanked by small rock outcrops. Climbing techniques were used, with a mixture of temporary rock anchors and pitons providing security.

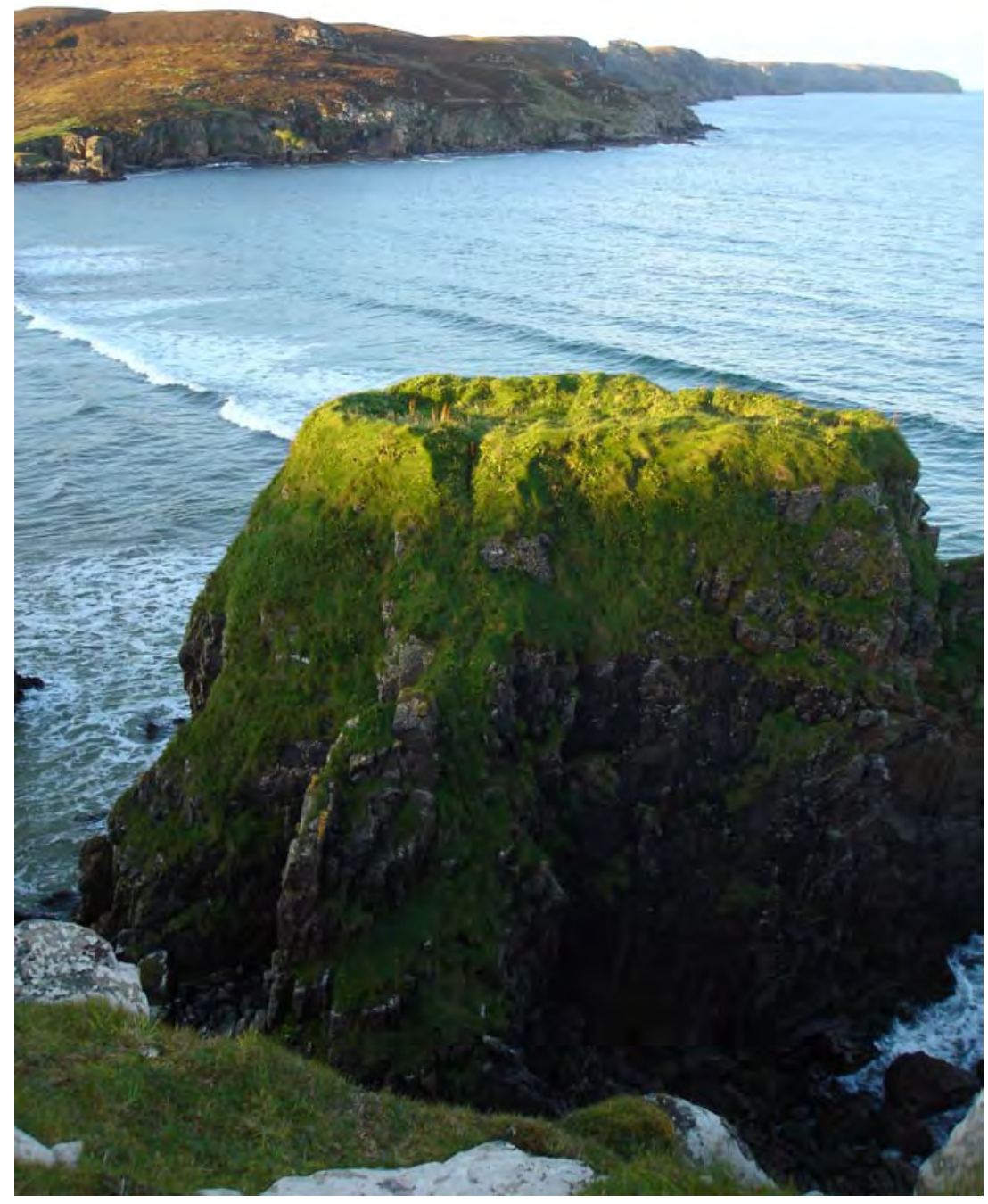

Illus 53 Caisteal a'Mhorair from the south 


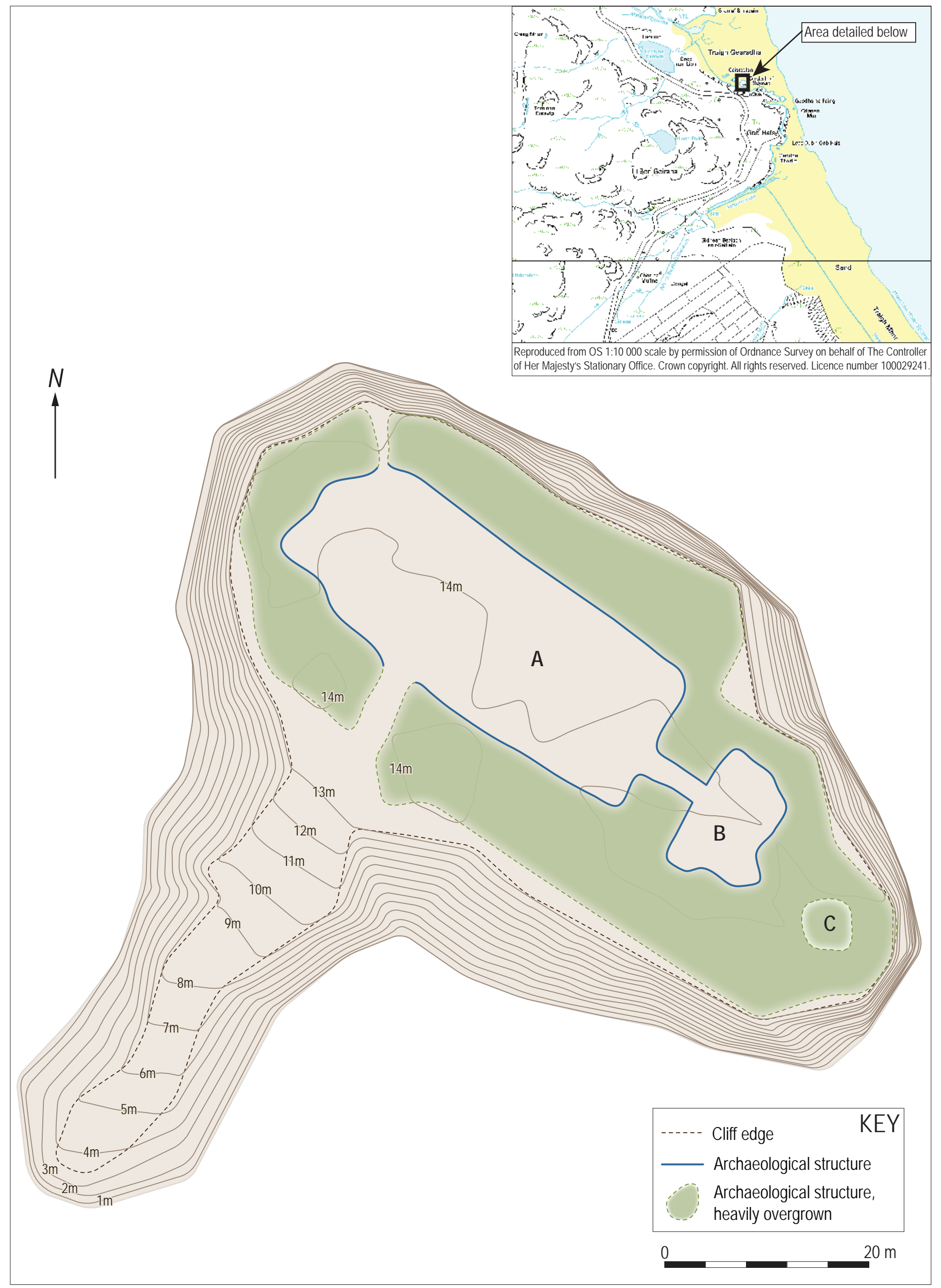




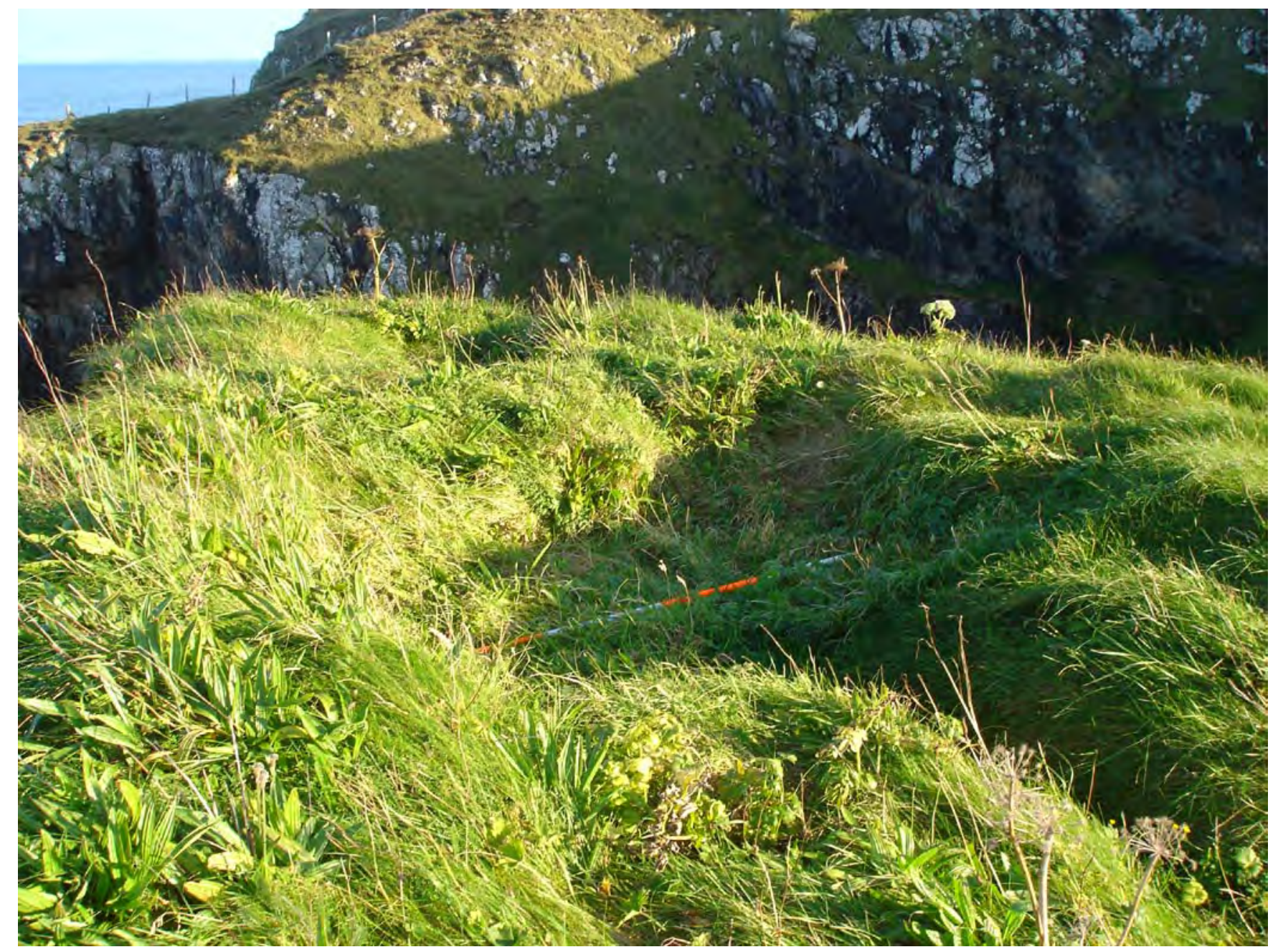

Illus 55 Caisteal a'Mhorair, Structure A from the south

\subsection{Previous work}

Caisteal a' Mhorair was not identified by Captain Thomas, and seems to have been first recorded by a Peter Liddel, Esq., Gress, Lewis, who wrote to the Proceedings of the Society of Antiquaries, 8 June 1874:

Castle Rock at North Tolsta - This ancient strength ... is built on a near-perpendicular stack of rock 100 feet high, and isolated at high water. The building, which the inhabitants of the district call 'The castle', consists of an oblong chamber of irregularly rectangular shape, nearly 40 feet long and 13 feet wide, with a smaller chamber about 10 feet by 8 , opening off it by a door 2 feet wide in the centre of the end wall. Close to this end of the building there is a circular space nearly 6 feet in diameter and 3 feet deep, which has been quarried out of the rock, and may have been a well. Fragments of the coarse pottery called 'craggans' were found in it. I dug all over the floor of the chamber. The walls are of unhewn stones, backed with earth. There had been a fireplace at each side of the door, close beside the wall. Broken 'craggans' and stones that had been used as hammers or pounders were found all over the floor. There were but a few bones, which may be accounted for by the facilities they had for disposing of them by throwing them at once over the rock.

The site was mapped on the second edition of the Ordnance Survey of Lewis in 1898, but was not described in detail until the 1928 RCAHMS Inventory:

There is a dun on Caisteal a' Mhorair. This is a pinnacle of rock rising some $70 \mathrm{ft}$ above the sand on the S side of Traigh Geiraha.

The flat, oval summit, measuring some $60 \mathrm{ft}$ from ESE to WNW by about $24 \mathrm{ft}$, is encircled by a wall now 4-6ft wide and 1/1/2ft high. The greater part, towards the NW, is occupied by a roughly rectangular chamber $32 \mathrm{ft}$ long and 14ft broad, entered $11 \mathrm{ft}$ from the NW end by a passage in the SW 
flank $2 \mathrm{ft}$ 9ins broad and walled for a length of $14 \mathrm{ft}$. Access to this entrance is obtained by climbing a dangerously steep rib of rock opposite it, the cliff otherwise being unclimbable.

'Opening from the SE end of the main chamber through a passage about $2 \mathrm{ft}$ wide and $4 \mathrm{ft}$ long is a smaller chamber lying transversely across the summit, 101/2 $\mathrm{ft}$ long and $7 \mathrm{ft}$ broad. Between this latter division and the SE extremity of the summit, which contracts to a width of about $15 \mathrm{ft}$, is a circular stone lined hollow $5 \mathrm{ft}$ in diameter

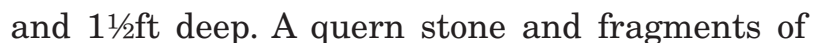
rough hand-made pottery have been found here.' (RCAHMS 1928, visited 3 July 1914)

It was surveyed at a scale of 1:10 000 by the Ordnance Survey in 1969.

\subsection{The survey (illus 54)}

The site was as described by the RCAHMS, with one building taking up the whole of the summit. This building had three compartments, and an access track wound steeply up the west face of the stack, leading straight to the entrance of the main compartment.

\section{Structure A}

Structure A was the largest enclosure on the top of the stack. It was sub-rectangular, orientated E/ $\mathrm{W}$, with its western wall set $c 0.5 \mathrm{~m}$ away from the perimeter of the stack and its eastern wall on the edge of the stack (illus 55). It measured $c 9.5 \times 4 \mathrm{~m}$ internally, with stone walls $1-1.5 \mathrm{~m}$ thick. It was entered from the access route by a narrow, southfacing door $c 0.8 \mathrm{~m}$ wide, but another opening, $c 0.5 \mathrm{~m}$ wide, was present in the north-eastern corner of the building.

\section{Structure B}

Structure B adjoined Structure A via an entrance in the eastern wall of the latter. It was a rectilinear room, $c 3 \times 2 \mathrm{~m}$ internally, with no other obvious openings in its walls. It was similarly constructed of stone (illus 56).

\section{Structure $C$}

Structure C adjoined Structure B to the east but there was no obvious entrance and it was much

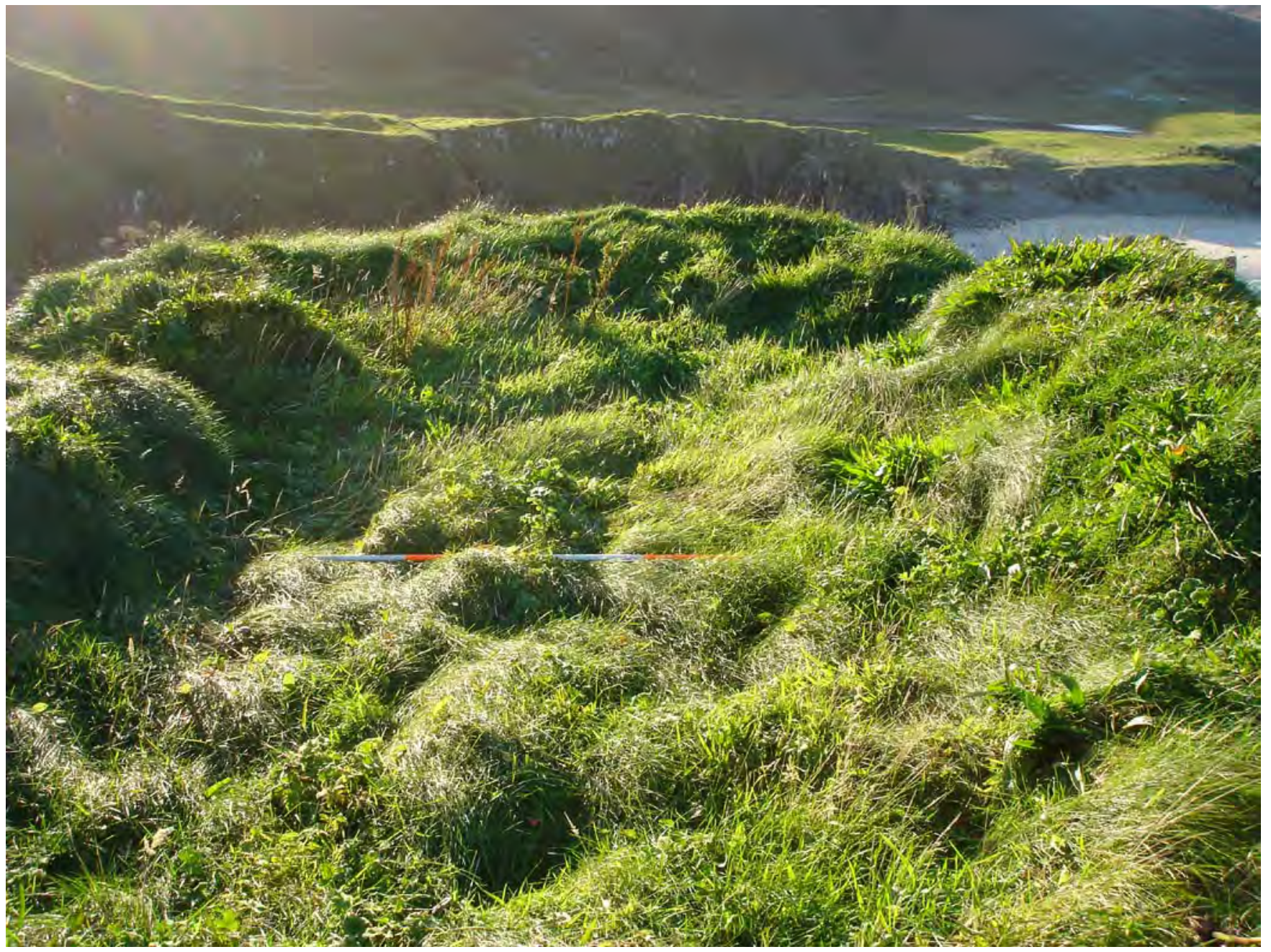

Illus 56 Caisteal a' Mhorair Structures B and C from the north 
less well constructed than either Structure A or B. It consisted of a circular rubble and turf wall with an internal diameter of $c 1 \mathrm{~m}$. It fully occupied the eastern end of the stack. The surviving width of its walls varied between 1 and $2 \mathrm{~m}$.

\subsection{Discussion}

Caisteal a' Mhorair (the Castle of the Big Man, or Nobleman) is one of the few possible medieval castles in the Isle of Lewis. Comparison with excavated structures at Dun Eistean (Barrowman, R C 2006; Barrowman, R C et al 2007) suggests that Structure B might have been a small tower.
Structure A is of a size to have been a small hall, although it is also possible that it was merely an enclosed courtyard.

Liddel's (1874) evidence is significant in that it would suggest that the site was actually occupied with fireplaces and debris such as pottery, bones and hammer/pounder stones.

There were no signs of erosion to the structure, or the stack on which it stands.

\subsection{Potential for future work}

The site is presently secure, with no signs of erosion to the structure, or the stack on which it stands. 


\section{STAC MOR GARRABOST}

\subsection{Physical description and location (illus 57)}

Stac Mor Garrabost (NGR: NB 4987 3310) is a roughly cylindrical stack, $c 5 \mathrm{~m}$ in diameter and $10 \mathrm{~m}$ tall. It is located on the north-west side of the Eye peninsula $30 \mathrm{~m}$ offshore from the landward cliff line, rising from a wave-cut platform which is exposed at low tide. The local geology is sedimentary, New Red Sandstone, forming conglomerate cliffs (Burgess \& Church 1997, 355).
There are no obvious structures at first inspection.

\subsection{Erosion}

The soft conglomerates of the area are suffering direct marine erosion from wave action (Burgess \& Church 1997, 353). The stack was most likely larger in the past, as suggested by the use of the adjective mor (big), in the place name.

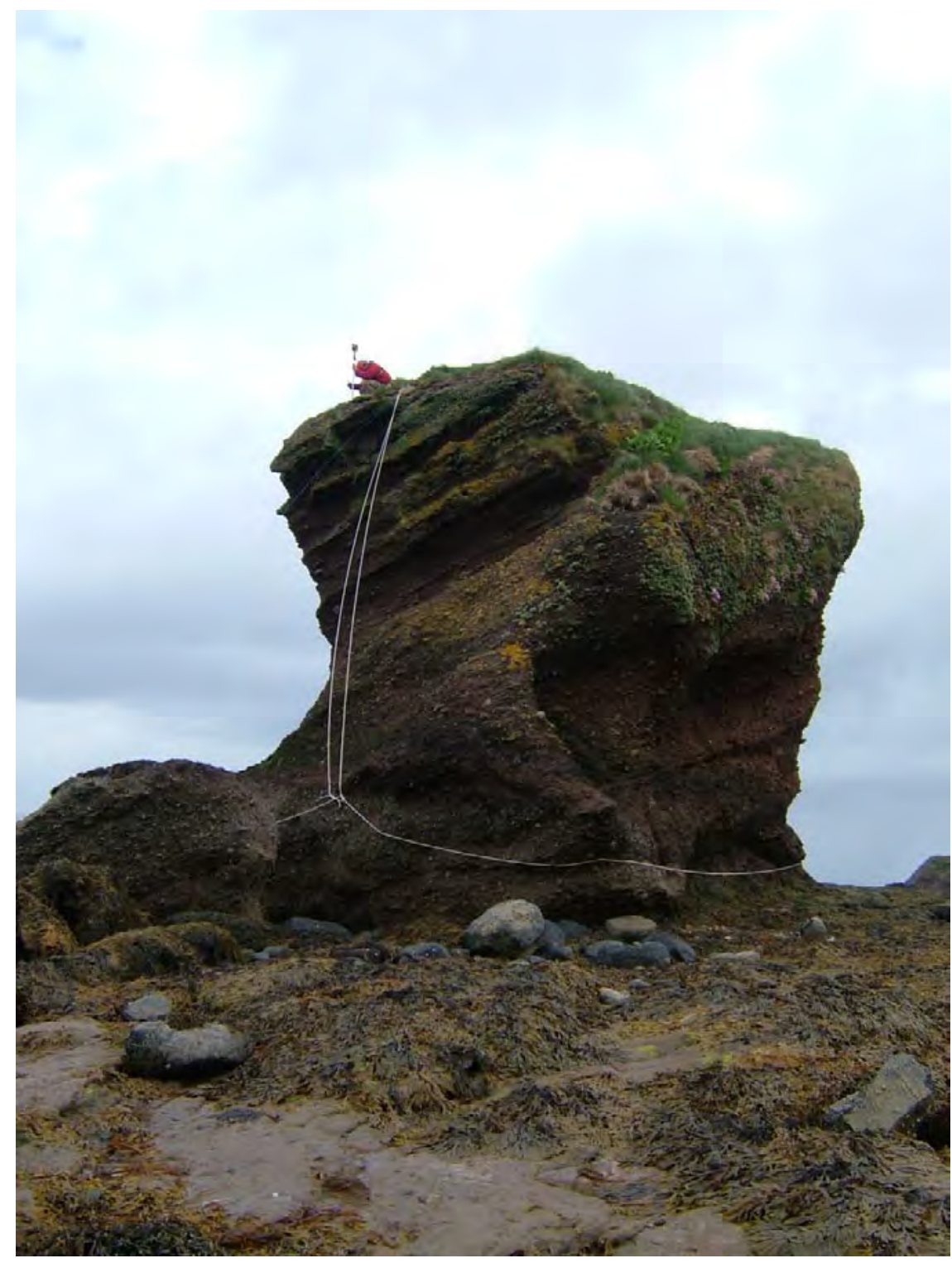

Illus 57 (above) Stac Mor Garrabost from the south

Illus 58 (opposite) Location map and topographic survey, Stac Mor Garrabost 


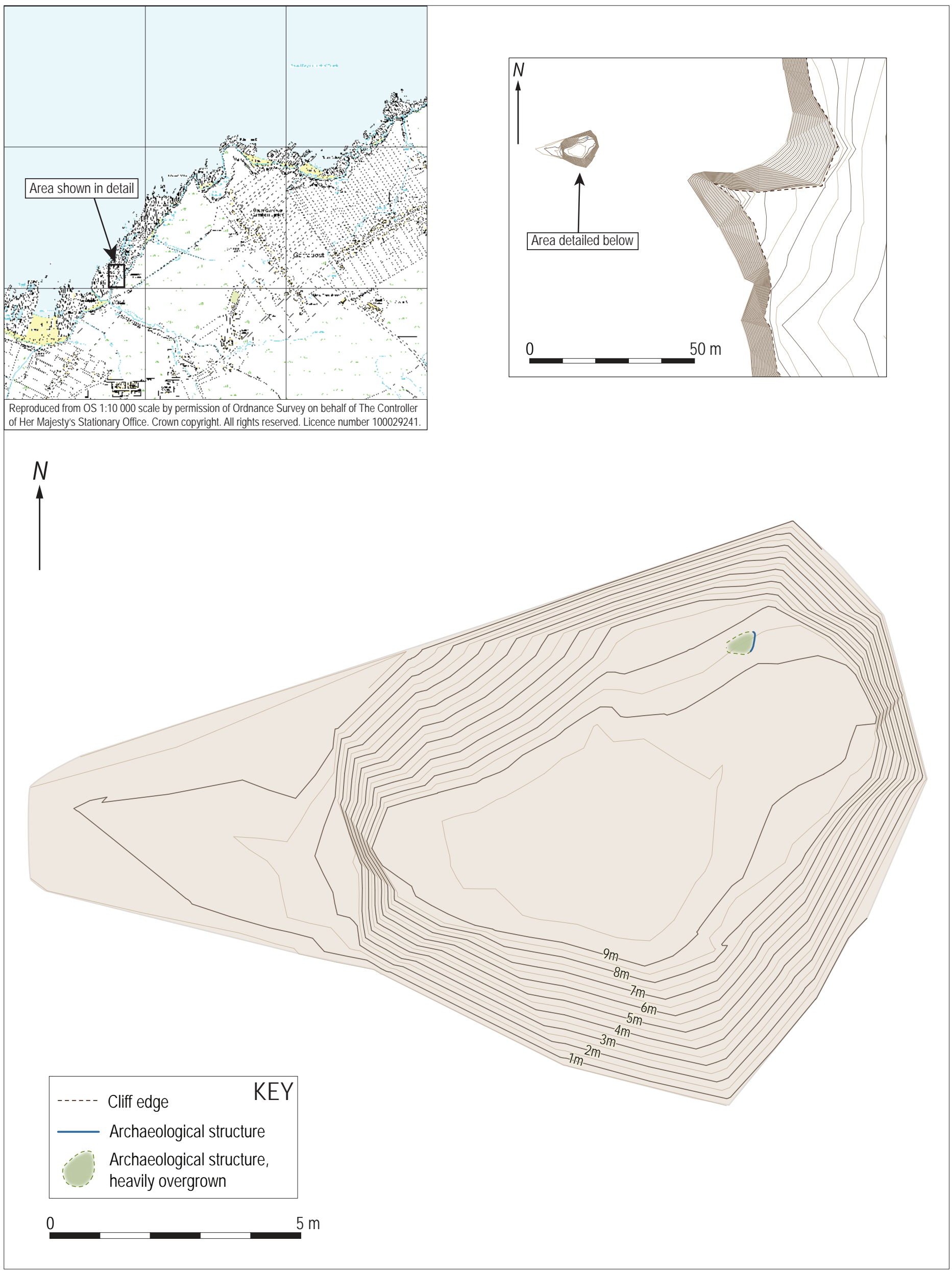




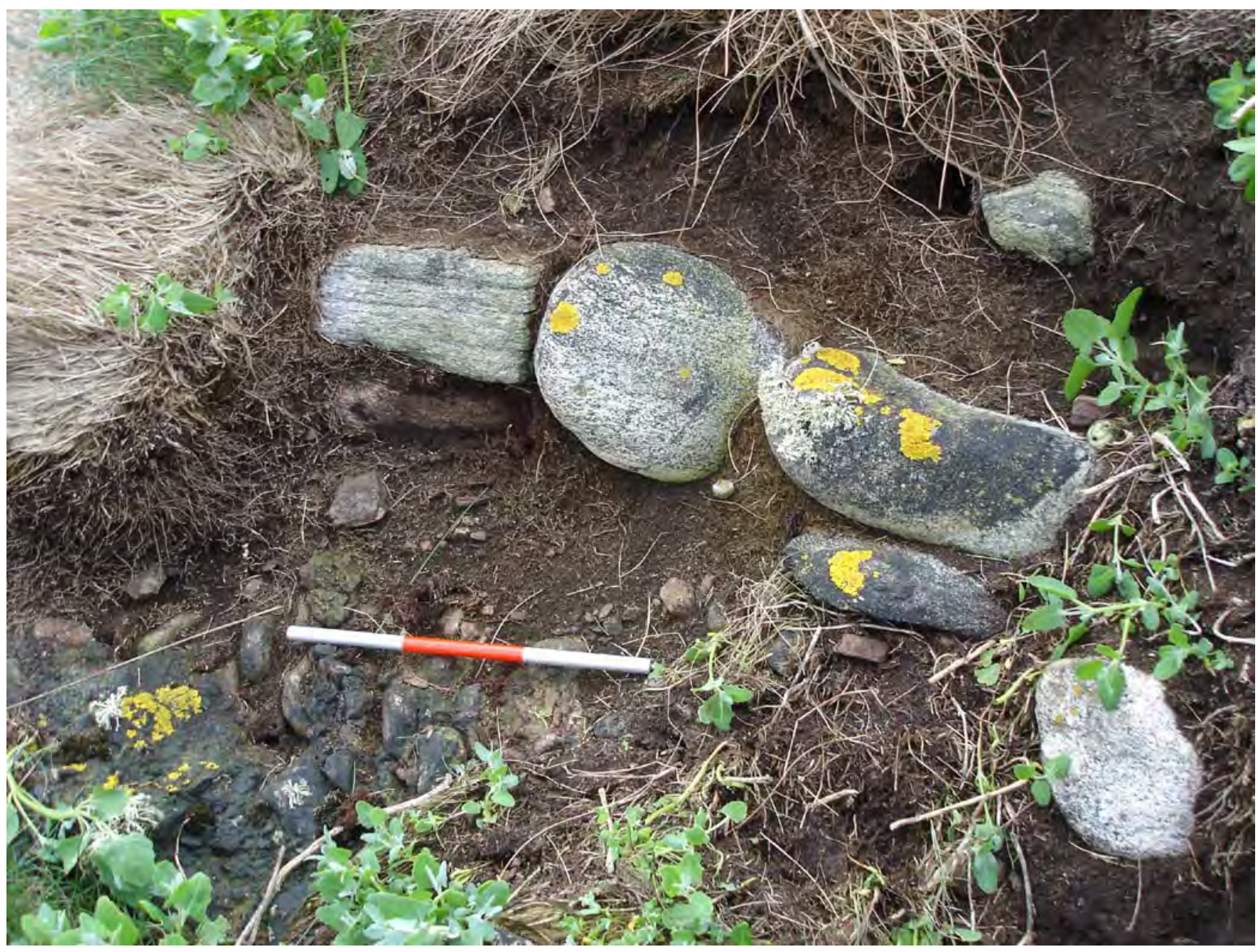

Illus 59 Wall on Stac Mor Garrabost from the north-west. Scale 0.3m long.

\subsection{Access}

Access was achieved via a steep but navigable path to the foreshore, and a walk across the rock platform at low tide. Access onto the stack from there was problematic, as none of the usual techniques could safely be used due to the crumbly nature of the conglomerate rock. Strong anchors could not be placed to enable safe climbing, so an alternative method had to be used. The problem was solved by throwing a weighted guide line over the whole stack, and pulling the usual double rope over and down to the other side. The ropes were then anchored by ropes stretched around the circumference of the base of the stack, above which a natural 'hip' ensured no slippage. When on the top of the stack, care had to be taken to stay on the opposite side of the plateau from that on which the ropes were anchored, however further ropes could be attached at any point around the base to safely enable full coverage of the stack.

\subsection{Previous work}

The site was identified as having a possible enclosure on it, by the Coastal Erosion Assessment, Lewis (Burgess \& Church 1997, 351).

\subsection{The survey}

The top surface of the stack was covered by soil, up to $0.7 \mathrm{~m}$ deep on the east side where it was exposed by an eroding scar and overgrown with a thick covering of grasses and sorrel. The summit was roughly flat (illus 58), with only one discernible topographic feature which may have been archaeological. This was a ledge descending spirally from the plateau for some $5 \mathrm{~m}$ on the landward side; this is just visible as a dark band of vegetation to the left of the figure in illus 57. If this had been an access route in antiquity then the lower section has been lost to erosion.

A small section of drystone walling was discovered on the north-eastern, seaward face of the stack (illus 59). The wall was $c 1 \mathrm{~m}$ long, of two courses 
in places and constructed from blocks of Lewisian gneiss, which stood out sharply from the conglomerate bedrock. These may have been sourced from the reef below the stack, where gneiss boulders can be found. The wall continued underneath the vegetation for at least $0.5 \mathrm{~m}$ to the landward side of the stack and may also have continued to the opposite side but was insubstantial if present. Further gneiss blocks were present higher up the slope, which may have originally been part of a larger wall or revetment.

One small body sherd and a fragment of non-diag- nostic pottery (see Appendix 3) were discovered in the soils immediately beneath the wall.

\subsection{Discussion}

Much like Stac na Cuibhig (Section 8), little interpretation can be made of the structural evidence at Stac Mor Garrabost. It is clear, however, that there once was a much larger site here which has suffered significant erosion due to the soft conglomerate rock of the stack. 


\section{GENERAL DISCUSSION AND CONCLUDING COMMENTS}

Eleven examples of a little-studied and vulnerable class of site have been surveyed and the results presented. These surveys build upon the large body of information collated by Burgess and Church in the Coastal Erosion Assessment, Lewis (Burgess \& Church 1997).

The surveys have highlighted a number of academic and practical issues crucial to our understanding and management of the monuments. Of first importance is the fact that, with care and even limited resources, such sites can be safely accessed, and can therefore be subject to more detailed research. Both survey and excavation on such sites are practical propositions, and there is therefore little excuse for the neglect of them as a class of monument.

Revisiting the Lewis Coastal Erosion Assessment has also demonstrated that, although these monuments are located on the interface between land and sea, and are therefore, as a class, particularly vulnerable to erosion, it cannot be assumed that they are all actively eroding. Nor can assumptions be made about which aspects or areas of even the eroding sites are most at risk. Each monument must be subject to individual assessment and monitoring in order to determine which aspects, if any, of its archaeology are under threat or in the process of destruction. Caisteal a' Mhorair, for example, appears to be stable and retains its original ground plan.

Academically, however, even a project on such a limited scale as this one has revealed the limitations of our understanding of stack and coastal promontory sites. The past assumption that they are largely Iron Age in date (Branigan \& Foster 2002, 86, and the previous understanding after Lamb 1980, 1973) should now be abandoned. There is clear evidence of Neolithic presence and use at Dunasbroc (see Part III and Section 9), Stac Domhnuill Chaim (Section 6) and Eilean nan Luchruban (Section 11). In contrast, excavations at Dun Eistean have shown that site to be wholly medieval and late medieval in date (Barrowman, R C 2007; Barrowman, R C et al 2007), with none of the underlying Iron Age use initially expected (Barrowman, C S 2000, 20-1). Dun Arnistean (Section 10) has produced evidence of Iron Age occupation, as has Dunasbroc (see Part III below), yet neither site appears to have monumental Middle Iron Age buildings. Stac a' Chaisteal (Section 7), in contrast, does have a monumental building, and this is the first time that the existence of an Iron Age blockhouse of the Shetland type (Lamb 1980), suggested previously by Burgess (1999), has been confirmed in the Western Isles. It is possible from the ceramic evidence that there might even have been Norse period use of Dun Arnistean (Lane 1995, 5). As yet we do not have evidence for Bronze Age use of these promontory and stack sites, but perhaps we should expect such evidence to emerge in the future.

As changing and shifting geological sites, stacks and promontories can effectively be treated as a group. Their liminal position between land and sea must always have been attractive, and may well have influenced their archaeological functions. Many of the sites, for example Stac a' Chaisteal, Stac Domhnuill Chaim, Dun Eistean, Caisteal a' Mhorair, seem also to have been located on the fringes of cultivatable land, on or near boundaries between townships, liminal zones in more ways than one. Some of these sites seem likely, both from their structural and traditional evidence, to have functioned as Medieval or Early Modern lookout posts and refuges, whether for outlaws (such as Stac Domhnuill Chaim) or for clan authorities (such as Dun Eistean). However, we cannot assume that their earlier use, where present, was of the same nature; the excavations at Dunasbroc have demonstrated a rather less straightforward sequence of events (see below for further discussion).

Further surveys around the Atlantic edge and targeted excavation of selected sites are required to approach a full understanding of the archaeology of stack, island and promontory locations, and the motivations that lay behind successive occupations. There is some degree of urgency if this goal is to be achieved before some of these sites are lost to erosion in the next few decades. 


\section{PART III: THE DUNASBROC EXCAVATION REPORT}





\section{INTRODUCTION}

A full description of the site, its setting and history can be found with the access and survey results in Section 9.

Dunasbroc was chosen over the other threatened stack sites for further investigation because of pragmatic reasons. The site was threatened by further erosion, and had already produced both Neolithic and Iron Age pottery (Section 9.5), but it was also relatively easy to access. As only two weeks of excavation were available, it was judged to be the site most likely to produce informative results in the limited period of time. A full discussion of the issues involved can be found in Appendix 1.

The aims of the excavation were to characterise and record the site in as much detail as possible in the time available. This included the retrieval of stratigraphic and depositional evidence, dating evidence, artefactual evidence and environmental residues (Barrowman \& McHardy 2005).

It was decided to position Trench 1 , which measured $10 \times 1.5 \mathrm{~m}$, across the main extant features, ie the plateau and walls, in order to achieve a crosssection through these deposits and to investigate and establish relationships between them. Trench 2 , measuring $2 \times 1 \mathrm{~m}$, was positioned over the eroding scar A (Section 9.5) from which Neolithic Hebridean
Ware pottery was discovered within a charcoal-rich context (Appendix 3 and illus 25).

All excavation was undertaken using small hand tools. All archaeological deposits were recorded using written context descriptions on standard proforma sheets; drawings in plan at a scale of 1:20 and sections and elevations at a scale of 1:10; and photography in monochrome print, colour slide and digital images. Matrices were drawn for the understanding and interpretation of the site (Appendix 2).

Spoil was dry-sieved for stray finds (Appendices 4 and 5) with a $6 \mathrm{~mm}\left(1 / 4^{\prime \prime}\right)$ riddle, and samples were taken of every excavated context (including the topsoil for comparison) for wet-sieving and environmental analysis (Appendices 6 and 7). Small Kubiena tin samples of Context 005 were also taken for micromorphological study (Appendix 8).

Surveying of all co-ordinates (including small finds, trench edges, sections) was undertaken using PENMAP 4.34b Series 1000:600 software (Strata Software and Consultancy Ltd) in conjunction with a Leica TCR 307 Electronic Total Station and mini prism. The data was logged on a hand-held Strata field computer and downloaded nightly. These coordinates were all added as layers of information to the pre-existing Digital Terrain Model produced by the survey in 2004. 


\section{THE EXCAVATION}

\subsection{Trench 1}

Turf and topsoil (Context 001) were removed across the whole of Trench 1 . The high numbers of finds, including Neolithic Hebridean Ware, and burnt and unburnt mammal bone, and the very thinness of this deposit $(20-30 \mathrm{~mm})$ on the plateau area of the trench, suggests that it may have been the stabilised surface of the underlying Context 002, which was revealed on its removal.

Context 002 was a grey, gritty sand which covered all of the upper plateau area of the trench, up to the wall on the landward break of slope (Context 025; illus 60). In its southern part, adjacent to the wall, the context contained disordered sub-angular stonework of up to $400 \times 400 \mathrm{~mm}$, which was interpreted as collapse from the wall 025. Throughout, the deposit appeared to contain little organic material, which may have been leached out due to its exposed position. It was, however, rich in finds, containing 12 pieces of worked stone, mostly quartz, but three of which were flint; 12 sherds of Neolithic Hebridean Ware; burnt and unburnt bone, a small amount of charcoal, and heat-cracked stone. The mixture of burnt and unburnt artefacts suggests that this deposit derives from a mixture of activities, including the clearance of the remains of at least one fire.
A layer of orange-brown gritty sand, Context 018, was underneath Context 002. This was similar in texture and colour to Context 005 (below), but was devoid of finds and ecofacts.

Beneath 018, Context 004, a dark grey, sandy clay covered the whole width of the trench, from wall 025 northwards for $c 2.5 \mathrm{~m}$. The context contained a moderate amount of sub-angular stones of a similar size to Context 002. It was thought to be ash-rich upon excavation due to its colour and texture, although it contained little visible charcoal despite its colour.

Finds from Context 004 were concentrated in the southern lower part of the context near wall 025, and consisted of quartz flakes and pebbles, heat-cracked stone, smooth sandstone pebbles - unusual in Lewis - including one with pecking (SF39), calcined cattle bone and pottery. SF111 (Vessel 77) was Iron Age pottery, the rest of the ceramic material was Neolithic Hebridean Ware. Bulk samples were taken from both the northern and southern ends of this context. Sample 7a, from the northern end, returned a radiocarbon date (SUERC 13548/GU 15117) from birch wood (Betula) charcoal of $4705 \pm 30$ BP. Sample $7 \mathrm{~b}$ however, from the southern half of the deposit, returned a date of $2040 \pm 35$ BP (SUERC 13549/ GU 15118) from a charred grain of six-row barley (Hordeum vulgare sl.; table 3). The presence of Iron

Table 3 Radiocarbon dates

\begin{tabular}{|c|c|c|c|c|c|}
\hline \multirow[t]{2}{*}{ Lab code } & \multirow[t]{2}{*}{ Sample material } & \multirow[t]{2}{*}{ Lab age BP } & \multirow[t]{2}{*}{${ }_{\partial}{ }^{13} \mathrm{C}$} & \multicolumn{2}{|c|}{ Calibrated dates } \\
\hline & & & & 1-sigma & 2-sigma \\
\hline $\begin{array}{l}\text { SUERC-13547 } \\
\text { (GU-15116) }\end{array}$ & $\begin{array}{l}\text { Charred grain: } \\
\text { Hordeum vulgare sl. }\end{array}$ & $2110 \pm 35$ & $-18.5 \%$ & $190-50 \mathrm{BC}$ & $350-40$ вс \\
\hline $\begin{array}{l}\text { SUERC-13548 } \\
\text { (GU-15117) }\end{array}$ & Betula charcoal & $4705 \pm 30$ & $-26.2 \%$ & $3630-3370$ вс & $3630-3700$ вс \\
\hline $\begin{array}{l}\text { SUERC-13549 } \\
\text { (GU-15118) }\end{array}$ & $\begin{array}{l}\text { Charred grain: } \\
\text { Hordeum vulgare sl. }\end{array}$ & $2040 \pm 35$ & $-27.3 \%$ & $100 \mathrm{BC}-20 \mathrm{AD}$ & $170 \mathrm{BC}-50 \mathrm{вC}$ \\
\hline $\begin{array}{l}\text { SUERC-13550 } \\
\text { (GU-15119) }\end{array}$ & $\begin{array}{l}\text { Charred grain: } \\
\text { Indet. cereal }\end{array}$ & $2125 \pm 35$ & $-24.3 \%$ & $210-90$ вс & $350-40$ вс \\
\hline $\begin{array}{l}\text { SUERC-13551 } \\
\text { (GU-15120) }\end{array}$ & Salix charcoal & $4630 \pm 35$ & $-26.7 \%$ & $3500-3360$ вс & $3520-3340$ вс \\
\hline $\begin{array}{l}\text { SUERC-13555 } \\
\text { (GU-15121) }\end{array}$ & Betula charcoal & $4815 \pm 35$ & $-26.9 \%$ & $3650-3530$ вс & $3660-3520$ вс \\
\hline $\begin{array}{l}\text { SUERC-13556 } \\
\text { (GU-15122) }\end{array}$ & Betula charcoal & $4570 \pm 35$ & $-26.2 \%$ & $3490-3120$ вс & $3500-3100$ вс \\
\hline $\begin{array}{l}\text { SUERC-13557 } \\
\text { (GU-15123) }\end{array}$ & $\begin{array}{l}\text { Charred grain: } \\
\text { Hordeum vulgare sl. }\end{array}$ & $2125 \pm 35$ & $-23.4 \%$ & $210-90 \mathrm{BC}$ & $350-40 \mathrm{BC}$ \\
\hline $\begin{array}{l}\text { SUERC-13558 } \\
\text { (GU-151224) }\end{array}$ & $\begin{array}{l}\text { Pot residue: } \\
\text { Carbonised organic }\end{array}$ & $4660 \pm 35$ & $-26.7 \%$ & $3510-3360$ вс & $3620-3360$ вс \\
\hline
\end{tabular}




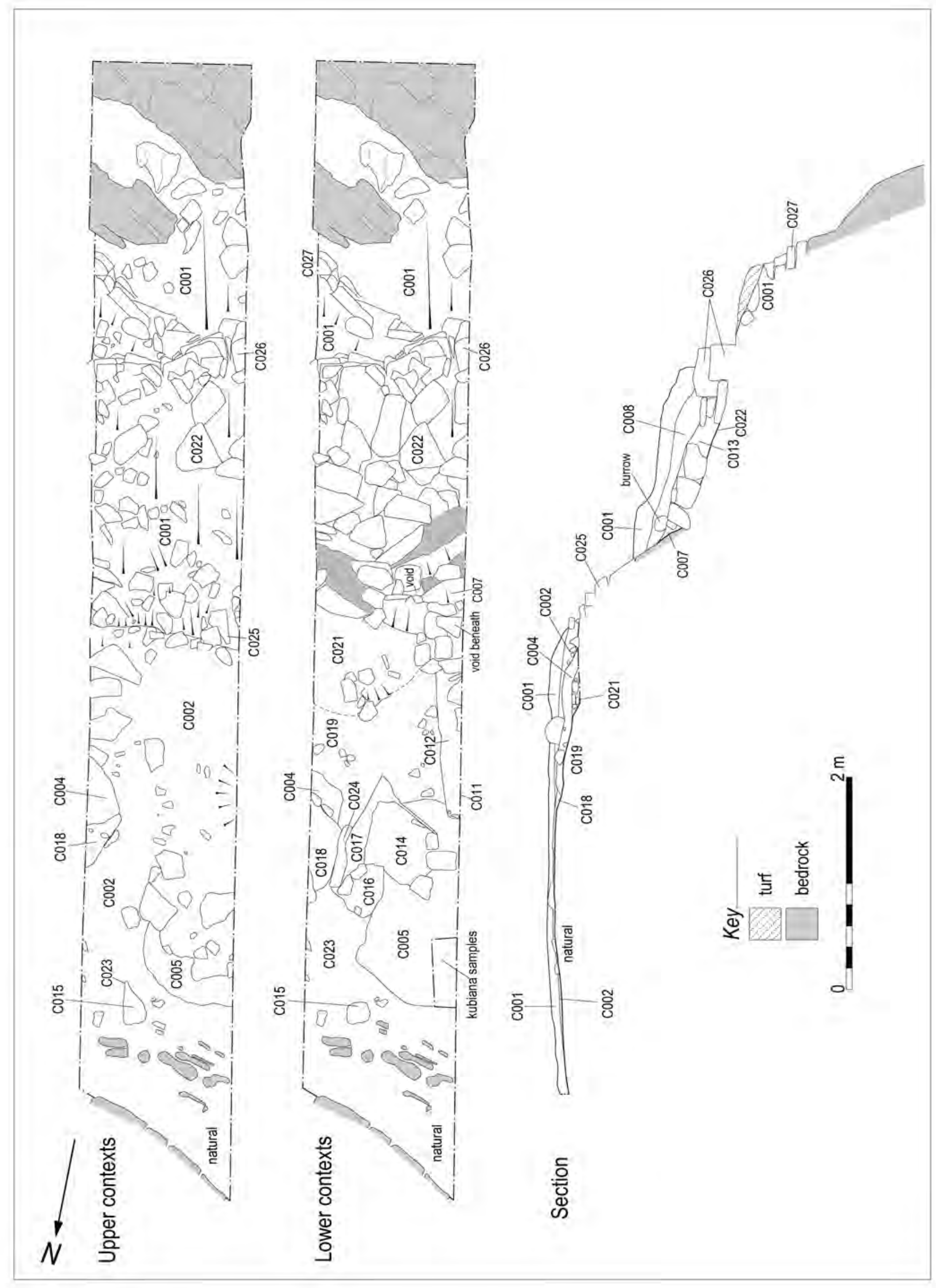

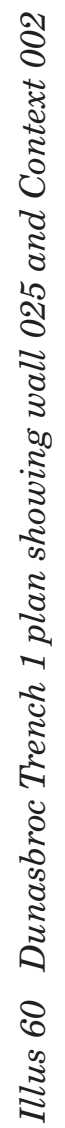




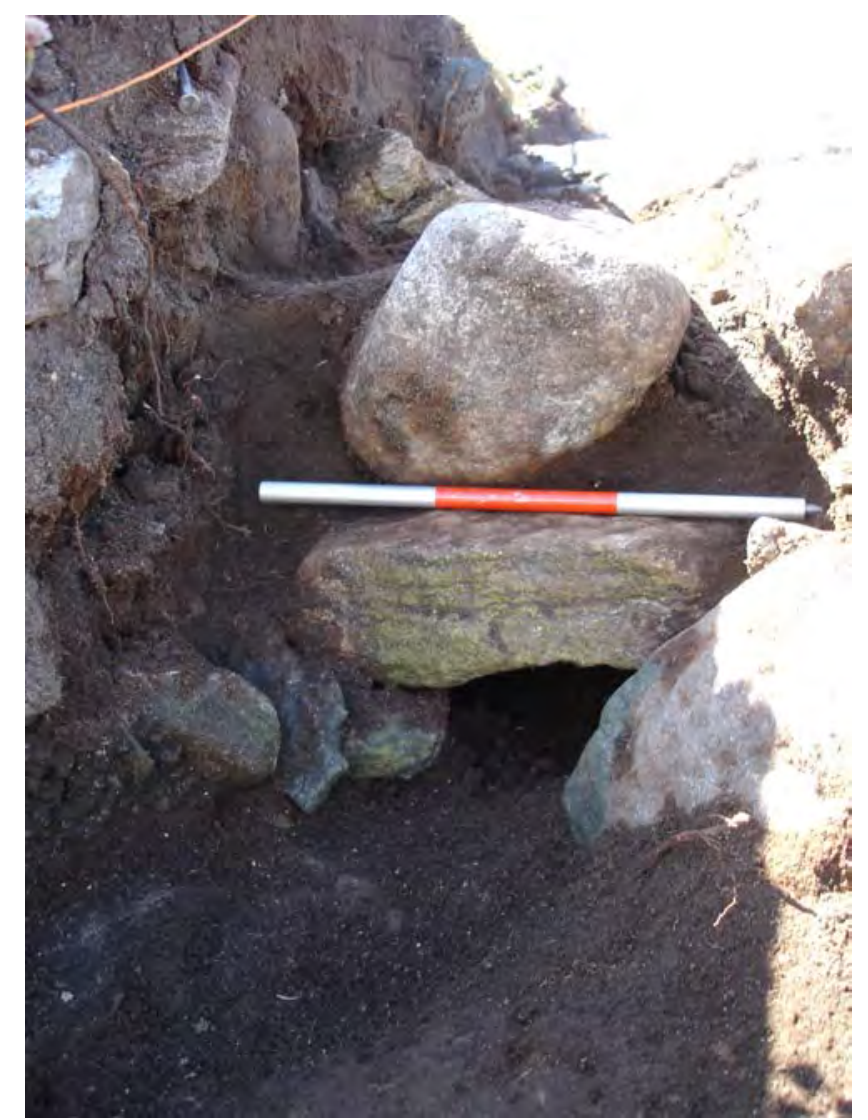

Illus 61 Flue/drain feature in Trench 1,

Dunasbroc from the north. Scale $0.3 \mathrm{~m}$ long.

Age pottery suggests an Iron Age date for this and the overlying deposits, confirmed by the date from the charred grain.

The removal of Context 004 on the plateau revealed a complex group of sealed deposits and probable features, not all of which we had time to fully investigate. Illus 60 shows Contexts 005, 011, 012, 014, 015, 016, 017, 019, 020, 021 and 023 all within this area, north of wall 025.

In the centre of the plateau, Context 014, a compact, light coloured, yellow-orangey-brown sandy clay, was at first very difficult to distinguish from Context 005 to the north, but a sondage revealed that it covered part of Context 005 with a thin lens. The main part of Context 014 lay to the south of Context 005. Context 014 appeared to be burnt only on its northern edge, and contained three flagstones, fragments of charcoal and a piece of burnt (rather than fired) clay, as well as a single piece of calcined indeterminate mammal bone, birch, heather and spruce/larch charcoal, and six-row barley. It was interpreted as a possible floor surface during excavation due to its compact nature. A single charred grain of naked six-row barley (Hordeum vulgare sl.) from within the context returned a radiocarbon date of $2125 \pm 35$ вP (SUERC 13557/GU 15123), confirming an Iron Age date for its deposition (table 3).

Context 024 was virtually identical to 014 on its surface and is thought to be the eastern extent of the context, separated by features 016 (possible pit) and 017 (linear feature, V-shaped in plan). Nearby was Context 018, a patch of red, gritty sand. All of these contexts remain un-excavated, and their stratigraphic relationships are therefore unconfirmed.

Linear feature 011, also sealed by Context 004, ran from (just) under Context 014 in the centre of the plateau, to Context 025, the uppermost part of the wall, where it had a (collapsed) termination that seemed to have been built into the wall. It was $150 \mathrm{~mm}$ deep, but was shallower towards its northern end, and was $1.8 \mathrm{~m}$ long. Unfortunately, only one side of the feature was present in the trench, so its width is unknown. The excavated eastern side had a flat bottom with gently sloping sides, except at its termination at Context 025, where rectangular slabs had been placed to create a solid vertical side and base (illus 61). The cut was filled with Context 012, a dark-grey sand containing a small proportion of clay, several flat slabs towards the south end, as well as charcoal of heather, spruce/larch and unburnt cattle bone. This is the only excavated context that contained exclusively unburnt bone. The slabs appear to have originally covered the feature as a drain might be covered, and to have collapsed inwards. The slab in the base of Context 011 at its termination at wall 025 covered a second void beneath (illus 61 ), but time did not allow for further investigation. A third void, again covered with what appeared to be a lintel, could be seen in wall 025, c 200mm below the base of feature 011, and yet another similar feature was found in Context 026, the next wall down the slope (see below) (illus 62).

Feature 011/012 cut Contexts 019 and 021 (below). The stratigraphic relationship between the feature and wall 025 is unresolved; the stonework of the termination of 011 seemed to be an integral part of the wall, but it equally might have been built (later) into the wall after activity on the plateau had already begun.

To the south of 024, Context 004 overlay Contexts 019 and 021, both unexcavated. Context 019 was a brown-grey, gritty sand, and above and to the south of it (illus 60), Context 021 was a grey-brown mottled silty sand, containing stones $c 10 \mathrm{~mm}$ in size. Context 021 might originally have been turf, its mottled colouring being similar to deposits experienced when excavating ancient turf banks. It lay immediately north of wall 025 , the uppermost wall, which appeared to form an edge to the deposit. However, given the relationship noted above between feature 011/012 and wall 025, it is possible that 019 and 021 may have been present before any activity took place on the site, and may represent the original ground surface. Further excavation would be necessary to resolve this issue.

In the north of the trench, Context 005, a brownish-orange gritty-sand, was indistinguishable from the natural subsoil in composition and, when a small sondage was excavated, there was no discernible horizon in section. It covered approximately a quarter of the area of the plateau and contained a 


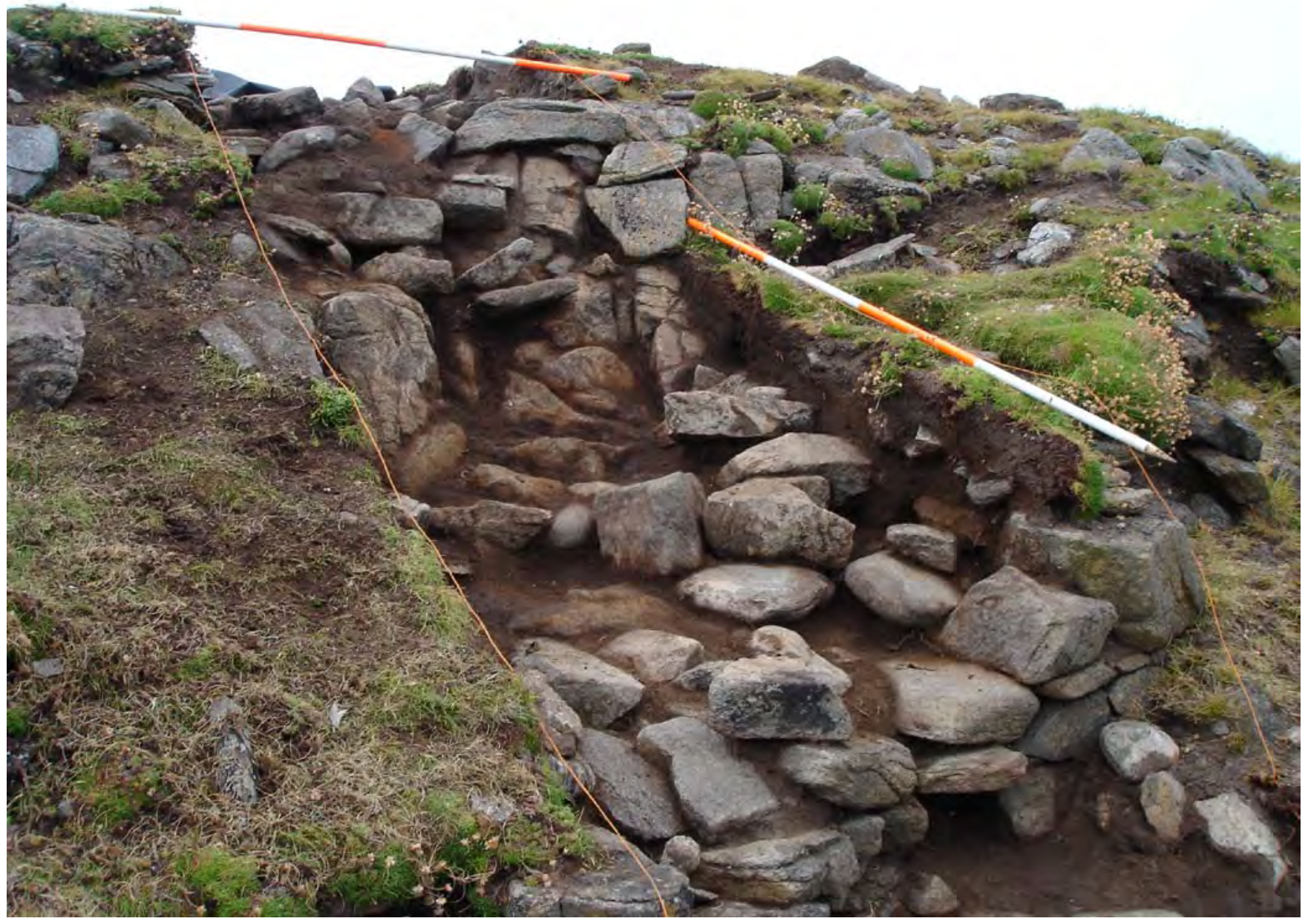

Illus 62 Flue/drains beneath wall 025/026, Dunasbroc from the east. Scales $2 m$ long.

few finds: four pieces of burnt and calcined animal bone from its upper surface - one from cattle, the rest indeterminate, as well as the carbonised remains of birch, spruce/larch, naked six-row barley and the only grain of emmer wheat from the site (see Appendices 6 and 7). A radiocarbon sample taken from an indeterminate cereal grain from this context provided a date of $2125 \pm 35 \mathrm{cal}$ BP (SUERC 13550/GU 15119; table 3).

The major visible difference between Context 005 and the natural subsoil was in colour, the natural being yellowy-brown. It had been thought possible that Context 005 was originally natural subsoil, burnt in situ and chemically changed by heat, but the micromorphology report (Appendix 8, illus 63) verified that, although Context 005 had been strongly heated from above and was very similar to the subsoil, it had been anthropogenically deposited and moreover, probably contained more than one depositional episode. It was also noted that despite the evidence for heating, the context was clean and lacked fuel residues, which suggested that the upper surface of the deposit was regularly cleaned after burning. The finds mentioned above came exclusively from the top $20 \mathrm{~mm}$ of the context, and it is possible that this was also the case for the botanical material, but this material was not sampled for soil micromorphology.

A small posthole Context 023 (illus 64) was found in the northern part of the trench where it had been dug into the natural subsoil. It contained three small but vertically placed packing stones around the edge of the cut, and was filled with Context 015, a dark brown, silty clay, but no finds. Posthole 023 had vertical sides and a rounded bottom, and was $170 \mathrm{~mm}$ in diameter and $100 \mathrm{~mm}$ in depth. It is possible that this posthole was truncated. Charcoal of the birch (Betula) species found within its fill returned a radiocarbon age of $4570 \pm 35$ ВP (SUERC 13556/GU 15122).

Wall 025 is constructed in dry-stone masonry, exclusively from rough slabs of Lewisian gneiss of the same colour and texture as that of the stack itself. Each stone was no larger than $400 \mathrm{~mm}$ in length or width, and $200 \mathrm{~mm}$ in thickness, but generally they were smaller and not big enough to provide the foundations for a substantial wall. The wall was not free-standing but was positioned to fit into or against the natural bedrock outcrop around the edge of the plateau. The wall seems to 


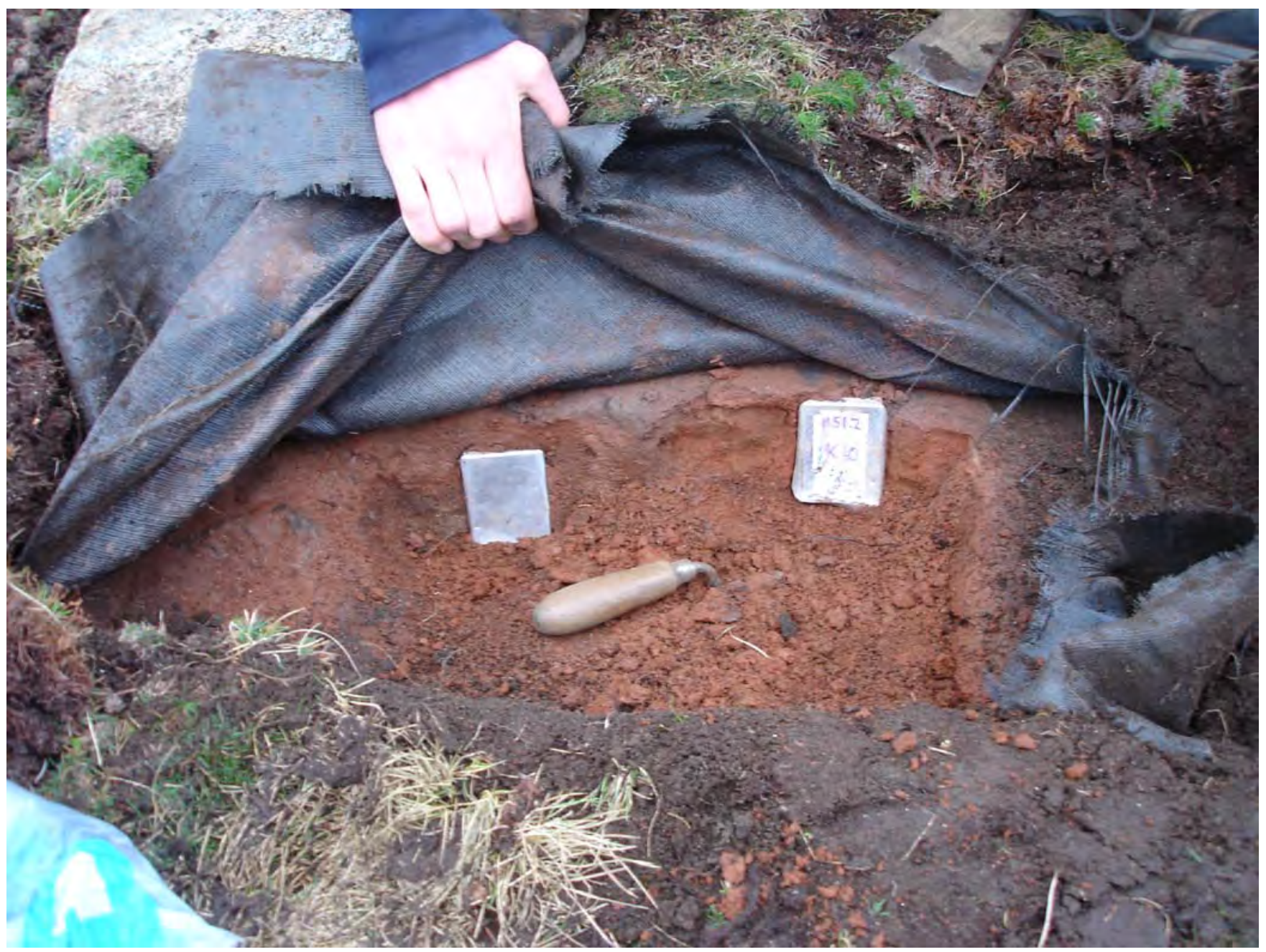

Illus 63 (above) Sampling using Kubiena tins for micromorphological analysis

Illus 64 (right) Posthole 015/023 in Trench 1, Dunasbroc from the west. Scale $0.3 \mathrm{~m}$ long.

bridge a natural gully at the edge of the plateau, which would otherwise have cut a V-shape into its sub-circular plan. This gully may have extended all the way down the side of the stack, as it reappeared beneath the lower wall, Context 026 (illus 62).

Context 007, a burnt, reddish-brown silty clay, had collected between the small ledges of wall 025 . Although unexcavated, Context 007 was related to the uppermost southern deposits down-slope, where it was found to lie underneath Contexts 008 and then 013 (both interpreted as uppermost layers of collapse, see illus 60 for section drawing) and topsoil.

Below the break of slope, between walls 025 and 026 , a number of deposits had accumulated (illus 60). The topsoil here was much deeper than elsewhere on the stack (up to $400 \mathrm{~mm}$ ), no doubt because it had accumulated against wall 026 . Immediately beneath the topsoil was Context 008, a reddish-brown, silty

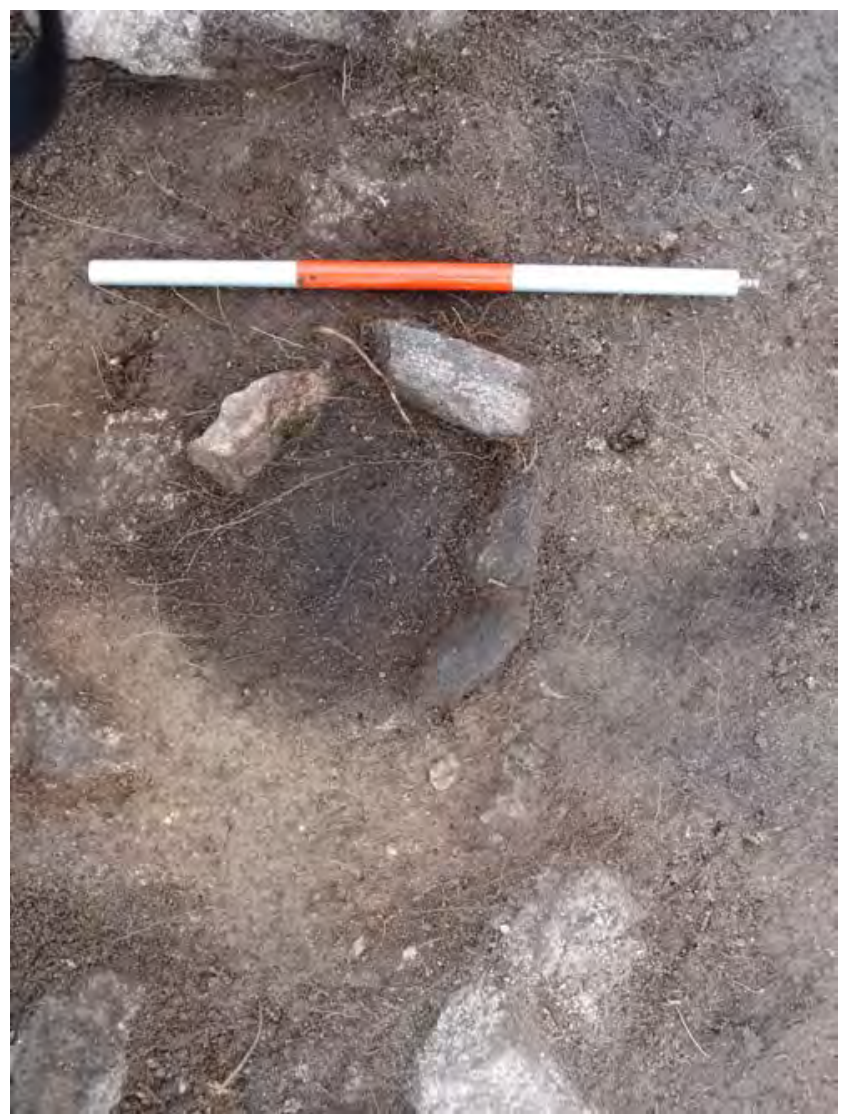



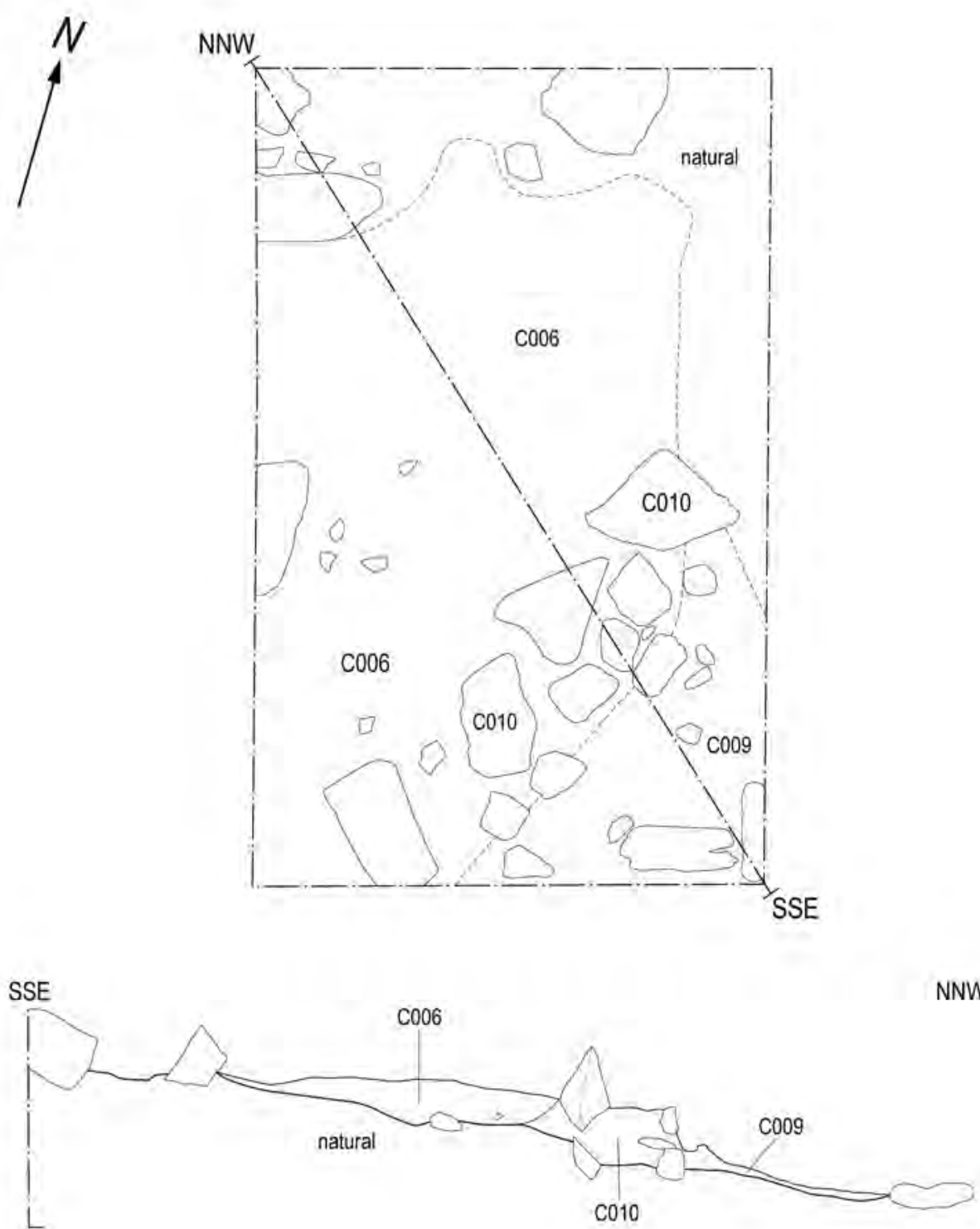

Illus 65 Trench 2 plan and section, Dunasbroc

clay with charcoal, containing the lithics of quartz, flint and the local gneiss, burnt bone, fire-cracked stone, and both Iron Age (SF160) and Neolithic (SF183) pottery.

Below 008, Context 013 was a yellowish-brown, sandy silt, with occasional tumbled stone slabs of around $200-300 \times 200-300 \times 100 \mathrm{~mm}$, as well as charred heather and spruce/larch remains. The size of the stone slabs suggested that they might have derived from wall 025 and come to rest here due to the ledge created by the lower wall, Context 026. Both of these contexts (008 and 013) were contaminated by burrowing animals and contained relatively few finds.
Context 022 lay beneath 013 , but remained unexcavated due to lack of time. It was clear from cleaning that Context 022 was mostly tumbled stonework of consistently larger $(400 \times 400 \mathrm{~mm})$ roughly square blocks of locally sourced Lewisian gneiss. It was thought possible that these derived from Context 026, which has similar-sized and -shaped blocks that could have collapsed inwards or to the north.

Wall 026 was of a much higher quality construction than wall 025 and survived to at least three courses running NE/SW, rising as it rounded the contour of the stack, with another wall, Context 027, directly underneath it heading off at $45^{\circ}$, or due E/W. Wall 026 created a $2 \mathrm{~m}$-wide platform, which ascended as 
it rounded the contour of the stack, heading in an anti-clockwise direction towards the plateau, where a possible junction of the two could be detected. The lowest wall (027) was noticed as continuing along the contour for $1-2 \mathrm{~m}$ beyond the trench edge before terminating at a bedrock outcrop.

Wall 026 was also constructed of dry-stone masonry, although the blocks and slabs of stone were larger than elsewhere. Its slabs were up to $0.6 \mathrm{~m}$ length/width and $0.2 \mathrm{~m}$ thick and predominated in the lower courses, whilst square blocks of $c 400 \times 400 \mathrm{~mm}$ were found above. Wall 027 beneath this was constructed of similarly-sized stones as wall 025 , although unlike wall 025 it was very well constructed of four to five courses, and seemed to function as a structural support for wall 026. At the base of wall 026, just above wall 027, there was another void with a covering lintel and supporting sides (illus 62), very similar to those described in 025 .

\subsection{Trench 2}

After removal of the topsoil and turf Context 001, the western part of Trench 2 was found to have an even covering of Context 003, a dark, brown-yellow, sandy grit very similar to Context 002 in Trench 1. Context 003 contained a patinated flint blade, a quartz flake and chunk, unburnt sheep/goat and cattle bones and the burnt remains of birch, heather and willow. The apparent depletion of organic material in the context may be the result of weathering. The finds show the same mixture of burnt and unburnt material as was typical of Trench 1 .

Underlying Context 003 was Context 006, an even, dark, grey-brown, silty clay covering most of the trench, which contained the majority of the finds recovered from the site. These included a broken leaf-shaped arrowhead of imported flint (SF100), flint blades and flakes, both burnt and unburnt, quartz blades and flakes, a banded siliceous flake (SF48), large amounts of Neolithic Hebridean Ware, burnt and unburnt animal bone, as well as birch, hazel, willow and heather charcoal. The context was excavated in spits of $30 \mathrm{~mm}$ depth. Two radiocarbon samples were taken from the top and the bottom of Context 006. Radiocarbon sample 006, a charred grain of naked six-row barley from the upper part of the context returned a date of $2110 \pm 35$ BP (SUERC $13547 /$ GU 15116), whereas sample 008, taken from willow charcoal in the base of the context, returned a date of $4630 \pm 35$ вP (SUERC 13551/GU 15120), however, no contextual change could be discerned within the deposit. A pot sherd uncovered midway through excavating Context 006 (SF146) had carbonised organic residue remaining within it, which returned a radiocarbon date of $4660 \pm 35$ BP (SUERC 13558/GU 15124; table 3).

Beneath Context 006 was Context 010, a rough revetment down-slope of the bulk of Context 006 , and underlying it (illus 65). It had a matrix of brown clayey sand, which also contained finds: a quartz flake (SF172), Neolithic Hebridean Ware (eg SF174), and Iron Age pottery (SF175), and birch, willow and heather charcoal. Unusually, it contained no animal bone. A radiocarbon date from Context 010 returned a date of $4815 \pm 35$ вP (SUERC 13555/GU15121; table 3 ), although the Iron Age pottery would suggest that this date, as noted above, represents material that was re-deposited in the Iron Age.

A further context, 009, an orange-brown, sandy clay, was discovered underlying revetment 010 and continuing down slope (illus 65). The upper part of Context 006 had slumped or washed down over Context 009 and 010. Context 009 contained three quartz flakes, one of which was patinated (SF179), and birch, hazel and heather charcoal. All of these deposits directly overlay Context 020, a light-grey sandy clay, which contained birch, heather and willow charcoal. This context was very similar to Context 005 in Trench 1. 


\section{INTERPRETATION AND DISCUSSION}

\subsection{Site morphology}

The morphology of the site, and its relationship to the coastline, is likely to have changed over the years. Sea level rise, estimated at perhaps $6 \mathrm{~m}$ (Section 3.3 above) has affected the coastline and direct wind and wave action may well have changed the shape of the stack itself. Archaeological deposits and walls survive at the top of the stack at $18.2 \mathrm{~m} \mathrm{OD}$, down to $11 \mathrm{~m}$ OD on its landward side. The morphology of this part of the stack may not have changed significantly since the walls were constructed. We still do not know, however, whether these walls were built in the Neolithic or Iron Age.

Cliff erosion and sediment movement have produced deposits of large, rounded boulders in the adjacent geos and between the stack and the adjacent mainland. The depth of these deposits is unknown, and it is therefore possible that even when the sea levels were lower, the stack may have been free-standing.

Taking these factors into account, it seems most probable that during the Neolithic period Dunasbroc was a small, well-defined coastal hillock, at least $7 \mathrm{~m}$ high, very close to the edge of steep $c 17 \mathrm{~m}$ high seacliffs. The geos at each side and the gap between it and the mainland may have been present to some extent, although it is difficult to know to what degree. Dunasbroc would still have been a dramatic coastal site.

\subsection{Neolithic use of the site}

There is unambiguous evidence from the two small excavated areas on the stack for intensive Neolithic use of the site. The volume of ceramics ( 477 sherds of Neolithic or probably Neolithic pottery) and lithics fits with the wider pattern of finds-rich Hebridean Neolithic sites (eg Armit 1987, Branigan \& Foster 1995), although no geographically similar site has previously been excavated.

Of the structures and deposits excavated, only one feature can be strongly argued to have survived from the Neolithic use of the site. This is the truncated posthole 023 , filled with deposit 015 (illus 64 ), which cut the natural subsoil. The radiocarbon date of $4570 \pm 35$ вP (SUERC 13556/GU 15122) from birch charcoal from this context suggests a Neolithic date that was not contradicted by any stratigraphic relationship. Its small size (diameter $c 100 \mathrm{~mm}$ ) makes it unlikely to have been part of any sort of substantial structure or habitation, although it would also seem to have been too small for a free-standing post, unless it was severely truncated.
It is also worth considering the possibility that the lowest of the deposits on the top of the stack, identified in the soil micromorphology report (Appendix 8) as the lower part of Context 005, might belong to this period. The report indicated that a distinct context, formed of three dumps of redeposited natural subsoil and weathered gneiss $(2 \mathrm{~b}, \mathrm{c}$ and $\mathrm{d}$ in Appendix 8), underlay a truncation horizon, and had been influenced by heat from above. This was interpreted as a construction deposit, levelling the natural platform on the top of the stack for use. There were no finds and no radiocarbon dates from this deposit, and no anthropogenic materials were identified within it under microscopic examination. However, it was, stratigraphically, the earliest context excavated.

There is no stratigraphic reason why the walls within the excavated area $(025,026,027)$ could not have been Neolithic in their original construction, though there was evidence (see below) for modification or rebuilding during the Iron Age use of the site. Their age remains unclear because all of the excavated contexts, which post-dated but were associated with the walls, could be clearly Iron Age in date (see below).

The lack of solely Neolithic deposits also means that it is very difficult to discuss the nature and duration of the use of the site at that time. All the Neolithic radiocarbon dates came from wood charcoal, willow or birch, of which there were large quantities in most deposits. There was therefore clearly at least one significant burning episode in the Neolithic. However, though a little of the pottery showed sooting or charred residues (eg SF111, SF146) no secondary burning was recorded on the pottery, nor on the leaf-shaped arrowhead and many other lithics. Although fire was used at the site, the burning had not affected all the objects that were presumably present on the site at the time.

It is not possible to say whether the burnt and unburnt animal bone from the site may have included Neolithic material, as there are no dates from the bone finds, which all came from deposits with both Neolithic and Iron Age evidence. Unfortunately, the situation is the same with all of the walls and flues/drains, which although stratigraphically earlier than some deposits cannot be shown to belong to either period without further investigation.

The Neolithic date range from the radiocarbon samples stretches from $4815 \pm 35$ BP (SUERC $13555 /$ GU 15121) to $4570 \pm 35$ вP (SUERC 13556/ GU 15122), ie from 3660 cal BC to 3100 cal BC (at 2sigma level of confidence; see table 3), a maximum range of 550 years. Although it is, of course, impossible to say what evidence may have been lost from 
the site in the Iron Age reworking of the material (see below) it does suggest a relatively short period of use of the site during the Neolithic period.

\subsection{Iron Age use of the site}

In contrast to the Neolithic assemblage, the Iron Age deposits yielded only a small number of diagnostic Iron Age finds. Three Iron Age sherds are described in the pottery report (Appendix 3 - SF111, SF160 and SF175), though some of the undiagnostic body sherds could probably be either Iron Age or Neolithic. There were no diagnostic Iron Age lithics, though again, it is possible that some of the less diagnostic quartz could potentially have dated to this period.

Despite the dearth of artefactual evidence, most deposits are stratigraphically Iron Age in date. Context 005, underlying the majority of the excavated contexts, and overlying natural subsoil, provided an Iron Age date from an indeterminate cereal grain ( $2125 \pm 35$ вP, SUERC 13550/GU 15119; see table 3). This date came from near the top of the deposit (see above, Trench 1), and soil micromorphological analysis (Appendix 8) indicated that much of the context was clean of anthropogenic content. As discussed above, the lower part of the context (2b, c and d in Appendix 8) consisted of dumps of redeposited natural soil and weathered gneiss, very similar to the subsoil. These slanting dumps were horizontally truncated, and overlain by a weathered deposit of similar material imported from elsewhere, which formed the upper part of Context 005. It was this upper part of the deposit that contained the finds and some charred organic remains, yielding the Iron Age date. The lower part of this deposit could therefore potentially have been laid down in the Neolithic, but given the lack of evidence we can only say that these deposits were deposited no later than the Iron Age (an Iron Age terminus ante quem).

The stratigraphic relationship between Context 005 and wall 025 is not resolved, and the date of the construction of wall 025 , and whether it was modified afterwards, is therefore similarly undecided. This also follows for the other walls, 026 and 027 . As before, this uncertainty means that the most accurate dating we can ascribe to these features is a terminus ante quem of $\mathrm{AD} 0-200$, or Middle Iron Age.

Wall 025 was insubstantial, and quite unlike the base of a structural wall. There seemed to have been a natural gully in the stack on the landward side, which was bridged by wall 025 and wall 026 , so that traces of it only reappeared lower down the stack beneath 026. Linear feature 011/012 was built into this gully, and its end was integrated into wall 025 . The stratigraphic relationships of feature 011/012, which was above Context 021, make it possible that it was Iron Age in date. The fill of this feature (Context 012) was the only deposit on site not to contain burnt artefacts or burnt bone, though the ubiquitous charcoal was present, suggesting less direct fire influence on the contents of 011 than on the other deposits on the site.

Given that the amount of evidence reviewed so far points to large-scale burning, the possibility that this feature was a flue must be considered. Its position seemed ideal for such a function, taking air from outwith and underneath the plateau and feeding it straight into the centre, which would also presumably have been the centre of the fire. The apparent double level construction of the feature, visible in wall 025, was of unknown function. Perhaps the lower void transported air further into the plateau than the excavated one. It is also possible that the feature was a drain, ensuring the plateau could not become waterlogged. This, however, seems less likely, as the site is not prone to flooding, and this does not help to explain the double level of the feature. Neither was there much to indicate the purpose of a further built void in the wall just $400 \mathrm{~mm}$ beneath and a little to the north (illus 62), which had an intact lintel and supports. Perhaps these features also performed either or both of the above functions.

A void in wall 026 , similar to the features described in wall 025 , was present close to the base of wall 026 . The void was $c 100 \times 200 \mathrm{~mm}$ in dimension and had a lintel stone held up by two lateral supports. Given the distance from the plateau $c 3.5 \mathrm{~m}$, or $2 \mathrm{~m}$ vertically, this feature seems less likely to have been a flue, and could perhaps be more sensibly interpreted as a drain. Certainly the horizontal ledge formed by wall 026 would tend to gather water, which could damage the wall.

Wall 026 appeared to be a retaining wall, creating a $2 \mathrm{~m}$-wide platform spiralling anti-clockwise up and around the stack, interpreted in the field as an access route to the plateau. This may not necessarily have been the case. The Coastal Erosion Assessment, Lewis describes Dunasbroc as a 'stack enclosed by a wall' (Burgess \& Church 1997, 267), with wall 026 the only candidate which would have been visible enough for this. The wall was reasonably substantial, and could possibly have been taller, and used either defensively or as an enclosure, with its extra stonework having since been lost to the sea. If this was the case, it seems strange that the wall was not horizontal, and also that it did not continue around the south-west side of the stack. It may be that the prevailing south-westerly storms have destroyed the southern section of the wall and caused the remainder to slip, but there was no evidence for this.

If wall 026 was a platform forming an access track to the plateau, its lower termination would have been at the south-eastern corner, where access was easiest in modern times. A small ledge climbs to this point from the head of the neck of rock that joins the stack to the mainland, and could easily have met with the terrace formed by wall 026. Although, as noted above, we cannot be sure what shape this lower part of the stack took in antiquity, this seems the most likely interpretation. 
The excavated deposits that lay between walls 025 and 026 supported the interpretation of this area as having a different function from the top of the stack. Contexts 008, 013 and 022 contained large amounts of rubble, surrounded by a soil matrix, which seemed to have come from the walls. The presence in Context 008, the uppermost, of the characteristic suite of artefacts and ecofacts found in the deposits on the top of the stack, burnt and unburnt bone, lithics, Iron Age and Neolithic ceramics, raised the possibility that this deposit, which accumulated during the Iron Age, did so in between walls which were already to a greater or lesser degree dilapidated.

Wall 027 seemed clearly functional, providing support for wall 026 on the $50-70^{\circ}$-angled slope. It was very well made even if slight, and did not appear to have slipped significantly. It was clearly built before the larger wall 026, as it lay beneath it, and formed a foundation for the later wall.

The other deposits on top of the stack, which clearly post-dated both linear feature 011/012, and wall 025, and overlay Context 005, were all Iron Age in date. The earliest of these was Context 014, which with Context 024 was compact, and had a few burnt finds. This may represent a resurfacing of the plateau, later than the resurfacing demonstrated in Context 005. The deposits which overlay it, Contexts 004, 018 and 002, all with a mixture of burnt and unburnt finds, would seem to correspond to Contexts 003, 006 and 009 in Trench 2. They seem to have been the result of clearing back the surface of the stack, and mixing burnt and unburnt material in the process. Interestingly, the residual Neolithic finds, particularly the ceramics, do not show any significant wear on their edges, which suggests that the distance that they were moved, and the amount of disturbance caused by the move of the Neolithic deposits, was small. The contexts in Trench 2 were revetted by the slight accumulation of stones 010 , showing a concern to retain material on the top of the stack, possibly to maintain the upper surface of the plateau, but perhaps also from a concern for the material itself.

All the Iron Age dates from the site came from cereal grains, in contrast to the Neolithic dates (see table 3), which were from charcoal. The date range was even tighter than that for the Neolithic, from $210 \mathrm{cal} \mathrm{BC}$ (SUERC 13550/GU15119) to 50 cal AD (SUERC 13549/GU 15118; at 2-sigma level of confidence), less than 300 years. 


\section{CONCLUSIONS}

The presence of Neolithic charcoal, pottery and lithics from the site, and the Iron Age evidence for burning in the excavated area provide an interesting, though unprovable suggestion of continuity of use of the site. However, the truncation and redeposition of Neolithic deposits, coupled with the absence of Bronze Age evidence, suggests that there were two very distinct periods of use.

What conclusions may be drawn? The relatively small area, both of the excavation and of surface of the stack limit the conclusions that can be derived from the excavation. Though there is a wide variety and large number of Neolithic finds from the excavation, they do not appear to represent a conventional domestic assemblage in that lithics were not manufactured on site (no debitage was found on the site, see Appendix 4).

A variety of wood types were burnt at this time, including what was probably exotic driftwood (spruce/larch) as well as native woods, particularly willow. This probably reflects the availability of fuel in the area, though there is a possibility that the high concentration of willow could have resulted from the burning of wicker. It is also interesting to note that every available type of wood seems to have been used. This burning is also reflected in the presence of burnt bone, and heat-affected lithics. The bone is undated, but the lithic assemblage contained no diagnostic Iron Age material, and is probably all Neolithic (C S Barrowman, pers comm). It is possible that previously burnt material was imported onto the site during the Neolithic period; however, this seems unlikely and the lack of secondary wear on the artefacts supports the presumption that the burning took place on the top of the stack.

One grain of emmer wheat may be Neolithic, coming from posthole Context $015 / 023$, but all the other grain that was dated derived from the Iron Age use of the site. The occurrence of a broken saddle quern may have related to the presence of this grain. However, large-scale grain processing seems very unlikely, given the relatively small amounts of charred grain found and the topography of the site.

Two prestigious and rare finds, a beautiful, but broken, leaf or lozenge-shaped arrowhead of imported flint from Context 006 (SF100), and a large oval stone with one smoothly polished side, a surface find from the site survey (SF3:2004) are probably Neolithic in deposition. The leaf-shaped arrowhead (SF100) has a parallel in an artefact from nearby in Ness (Barrowman, C S 2007), and is diagnostically Neolithic in manufacturing date (Appendix 4, Section 7). The stone has no known parallels in the islands, and its function is unclear.

The Neolithic produce and raw materials found at Dunasbroc could be argued to represent many if not most aspects of life in that age, and it is suggested that their collective burning there was a kind of votive deposit or offering. The exact meaning of this is not known, but it seems probable that the site's geographical location was significant.

It can be deduced from the stratigraphic analysis that there was at least one, and were possibly two, very hot fires on the same area during a very short period of the Iron Age. The scant Iron Age finds included a few sherds of diagnostic pottery, and the charred barley grains that provided the Iron Age radiocarbon dates. The undated bone fragments, both burnt and unburnt, must be assumed on stratigraphic grounds to belong to this period as well. Interestingly, there is no dated charcoal from the Iron Age use of the site. This may reflect the small sample size provided by the excavation, or a greater concern with grain by that time. Heather was found in many contexts, as were plants thought to derive from turf, possibly imported as peat fuel, such as grass/sedge stems, underground rhizomes, chickweed/mouse ear and dock. The 'weed' type plants are not found in context with the cereals, indicating that the 'cereals were fully cleaned before being brought to the stack' (Appendix 6).

Although we cannot be sure, the nature of the activities taking place seems to imply that this subsequent re-use in the Iron Age may have had some reference to the original use of the site. In this respect it may be relevant to note the numerous instances of Iron Age activity documented at Neolithic chambered tombs in the Western Isles, such as the pottery found at (amongst others) Clettraval (Lindsay Scott 1947-8), Unival (Lindsay Scott 1934-5) and probably Barpa Langass, North Uist (Henshall 1972, 503), and in Orkney, the clearing aside of Neolithic deposits and deposition of Iron Age such as Calf of Eday (Calder 1936-7), Knowe of Rowiegar (RCAHMS 1946), Howe (Ballin Smith 1994) and Huntersquoy lower chamber (Henshall 1963, 205) as discussed by Hingley (1996).

The excavation at Dunasbroc has provided a tantalising glimpse into a ritual site, re-used over time with, as yet, no excavated parallels elsewhere in Britain. This relatively small site has raised more questions than it has answered, but has also confirmed the thesis that coastal stack and promontory sites have a much longer and more diverse history than has previously been thought. Clearly no assumptions can be made about the dates or 
functions of such sites, and further research will be necessary to understand them. The vulnerability to erosion that has provided this new evidence also means that further research and fieldwork are a matter of great urgency, as the resource diminishes year on year. 


\section{ACKNOWLEDGEMENTS}

Many people were invaluably helpful to the process of carrying out the fieldwork for this project, including Mary MacLeod and Comhairle nan Eilean Siar for general support and project management, Museum nan Eilean for the assistance of their conservator (Mark Elliott), and their academic advice, secretarial support and printing of interim reports. Thanks are also extended to numerous grazings clerks for permission to gain access to sites from all around the coast of Lewis.

A debt of gratitude is owed to the funders of the project throughout the three years of fieldwork, namely Historic Scotland, the Russell Trust and Comhairle nan Eilean Siar and SCAPE. Tom Dawson of SCAPE assisted with funding applications. Sally Foster, Rod McCullagh and John Raven, all of Historic Scotland, offered help and advice throughout. There are also many individuals from various institutions who gave free advice and information on various aspects of the work, namely Trevor Cowie (National Museums of Scotland) and Michael Robson, Ness, and the Islands Book Trust, and Dr Richard Jones and Dr Jim Hansom, both Glasgow
University, for advice concerning fire temperatures and sea levels respectively.

The Uig, Tolsta and Ness Commainn Eachdraidh offered much helpful local knowledge and practical advice, as did many individuals from all areas of Lewis, especially Donald and Calum MacKenzie of Eorodale, Donald Murray of Tolsta and Alec Dan Murray, Donald Morrison and Angus Smith of North Dell. The excavation of Dunasbroc would never have been achieved without the help of Donald Gillies of South Dell and his tractor. We are grateful to Aggie Murray of Ness for translating Gaelic for the project, and thank not only the hard work of all those directly involved in the fieldwork but also their families for good humour and support throughout what has been a rather strenuous undertaking.

Finally, thanks are expressed to Beverley Ballin Smith for managing the final stages of the work, to John Arthur, Gillian McSwan and Ingrid Shearer for their illustrative expertise, and to Jen Cochrane for administrative support and desk-top publishing: all at GUARD, University of Glasgow. 


\section{REFERENCES}

Angus, S 1997 The Outer Hebrides; The Shaping of the Islands. Cambridge: Cambridge University Press.

Armit, I 1987 'Excavation of a Neolithic Island Settlement in Loch Olabhat, North Uist 1987: 2nd Interim Report'. Edinburgh: University of Edinburgh, Department of Archaeology Project Paper 8, October 1987.

Armit, I 1992 'The Hebridean Neolithic', in N Sharples \& A Sheridan, 307-21.

Armit, I and MacSween, A 1993 'Pottery', in A Crone, $370-5$.

Armit, I 1996 The Archaeology of Skye and the Western Isles. Edinburgh: Edinburgh University Press.

Ashmore, P J 1994 Archaeology and the Coastal Erosion Zone: Towards a Historic Scotland Policy. Edinburgh: Historic Scotland.

Ashmore, P J 2003 'Archaeology and the coastal erosion zone', in T Dawson (ed.) 2003 Coastal Archaeology and Erosion in Scotland.Edinburgh: Historic Scotland.

Ashmore, $\mathrm{P}$ forthcoming 'Calanais, Isle of Lewis, Western Isles' (to be submitted to the Proc Soc Antiq Scot)

Ballin, T B 2000 'Classification and description of lithic artefacts: a discussion of the basic lithic terminology', Lithics 21, 9-15.

Ballin, T B 2004 'The worked quartz vein at Cnoc Dubh, Uig parish, Isle of Lewis, Western Isles', Edinburgh: Scottish Archaeological Internet Report (SAIR) 11, 2004.

Ballin T B forthcoming 'Recognition of burnt quartz and its relevance to the interpretation of prehistoric sites' (to be submitted to Lithics).

Ballin Smith, B 1994 Howe: Four Millennia of Orkney Prehistory. Edinburgh: Society of Antiquaries of Scotland Monograph Series No. 9.

Barber, J W 2003 Bronze Age farms and Iron Age farm mounds of the Outer Hebrides. Edinburgh: Scottish Archaeological Internet Report (SAIR) 3.

Barrowman, C S 2001 'Dun Eistean, Ness, Lewis (Barvas Parish) Promontory enclosure and dun', in Discovery and Excavation in Scotland. Edinburgh: Council for Scottish Archaeology, 99.

Barrowman, C S 2002‘Dun Eistean, Lewis: Geophysical Survey and Trial Excavation' - description of the archaeological structures with contributions by D. Maguire. Unpublished interim report 716.2 and 716.3. University of Glasgow: GUARD.

Barrowman, C S 2004 'Dun Eistean, Lewis'. Unpublished interim report 713.4. University of Glasgow: GUARD.
Barrowman, C S, McHardy, I and MacLeod, M A 2004 Severe Terrain Archaeological Campaign (STAC): Rope Access and Topographical Survey. Stornoway, Comhairle nan Eilean Siar.

Barrowman, C S 2006 'Ness Archaeological Landscape Survey, Desk-based Assessment'. Unpublished interim report. University of Glasgow: GUARD.

Barrowman, C S 2007 a) Ness Archaeological Landscape Survey, Field Survey 2006. University of Glasgow: GUARD Project 2217.

Barrowman C S 2007 b) Ness Archaeological Landscape Survey, Field Survey 2007. University of Glasgow: GUARD Project 2378.

Barrowman, C S and Driscoll, S 2000 'Dun Eistean, Lewis, Archaeological and Topographical Survey'. Unpublished structures report. University of Glasgow: GUARD 716.1.

Barrowman, C \& McHardy, I 2005 STAC: Severe Terrain Archaeological Campaign: Rope Access and Topographical Survey, Isle of Lewis 2004. Stornoway: Comhairle nan Eilean Siar.

Barrowman R C 2006 Dùn Ėistean Archaeology Project Excavations 2005. Unpublished interim report. University of Glasgow: GUARD Project 2000.

Barrowman R C; Beckett A; Dalglish, C and McHardy, I 2007 Dùn Eistean Archaeology Project Excavations 2006. Unpublished interim report. University of Glasgow: GUARD Project 2217.

Beijerinck, W 1947 Zadenatlas der Nederlandschen Flora. Wageningen: Veenman \& Zonen.

Brady, K 2002 'Brei Holm, Papa Stour: in the Footsteps of the papar?, in B Crawford (ed.) 2002 The papar in the North Atlantic: environment and history: the proceedings of a day conference held on 24th Februrary 2001. St. Andrews: University of St Andrews, 69-82.

Brady, K; Duncan, J and McHardy, I 2000 Brei Holm Survey and Excavations. Papa Stour, Shetland. University of Glasgow: Unpublished Department of Archaeology Report,

Branigan, K and Foster, P 1995 Barra: Archaeological Research on Ben Tangaval. Sheffield: Sheffield Academic Press.

Branigan, K and Foster, P. 2000 From Barra to Berneray. Sheffield:, Sheffield Academic Press, SEARCH 5

Brown, N 'Eilean Domhnuill Loch Olabhat Pottery'. Unpublished report.

Bullock, P; Federoff, N; Jongerius, A; Stoops, G; Tursina, T and Babel, U 1985 Handbook for Soil Thin Section Description. Wolverhampton: Waine Research Publications. 
Burgess, C 1999 'Promontory Enclosures on the Isle of Lewis, the Western Isles, Scotland' in 'Papers presented to Keith Blood'. Northern Archaeology Vol. 17 / 18, 93-104.

Burgess, C 2000 'Lewis, Mesolithic to Modern'. Unpublished PhD. University of Edinburgh.

Burgess, C and Church, M 1996 'Uig Landscape Survey, interim report 1, 1995-1996'. Unpublished interim report.

Burgess, C and Church, M 1997 Coastal Erosion Assessment, Lewis. Edinburgh: University of Edinburgh.

Burgess, C; Dempsey, J; Gilmour, S and Jackson, A 1996 'Gob Eirer, Promontory Fort (Uig Parish)' in Discovery and Excavation in Scotland. Edinburgh: Council for Scottish Archaeology, 111.

Calder, C T S 1936-7 'A Neolithic double-chambered cairn of the stalled type and later structures on the Calf of Eday'. Proc Orkney Antiq Soc, 71, 115-56.

Campbell, E 2002 'The Western Isles Pottery Sequence' in B Ballin Smith and I Banks, In the Shadow of the Brochs. Stroud:T empus Publishing Ltd, 139-44.

Carter, R W G 1988 Coastal Environments. London: Academic Press.

Close-Brooks, J 1995, 'Excavation of a cairn at Cnip, Uig, Isle of Lewis', PSAS 125, 253-77.

Coles, G M and Burgess, C 1995 West of Lewis Landscape Survey. Unpublished interim report. Edinburgh: University of Edinburgh.

Courty, M A; Goldberg, P and Macphail, R I 1989 Soils and Micromorphology in Archaeology. Cambridge: Cambridge University Press.

Cowie, T G 1995 Coastal Erosion and Archaeology Assessment in Lewis and Harris. Edinburgh: National Museum of Scotland unpublished draft archive report.

Cowie, T forthcoming Barvas 2, Isle of Lewis, Western Isles.

Cox, R A V 2006 Draft report the place names of Ness. Lewis: Dun Eistean Archaeology Project, Ness, Lewis.

Crone, A 1993 'Excavation and Survey of Sub-peat Features of Neolithic, Bronze and Iron Age Date at Bharpa Carinish, North Uist, Scotland', Proc Prehist Soc 59, 361-82.

Davidson, D A and Simpson, I A 2001 Archaeology and Soil Micromorphology, in D R Brothwell, and A M Pollard (eds.) Handbook of Archaeological Sciences. Chichester: Wiley, 167-177.

Dawson,T(ed) 2003 Coastal Archaeology and Erosion in Scotland. Edinburgh: Historic Scotland.

Dickson J H 1992 'North American driftwood, especially Picea (spruce), from archaeological sites in the Hebrides and Northern Isles of Scotland'. Review of Palaeobotany and Palynology 73, 49-56.

Dickson, C A and Dickson, J H 2000 Plants and People in Ancient Scotland. Stroud: Tempus Publishing Ltd.
Dwelly, E 1994 (11 ${ }^{\text {th }}$ edition) The Illustrated GaelicEnglish Dictionary. Glasgow: Gairm.

Dymes, J 1630 Unpublished manuscript in British Museum cited in MacGregor 1967, 176.

Edmonds, M 1995 Stone Tools and Society. London: Batsford.

Fitzpatrick, E A 1993 Soil Microscopy and Micromorphology. Chichester: John Wiley and Sons.

Gibson, A 1995 'The Neolithic Pottery from Allt Chrisal', in K Branigan and $\mathrm{P}$ Foster (eds.), Barra: Archaeological Research on the Tangaval Peninsula. Sheffield: Sheffield Academic Press (SEARCH), 100-115.

Gibson, A 2002 Prehistoric Pottery in Britain and Ireland. Stroud: Tempus Publishing Ltd.

Grant, A 1982 'The use of tooth wear as a guide to the age of domestic ungulates' in B Wilson; C Grigson and S Payne (eds.) Ageing and Sexing Animal Bones from Archaeological Sites. Oxford: BAR British Series 109, 55-71.

Green, S H 1980 The Flint Arrowheads of the British Isles. Oxford: BAR Brit Series 75.

Henshall, A S 1963 The Chambered Tombs of Scotland, Vol.1. Edinburgh: Edinburgh University Press.

Henshall, A S 1972 The Chambered Tombs of Scotland, Vol.2. Edinburgh: Edinburgh University Press.

Hingley R 1996 'Ancestors and Identity in the Later Prehistory of Atlantic Scotland: The Reuse and Reinvention of Neolithic Monuments and Material Culture'. World Archaeology 28, 231-243.

Hunter J R and MacSween, A 1991 'A sequence for the Orcadian Neolithic?', Antiquity 65, 911-14.

Jacomet, S 1987 Prähistorische Getreidefunde, Eine Anleitung zur Bestimmung Prähistorischer Gersten und Weizen Funde. Basel: Herausgegeben im Eigenverlag.

Johnson, M 2006 'Pottery', in Simpson et al 2006, 44-69.

Lacaille, A D 1937 'A Stone Industry, Potsherds and a Bronze Age Pin from Valtos, Uig, Lewis', Proc Soc Antiq Scot 71 (1936-7), 279-96.

Lamb, R G 1973 'Coastal Settlements of the North', Scottish Archaeological Forum, Vol 5, 76-98.

Lamb, R G 1976 'The Burri Stacks of Culswick, Shetland and other paired-stack settlements', Proc Soc Antiq Scot 107, 144-54.

Lamb, R G 1980 Iron Age Promontory Forts in the Northern Isles. Oxford: BAR British Series 79.

Lane, A 1995 'Erosion Survey Pottery Analysis' draft report. Edinburgh: National Museums of Scotland.

Liddel, P 1874 'Note of an Underground Structure at Gress, nr Stornoway, and other Ancient Remains in the Island of Lewis'. Proc Soc Antiq Soc Vol. $10,741-4$

Lindsay Scott, W 1934-5 'The chambered cairn at Clettraval, North Uist'. Proc Soc Antiq Soc, 69, 480-536.

Lindsay Scott, W 1947-8 'The chambered cairn at 
Unival, North Uist'. Proc Soc Antiq Soc, 82, $1-48$.

Lindsay Scott, W 1951 'Eilean an Tighe: A pottery workshop of the second millennium BC', Proc Soc Antiq Scot 85 (1951), 1-37.

MacDonald, D 1967 Tales and Traditions of the Lews. Private: Mrs MacDonald.

MacDonald, J G and Burton, C (eds.) 2003 Collins Dictionary of Geology: New Edition. Glasgow: Harper Collins.

MacGibbon, D and Ross T 1896-7 The Ecclesiastical Architecture of Scotland from the earliest Christian Times to the 17th Century. Edinburgh: David Douglas.

MacGregor, A A 1933 The Haunted Isles: Life in the Hebrides. London: Alexander Maclehose.

MacGregor, A A 1967 The Enchanted Isles: Hebridean Portraits and Memories. London: Michael Joseph.

McHardy, I 2005 a) 'Severe Terrain Archaeological Campaign (STAC) Project Design 2005'. Unpublished report. Stornoway: Comhairle nan Eilean Siar.

McHardy, I 2005 b) 'The STAC Project, 2005 Data Structures Report'. Unpublished report. Stornoway: Comhairle nan Eilean Siar.

McKenzie, J T 2006 'Deep anthropogenic topsoils in Scotland: an archaeological and historical investigation into distribution, character, and conservation under modern land cover'. Unpublished $\mathrm{PhD}$ thesis, University of Stirling.

Mackenzie, W C 1905 'Notes on the Pigmies Isle, at the Butt of Lewis, with results of the recent exploration of the "Pigmies' Chapel" there'. Proc Soc Antiq Scot 39 (1904-5), 248-58.

MacLeod, F 1997 The Chapels in the Western Isles. Stornoway: Acair.

MacLeod, M 2003 'Severe Terrain Archaeological Campaign Project Design'. Unpublished report. Stornoway: Comhairle nan Eilean Siar.

MacSween, A 1995 'Grooved Ware from Scotland: Aspects of decoration', in I Kinnes and G Varndell Unbaked urns of rudely shape: Essays on British and Irish Pottery for Ian Longworth, Oxford: Oxbow Monograph 55, 41-8.

Martin Martin 1703 A Description of the Western Islands of Scotland c 1695. London: Printed for Andrew Bell.

Mays, S 1998 The Archaeology of Human Bones. London: Routledge.

Mellor, C 2002 The Stack-Climbing Guide to Britain, http://www.ukclimbing.com/articles/page. php?id $=25$

Mowbray C L 1936 'Excavation at the Ness of Burgi, Shetland', Proc Soc Antiq Scot 70 (1935-6), 381-6.

Muir, T S 1861 Characteristics of Old Church Architecture etc in the Mainland and Western Islands of Scotland. Edinburgh: Edmundston and Douglas.

Ordnance Survey, Object Name Books of the Ordnance Survey (various years)

Parker Pearson, M; Marshall, P; Mulville, J and Smith, H 2009 'The Prehistoric Village at
Cladh Hallan' Part I, Part II and Part III. [Online]. Available from: http://www.sheffield. ac.uk/archaeology/research/cladh-hallan http://www.sheffield.ac.uk/archaeology/ research/cladh-hallan/cladh-hallan02.html http://www.sheffield.ac.uk/archaeology/ research/cladh-hallan/cladh-hallan03.html

[accessed 25 November 2009]

Richards, C 2005 Dwelling among the monuments: Excavations at Barnhouse and Maeshowe. Cambridge: McDonald Institute Monographs.

Ritchie, W 1985 'Inter-tidal and sub-tidal organic deposits and sea-level change in the Uists, Outer Hebrides', Scottish Journal of Geology 21, $161-76$

RCAHMS 1928 Ninth Report and Inventory: Outer Hebrides, Skye and the Small Isles. Edinburgh: HMSO.

RCAHMS 1946 Inventory of Ancient Monuments in Orkney and Shetland. Edinburgh: HMSO.

Robson, M. 2004 Forts and Fallen Walls: The Duns of Northern Lewis. Port of Ness: 10 Calicvol.

Saville, A and Ballin, T B 2000 'Quartz technology in Scottish prehistory', Lithics 21, 45-51.

Schweingruber, F H 1990 Anatomy of European Woods. Bern and Stuttgart: Haupt.

Scott, W L $1951^{'}$ Eilean an Tighe: A pottery workshop of the second millennium BC', Proc Soc Antiq Scot 85 (1951), 1-37.

Sharples, N and Sheridan, A 1992 Vessels for the Ancestors: Essays on the Neolithic of Britain and Ireland. Edinburgh: Edinburgh University Press.

Sheridan, A 1999 'Grooved Ware from the Links of Noltland, Westray, Orkney', in R Cleal and A MacSween, Grooved Ware in Britain and Ireland. Oxford: Oxbow Books, 112-24.

Simpson, D D A 1976 'The later Neolithic and beaker settlement at Northton, Isle of Harris', in C Burgess and R Miket (eds.) Settlement and economy in the third millennium BC. Oxford: BAR British Series 33, 209-220.

Simpson, D D A; Murphy, E M and Gregory, R A 2006 Excavations at Northton, Isle of Harris. Oxford: BAR British Series 408.

Simpson, I A; Vesteinsson, O; Adderley, W P and McGovern, T H 2003 'Fuel resource utilisation in landscapes of settlement', Journal of Archaeological Science 30, 1401-20.

Sharples, $\mathrm{N}$ forthcoming Dalmore, Isle of Lewis, Western Isles.

Stace, C 1997 New Flora of the British Isles, $2^{\text {nd }} \mathrm{Ed}$. Cambridge: Cambridge University Press.

Stevenson, R B K 1946 'Jottings on early pottery', Proc Soc Antiq Soc 80 (1945-6), 141-43.

Stoops, G 2003 Guidelines for the analysis and description of soil and regolith thin sections. Madison, WI: Soil Science Society of America.

Thomas, A C 1971 The Early Christian Archaeology of North Britain: The Hunter Marshall Lectures 1968. London: Oxford University Press for the University of Glasgow. 
Thomas, F W L 1859 'Notice of the beehive houses in Harris and Lewis; with traditions of the eachuisge, or water-horse, connected therewith', Proc Soc Antiq Scot 3 (1857-9), 127-44.

Thomas, F W L 1890 'On the duns of the Outer Hebrides', Archaeologia Scotica 5, 365-415.

Warren, G forthcoming a) 'Stone tool industries of the earlier Neolithic in eastern Scotland'.

Warren, G forthcoming b) 'Chipped Stone', report reproduced for the Calanais Fields Project, University of Edinburgh.

Warren, G and Neighbour, T 2004 'Quality Quartz: Working Stone at a Bronze Age Kerbed Cairn at Olcote, near Calanais, Isle of Lewis',
Norwegian Archaeological Review, Vol 37, No. $2,83-94$.

Wickham-Jones, C 1995 'Flaked stone tools', in K Brannigan and S Foster (eds.) 1995 Barra: Archaeology on Ben Tangaval. Sheffield: Sheffield Academic Press.

Working at Height Regulations 2005: Statutory Instrument 2005 No. 735. London: Stationery Office Ltd.

Zohary, D and Hopf, M 2000 Domestication of Plants in the Old World. Oxford: Oxford University Press.

www.irata.org

www.hse.gov.uk/research/rrpdf/rr116.pdf 
PART IV: APPENDICES 



\section{APPENDIX 1: SEVERE TERRAIN ARCHAEOLOGICAL CAMPAIGN (STAC), PROJECT DESIGN 2005}

\subsection{Summary}

The Severe Terrain Archaeological Campaign (STAC) was established as a pilot project in 2003 to overcome the risks of accessing otherwise dangerous archaeological sites around Lewis. The project uses rope access systems in accordance with IRATA (Industrial Rope Access Trade Association) and British Standard safety guidelines, approved by the HSE.

After a pilot season in 2003 in which a range of different sites were visited, a specific project design was settled upon (Barrowman, C S et al 2004) which led to a list of 11 suitable sites. To date, eight sites from this project definition have been surveyed and assessed, which leaves three remaining for the coming season: Dun Othail near Tolsta, Stac mor Garrabost in Point and Stac na Chuibhig near Dalmore. It is also proposed to excavate a small exploratory trench in Dunasbroc, one of the sites surveyed last year, in order to more fully explore and understand it and the wider type of site we are dealing with.

\subsection{Introduction and previous work}

Recent coastal erosion assessments commissioned by Historic Scotland in the Western Isles (eg Burgess \& Church 1997) have highlighted the presence of classes of coastal site about which very little is known, in particular, stack and promontory settlements. These sites often overlap with areas exhibiting rapid coastal erosion. In the proceedings of a Historic Scotland seminar on coastal erosion, the threat to such sites was emphasised, concluding that, 'erosion of sites such as promontory forts on incised cliffs ... (is) of main concern' (Ashmore, 2003, 209).

Stack sites in the Northern and Western Isles have commonly been attributed to the Iron Age, and interpreted as either fortifications or monastic settlements (Lamb 1980). Recent work, however, such as excavations at Brei Holm, Papa Stour, Shetland (Brady 2002), Dun Eistean, Ness, Isle of Lewis (Barrowman \& Driscoll 2000; Barrowman, C S 2002) and Gob Eirer, Uig, Isle of Lewis (Burgess et al 1996), as well as coastal surveys of Barra and nearby islands (Branigan \& Foster 2000), suggest that these sites have a broad chronological range from the Neolithic to the sixteenth century, with a correspondingly large range of structural, and perhaps functional, variety.

The STAC project is now entering its third year of investigation of such sites, having achieved archaeo- logical and topographical surveys of eight sites to date.

\subsection{Management of the sea stack sites}

The majority of stack sites in Lewis suitable for the attention of STAC have now been surveyed, and having witnessed the nature of erosion at each site the team is now also inclined to consider the management issues involved.

\subsubsection{The nature of erosion}

The stack sites surveyed so far are subject to two main forms of erosion, which are described here as 'gradual' and 'episodic'.

Gradual erosion occurs at three of the sites studied to date: Creag Dubh, Dunasbroc and Dun Arnistean. All are low-lying and have a thin covering of topsoil. Erosion of these stacks is taking place through open scars where vegetation cover has been lost and/or the remaining sediments are slipping down slope. In all cases studied to date the underlying geology is stable.

It is difficult to estimate at what speed this erosion will continue, with little evidence from previous years with which to make an estimate. However, Dun Arnistean has received previous study (see Barrowman \& McHardy 2005), and would appear to have been in a similar state in the 1970s, with open erosion scars yielding large quantities of pottery. However, in the absence of photographs or more detailed description, this does not actually help gauge the speed of erosion in the intervening period. In the observed state, Dunasbroc has the most advanced erosion of this type, with much less sediment left overall and a greater ratio of open sediment area to vegetation cover. However, whatever the speed, it is clear that archaeological deposits are being lost at all of these sites due to this erosion.

The other form of erosion is 'episodic'. This occurs at three sites; Stac a' Chaisteal, Stac Domhnuill Chaim and Dun Eòradail, and seriously affects Eilean nan Luchruban. Here, dramatic episodes of sudden rockfall are evident, affecting the underlying geology and access to the stack as well as the archaeology, whilst sediments and vegetation cover are generally perfectly healthy due to the heights of the stacks. What is most alarming is the great swathes of rock and archaeology that can disappear overnight, in a very different dynamic from that described above.

The speed of this erosion can be estimated from 
previous surveys and local anecdotes. It is clear that at both Stac Domhnuill Chaim and Stac a' Chaisteal, access by foot was straightforward as little as 30 years ago (Barrowman, McHardy \& McLeod 2004 and Barrowman \& McHardy 2005), and is now impossible without climbing near vertical cliffs. At Dun Eòradail access was also significantly easier before rock falls in living memory. Archaeological parallels (see Lamb 1980) suggest that Stac a' Chaisteal was a promontory-type fort in antiquity and has only become a stack more recently due to this type of erosion.

Episodic erosion is also destroying archaeology at many sites, as well as access routes. It seems safe to assume it will continue to cause a significant loss of archaeology each winter.

\subsubsection{Further work}

There are no strategies available to slow either type of erosion in such places, and neither is consolidation of the archaeology a possibility. It appears that archaeological investigation and further recording of the sites before they disappear is the only way to save knowledge of them. It is therefore proposed that the project this year follows the following format:

- Firstly, topographic and archaeological surveys will be carried out for the remaining three sites in our project definition as discussed above.

- Secondly, a small-scale exploratory excavation will be carried out at a suitable stack over the remaining project time.

Dunasbroc is considered the most suitable candidate for this, with archaeological deposits actively being lost from a clearly important and interesting site, but without the practical difficulties and time required for excavating sites such as Stac a' Chaisteal or Stac Domhnuill Chaim. These sites will be considered in due course.

\subsection{Fieldwork}

\subsubsection{Lessons from previous sea stack excavations}

The author and project manager have previously been involved with the excavation of two sea stacks, namely Brei Holm near Papa Stour in Shetland (Brady 2000) and Dun Eistean in Ness, Isle of Lewis (Barrowman \& Driscoll 2000, Barrowman, C S 2001, Barrowman, C S 2002). Various lessons have been learnt during the course of these projects:

- Access systems must be efficient and easy to use. At Brei Holm, horizontal tensioned ropes provided access across the high-tide channel, but were positioned too low down. This meant that the team, and more importantly the equipment, had first to descend to the traverse, cross it, then ascend back up the cliff face of the stack. When it came to transporting heavy essentials such as water and food across to the stack it was clear that this system required a great deal of needless effort and time. At Dun Eistean the tensioned rope traverse was created from on top of the landward cliff to the top of the stack, cutting out all the extra ascent and descent. This was incomparably more practical.

- However, the amount of anchorage required to make safe this type of traverse for team members as well as equipment is large and may not suit every site. Anchorage on the tops of cliffs is usually difficult due to the lack of outcropping rock, so large metal stakes were designed to overcome this at Dun Eistean. Obviously these can not be used in areas thought to have archaeology, or where the position of the archaeology is not known. A tensioned rope solely for the transportation of equipment requires less anchorage and will often be a more practical option. In this case team members can access the stack via the conventional route.

- The depth and preservation of deposits at both these sites exceeded expectations. Trench size is then of critical importance.

\subsubsection{Purpose and aims of fieldwork}

In the broadest sense the aim of trial excavation at Dunasbroc will be to characterise the nature and extent of the deposits as far as is possible. More specifically, we hypothesise that Dunasbroc sustained occupation within a building, possibly during prehistoric times (cf diagnostic pottery discovered last year (Barrowman \& McHardy 2005) pending specialist opinion) for an unknown period, and we wish to establish firstly whether this is true and secondly, if it is, to refine our understanding of it.

There are two specific questions which follow from these aims which we hope to answer, relating to features observed at the site. The first relates to the summit plateau, where the diagnostic pottery was discovered. This plateau could consist entirely of cultural deposits, and may be the remains of a building. We wish to find out if this is the case. The second relates to the largest extant wall, which is rather insubstantial and in an odd position for the structural wall of a building. There are three other such walls, which appear to be even more puzzling, surrounded on all sides by bedrock. We think that these may be outworks relating to the original access route up to the suggested building, but could alternatively be from a different and separate phase of activity altogether. Therefore we wish to find out if the main wall has any stratigraphic relationship with either the hypothesised structure(s) immediately above or possible unknown features immediately below. 


\subsubsection{Fieldwork methodology}

\subsubsection{Survey}

The survey methodology for Dun Othail, Stac Mor Garrabost and Stac na Chuibhig will follow those laid out in previous reports (Barrowman \& McHardy 2005)

\subsubsection{Excavation}

Excavations will be carried out in general accordance with procedures laid down by the Museum of London Archaeology Service Site Manual, excavating and recording one context at a time, although our plans may incorporate more than one context if we see fit. All contexts will be drawn at 1:20 in plan and 1:10 in section. Pre- and post-excavation plans will be made. A photographic record using colour and black and white slide film, as well as in digital media, will also be kept of all archaeologically significant features and contexts. Each context will be described using a pro-forma record sheet, and two bulk samples (c 10 litres) of every undisturbed archaeological context saved for environmental analysis. The position of trenches and any finds recovered will be three-dimensionally recorded using a Total Station, and embedded into the existing topographic survey.

All contexts, samples and finds will have separate numbers and be cross-referenced in pro-forma log sheets and a site notebook.

Emergency on-site conservation for finds will be provided by Mark Elliott, Conservator for the Museum Nan Eilean Siar and STAC team member. If further conservation is required then it will be through the Historic Scotland Conservation Callout Contract.

Further techniques such as soil thin section analysis have been considered but are not thought practical at this stage. Carbonised material will be collected for dating if possible.
At the end of excavation the site will be backfilled onto Terram sheeting and the turf replaced. We will endeavour to return the site as far as possible to its original appearance.

\subsubsection{Trench position}

It would seem sensible to excavate across a 'slice' of the plateau and steeply sloping area, including but not removing the extant walling. This would both explore the plateau and gain a section across all the areas of interest. This central position is also most assured of gaining relevant environmental evidence, carbonised deposits for dating and diagnostic artefacts. This trench will measure $10 \times 1.5 \mathrm{~m}$, a figure derived from previous sea stack excavation experience, stretching roughly N/S, perpendicular to the contour. This will be termed Trench 1 .

\subsubsection{Outcomes and future work}

The immediate outcomes of the 2005 project will be a Data Structure Report to Historic Scotland standards, a costed post-excavation design, and a summary of work for inclusion in Discovery \& Excavation in Scotland.

The 2005 season will also allow a more accurate assessment of the difficulties and possibilities involved in excavating stacks and provide invaluable experience for any future excavations upon more challenging sites.

It is hoped that further excavation will be carried out in the coming years on the other threatened sites in Lewis, culminating in a full report for publication. Local involvement will be sought wherever possible and it is hoped to create a travelling exhibition to disseminate information to the network of local historical societies. 


\section{APPENDIX 2: MATRICES}

Trench 2

001

003

006

010

009

020

Trench 1

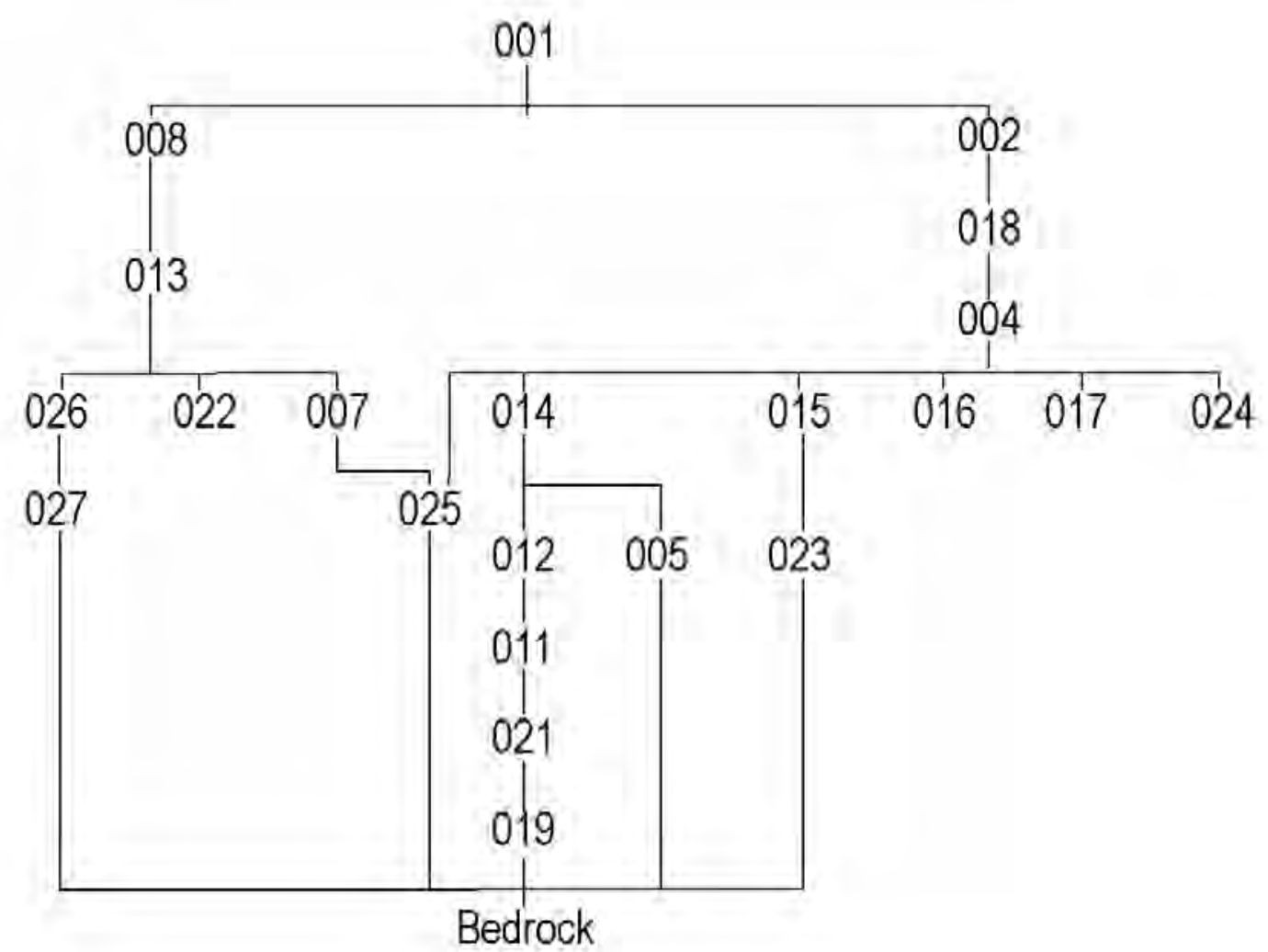




\section{APPENDIX 3: REPORT ON THE POTTERY WITH OBSERVATIONS ON NEOLITHIC POTTERY FROM THE WESTERN ISLES (and table 4 for pottery catalogue),}

by Ann MacSween

\subsection{Introduction}

Consideration of the assemblage from Dunasbroc raised a number of general questions about the later Neolithic pottery of the Western Isles which this short review will address. The assemblage from Dunasbroc, being relatively small, does not help to answer any of the questions, but the recovery of Hebridean Neolithic pottery from an atypical site, and the publication of the assemblage from Northton, Harris (Simpson et al 2006) prompted this review of the current understanding of Neolithic pottery from the Western Isles. The publication of the pottery from the island settlement site of Eilean Domhnuill (Armit 1992, 309) will provide much information relevant to addressing the areas of interest outlined here, but it is hoped that this review will be of use in raising some of the wider questions for debate in advance of the publication of that assemblage.

\subsection{Composition of the assemblages}

Our understanding of the Neolithic pottery from the Western Isles is hampered by a lack of well stratified material. The largest published assemblages are from the domestic sites of Northton (Johnson 2006) and Eilean an Tighe (Lindsay Scott 1951), both on the Isle of Harris; and Allt Chrisal, on Barra (Gibson 1995). Smaller assemblages have been found at the settlement sites of Bharpa Carinish, North Uist (Armit \& MacSween 1993) and at Dunasbroc.

Over 2700 sherds of pottery were recovered during the excavations at Northton (Johnson 2006, 40), from a charcoal-rich layer of black sandy clay interpreted as a Neolithic midden deposit. This layer contained pottery, worked stone, bone and faunal remains, as well as scatters of stones and boulders which may indicate former structures. Due to the lack of context information the material from the midden was treated as if it were from a single deposit. A sample of animal bone from the midden at Northton provided a date of 3350-2890 cal BC at 2-sigma level of confidence, although this date is helpful only in that it provides a date which attributes some of the midden material to the later Neolithic.

Johnson (ibid 63) identified four main groups of pottery - uncarinated bowls (simple bowls with open mouths; bowls with constricted necks forming a bagshaped vessel; and bowls with simple in-turned rims to form a closed mouth); carinated bowls (bipartite bowls with upright or constricted necks and closed mouths); multiple-ridged jars (simple bag shapes or vessels with more globular bodies) and Unstantype bowls (wide, shallow, round-based bowls with a vertical collar, usually decorated).

At Northton, Unstan bowls constituted over 50\% of the number of recognised vessel types, followed by multiple-ridged jars. How far this can be taken as representing the typical composition of a Hebridean Neolithic assemblage is questionable. Firstly, as has been noted above, no context information was available for the Neolithic levels on the site, so this assemblage could represent the combination of a number of phases of occupation even although the deposit appeared to be the same. Secondly, as Johnson (ibid, 64) has pointed out, the Unstan vessels are the most easily recognised vessels and are probably over-represented.

In her discussion of the assemblage, Johnson compares the overall attributes of the assemblage with the overall attributes of the other assemblages from the Western Isles, noting, for example, that at Eilean Domhnuill, North Uist (Brown nd, quoted in Johnson ibid, 67), the most common vessel types are multiple-ridged jars and uncarinated bowls, followed by Unstan-type bowls. The excavations at Bharpa Carinish, a settlement site in the south of North Uist (Crone 1993), produced over 400 sherds, representing around 100 vessels (Armit \& MacSween 1993). For Bharpa Carinish, charcoal from the four excavated Neolithic hearths was dated but the lack of precision of some of the dates means that the most we can say is that they cluster in the late $4 \mathrm{th} /$ early 3rd millennium BC. Most of the sherds from the assemblage were too small to give any indication of vessel form but many were carinated and were interpreted as round-based carinated jars or bowls, some with incised decoration, and there is a possible fragment of an Unstan bowl. Johnson (ibid 68) notes that 'Many of the Neolithic forms one would expect to see are missing ...' Whether comparing the overall composition of these assemblages is meaningful is open to debate, as in taking this approach, the assumption is that there is a 'Hebridean Neolithic' assemblage. From the limited amount of stratified material available, it is perhaps more likely that there is a general ceramic sequence for the Hebridean Neolithic, and that within that general sequence, variations can be expected, depending on, for example, cultural preferences, or the activities being carried out on a site. 
Table 4 Catalogue of pottery from all sites

Dunasbroc Trench 2

\begin{tabular}{|c|c|c|c|c|c|c|}
\hline Context & Vessel & SF & \begin{tabular}{|l|} 
Sherd \\
numbers
\end{tabular} & Description & \begin{tabular}{|c|} 
Thickness \\
(mm)
\end{tabular} & $\begin{array}{l}\text { Weight } \\
\text { (g) }\end{array}$ \\
\hline \multirow[t]{9}{*}{ Context 6} & V1 & $\begin{array}{l}169 \\
102\end{array}$ & $\begin{array}{l}1 \text { rim \& } 2 \text { body } \\
\text { sherds } \\
1 \text { rim, } 2 \text { body \& } 1 \\
\text { frag (body sherds } \\
\text { probably from this } \\
\text { vessel) }\end{array}$ & $\begin{array}{l}\text { From the upper part of a Hebridean vessel with an } \\
\text { internally bevelled rim. The rim bevel is decorated with } \\
\text { oblique grooves } 2 \mathrm{~mm} \text { wide and } 2 \mathrm{~mm} \text { apart. Just below } \\
\text { the rim on the exterior are grooves } 2 \mathrm{~mm} \text { wide and } 2 \mathrm{~mm} \\
\text { apart finishing just above a slight carination. Between } \\
\text { this and a more pronounced carination are lines } \\
\text { arranged more obliquely, with lines arranged almost } \\
\text { vertically below that carination. The grooved decora- } \\
\text { tion is incised into a thin, smoothed, wet-hand slip. The } \\
\text { fabric is coarse sandy clay which has fired hard and is } \\
\text { grey with a brown exterior surface. }\end{array}$ & $\begin{array}{l}8 \mathrm{~mm} \\
8 \mathrm{~mm}\end{array}$ & $\begin{array}{l}89 \mathrm{~g} \\
24 \mathrm{~g}\end{array}$ \\
\hline & V2 & 169 & 1 body sherd & $\begin{array}{l}\text { The exterior surface is smoothed and decorated with } \\
\text { incised lines (incised with a point or blade). The interior } \\
\text { surface is smoothed and combed. The fabric is coarse } \\
\text { sandy clay which has fired hard and is grey. }\end{array}$ & $6 \mathrm{~mm}$ & $4 \mathrm{~g}$ \\
\hline & V3 & $\begin{array}{l}103 \\
53\end{array}$ & $\begin{array}{l}1 \mathrm{rim} \\
1 \mathrm{rim}\end{array}$ & $\begin{array}{l}\text { Rim sherds (join) with an interior bevel. The exterior } \\
\text { surface is slipped and smoothed. The bevel is decorated } \\
\text { with oblique grooves } c 3 \mathrm{~mm} \text { wide and } 3 \mathrm{~mm} \text { apart. There } \\
\text { is fine fingernail fluting on the underside of the lip. The } \\
\text { exterior of the vessel is decorated with grooves } c 3 \mathrm{~mm} \\
\text { wide and } 3 \mathrm{~mm} \text { apart arranged in alternating vertical } \\
\text { and horizontal panels. The fabric is coarse sandy clay } \\
\text { which has fired hard and is grey with a brown interior } \\
\text { surface. The exterior and the rim bevel are sooted. }\end{array}$ & $\begin{array}{l}7 \mathrm{~mm} \\
7 \mathrm{~mm}\end{array}$ & $\begin{array}{l}14 \mathrm{~g} \\
13 \mathrm{~g}\end{array}$ \\
\hline & V4 & 53 & 1 rim \& 4 frags & $\begin{array}{l}\text { Rim (plain) from a straight-sided vessel. The exterior } \\
\text { surface is smoothed. The fabric is coarse sandy clay } \\
\text { which has fired hard and is grey with brown surfaces. } \\
\text { Diameter } 100 \mathrm{~mm} \text {. }\end{array}$ & $7 \mathrm{~mm}$ & $30 \mathrm{~g}$ \\
\hline & V5 & 53 & $1 \mathrm{rim}$ & $\begin{array}{l}\text { Rim with an overhanging flange. Probably wet-hand } \\
\text { smoothed on the exterior. The rim is badly abraded but } \\
\text { there are traces of decoration (oblique grooved lines) on } \\
\text { the lip. Below the lip are oblique lines } 3 \mathrm{~mm} \text { wide and } \\
1 \mathrm{~mm} \text { apart. The fabric is coarse sandy clay which has } \\
\text { fired hard and is grey with a brown exterior surface. } \\
\text { Diameter } 160 \mathrm{~mm} \text {. }\end{array}$ & $7 \mathrm{~mm}$ & $22 \mathrm{~g}$ \\
\hline & V6 & 8 & $\begin{array}{l}1 \text { rim, } 2 \text { body \& } 5 \\
\text { fragments }\end{array}$ & $\begin{array}{l}\text { Rim with an interior bevel. The exterior of the bevel is } \\
\text { slipped and smoothed/burnished. The bevel is decorated } \\
\text { with oblique lines } c 3 \mathrm{~mm} \text { wide and } 3 \mathrm{~mm} \text { apart. The } \\
\text { exterior is decorated below the rim with oblique lines } \\
4 \mathrm{~mm} \text { wide and } 2-5 \mathrm{~mm} \text { apart. At one point they are } \\
\text { fairly deep, with the slip squashed up between the } \\
\text { grooves. } 35 \mathrm{~mm} \text { below the rim is a pronounced carina- } \\
\text { tion and below this is no trace of decoration. The fabric } \\
\text { is coarse clay which has fired hard and is grey with } \\
\text { brown surfaces. } \\
\text { Diameter } 400 \mathrm{~mm} \text {. }\end{array}$ & $11 \mathrm{~mm}$ & $139 \mathrm{~g}$ \\
\hline & V7 & ? & $\begin{array}{l}\text { Carination and outer } \\
\text { fragment } \\
26 \text { fragments and } \\
\text { a carinated sherd } \\
\text { (joins) }\end{array}$ & $\begin{array}{l}\text { Carination and outer fragment (exterior skin only) } \\
\text { showing that the carination was applied as a separate } \\
\text { roll of clay. The exterior surface is smoothed (smoothing } \\
\text { striations). The fabric is coarse clay which has fired } \\
\text { hard and is grey with brown surfaces. }\end{array}$ & - & $80 \mathrm{~g}$ \\
\hline & V8 & $\begin{array}{l}129 \\
42 \\
69 \\
11 \\
126\end{array}$ & $\begin{array}{l}2 \text { rim \& } 1 \text { body } \\
25 \text { small frags } \\
1 \text { rim frag, } 3 \text { body, } \\
13 \text { frags (combed } \\
\text { interior) } \\
11 \text { frags } \\
1 \text { rim frag (possibly } \\
\text { from this vessel) }\end{array}$ & $\begin{array}{l}\text { Rim with a very wide interior bevel, decorated with } \\
\text { grooves } c 3 \mathrm{~mm} \text { wide and } 105 \mathrm{~mm} \text { apart. The exterior } \\
\text { surface is burnished. The fabric is coarse sandy clay } \\
\text { which has fired hard and is grey with brown surfaces. } \\
\text { Diameter } 360 \mathrm{~mm} \text {. }\end{array}$ & $10 \mathrm{~mm}$ & $\begin{array}{l}81 \mathrm{~g} \\
20 \mathrm{~g} \\
61 \mathrm{~g} \\
\\
4 \mathrm{~g} \\
8 \mathrm{~g}\end{array}$ \\
\hline & V9 & 146 & $1 \mathrm{rim}$ & $\begin{array}{l}\text { Rim sherd with an interior bevel. The exterior and } \\
\text { bevel are wet smoothed. The sherd is decorated on } \\
\text { the bevel with oblique incised lines } c 2 \mathrm{~mm} \text { wide and } \\
2 \mathrm{~mm} \text { apart. On the exterior below the rim the exterior } \\
\text { surface is decorated with oblique lines (running in the } \\
\text { opposite direction to those on the bevel) } 1 \mathrm{~mm} \text { wide and } \\
1 \mathrm{~mm} \text { apart. The fabric is sandy clay which has fired } \\
\text { hard and is grey with brown surfaces. The exterior } \\
\text { surface is sooted. }\end{array}$ & $6 \mathrm{~mm}$ & $12 \mathrm{~g}$ \\
\hline
\end{tabular}


Table 4 (cont.)

\begin{tabular}{|c|c|c|c|c|c|c|}
\hline Context & Vessel & SF & $\begin{array}{l}\text { Sherd } \\
\text { numbers }\end{array}$ & Description & $\begin{array}{c}\text { Thickness } \\
(\mathbf{m m})\end{array}$ & $\begin{array}{l}\text { Weight } \\
\text { (g) }\end{array}$ \\
\hline \multirow[t]{22}{*}{ Context 6} & V10 & 146 & \begin{tabular}{|l|} 
rim \\
(different bag) 1 body \\
1 exterior fragment
\end{tabular} & $\begin{array}{l}\text { Flat rim with a slight lip to the exterior. Decorated with } \\
\text { shallow grooves c2mm wide and } 1 \mathrm{~mm} \text { apart obliquely } \\
\text { across the lip. The exterior surface is smoothed and } \\
\text { decorated with vertical lines of oval stabs } c 2 \mathrm{~mm} \text { long } \\
\text { and } 1 \mathrm{~mm} \text { wide. The fabric is sandy clay with } c 10 \% \text { of } \\
\text { angular rock fragments which has fired hard and is } \\
\text { grey. }\end{array}$ & $9 \mathrm{~mm}$ & $\begin{array}{l}6 \mathrm{~g} \\
5 \mathrm{~g} \\
1 \mathrm{~g}\end{array}$ \\
\hline & V11 & 145 & $\begin{array}{l}3 \text { rim, } 1 \text { from rim (no } \\
\text { lip), } 5 \text { body, } 1 \text { frag }\end{array}$ & $\begin{array}{l}\text { Very fragmentary remains of a vessel with an interior } \\
\text { bevelled rim. The bevel is decorated with oblique } \\
\text { grooves c3mm wide and c3mm apart. The exterior and } \\
\text { interior surfaces are smoothed (smoothing striations). } \\
\text { The fabric is coarse sandy clay which has fired hard } \\
\text { and is grey with red/brown surfaces. A coil forming the } \\
\text { rim joins the body at the point of inflection of the rim } \\
\text { with the body. }\end{array}$ & $7 \mathrm{~mm}$ & $95 \mathrm{~g}$ \\
\hline & V12 & 106 & 5 body \& 3 fragments & $\begin{array}{l}\text { Exterior surface smoothed. The fabric is coarse sandy } \\
\text { clay. Grey with a brown surface. }\end{array}$ & $14 \mathrm{~mm}$ & $137 \mathrm{~g}$ \\
\hline & V13 & 67 & 1 body \& 1 fragment & Coarse sandy clay. Red. & $14 \mathrm{~mm}$ & $15 \mathrm{~g}$ \\
\hline & V14 & 177 & 1 body & $\begin{array}{l}\text { Exterior and interior surfaces burnished. Sandy clay. } \\
\text { Grey with a brown exterior surface. }\end{array}$ & $9 \mathrm{~mm}$ & $12 \mathrm{~g}$ \\
\hline & V15 & 56 & 1 body sherd & $\begin{array}{l}\text { Exterior surface is smoothed (striations). Coarse sandy } \\
\text { clay. Grey with brown margins. }\end{array}$ & $10 \mathrm{~mm}$ & $33 \mathrm{~g}$ \\
\hline & V16 & 58 & 1 body sherd & Coarse sandy clay. Grey with a brown exterior surface. & $8 \mathrm{~mm}$ & $2 \mathrm{~g}$ \\
\hline & V17 & 83 & $\begin{array}{l}3 \text { very crumbly } \\
\text { fragments, one from } \\
\text { the rim }\end{array}$ & Coarse sandy clay. Grey with brown surfaces. & $10 \mathrm{~mm}$ & $24 \mathrm{~g}$ \\
\hline & V18 & 80 & 2 small sherds & $\begin{array}{l}\text { Exterior surface smoothed. One sherd is decorated with } \\
\text { incisions, the other with shallow grooves. Coarse sandy } \\
\text { clay. Grey with a brown interior surface. Smoothing } \\
\text { striations on the interior of one sherd. }\end{array}$ & $5 \mathrm{~mm}$ & $3 \mathrm{~g}$ \\
\hline & V19 & - & Sieved 1 body sherd & $\begin{array}{l}\text { Shallow grooves on the exterior. Sandy clay with } c 10 \% \\
\text { of rock fragments. Grey. }\end{array}$ & $7 \mathrm{~mm}$ & $2 \mathrm{~g}$ \\
\hline & V20 & 88 & 3 body sherds & $\begin{array}{l}\text { Exterior surface smoothed. Coarse sandy clay. Grey } \\
\text { with a brown exterior surface. }\end{array}$ & $4 \mathrm{~mm}$ & $5 \mathrm{~g}$ \\
\hline & V21 & 88 & 1 body sherd & $\begin{array}{l}\text { Exterior surface smoothed and there are smoothing } \\
\text { striations in the interior. The exterior surface is } \\
\text { decorated with incisions made with a sharp-pointed } \\
\text { implement } 1 \mathrm{~mm} \text { wide. Grey. Exterior surface sooted. }\end{array}$ & $5 \mathrm{~mm}$ & $3 \mathrm{~g}$ \\
\hline & V22 & 88 & 2 body sherds & $\begin{array}{l}\text { One sherd is from the point of inflection of the neck and } \\
\text { the body. Coarse sandy clay. Grey. Exterior sooted. }\end{array}$ & $6 \mathrm{~mm}$ & $4 \mathrm{~g}$ \\
\hline & V23 & 74 & 1 fragment & Sandy clay. Grey. & - & $1 \mathrm{~g}$ \\
\hline & V24 & 167 & 4 fragments & Coarse sandy clay with c10\% rock fragments. Grey. & - & $8 \mathrm{~g}$ \\
\hline & V25 & 57 & 1 body sherd & $\begin{array}{l}\text { The exterior surface is decorated with shallow grooves. } \\
\text { Coarse sandy clay. Grey with a brown interior surface. }\end{array}$ & $9 \mathrm{~mm}$ & $8 \mathrm{~g}$ \\
\hline & V26 & 92 & $\begin{array}{l}1 \text { rim sherd and body } \\
\text { sherd }\end{array}$ & Exterior smoothed. Coarse sandy clay. Grey. & $6 \mathrm{~mm}$ & $7 \mathrm{~g}$ \\
\hline & V27 & 89 & 1 body sherd (split) & $\begin{array}{l}\text { Exterior smoothed and decorated with shallow grooves } \\
\text { in various directions. Coarse sandy clay. Grey with a } \\
\text { brown exterior surface. }\end{array}$ & $5 \mathrm{~mm}$ & $6 \mathrm{~g}$ \\
\hline & V28 & 34 & 11 fragments & Coarse sandy clay. Grey with brown surfaces. & - & $11 \mathrm{~g}$ \\
\hline & V29 & 61 & $\begin{array}{l}1 \text { body sherd \& } 5 \\
\text { fragments }\end{array}$ & $\begin{array}{l}\text { Incisions on body sherd. Coarse sandy clay. Black. } \\
\text { Exterior sooted. }\end{array}$ & $6 \mathrm{~mm}$ & $7 \mathrm{~g}$ \\
\hline & V30 & Sieved & 14 small fragments & $\begin{array}{l}\text { Some fragments decorated with incisions or shallow } \\
\text { grooves. One fragment is from the point of inflection } \\
\text { of the neck with the body. Coarse sandy clay. Grey. } \\
\text { Sooting. Probably from more than one vessel. }\end{array}$ & - & $12 \mathrm{~g}$ \\
\hline & V31 & 107 & $\begin{array}{l}9 \text { abraded } \\
\text { sherds/fragments }\end{array}$ & $\begin{array}{l}\text { Two fragments are from the rim. Coarse sandy clay. } \\
\text { Grey with red exterior. }\end{array}$ & $8 \mathrm{~mm}$ & $30 \mathrm{~g}$ \\
\hline
\end{tabular}


Table 4 (cont.)

\begin{tabular}{|c|c|c|c|c|c|c|}
\hline Context & Vessel & SF & $\begin{array}{l}\text { Sherd } \\
\text { numbers }\end{array}$ & Description & $\begin{array}{c}\text { Thickness } \\
\text { (mm) }\end{array}$ & $\begin{array}{l}\text { Weight } \\
\text { (g) }\end{array}$ \\
\hline \multirow[t]{22}{*}{ Context 6} & V32 & 84 & 3 fragments & $\begin{array}{l}\text { One fragment has shallow grooves, the other two have } \\
\text { sharp incisions. Coarse sandy clay. Grey (2), brown (1). } \\
\text { Probably from different vessels. }\end{array}$ & & $2 \mathrm{~g}$ \\
\hline & V33 & Sieved & $\begin{array}{l}2 \text { body sherds } \\
\text { (different vessels) }\end{array}$ & Coarse sandy clay. Grey with a brown exterior surface. & $\begin{array}{l}8 \mathrm{~mm} \& \\
11 \mathrm{~mm}\end{array}$ & $6 \mathrm{~g}$ \\
\hline & V35 & Sieved & $\begin{array}{l}5 \text { body, } 4 \text { frags \& } \\
\text { rim frag (different } \\
\text { vessels) }\end{array}$ & $\begin{array}{l}2 \text { of the body sherds are decorated with } 2 \mathrm{~mm} \text { wide } \\
\text { grooves. Coarse sandy clay. Grey (brown surfaces). } \\
\text { Some sooting. }\end{array}$ & $3-4 \mathrm{~mm}$ & $15 \mathrm{~g}$ \\
\hline & V36 & 103 & 1 body & $\begin{array}{l}\text { Exterior burnished. Coarse sandy clay. Grey with brown } \\
\text { exterior. }\end{array}$ & $10 \mathrm{~mm}$ & $11 \mathrm{~g}$ \\
\hline & V37 & 103 & $\begin{array}{l}2 \text { body \& } 1 \text { rim (all } \\
\text { different vessels) }\end{array}$ & $\begin{array}{l}\text { Larger body sherd has shallow grooves on the exterior. } \\
\text { The rim sherd has grooves on the interior. Coarse sandy } \\
\text { clay. Large sherd is brown with grey surfaces. Other } \\
\text { sherds are grey with brown surfaces. }\end{array}$ & $\begin{array}{l}3 \mathrm{~mm} \& \\
8 \mathrm{~mm}\end{array}$ & $7 \mathrm{~g}$ \\
\hline & V38 & 84 & $\begin{array}{l}1 \text { body, } 2 \text { frags (prob } \\
\text { different vessels) }\end{array}$ & Coarse sandy clay. Grey/brown & $8 \mathrm{~mm}$ & $6 \mathrm{~g}$ \\
\hline & V39 & 127 & $\begin{array}{l}8 \text { fragments, } 2 \text { body } \\
\text { sherds }\end{array}$ & $\begin{array}{l}\text { Coarse sandy clay. Grey with brown surfaces. Exterior } \\
\text { sooted. }\end{array}$ & $8 \mathrm{~mm}$ & $53 \mathrm{~g}$ \\
\hline & V40 & 135 & 4 body sherds & $\begin{array}{l}\text { Exterior burnished. Decorated with sets of oblique } \\
\text { parallel grooves. Sandy clay. Grey with brown interior } \\
\text { surface. }\end{array}$ & $4-8 \mathrm{~mm}$ & $21 \mathrm{~g}$ \\
\hline & V41 & 135 & 1 body & $\begin{array}{l}\text { Incisions on exterior surface. Coarse sandy clay. Grey } \\
\text { with a brown exterior surface. }\end{array}$ & $9 \mathrm{~mm}$ & $3 \mathrm{~g}$ \\
\hline & V42 & 141 & 1 rim fragment & $\begin{array}{l}\text { Shallow incisions on rim bevel. Coarse sandy clay. Grey } \\
\text { with brown surfaces. }\end{array}$ & - & $2 \mathrm{~g}$ \\
\hline & V44 & 82 & 1 rim sherd & $\begin{array}{l}\text { Rim with interior bevel. Parallel incised lines on bevel. } \\
\text { Coarse sandy clay. Grey with brown surfaces. }\end{array}$ & $8 \mathrm{~mm}$ & $5 \mathrm{~g}$ \\
\hline & V45 & 82 & 1 body & Coarse sandy clay. Grey. & $7 \mathrm{~mm}$ & $6 \mathrm{~g}$ \\
\hline & V46 & $\begin{array}{l}125 \\
150 \\
91\end{array}$ & $\begin{array}{l}1 \text { body } \\
1 \text { body } \\
1 \text { body }\end{array}$ & $\begin{array}{l}\text { Parallel shallow grooves on exterior. Coarse sandy clay } \\
\text { with organics (voids - ?seeds or shell). Grey. }\end{array}$ & $6 \mathrm{~mm}$ & $\begin{array}{r}13 \mathrm{~g} \\
25 \mathrm{~g} \\
7 \mathrm{~g}\end{array}$ \\
\hline & V47 & 125 & 3 body, 12 fragments & Coarse sandy clay. Grey with brown exterior surface. & $7 \mathrm{~mm}$ & $39 \mathrm{~g}$ \\
\hline & V48 & 60 & $\begin{array}{l}2 \text { body (different } \\
\text { vessels) }\end{array}$ & $\begin{array}{l}\text { One sherd has shallow grooves. Coarse sandy clay. Grey } \\
\text { with brown surfaces. }\end{array}$ & $\begin{array}{c}3 \mathrm{~mm} \& 7 \\
\mathrm{~mm}\end{array}$ & $4 \mathrm{~g}$ \\
\hline & V49 & 91 & $\begin{array}{l}2 \text { body, } 1 \text { fragment } \\
\text { (different vessels) }\end{array}$ & $\begin{array}{l}\text { One body sherd is decorated with incised lines. Grey } \\
\text { with brown surfaces. }\end{array}$ & $\begin{array}{c}5 \mathrm{~mm} \& 9 \\
\mathrm{~mm}\end{array}$ & $13 \mathrm{~g}$ \\
\hline & V50 & $?$ & $\begin{array}{l}3 \text { rim sherds }(2 \\
\text { different vessels })\end{array}$ & $\begin{array}{l}\text { Interior bevels (one with oblique shallow grooves). } \\
\text { Coarse sandy clay. Grey with brown surfaces. }\end{array}$ & $8 \mathrm{~mm}$ & $25 \mathrm{~g}$ \\
\hline & V51 & 150 & $\begin{array}{l}1 \text { rim bevel (grooved), } \\
\text { body fragment, } 2 \\
\text { fragments }\end{array}$ & Coarse clay. Rim - red, other fragments - grey. & $\begin{array}{l}\operatorname{rim} 5 \mathrm{~mm} \\
\& \operatorname{body} 4 \\
\mathrm{~mm}\end{array}$ & $12 \mathrm{~g}$ \\
\hline & V52 & 52 & $\begin{array}{l}1 \text { rim fragment, } 12 \\
\text { fragments, } 2 \text { body }\end{array}$ & Exterior surface has incised lines. Grey. & $15 \mathrm{~mm}$ & $18 \mathrm{~g}$ \\
\hline & V53 & 132 & $\begin{array}{l}6 \text { body, } 8 \text { fragments } \\
(2 \text { different vessels })\end{array}$ & $\begin{array}{l}\text { Smoothing striations on exterior. Coarse sandy clay. } \\
\text { Grey with brown surfaces. }\end{array}$ & $8-12 \mathrm{~mm}$ & $150 \mathrm{~g}$ \\
\hline & V54 & 146 & $\begin{array}{l}2 \text { rim (different } \\
\text { vessels) }\end{array}$ & $\begin{array}{l}\text { Angle of rim not determined. Both incised. Coarse } \\
\text { sandy clay. One grey, the other grey with brown } \\
\text { surfaces. }\end{array}$ & $7 \mathrm{~mm}$ & $8 \mathrm{~g}$ \\
\hline & V55 & 146 & $\begin{array}{l}3 \text { body, } 1 \text { fragment } \\
\text { (different vessels) }\end{array}$ & Decorated with incised lines. Coarse sandy clay. Grey & $4-5 \mathrm{~mm}$ & $13 \mathrm{~g}$ \\
\hline
\end{tabular}


Table 4 (cont.)

\begin{tabular}{|c|c|c|c|c|c|c|}
\hline Context & Vessel & SF & $\begin{array}{l}\text { Sherd } \\
\text { numbers }\end{array}$ & Description & \begin{tabular}{c|} 
Thickness \\
$(\mathbf{m m})$
\end{tabular} & $\begin{array}{l}\text { Weight } \\
\text { (g) }\end{array}$ \\
\hline \multirow[t]{3}{*}{ Context 6} & V57 & $?$ & $\begin{array}{l}14 \text { body sherds }(c 3 \\
\text { different vessels) }\end{array}$ & Coarse sandy clay. Grey with brown exterior. & $5-10 \mathrm{~mm}$ & $109 \mathrm{~g}$ \\
\hline & V58 & 152 & \begin{tabular}{|l|}
$\begin{array}{l}\text { body sherds } \\
\text { (different vessels) }\end{array}$ \\
\end{tabular} & $\begin{array}{l}\text { Some sherds have incisions/grooves. Coarse sandy clay. } \\
\text { Grey some with brown exterior. Some sooting. }\end{array}$ & $5-7 \mathrm{~mm}$ & $45 \mathrm{~g}$ \\
\hline & V59 & 146 & $\begin{array}{l}38 \text { sherds/frags } \\
\text { (different vessels) }\end{array}$ & $\begin{array}{l}\text { A few sherds have incisions/grooves on the exterior } \\
\text { surface. Coarse sandy clay. Grey with brown exterior. } \\
\text { Residue on some sherds. }\end{array}$ & $5-13 \mathrm{~mm}$ & $210 \mathrm{~g}$ \\
\hline \multirow[t]{7}{*}{ Context 1} & V60 & $\begin{array}{l}\text { ?below } \\
\text { bank A }\end{array}$ & $\begin{array}{l}3 \text { abraded sherds, } 2 \\
\text { from flat part of base } \\
\text { (?different vessels) }\end{array}$ & Coarse sandy clay. Grey. & - & $24 \mathrm{~g}$ \\
\hline & V61 & 194 & 1 body & $\begin{array}{l}\text { Coarse sandy clay. Grey with red interior margin. } \\
\text { Exterior sooted. }\end{array}$ & $9 \mathrm{~mm}$ & $7 \mathrm{~g}$ \\
\hline & V62 & 21 & 2 body & One may be a clay fragment. Other is coarse sandy clay. & & $2 \mathrm{~g}$ \\
\hline & V63 & 14 & 5 fragments & Shallow grooves on 2 fragments. Coarse sandy clay. & - & $3 \mathrm{~g}$ \\
\hline & V64 & 1 & $\begin{array}{l}3 \text { abraded } \\
\text { sherds/fragments }\end{array}$ & Coarse sandy clay. 2 grey, 1 red. & - & $7 \mathrm{~g}$ \\
\hline & V65 & 7 & $\begin{array}{l}5 \text { fragments }(2 \\
\text { vessels })\end{array}$ & Coarse sandy clay. $4 \times$ grey, $1 \times$ red. & - & $3 \mathrm{~g}$ \\
\hline & V66 & Sieved & 1 body \& 4 fragments & $\begin{array}{l}\text { One fragment has shallow grooves. Coarse sandy clay. } \\
\text { Grey. }\end{array}$ & $\begin{array}{l}5 \mathrm{~mm} \\
\text { (body) }\end{array}$ & $4 \mathrm{~g}$ \\
\hline \multirow[t]{10}{*}{ Context 2} & V67 & 96 & 1 body & Coarse sandy clay. Grey with red margins. & $7 \mathrm{~mm}$ & $3 \mathrm{~g}$ \\
\hline & V68 & 27 & 2 fragments & Coarse sandy clay. Grey with red surfaces. & - & $3 \mathrm{~g}$ \\
\hline & V69 & 97 & 1 body & Coarse sandy clay. Grey with brown margins. & $7 \mathrm{~mm}$ & $5 \mathrm{~g}$ \\
\hline & V70 & 30 & 1 body & Coarse sandy clay. Grey with red exterior margin. & $8 \mathrm{~mm}$ & $19 \mathrm{~g}$ \\
\hline & V71 & Sieving & $\begin{array}{l}7 \text { body (different } \\
\text { vessels) }\end{array}$ & $\begin{array}{l}\text { Coarse sandy clay and sandy clay. Grey with red } \\
\text { margins. }\end{array}$ & $5-10 \mathrm{~mm}$ & $26 \mathrm{~g}$ \\
\hline & V72 & 26 & 1 body & Coarse sandy clay. Grey. & $7 \mathrm{~mm}$ & $5 \mathrm{~g}$ \\
\hline & V73 & 94 & $\begin{array}{l}1 \text { interior fragment } \\
\text { (abraded) }\end{array}$ & $\begin{array}{l}\text { Coarse sandy clay plus } 10 \% \text { angular fragments. Grey } \\
\text { with red interior surface. }\end{array}$ & - & $13 \mathrm{~g}$ \\
\hline & V74 & 99 & 1 fragment & Coarse sandy clay. Grey. & - & $2 \mathrm{~g}$ \\
\hline & V75 & 32 & $\begin{array}{l}1 \text { body sherd } \\
\text { (abraded) }\end{array}$ & $\begin{array}{l}\text { Traces of lines and dots. Coarse sandy clay. Grey with } \\
\text { red margins. }\end{array}$ & - & $15 \mathrm{~g}$ \\
\hline & V101 & 23 & \begin{tabular}{|l|}
$\begin{array}{l}1 \text { body } \& 1 \text { fragment } \\
\text { (different vessels). }\end{array}$ \\
\end{tabular} & Coarse sandy clay. Grey, one with red surfaces. & $8 \mathrm{~mm}$ & $6 \mathrm{~g}$ \\
\hline \multirow[t]{11}{*}{ Context 4} & V76 & 110 & $\begin{array}{l}1 \text { rim \& } 2 \text { body } \\
\text { (abraded) (possibly } \\
\text { same vessel) }\end{array}$ & $\begin{array}{l}\text { One sherd has traces of impressed dot decoration. } \\
\text { Coarse sandy clay. Grey with red exterior margin. }\end{array}$ & $8 \mathrm{~mm}$ & $16 \mathrm{~g}$ \\
\hline & V77 & 111 & $1 \mathrm{rim}$ & $\begin{array}{l}\text { Everted rim. Exterior smoothed. Coarse sandy clay. } \\
\text { Grey with red exterior margin. Exterior sooted. }\end{array}$ & $7 \mathrm{~mm}$ & $8 \mathrm{~g}$ \\
\hline & V78 & 157 & 1 body & Coarse sandy clay. Red with grey core. & $11 \mathrm{~mm}$ & $8 \mathrm{~g}$ \\
\hline & V79 & 112 & 3 body & $\begin{array}{l}\text { Coarse sandy clay. } 2 \times \text { grey with red exterior margin } \\
\text { (same vessel) } 1 \times \text { red. }\end{array}$ & $6-7 \mathrm{~mm}$ & $13 \mathrm{~g}$ \\
\hline & V80 & 115 & \begin{tabular}{|l|}
2 body (probably \\
same vessel)
\end{tabular} & $\begin{array}{l}\text { Coarse sandy clay with } 10 \% \text { angular fragments. Grey } \\
\text { with red exterior margin. }\end{array}$ & $8 \mathrm{~mm}$ & $10 \mathrm{~g}$ \\
\hline & V81 & 158 & 1 body & Coarse sandy clay. Red with grey interior margin. & $10 \mathrm{~mm}$ & $8 \mathrm{~g}$ \\
\hline & V82 & 113 & 1 body & $\begin{array}{l}\text { Coarse sandy clay. Grey with red margins. Exterior } \\
\text { sooted. }\end{array}$ & $7 \mathrm{~mm}$ & $14 \mathrm{~g}$ \\
\hline & V83 & 95 & $\begin{array}{l}1 \text { basal sherd from } \\
\text { flat part of base }\end{array}$ & $\begin{array}{l}\text { Coarse sandy clay and grass impressions. Grey with } \\
\text { brown margins. }\end{array}$ & $9 \mathrm{~mm}$ & $16 \mathrm{~g}$ \\
\hline & V84 & 119 & $\begin{array}{l}1 \text { body (broken \& } \\
\text { abraded) }\end{array}$ & Coarse sandy clay. Grey with red exterior margin. & - & $8 \mathrm{~g}$ \\
\hline & V85 & 121 & $\begin{array}{l}4 \text { body (different } \\
\text { vessels) }\end{array}$ & $\begin{array}{l}1 \text { coarse sandy clay, } 3 \text { sandy clay. } 1 \times \text { buff, } 1 \times \text { grey with } \\
\text { red margins, } 1 \text { grey. Sooting. }\end{array}$ & $7-9 \mathrm{~mm}$ & $13 \mathrm{~g}$ \\
\hline & V86 & Sieving & 1 rim (abraded) & Coarse sandy clay. Red with grey interior. & - & $3 \mathrm{~g}$ \\
\hline
\end{tabular}


Table 4 (cont.)

\begin{tabular}{|c|c|c|c|c|c|c|}
\hline Context & Vessel & SF & $\begin{array}{l}\text { Sherd } \\
\text { numbers }\end{array}$ & Description & \begin{tabular}{c|} 
Thickness \\
$(\mathbf{m m})$
\end{tabular} & $\begin{array}{l}\text { Weight } \\
(\mathrm{g})\end{array}$ \\
\hline \multirow[t]{4}{*}{ Context 4} & V87 & 188 & $\begin{array}{l}2 \text { body (different } \\
\text { vessels) }\end{array}$ & $\begin{array}{l}1 \text { sandy clay, } 1 \text { coarse sandy clay. Grey with brown } \\
\text { surfaces. }\end{array}$ & $6-10 \mathrm{~mm}$ & $10 \mathrm{~g}$ \\
\hline & V88 & 192 & 1 body & $\begin{array}{l}\text { Coarse sandy clay. Grey with red exterior margin. } \\
\text { Interior sooted. }\end{array}$ & $15 \mathrm{~mm}$ & $7 \mathrm{~g}$ \\
\hline & V89 & 191 & 1 body & Coarse sandy clay. Grey with brown exterior margin. & $9 \mathrm{~mm}$ & $3 \mathrm{~g}$ \\
\hline & V90 & 195 & 1 body (broken in 2 ) & Coarse sandy clay. Brown with a grey core. & $8 \mathrm{~mm}$ & $5 \mathrm{~g}$ \\
\hline \multirow[t]{4}{*}{ Context 8} & V91 & Sieved & $\begin{array}{l}2 \text { body (different } \\
\text { vessels) }\end{array}$ & Coarse sandy clay. Grey/brown. & $9-10 \mathrm{~mm}$ & $16 \mathrm{~g}$ \\
\hline & V92 & Sieved & 1 body (abraded) & Sandy clay. Brown with a grey core. & $11 \mathrm{~mm}$ & $5 \mathrm{~g}$ \\
\hline & V93 & 185 & 1 body & $\begin{array}{l}\text { Possible ridged decoration. Sandy clay with } c 10 \% \\
\text { angular rock fragments. }\end{array}$ & $6-9 \mathrm{~mm}$ & $10 \mathrm{~g}$ \\
\hline & V94 & 160 & $\begin{array}{l}1 \text { body (abraded) \& } \\
\text { part of a pinched } \\
\text { neck band (Iron Age) }\end{array}$ & $\begin{array}{l}\text { Body sherd is coarse sandy clay. Neck band is coarse } \\
\text { sandy clay with } 10 \% \text { of angular rock fragments. }\end{array}$ & $9 \mathrm{~mm}$ & $10 \mathrm{~g}$ \\
\hline \multirow[t]{4}{*}{ Context 10} & V95 & 175 & $\begin{array}{l}2 \text { body (different } \\
\text { vessels) }\end{array}$ & $\begin{array}{l}\text { Exterior smoothed. One sherd has a trace of where a } \\
\text { neck band has detached. Coarse sandy clay. Grey with } \\
\text { brown surfaces. }\end{array}$ & $6 \mathrm{~mm}$ & $10 \mathrm{~mm}$ \\
\hline & V96 & 174 & $\begin{array}{l}2 \text { body sherds (same } \\
\text { vessel) }\end{array}$ & $\begin{array}{l}\text { Exterior decorated with shallow grooves (parallel sets). } \\
\text { Interior smoothed (striations). Grey. }\end{array}$ & $4-6 \mathrm{~mm}$ & $14 \mathrm{~g}$ \\
\hline & V97 & 173 & $\begin{array}{l}2 \text { body (different } \\
\text { vessels) }\end{array}$ & $\begin{array}{l}\text { Exterior burnished. Coarse sandy clay. Grey with brown } \\
\text { surfaces. }\end{array}$ & $6-8 \mathrm{~mm}$ & $12 \mathrm{~g}$ \\
\hline & V98 & 171 & 2 body \& 1 fragment & $\begin{array}{l}\text { One sherd and fragment have shallow grooves. Sandy } \\
\text { clay. Brown. Exterior sooted. }\end{array}$ & $4 \mathrm{~mm}$ & $7 \mathrm{~g}$ \\
\hline \multirow[t]{3}{*}{ Context 9} & V99 & Sieved & 2 fragments & One fragment is burnished. Sandy clay. Brown. & - & $2 \mathrm{~g}$ \\
\hline & V100 & 180 & $\begin{array}{l}1 \text { body, } 1 \text { basal (flat } \\
\text { part of base) \& } 1 \\
\text { fragment (probably } \\
\text { same vessel) }\end{array}$ & $\begin{array}{l}\text { Exterior smoothed. Fine sandy clay with } 10 \% \text { rock } \\
\text { fragments. }\end{array}$ & $7 \mathrm{~mm}$ & $29 \mathrm{~g}$ \\
\hline & V102 & 178 & 1 body \& 1 fragment & $\begin{array}{l}\text { Exterior smoothed/burnished. Sandy clay with } c 20 \% \\
\text { angular rock fragments. }\end{array}$ & $11 \mathrm{~mm}$ & $16 \mathrm{~g}$ \\
\hline Context 21 & V103 & 193 & $1 \mathrm{rim}$ & $\begin{array}{l}\text { Flat rim. Coarse sandy clay with } 5 \% \text { large quartz } \\
\text { fragments. Grey with brown margins. }\end{array}$ & $10 \mathrm{~mm}$ & $18 \mathrm{~g}$ \\
\hline
\end{tabular}

\section{Stac Mor, Garabost}

\begin{tabular}{|c|c|c|c|c|c|c|}
\hline Context & Vessel & SF & Sherd numbers & Description & $\begin{array}{l}\text { Thickness } \\
(\mathrm{mm})\end{array}$ & Weight (g) \\
\hline \multirow[t]{2}{*}{$1 \mathrm{~m}$} & V1 & & $\begin{array}{l}\text { Body sherd with clear } \\
\text { finger prints in the } \\
\text { interior }\end{array}$ & $\begin{array}{l}\text { The fabric is fine sandy clay with } c 10 \% \text { coarser quartz } \\
\text { which has fired hard and is grey with red margins. }\end{array}$ & $5 \mathrm{~mm}$ & $11 \mathrm{~g}$ \\
\hline & $\mathrm{V} 2$ & & Fragment & $\begin{array}{l}\text { The fabric is sandy clay with } c 10 \% \text { coarse quartz which } \\
\text { has fired hard and is red. }\end{array}$ & - & $5 \mathrm{~g}$ \\
\hline
\end{tabular}

\section{Stac Domhnuill Chain}

\begin{tabular}{|l|l|l|l|l|l|}
\hline Context & Vessel & SF & Sherd numbers & $\begin{array}{l}\text { Description } \\
\text { (mm) }\end{array}$ & $\begin{array}{l}\text { Weight } \\
\text { (g) }\end{array}$ \\
\hline & V1 & & Body sherd & $\begin{array}{l}\text { The fabric is sandy clay with } c 10 \% \text { coarse quartz } \\
\text { fragments. It is fired hard and is grey. The exterior is } \\
\text { smoothed and decorated with two horizontal incised } \\
\text { bands 4mm wide } 5-7 m m \text { mart) with obliquely } \\
\text { arranged lines 3mm wide and 5-10mm apart below } \\
\text { this and four oblique parallel grooves. The sherd is } \\
\text { probably from a Hebridean Neolithic vessel. Thick } \\
\text { diagonal grooving is typical of this type of vessel (cf V6 } \\
\text { Dunasbroc). }\end{array}$ \\
\hline
\end{tabular}


Table 4 (cont.)

Eilean nan Luchruban

\begin{tabular}{|c|c|c|c|c|c|c|}
\hline Context & Vessel & SF & Sherd numbers & Description & $\begin{array}{c}\text { Thickness } \\
\text { (mm) }\end{array}$ & $\begin{array}{l}\text { Weight } \\
\text { (g) }\end{array}$ \\
\hline & V1 & & $\begin{array}{l}\text { Basal sherd - flat } \\
\text { base with angled } \\
\text { walls }\end{array}$ & Sandy clay. Grey with a buff exterior margin. & $8 \mathrm{~mm}$ & $10 \mathrm{~g}$ \\
\hline & V2 & & Body sherd & Coarse sandy clay. Buff. & $8 \mathrm{~mm}$ & $9 \mathrm{~g}$ \\
\hline & V3 & & Body sherd & Sandy clay. Grey with buff surfaces. & $9 \mathrm{~mm}$ & $2 \mathrm{~g}$ \\
\hline
\end{tabular}

\section{Dunasbroc, Ness}

\begin{tabular}{|c|c|c|c|c|c|c|}
\hline Context & Vessel & SF & Sherd numbers & Description & $\begin{array}{l}\text { Thickness } \\
\text { (mm) }\end{array}$ & $\begin{array}{l}\text { Weight } \\
\text { (g) }\end{array}$ \\
\hline & V1 & & $\begin{array}{l}\text { Small plain rim } \\
\text { sherd }\end{array}$ & $\begin{array}{l}\text { Sandy clay. Grey with a brown exterior surface. Interior } \\
\text { sooted. }\end{array}$ & $6 \mathrm{~mm}$ & $3 \mathrm{~g}$ \\
\hline & $\mathrm{V} 2$ & & $\begin{array}{l}\text { Interior fragment, } \\
\text { broken in two }\end{array}$ & $\begin{array}{l}\text { The fabric is sandy clay with } 10 \% \text { large fragments. Grey } \\
\text { with brown exterior margin. Interior sooted. }\end{array}$ & - & $2 \mathrm{~g}$ \\
\hline & V3 & & Interior fragment & $\begin{array}{l}\text { Sandy clay with c30\% of large quartz fragments. Grey. } \\
\text { Interior sooted. }\end{array}$ & - & $5 \mathrm{~g}$ \\
\hline & V4 & & $\begin{array}{l}\text { Flat base with } \\
\text { angled sides, and a } \\
\text { small body sherd }\end{array}$ & $\begin{array}{l}\text { Coarse sandy clay. Grey with a red exterior margin. } \\
\text { Interior sooted. }\end{array}$ & $\begin{array}{c}9 \mathrm{~mm} \\
\text { (walls), } 15 \\
\text { mm (base) }\end{array}$ & $38 \mathrm{~g}$ \\
\hline & V5 & & $\begin{array}{l}5 \text { abraded body } \\
\text { sherds (probably } \\
\text { from } 2 \text { vessels) } \\
\end{array}$ & Sandy clay with $20 \%$ large quartz fragments. Abraded. & $8-13 \mathrm{~mm}$ & $106 \mathrm{~g}$ \\
\hline
\end{tabular}

\section{Dun Arnistean}

\begin{tabular}{|c|c|c|c|c|c|c|}
\hline Context & Vessel & SF & Sherd numbers & Description & $\begin{array}{c}\text { Thickness } \\
\text { (mm) }\end{array}$ & $\begin{array}{l}\text { Weight } \\
\text { (g) }\end{array}$ \\
\hline & V1 & 22 & $\begin{array}{l}\text { Flat part of base }(4 \\
\text { sherds) }\end{array}$ & $\begin{array}{l}\text { Sandy clay with } c 10 \% \text { coarser quartz. Red with buff } \\
\text { margins. Grass impressions on exterior surface. }\end{array}$ & $11 \mathrm{~mm}$ & $55 \mathrm{~g}$ \\
\hline & $\mathrm{V} 2$ & 16 & Body sherd & Sandy clay. Buff. & $5 \mathrm{~mm}$ & $1 \mathrm{~g}$ \\
\hline & V3 & 27 & $\begin{array}{l}\text { Top of coil junction } \\
\text { at neck of an everted } \\
\text { rim }\end{array}$ & $\begin{array}{l}\text { Sandy clay with c10\% angular quartz. Red with a grey } \\
\text { core. }\end{array}$ & $9 \mathrm{~mm}$ & $15 \mathrm{~g}$ \\
\hline & V4 & 8 & Body sherd & Fine clay. Red. Exterior sooted. & $4 \mathrm{~mm}$ & $2 \mathrm{~g}$ \\
\hline & V5 & 21 & $\begin{array}{l}\text { Part of a finger- } \\
\text { impressed neckband }\end{array}$ & Fine sandy clay. Red. & $6 \mathrm{~mm}$ & $2 \mathrm{~g}$ \\
\hline & V6 & 30 & Abraded body sherd & $\begin{array}{l}\text { The fabric is fine sandy clay with } c 10 \% \text { large quartz. } \\
\text { Grey with red margins. Interior sooted. }\end{array}$ & $5 \mathrm{~mm}$ & $4 \mathrm{~g}$ \\
\hline & V7 & 1 & Body sherd & Sandy clay. Red. & $6 \mathrm{~mm}$ & $4 \mathrm{~g}$ \\
\hline & V9 & 29 & $\begin{array}{l}\text { Body sherd. Exterior } \\
\text { surface smoothed }\end{array}$ & $\begin{array}{l}\text { Sandy clay with } c 30 \% \text { angular fragments. Brown } \\
\text { exterior, grey interior. }\end{array}$ & $10 \mathrm{~mm}$ & $9 \mathrm{~g}$ \\
\hline & V10 & 9 & Body sherd & $\begin{array}{l}\text { Fine sandy clay. Grey with a red exterior margin. } \\
\text { Interior sooted. }\end{array}$ & $7 \mathrm{~mm}$ & $8 \mathrm{~g}$ \\
\hline & V11 & 7 & $\begin{array}{l}\text { Body sherd and } \\
\text { fragment. Abraded }\end{array}$ & $\begin{array}{l}\text { Sandy clay with c10\% coarse fragments. Grey with buff } \\
\text { margins. }\end{array}$ & $7 \mathrm{~mm}$ & $11 \mathrm{~g}$ \\
\hline & V12 & 2 & $\begin{array}{l}\text { Body sherd with } \\
\text { a small section of } \\
\text { applied zig-zag } \\
\text { remaining. Exterior } \\
\text { smoothed }\end{array}$ & Sandy clay. Brown. Exterior surface sooted. & $7 \mathrm{~mm}$ & $15 \mathrm{~g}$ \\
\hline
\end{tabular}


Table 4 (cont.)

\begin{tabular}{|c|c|c|c|c|c|c|}
\hline Context & Vessel & SF & Sherd numbers & Description & $\begin{array}{c}\text { Thickness } \\
(\mathbf{m m})\end{array}$ & $\begin{array}{l}\text { Weight } \\
\text { (g) }\end{array}$ \\
\hline & V13 & 14 & $\begin{array}{l}\text { Body sherd with an } \\
\text { angular carination. } \\
\text { Above the carina- } \\
\text { tion is a line of nail } \\
\text { impressions. }\end{array}$ & $\begin{array}{l}\text { Coarse sandy clay. Grey with buff surfaces. Both } \\
\text { surfaces sooted. }\end{array}$ & $5 \mathrm{~mm}$ & $10 \mathrm{~g}$ \\
\hline & V14 & 31 & Body sherd & Coarse sandy clay. Grey with red surfaces. & $10 \mathrm{~mm}$ & $5 \mathrm{~g}$ \\
\hline & V15 & 25 & Body sherd (abraded) & Coarse sandy clay. Red with a black core. & - & $7 \mathrm{~g}$ \\
\hline & V16 & 28 & 2 fragments & Coarse sandy clay. Red. & & $2 \mathrm{~g}$ \\
\hline & V17 & 3 & $\begin{array}{l}2 \text { body sherds } \\
\text { (probably different } \\
\text { vessels) }\end{array}$ & Coarse sandy clay. Brown. Exterior sooted. & $5 \mathrm{~mm}$ & $9 \mathrm{~g}$ \\
\hline & V18 & 17 & $\begin{array}{l}\text { Sherd from the neck } \\
\text { of a vessel - broken } \\
\text { off along a coil } \\
\text { junction }\end{array}$ & $\begin{array}{l}\text { Sandy clay with } c 10 \% \text { angular fragments. Grey with } \\
\text { red surfaces. }\end{array}$ & $8 \mathrm{~mm}$ & $11 \mathrm{~g}$ \\
\hline & V19 & & $\begin{array}{l}3 \text { body sherds } \\
\text { (different vessels). } \\
\text { Possible impressed } \\
\text { decoration below } \\
\text { ?rim of one sherd. }\end{array}$ & Sandy clay. Red. & $6-7 \mathrm{~mm}$ & $13 \mathrm{~g}$ \\
\hline & V20 & & $\begin{array}{l}2 \text { body sherds } \\
\text { (different vessels). }\end{array}$ & $\begin{array}{l}\text { Coarse sandy clay. One sherd is abraded. Grey with buff } \\
\text { exterior surface. }\end{array}$ & $7 \mathrm{~mm}$ & $7 \mathrm{~g}$ \\
\hline & V21 & & $\begin{array}{l}\text { Body sherd and } \\
\text { fragment (different } \\
\text { vessels) }\end{array}$ & Coarse sandy clay. Red. & $7 \mathrm{~mm}$ & $4 \mathrm{~g}$ \\
\hline \multirow[t]{16}{*}{$\begin{array}{l}\text { Professor } \\
\text { Murray } \\
\text { Campbell } \\
\text { Collection }\end{array}$} & & & $\begin{array}{l}\text { Not catalogued } \\
\text { individually. } 2 \text { rim } \\
\text { sherds with long } \\
\text { everted/flared rims. } \\
2 \text { sherds with finger } \\
\text { impressions (?basal). } \\
47 \text { body sherds. }\end{array}$ & $\begin{array}{l}\text { Most sandy. Some are finer and thinner. No decoration } \\
\text { on the body sherds but some are ?wiped. Probably Iron } \\
\text { Age and later. }\end{array}$ & $8-10 \mathrm{~mm}$ & $540 \mathrm{~g}$ \\
\hline & V22 & 46 & $\begin{array}{l}\text { Basal sherd (flat part } \\
\text { of base) }\end{array}$ & Coarse sandy clay. Grey with red surfaces. & $9 \mathrm{~mm}$ & $7 \mathrm{~g}$ \\
\hline & V23 & 47 & Body sherd & Sandy clay. Grey with red surfaces. Interior sooted. & $5 \mathrm{~mm}$ & $3 \mathrm{~g}$ \\
\hline & V24 & 77 & Body sherd & $\begin{array}{l}\text { Coarse sandy clay. Grey with brown surfaces. Interior } \\
\text { sooted. }\end{array}$ & $11 \mathrm{~mm}$ & $14 \mathrm{~g}$ \\
\hline & V25 & 51 & Lump of fired clay & Coarse sandy clay. Grey with red surfaces. & - & $19 \mathrm{~g}$ \\
\hline & V26 & 65 & Body sherd & Sandy clay. Brown. & $4 \mathrm{~mm}$ & $2 \mathrm{~g}$ \\
\hline & V27 & 41 & $\begin{array}{l}\text { Body sherd. Exterior } \\
\text { surface wiped }\end{array}$ & $\begin{array}{l}\text { Sandy clay. Grey with red surfaces. Both surfaces } \\
\text { sooted. }\end{array}$ & $6 \mathrm{~mm}$ & $15 \mathrm{~g}$ \\
\hline & V28 & 50 & Body fragment & $\begin{array}{l}\text { Sandy clay with } c 10 \% \text { rock fragments. Grey with red } \\
\text { exterior surface. }\end{array}$ & - & $4 \mathrm{~g}$ \\
\hline & V29 & 43 & Body sherd & $\begin{array}{l}\text { Sandy clay with } c 10 \% \text { angular fragments. Grey with a } \\
\text { brown interior surface. Both surfaces sooted. }\end{array}$ & $8 \mathrm{~mm}$ & $13 \mathrm{~g}$ \\
\hline & V30 & 79 & Body sherd & $\begin{array}{l}\text { Coarse sandy clay. Red exterior, grey interior. Interior } \\
\text { sooted. }\end{array}$ & $10 \mathrm{~mm}$ & $18 \mathrm{~g}$ \\
\hline & V31 & 35 & $\begin{array}{l}\text { Body sherd. Exterior } \\
\text { smoothed }\end{array}$ & Coarse sandy clay. Red. & $5 \mathrm{~mm}$ & $1 \mathrm{~g}$ \\
\hline & V32 & 80 & Body sherd & Fine sandy clay. Brown. Exterior sooted. & $7 \mathrm{~mm}$ & $6 \mathrm{~g}$ \\
\hline & V33 & 54 & Body sherd & $\begin{array}{l}\text { Coil junctions not smoothed on the exterior. Coarse } \\
\text { sandy clay. Brown. }\end{array}$ & $16 \mathrm{~mm}$ & $56 \mathrm{~g}$ \\
\hline & V34 & 36 & Rim sherd (flat rim) & Coarse sandy clay. Grey. & $6 \mathrm{~mm}$ & $7 \mathrm{~g}$ \\
\hline & V35 & 61 & Body sherd & Coarse sandy clay. Grey with brown surfaces. & $11 \mathrm{~mm}$ & $8 \mathrm{~g}$ \\
\hline & V36 & 69 & Body sherd & Sandy clay. Grey with brown surfaces. & $8 \mathrm{~mm}$ & $8 \mathrm{~g}$ \\
\hline
\end{tabular}


Table 4 (cont.)

\begin{tabular}{|c|c|c|c|c|c|c|}
\hline Context & Vessel & SF & Sherd numbers & Description & $\begin{array}{c}\text { Thickness } \\
(\mathbf{m m})\end{array}$ & $\begin{array}{c}\text { Weight } \\
\text { (g) }\end{array}$ \\
\hline & V37 & 60 & Body sherd & Coarse sandy clay. Brown exterior, grey interior. & $7 \mathrm{~mm}$ & $5 \mathrm{~g}$ \\
\hline & V38 & 39 & $\begin{array}{l}1 \text { flat rim, } 2 \text { body, } 1 \\
\text { fragment }\end{array}$ & $\begin{array}{l}\text { Rim (abraded). Fine sandy clay. Brown. } \\
\text { Fragment. Coarse sandy clay. Brown/grey. } \\
\text { Body. Coarse sandy clay. Red. } \\
\text { Body. Burnished. Sandy clay. Brown with red exterior. }\end{array}$ & $\begin{array}{l}4 \mathrm{~mm} \\
- \\
8 \mathrm{~mm} \\
8 \mathrm{~mm}\end{array}$ & $\begin{array}{l}3 \mathrm{~g} \\
2 \mathrm{~g} \\
6 \mathrm{~g} \\
2 \mathrm{~g}\end{array}$ \\
\hline & V39 & 49 & Body sherd & Coarse sandy clay. Grey with a brown exterior surface. & $5 \mathrm{~mm}$ & $2 \mathrm{~g}$ \\
\hline & V40 & 33 & Body sherd & Sandy clay. Grey with red surfaces. & $9 \mathrm{~mm}$ & $9 \mathrm{~g}$ \\
\hline & V41 & 34 & $\begin{array}{l}\text { Body sherd with } \\
\text { ?part of a wavy band } \\
\text { adhering }\end{array}$ & Coarse sandy clay. Brown. & $6 \mathrm{~mm}$ & $7 \mathrm{~g}$ \\
\hline & V42 & 42 & Body sherd & Sandy clay. Buff. & $6 \mathrm{~mm}$ & $12 \mathrm{~g}$ \\
\hline & V43 & 45 & $\begin{array}{l}\text { Body sherd, or flat } \\
\text { part of a base }\end{array}$ & Sandy clay. Red. & $9 \mathrm{~mm}$ & $7 \mathrm{~g}$ \\
\hline & V44 & 32 & Body sherd & Coarse sandy clay. Grey with red surfaces. & $11 \mathrm{~mm}$ & $7 \mathrm{~g}$ \\
\hline & V45 & 38 & Body sherd (split). & Sandy clay. Grey with red exterior surfaces. & $7 \mathrm{~mm}$ & $6 \mathrm{~g}$ \\
\hline & V46 & 68 & $\begin{array}{l}\text { Body fragment \& } \\
\text { small rim sherd }\end{array}$ & $\begin{array}{l}\text { Body fragment. Sandy clay. Grey with a brown interior } \\
\text { surface. } \\
\text { Small rim sherd (flat). Fine sandy clay. Brown. }\end{array}$ & $\begin{array}{l}- \\
5 \mathrm{~mm}\end{array}$ & $\begin{array}{l}4 \mathrm{~g} \\
1 \mathrm{~g}\end{array}$ \\
\hline & V47 & 52 & \begin{tabular}{|l|}
2 body sherds \\
(different vessels)
\end{tabular} & Fine sandy clay. Red. & $7 \mathrm{~mm}$ & $5 \mathrm{~g}$ \\
\hline & V48 & 74 & $\begin{array}{l}\text { From the neck of a } \\
\text { vessel. }\end{array}$ & Coarse sandy clay. Brown. Exterior sooted. & $8 \mathrm{~mm}$ & $18 \mathrm{~g}$ \\
\hline & V49 & 48 & $\begin{array}{l}\text { Body sherd broken } \\
\text { off at the junction } \\
\text { with the neck. } \\
\text { Exterior wiped }\end{array}$ & Coarse sandy clay. Grey interior, brown exterior. & $14 \mathrm{~mm}$ & $54 \mathrm{~g}$ \\
\hline & V50 & 64 & $\begin{array}{l}2 \text { abraded body } \\
\text { sherds (different } \\
\text { vessels) }\end{array}$ & Coarse sandy clay. Grey with a red exterior margin. & $7 \mathrm{~mm}$ & $9 \mathrm{~g}$ \\
\hline & V51 & & $\begin{array}{l}3 \text { abraded body } \\
\text { sherds (different } \\
\text { vessels) \& basal } \\
\text { sherd (flat part of } \\
\text { base) }\end{array}$ & $\begin{array}{l}\text { Body sherd. Coarse sandy clay. Red. } \\
\text { Body sherd. Coarse sandy clay. Red. } \\
\text { Body sherd (from join with base). Fine sandy clay. Red. } \\
\text { Basal sherd (flat part of base). Coarse sandy clay. Grey. }\end{array}$ & $\begin{array}{r}12 \mathrm{~mm} \\
9 \mathrm{~mm} \\
7 \mathrm{~mm} \\
12 \mathrm{~mm}\end{array}$ & $\begin{array}{r}6 \mathrm{~g} \\
17 \mathrm{~g} \\
4 \mathrm{~g} \\
13 \mathrm{~g}\end{array}$ \\
\hline
\end{tabular}

Published sequences are limited to two sites, Eilean an Tighe, North Uist and Allt Chrisal, Barra.

In 1951 Lindsay Scott published the site of Eilean an Tighe, located on a tidal islet in North Uist, which he interpreted as a pottery workshop. This interpretation has been questioned on a number of occasions (eg Gibson 1995, 100). The interpretation of the stratigraphy is seldom referred to as a general model for the sequence of Neolithic pottery in the Western Isles but while the interpretation of the function of the site can be questioned, there is no reason to disregard the sequence. The sequence from Eilean an Tighe is described by Lindsay Scott as follows:

- Plain pots; pots with decoration on the rim; outturned flat rims

- Plain vessels continued to be made but at least half of the vessels were decorated; flat rims were replaced by in-bevelled rims; flanged bowls appear
- Up to two thirds of all pots were decorated; in-bevelled rims are standard on plain vessels; outbevelled rims have been introduced on decorated pots; two new and distinctive types appear, the ridged jar and the Unstan bowl

Lindsay Scott felt that the sequence was reliable as variations in phases across the site were recognisable from variations in soil type. The usefulness of this sequence, however, is limited by the lack of radiocarbon dates.

In his summary of the pottery from Allt Chrisal, Barra, Gibson (1995) notes that the typologically earliest vessels in the assemblage are the undecorated carinated bowls which were found throughout the levels of the excavated sections. He suggests that they form an undecorated element of the larger 'Hebridean assemblage'. Likewise, with Unstan bowls, he concludes that while comprising a small element of the assemblage in terms of number of vessels (18 vessels, $c 3 \%$ of the total assemblage) they appear to 
be found throughout the site's history. Taken with the evidence from Eilean an Tighe this could indicate that the assemblage from Allt Chrisal is slightly later than that from Eilean an Tighe, or if the two sites are contemporary, that there is a great deal of variation from one site to another within the Hebridean Neolithic, with the composition of the assemblage from a site perhaps depending more on site function or cultural preference than chronology. The dates for Allt Chrisal are $4470 \pm 50$ вP (GU-3923); $4700 \pm 100$ вР (GU-3467); and $4820 \pm 60$ вр (GU-3922).

The two tombs with the largest assemblages of Neolithic pottery are Clettraval and Unival, both on North Uist. Sherds from an estimated 23 vessels were recovered from the long cairn at Clettraval, a mix of shallow and deep bowls, usually bipartite, with varying depths of collar in relation to the overall height of the vessel. A similar assemblage was recovered from the square cairn at Unival, with a few flat-based vessels, one of which was identified as Grooved Ware (both sites reported in Henshall 1972). Neither at Clettraval nor at Unival were ridged bowls or Unstan bowls included in the assemblage, although the other elements of Hebridean assemblages are represented, an observation made by Lindsay Scott in his discussion of the pottery from Eilean an Tighe. The lack of dates makes it difficult to know whether this is related to chronology (ie whether deposition of pottery within tombs had gone out of fashion before ridged bowls and Unstan bowls were in production); whether they were deliberately not chosen for inclusion in the tombs; or whether they were being produced by a group that was culturally different from those making the tombs.

Sheridan and Sharples $(1992,7)$ note that while Unstan bowls are found over a wide area in the Northern and Western Isles and on the northern mainland, the broader assemblages within which such bowls are found in Orkney are not replicated elsewhere. They also note that it is interesting that what have been referred to as 'flanged' bowls, present in the Orkney assemblages, appear in larger numbers in the Hebrides. The presence of only a few vessels which could be likened to Hebridean ridged bowls in the Northern Isles, and the presence of Grooved Ware at only a few sites in the Western Isles, suggest that contact between the two areas lessened in the later part of the Neolithic. Ridged vessels are not paralleled anywhere else in the Neolithic of the British Isles, perhaps indicating that in the later part of the Neolithic the Western Isles became more insular. This can be contrasted with the Northern Isles, where the abundance of Grooved Ware indicates that the Northern Isles were part of a strong communications network with other areas of mainland Britain. This is another area of enquiry which it will be interesting to come back to as more sites are excavated (it should be remembered, however, that until relatively recently, Aberdeenshire was a Grooved Ware-free area, so the characterisation of the Western Isles as a 'Grooved Ware-poor' region should be used with caution).
While the publication of the sequence from Eilean Domhnuill will be valuable in progressing our understanding of the Neolithic pottery from the Western Isles, it will be important to bear in mind that some of the attributes may relate only to Eilean Domhnuill and the temptation to adopt it as the type site for the interpretation of the pottery from the Western Isles should be resisted. In Orkney, for example, the analysis of the pottery from a number of well-stratified sites including Barnhouse (Richards 2005), Links of Noltland (Sheridan 1999) and Pool (Hunter \& MacSween 1991) has not resulted in the identification of a clear sequence, in fact at least two distinct types of Grooved Ware have been identified, and there is a clear impression that while there are certain underlying traits, there is much local variation, perhaps much to do with the creativity of individual potters working within the general bounds of what was acceptable to their cultural group (see for example MacSween 1995).

\subsection{Evidence from the sites}

\subsubsection{Dunasbroc}

The assemblage from Dunasbroc comprises $c 480$ sherds and fragments. The assemblage includes the rim and upper portion of several Hebridean vessels dating to the Neolithic. The characteristic features of assemblages of Hebridean incised wares are a round-based, 'baggy' profile, out-turned rims, the horizontal division of the vessels either by carinations or incised lines, and decoration which comprises either incisions or wider grooves into the surface of the vessel. The multi-carinated wares are a localised Hebridean style, the largest published assemblage being that from Eilean an Tighe (Lindsay Scott 1951). Their association with Unstan Ware pots on some sites such as Allt Chrisal, Barra (Gibson 1995 , 100-115) and Eilean Domhnuill, Loch Olabat, North Uist (Armit 1987) suggests that they were in use before $3500 \mathrm{BC}$ (Gibson 2002, 77) but as yet there is no secure dating framework for this type of pottery.

While the majority of fragments and sherds in the assemblage can be attributed to the Neolithic from their fabrics and the presence of grooved decoration on many sherds, there are a few sherds which are Iron Age in character.

\section{Hebridean incised wares (illus 66)}

The Neolithic pottery from the site is very fragile and fragmented but enough survives of a few vessels (all from Context 6) to allow the profile of the upper portion of the vessel to be established. The best example is V1 (Vessel 1), which has an out-turned rim with an interior bevel. Below the rim on the exterior are three horizontal zones, delineated by carinations. The rim bevel is decorated with oblique, parallel grooves, and the zones are also decorated with parallel grooves, arranged in opposing directions. This was the most 

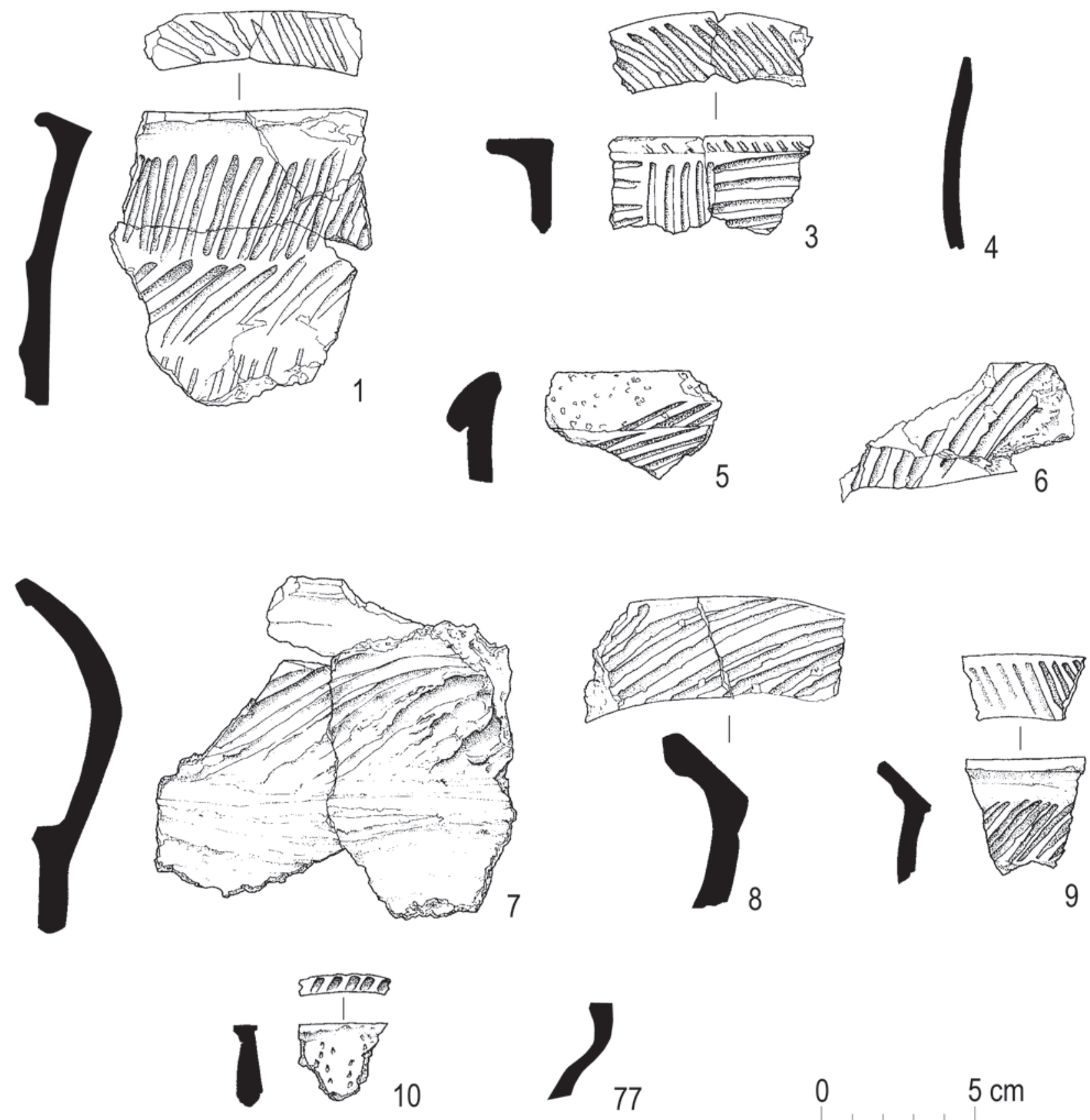

77

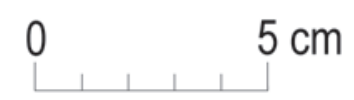

Illus 66 Hebridean incised wares from Dunasbroc Vessels 1, 3, 4, 5, 6, 7, 8, 9, 10 \& 77

.common form of decoration noted at Allt Chrisal, Barra (Gibson 1995, 104), and is also a decorative scheme in the Eilean an Tighe assemblage (Lindsay Scott 1951, 21, fig 8, 1.1). A variation in the layout of the decoration is noted on V3, where there is similar decoration on the rim bevel, but the decoration below the rim comprises alternating panels of horizontal and vertical grooves (unfortunately only the portion of the body just below the rim survives. Nicking along the exterior edge of the rim as on V3 is a feature also noted at other sites, eg Allt Chrisal (Gibson 1995, fig 4.32 , no. 73 ).

Not all vessels have decoration covering the whole vessel - V11 has a decorated rim but the exterior of .the body is smoothed, while V8 has a wide out-turned rim, again decorated with parallel grooves, and the exterior of the vessel is undecorated but burnished. In the case of $\mathrm{V} 6$ the decoration appears to be restricted to the portion of the vessel above the carination ( $\mathrm{cf}$ Eilean an Tighe, Lindsay Scott 1951, 22, fig 9, 2.3).

Hebridean assemblages usually include a variety of styles (cf the assemblage from Allt Chrisal, Barra; Gibson 1995, figs 4.32-34). In the case of Dunasbroc a flanged rim (also with grooved decoration - V5), is included, and there is a flat-rimmed vessel with grooved lines on the rim and impressed dot decoration on the exterior (V10). There is also a plain, straight-sided vessel from the same context (V4). 
The fabrics are generally coarse, sandy clays with little evidence that temper was being added. The vessels are coil-constructed, and V7 (an outer fragment) provides evidence that the carinations were, at least in some cases, added as a roll of clay smoothed onto the surface of the vessel.

\section{Iron Age}

As was noted (above) a few diagnostic sherds from Dunasbroc are of Iron Age date. These would include the everted rim (V77) from Context 4, the pinched neckband fragment (V94) from Context 19, and a sherd (V95) from Context 10 with the mark of a (now detached) neckband.

\subsubsection{Stac Mor, Garabost}

One sherd and one fragment of undiagnostic pottery.

\subsubsection{Stac Domhnuill Chaim}

One sherd of Hebridean incised ware (illus 5) and one sherd probably late prehistoric or later.

\subsubsection{Eilean nan Luchruban}

One basal sherd and two body sherds, probably late prehistoric or later.

\subsubsection{Dunasbroc, Ness}

One rim sherd, 8 body sherds and a flat base with angled sites. Probably late prehistoric or later.

\subsubsection{Dun Arnistean}

The assemblage from Dun Arnistean comprises $c 70$ sherds and a bag of unstratified material collected by Professor Murray Campbell. The majority of sherds are undiagnostic body sherds, but the assemblage includes a number of basal sherds from flat-based vessels (V1, V22, V51); sherds from vessels with an everted rim (V3, V18, V48, V49); a fragment of a finger-impressed neckband (V5); a body sherd with a small amount of applied zig-zag decoration (V12) and a second possible one (V41); and a body sherd with an angular carination with traces of decoration above (V13).

The Professor Murray Campbell collection was not recorded in detail, but two flaring rims are included in the assemblage. Also included in the collection are a number of fine sherds.

There is nothing in the assemblage to indicate a date earlier than the Iron Age. Finger-impressed bands and applied wavy decoration are common forms in 'middle' Iron Age, from the mid first century BC (Campbell 2002, 141) with the flaring rims dating slightly later, from the fourth to sixth centuries $\mathrm{AD}$ (ibid, 142). 


\section{APPENDIX 4: THE LITHIC ASSEMBLAGE FROM DUNASBROC by Chris Barrowman}

\subsection{Introduction}

The following report describes the flaked lithic material from the trial excavations at Dunasbroc, Ness, Isle of Lewis in 2005. The total number of lithics recovered from the excavation was 96 (see table 5 for catalogue).

\subsection{Methodology}

All the lithics recovered by hand and through dry sieving were present for analysis. All pieces were macroscopically classified according to standard analytical principles (Ballin 2000). Any lithics smaller than $10 \mathrm{~mm}$ in the maximum linear dimension are normally identified as waste or debitage from knapping. However, there were only two lithics of this size within the assemblage, and given that all spoil was sieved with a $1 / 4$-inch riddle $(c 6 \mathrm{~mm}$; McHardy 2005, 14) any waste material should have been recovered if present. As there was a policy adopted during excavation that all lithic debris would be recorded (McHardy pers comm), it must be concluded that there was no debitage in the contexts excavated.

\subsection{Raw material}

Approximately two thirds of the lithics were quartz, with the remainder flint. Three lithics were of a banded siliceous material, one patinated flake of orange agate (SF22), but the other two are very like flint (SF28 and SF48). These would have derived from a beach pebble source, indeed one of the pieces (SF28) is a beach pebble. The flint also derives from a pebble source (save one imported artefact - see below), likely to have been available in small amounts on local beaches, and comparable to other flint assemblages on Lewis (Warren forthcoming a)). Cortex is present on $30 \%$ of the flint, and it is heavily battered and pitted. There is one flint pebble with a spall scar present. The flint is greatly patinated ( $45 \%$ of all pieces), and $35 \%$ is burnt. Most of the flint is either grey or white in colour, and one piece is orange, indicating imported flint (see below).

The quartz utilised in the assemblage is a grey/ white opaque form which ranges in quality from very fragmented and crystalline in nature, to a clearer form with a more consistent and fine-grained body. The majority of the quartz is of the former type (79\%) and often has small flecks of feldspar throughout, while $15 \%$ of the pieces are of the higher-quality, more durable type. All of the quartz would have been available in the immediate locality, although it is impossible to say where the quartz in this assemblage derived from. Quartz is found across the whole of north-west Scotland (quartz assemblages from here are described as being from the Scottish quartz province) and there are known assemblages along the west coast of the island which would have utilised stone from either quartz veins running throughout the Lewisian gneiss, or from beach pebbles. A rock outcrop of quartz at Cnoc Dubh near Garynahine shows the marks of quarrying, and has been examined in detail by Ballin (Ballin 2004).

\subsubsection{Condition}

Only the condition of the flint assemblage can be described with confidence, given the tendency of quartz to fracture and split naturally. It is also hard to identify the effects of burning on quartz (although see Ballin forthcoming). Many of the pieces (41\% of quartz) do show signs of frosting however, indicating post-depositional changes in the material, presumably from weathering. Of the 31 flint pieces, $45 \%$ were fully patinated and $42 \%$ showed indications of burning. Although the patination gives an indication of postdepositional changes in the material, it is likely that the burnt pieces have undergone firing prior to deposition, given that these pieces are mixed with unburnt lithics in the same contexts (mainly Context 006).

Almost all the quartz and flint is fresh and shows little sign of abrasion as a result of being moved or rolled subsequent to their original deposition. It is likely that the material was either worked at the site or had been brought to it from nearby. Fourteen per cent of the assemblage showed signs of being snapped (these lithics being mostly flakes and blades). Edge damage occurs on 10 lithics $(10.5 \%$ of the assemblage), and a further 10 show possible edge damage (also $10.5 \%$ of the assemblage). This edge damage is likely to have occurred through use (see below).

\subsubsection{Assemblage composition}

The table (table 6) below shows the composition of lithic types within the assemblage by raw material.

The reduction process varies between the raw materials. Quarried and pebble quartz, pebble flint and pebble agate sources are all present, with a higher proportion of quartz chunks indicating the use of quartz from a quarried source. The three identified cores are all of flint, and show bipolar working techniques, which is expected given that small beach pebbles were the only available source. 


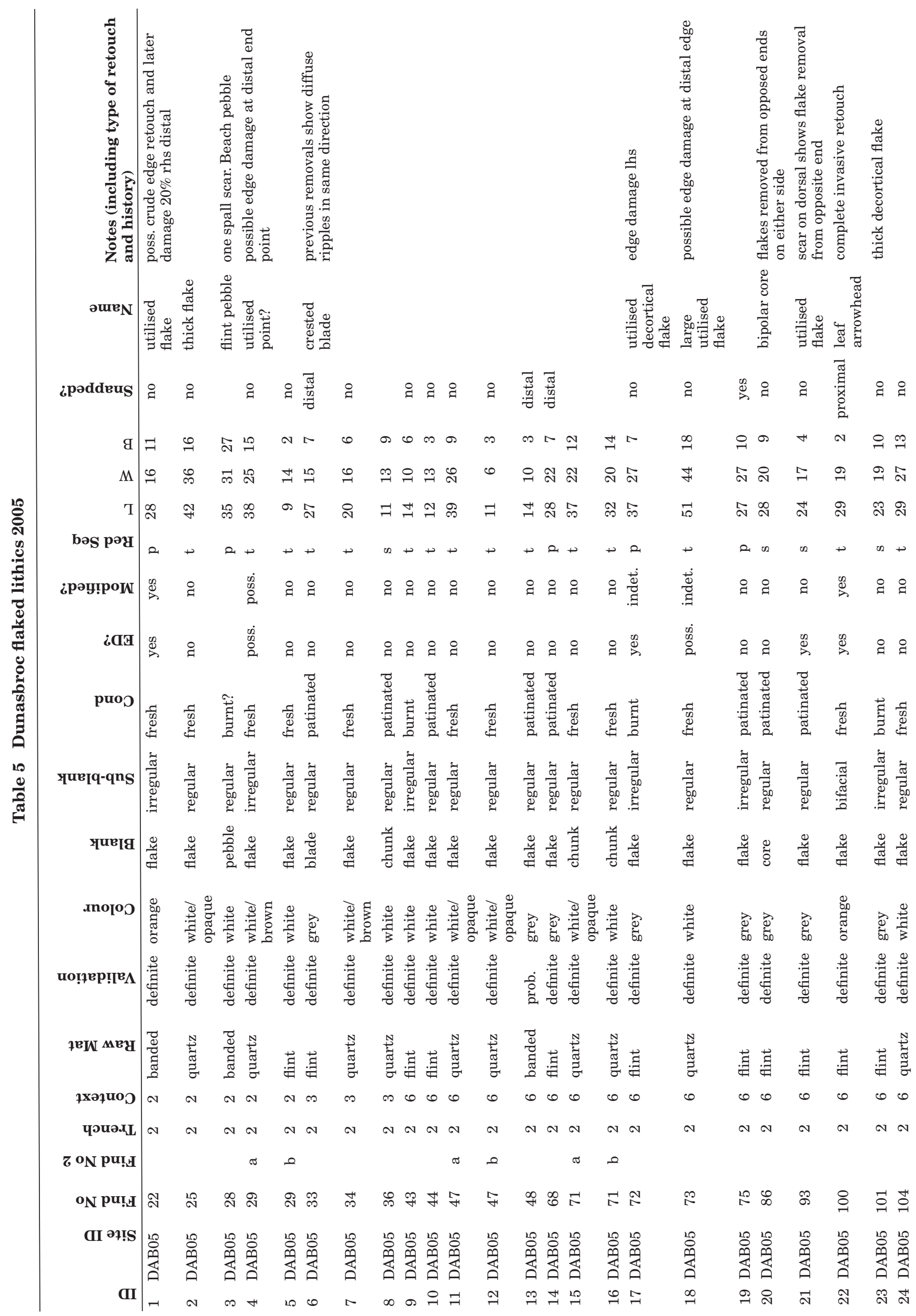




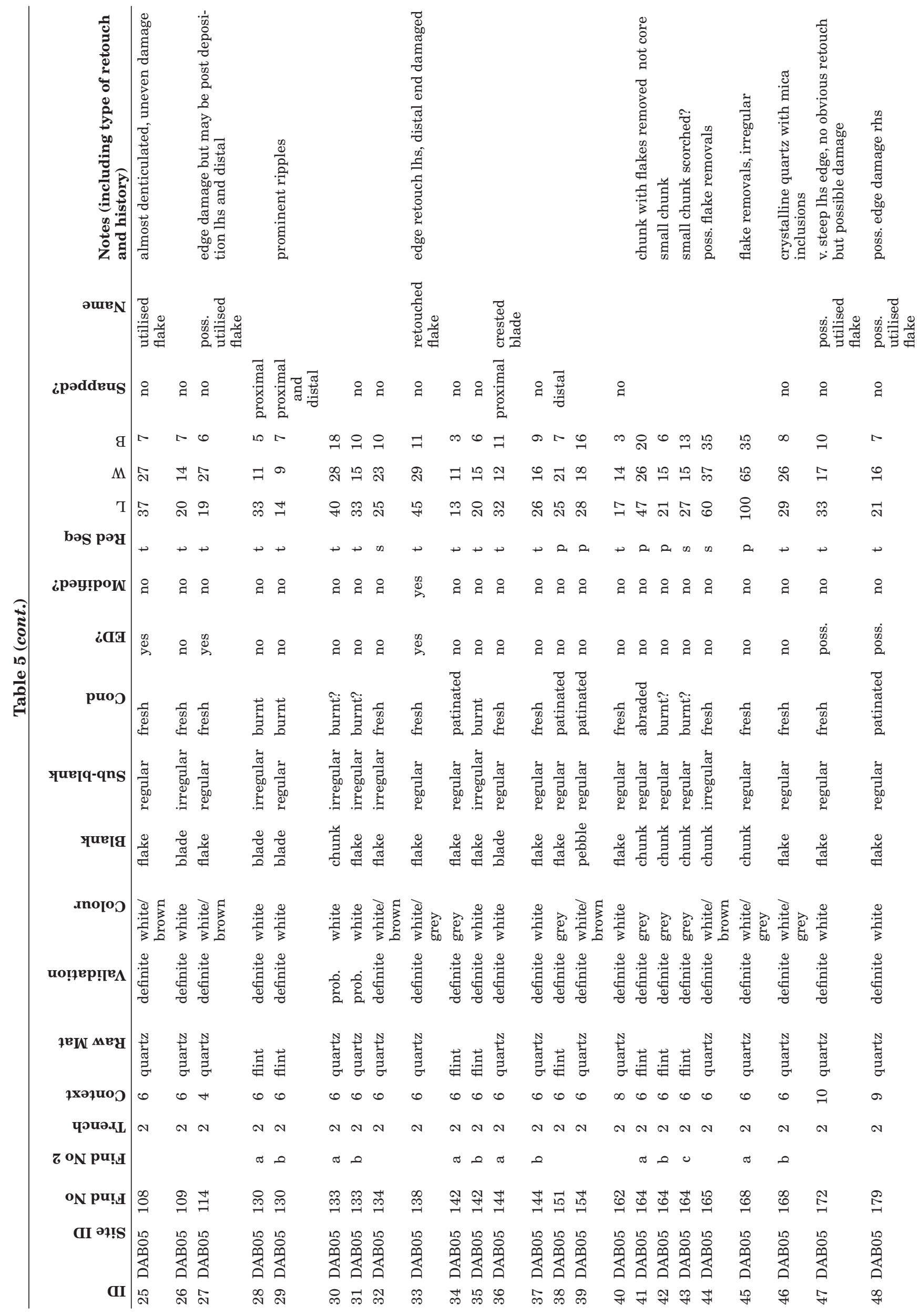




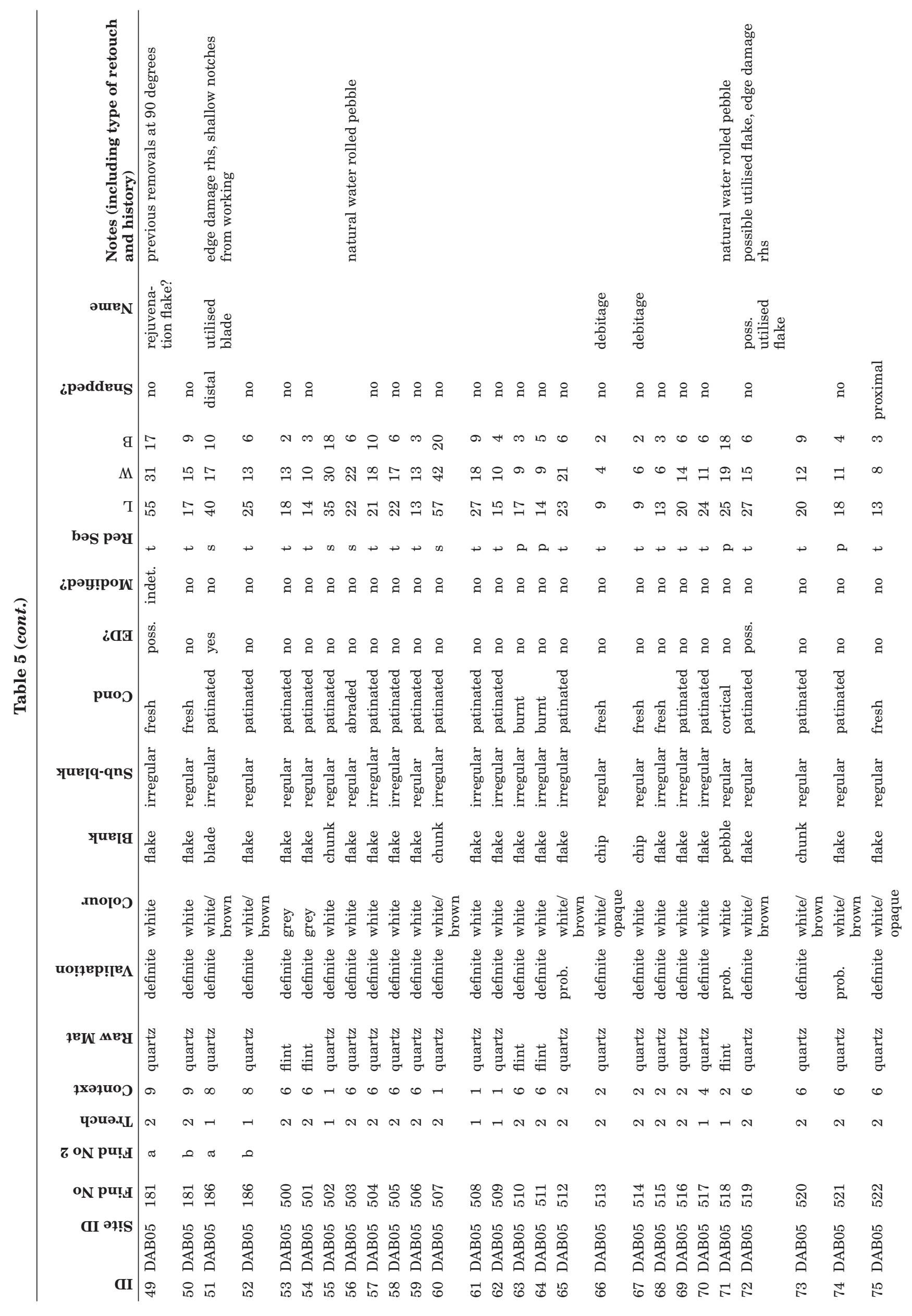




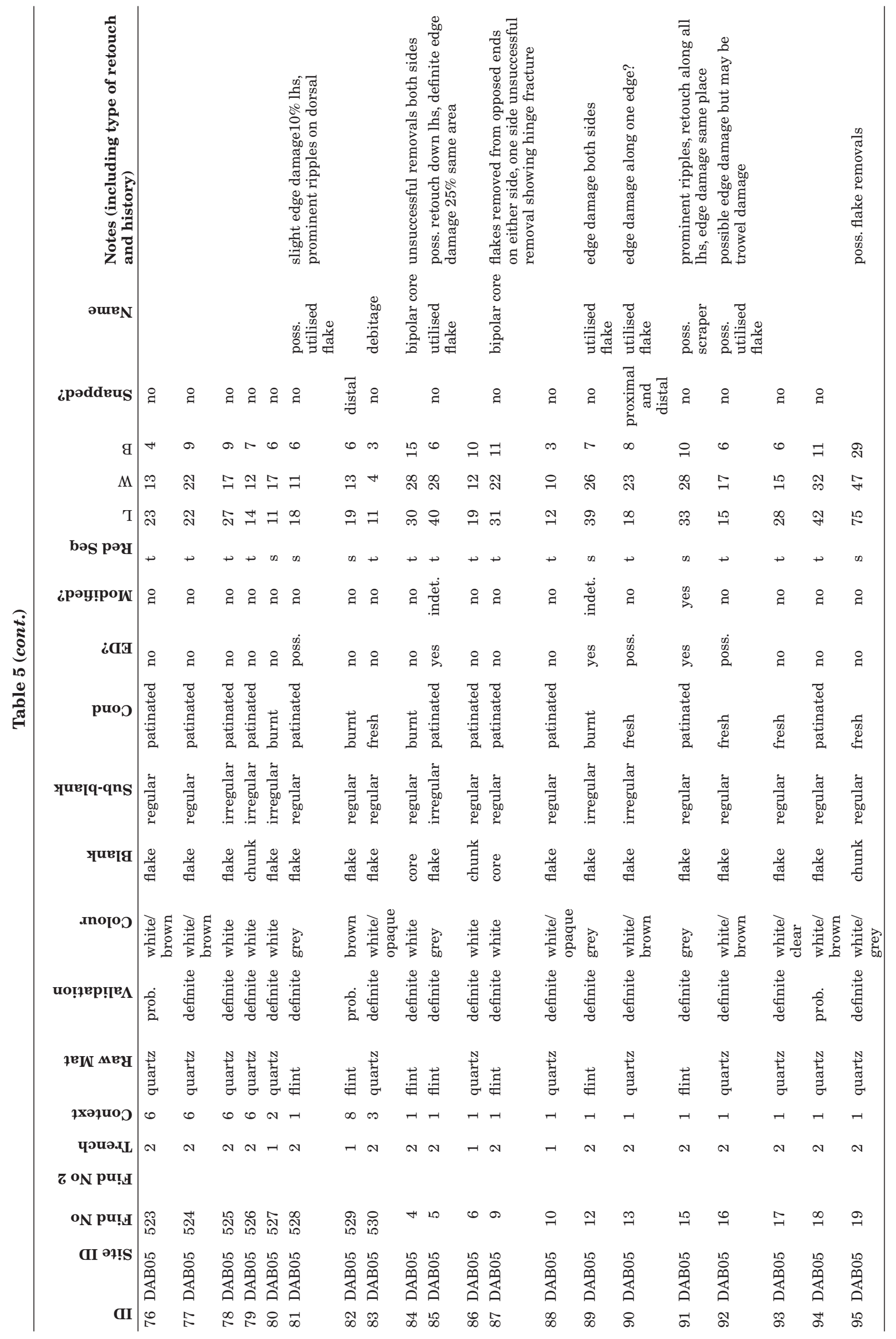


Table 6 Composition of Dunasbroc assemblage

\begin{tabular}{lcccc}
\hline Type & $\begin{array}{c}\text { Flint } \\
\text { (inc. \% of flint) }\end{array}$ & $\begin{array}{c}\text { Quartz } \\
\text { (inc. \% of quartz) }\end{array}$ & $\begin{array}{c}\text { Banded/ agate } \\
\text { (inc. \% of agate) }\end{array}$ & $\begin{array}{c}\text { \% of total } \\
\text { assemblage }\end{array}$ \\
\hline pebble & $\mathbf{1} 3.2 \%$ & $\mathbf{1} 1.6 \%$ & $\mathbf{1} 33.3 \%$ & $3.2 \%$ \\
chunk & $\mathbf{3} 9.7 \%$ & $\mathbf{1 2} 19.7 \%$ & & $15.8 \%$ \\
bipolar core & $\mathbf{3} 9.7 \%$ & & & $3.2 \%$ \\
flake & $\mathbf{2 1} 67.7 \%$ & $\mathbf{4 3} 70.5 \%$ & $\mathbf{2} 66.7 \%$ & $69.5 \%$ \\
blade & $\mathbf{3} 9.7 \%$ & $\mathbf{3} 4.9 \%$ & & $6.3 \%$ \\
chip & & $\mathbf{2} 3.3 \%$ & $\mathbf{3}$ & $2.1 \%$ \\
totals & $\mathbf{3 1}$ & $\mathbf{6 1}$ & & \\
\hline
\end{tabular}

Table 7 Size variation amongst flakes from Dunasbroc

\begin{tabular}{llll}
\hline & $\begin{array}{l}\text { Primary } \\
(\text { average } \mathbf{L} \times \mathbf{W} \times \mathbf{B} \mathbf{~ m m}(\mathbf{N}))\end{array}$ & $\begin{array}{l}\text { Secondary } \\
(\text { average } \mathbf{L} \times \mathbf{W} \times \mathbf{B} \mathbf{~ m m}(\mathbf{N}))\end{array}$ & $\begin{array}{l}\text { Tertiary } \\
(\text { average } \mathbf{L} \times \mathbf{W} \times \mathbf{B} \mathbf{~ m m}(\mathbf{N}))\end{array}$ \\
\hline Flint & & & \\
Regular & $29.2 \times 20.6 \times 11.6(\mathbf{5})$ & $24.8 \times 17.3 \times 8(\mathbf{6})$ & $18.7 \times 15 \times 5.8(\mathbf{9})$ \\
Irregular & $23.75 \times 18 \times 6.25 \mathbf{( 4 )}$ & $31 \times 22.5 \times 8.5(\mathbf{2})$ & $26.75 \times 16 \times 5.75(\mathbf{4})$ \\
Quartz & & & $25 \times 17.9 \times 7.7(\mathbf{3 3})$ \\
Regular & $48.6 \times 31.3 \times 18.3 \mathbf{( 3 )}$ & $35.75 \times 28 \times 15.5(\mathbf{4})$ & $25.6 \times 17.5 \times 8.8(\mathbf{1 6})$ \\
Irregular & & $38.6 \times 27.2 \times 16.2 \mathbf{( 5 )}$ & \\
\hline
\end{tabular}

These are all a similar shape and size, being rectangular, squat and narrow in profile. They all have crushed platforms at both ends, and flakes have been removed from both sides on all three. One is burnt (SF4; illus 67) and was recovered from the topsoil, while the other two are patinated, only one of which (SF86; illus 67) came from a secure context (006), the other (SF9; illus 67) coming from the topsoil.

Bipolar knapping would be expected for the final reduction of small cores, or as a technique applied to smaller pieces of raw material, which would be expected given that pebble flint was used. There is little evidence to suggest that direct percussion was practised on the flint material, although a few flakes and one blade may have prepared, rather than crushed platforms, therefore indicating a more managed knapping technique, for example flakes SF72, SF12 and blade SF33 (illus 67). These are slightly larger pieces (SF72 is a decortical flake) and perhaps indicate that initial pebbles were reduced through direct percussion rather than bipolar knapping alone. The rest of the flint flake assemblage could all have been derived from bipolar knapping.

It is interesting to note that no obvious bipolar working is evident from the quartz assemblage, even though there is evidence of this from other quartz assemblages on Lewis (Warren forthcoming a)). Although there are no obvious cores within the quartz material, there are a few chunks which show isolated flake removals, although these have not been developed into true cores (for example SFs 164a, 168, 19 and 165) and no platform preparation is evident. These chunks are relatively large $(70 \mathrm{~mm}$ length on average) and tabular in form, typical of quarried quartz. The lack of bipolar technique is presumably because there is an adequate supply of quartz material nearby, and quarried chunks could be reduced through direct percussion to remove larger flakes (supported by flake analysis, below).

\subsection{Flake analysis}

Table 7 above shows the size variation of the flakes from the assemblage.

The table indicates that the quartz flakes are on average larger in all dimensions than the flint. They are also on average longer and thinner than the flint flakes, which are more squat and square, a consequence of the raw material morphology and also the knapping techniques utilised. There are a large number of tertiary flakes (those without any cortex) within the quartz assemblage, and a proportionally high number of tertiary flakes in the flint assemblage.

The bulbs shown on the flakes were categorised into four types: absent, indeterminate, diffuse and prominent. Only four flakes of flint (20\% of flint flakes) had prominent bulbs, four were indeterminate and ten $(50 \%)$ were diffuse, suggesting soft-medium percussion. The quartz had a similar proportion of diffuse bulbs, at 19 (45.2\%), although a high number (18) had indeterminate bulbs, a common problem with quartz where successful conchoidal fracture 


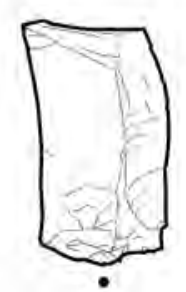

33
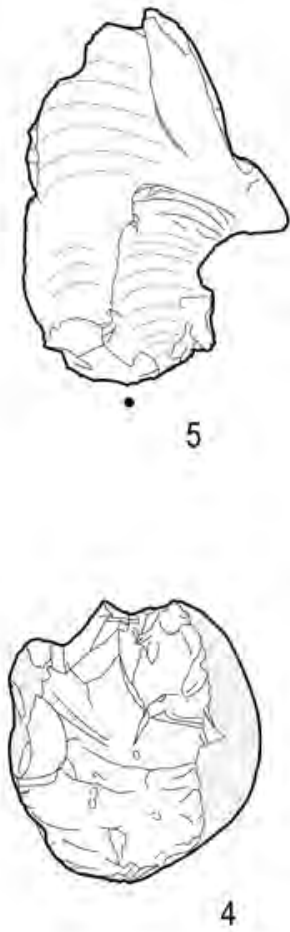

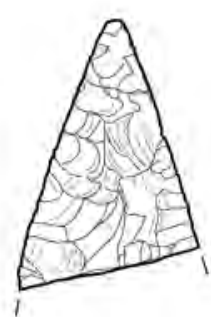

100
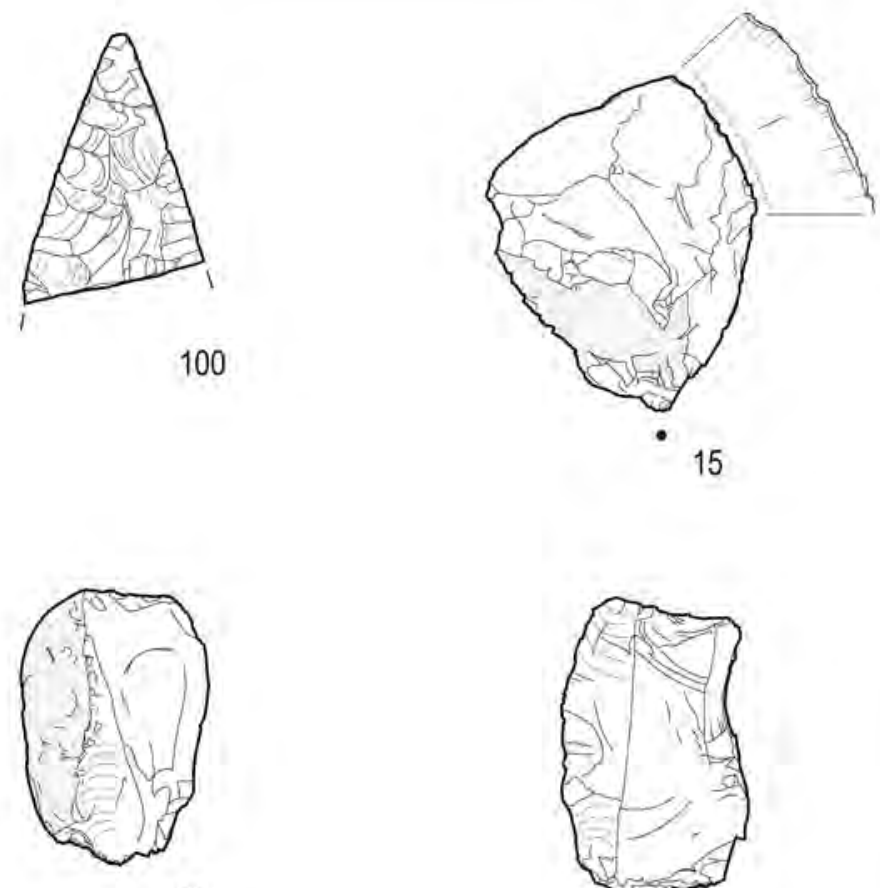

86

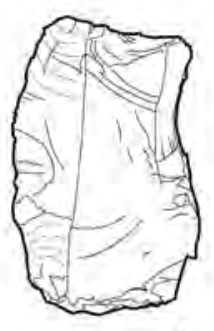

9

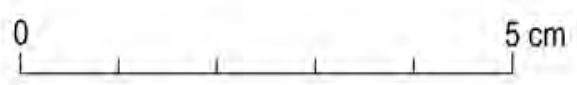

Illus 67 Lithic artefacts from Dunasbroc. SFs 4, 5, 9, 15, 33, $86 \& 100$

is dependent on the quality of the material, and in many cases flakes will not have obvious bulbs or ripples. Five flakes had no visible bulb. Platforms also ranged between simple and crushed examples, with the former being the most frequent for flint and quartz. There are more crushed platforms within the flint flakes than the quartz, again suggesting that bipolar knapping took place with the flint.

The presence of a quartz rejuvenation flake (SF181a from Context 009) indicates that quartz cores and platforms were being managed to some extent.

\subsection{Modified pieces}

Table 8 below shows the pieces with edge damage and modification.

Twenty lithics have either possible or definite edge damage. In general the modified lithics have nibbled retouch down one side and in four cases at the end (SFs 29, 73, 114 and 138). Both regular and irregular flakes have been utilised, and in one case a decortical flake has been possibly retouched and definitely used (SF72). It is clear that all types of flake were therefore used, with no obvious consideration as to the quality of the piece selected, for example SF5 (illus 67).

Only four lithics had definitely been modified by retouch (SFs 15, 22, 100 and 138), three of which have also been used, the other (SF100) may have edge damage but has been snapped. The diagnostic pieces were a possible side-scraper form (SF15; illus 67), a possible point (SF29) and a definite leaf-shaped arrowhead (SF100; illus 67). Three flakes (one is a long blade-like flake) have one serrated lateral edge, all are quartz and it is difficult to say whether 


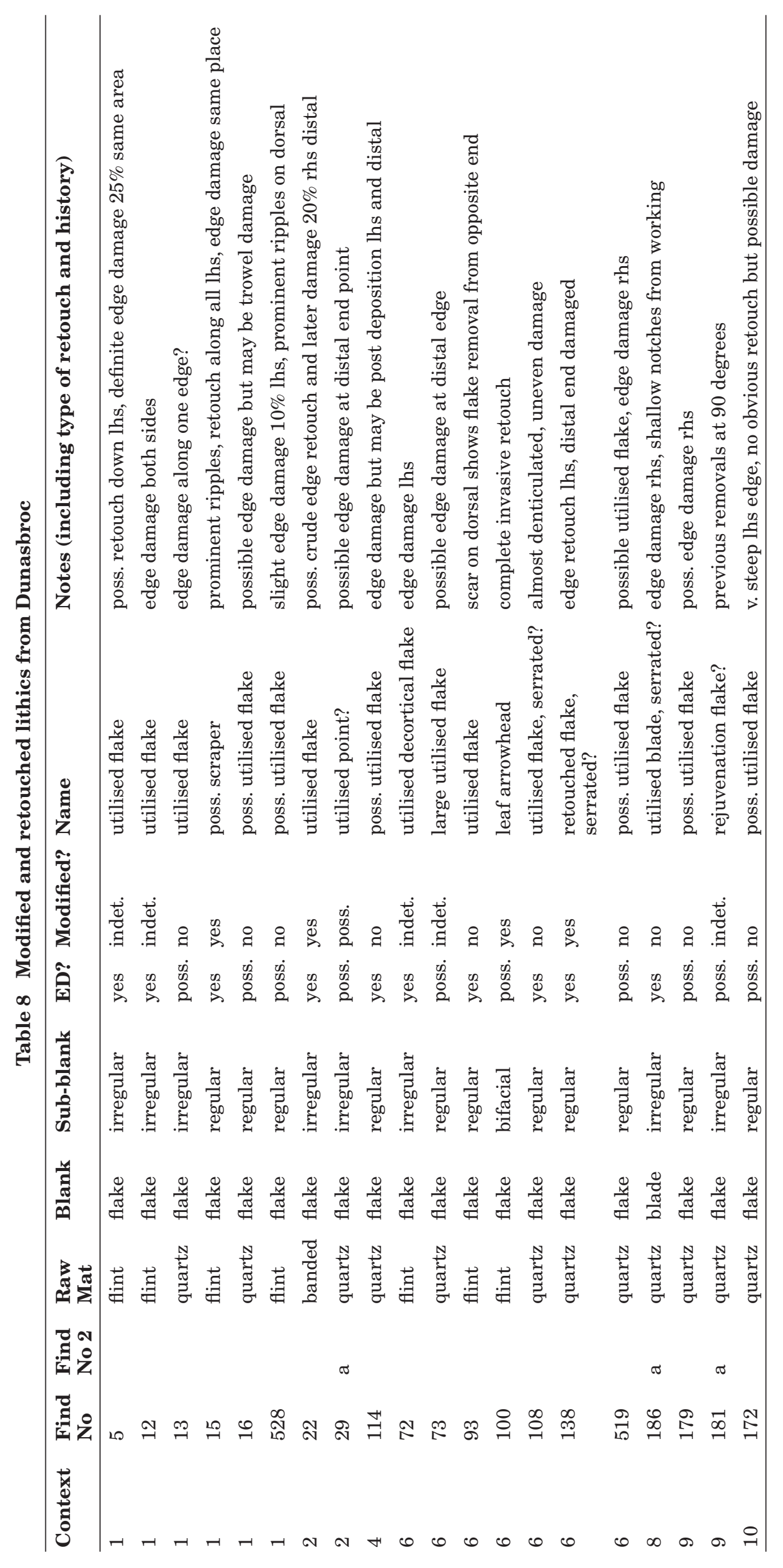




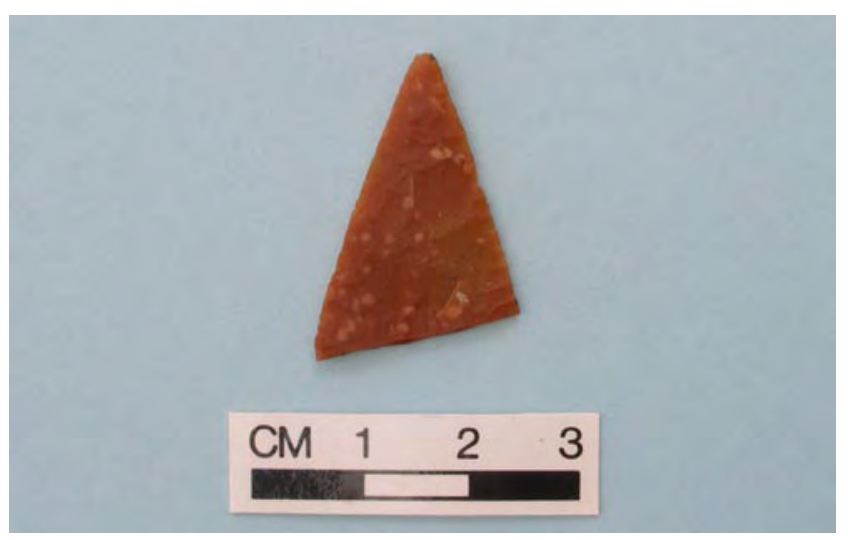

Illus 68 Tip of leaf-shaped arrowhead SF100

the serration was formed through retouch or edge damage, as it is very crude (SFs 108, 138, 186a).

The leaf-shaped arrowhead is made from imported orange flint and although only the distal half is present, it is assumed it has a kite form (illus 68). It has been snapped diagonally along the widest point. There are no obvious notches at the lateral points of the snap to suggest deliberate breakage, although the presence of several impact scars on the surface of the arrowhead indicates that it has been abraded or knocked frequently since its creation.

A long lozenge-shaped arrowhead with an almost identical point was found in 1985 by Dell River, over $3 \mathrm{~km}$ from Dunasbroc, during peat cutting. This was slightly wider, at $23 \mathrm{~mm}$ compared to $19 \mathrm{~mm}$, for the snapped arrowhead found at Dunasbroc. The invasive retouch on both is also similar, although typical of this form of arrowhead. A further leafshaped arrowhead of unknown form was recovered at the base of peat cuttings approximately $700 \mathrm{~m}$ to the south-east of Dunasbroc in 1951, but has subsequently been lost (NMRS no. NB46SE 10).

\subsection{Contextual analysis}

\section{Context 001}

Two cores (SFs 4 and 9, SF4 is burnt) came from the topsoil, along with four chunks and eleven flakes, three of which had edge damage and one with retouch (SF15).

\section{Context 002}

Twelve lithics came from this context, the majority being flakes (only one of which was burnt). One was modified and had edge damage (SF22) and one was possibly retouched with edge damage (SF29).

\section{Context 003}

One chunk, one bald and two flakes came from Context 003. None of the pieces were burnt or had modifications or edge damage.

\section{Context 004}

Two flakes came from this context; one had edge damage (SF114).

\section{Context 006}

The majority of the lithics came from this context (SF52, being $54.7 \%$ of total assemblage). Eight pieces were burnt, with a further five possibly burnt. One of the burnt pieces had edge damage (SF72). Of the unburnt lithics, five had definite edge damage (SFs $72,93,100,108,138)$, and two had possible edge damage (SF73, 519). There were also two retouched flakes (SF100 and SF138).

The remaining lithics had a mixture of conditions, and no obvious patterns emerged from the analysis. All types of lithic present in the total assemblage were represented in this context.

\section{Context 008}

A total of three flakes (one burnt, SF529) and one blade were present.

\section{Context 009}

Again three flakes were present, two with possible edge damage (SF179 and SF181a).

\section{Context 010}

One flake was present, which had signs of possible edge damage (SF172).

\subsection{Conclusions}

The assemblage demonstrates the use of bipolar and platform reduction techniques, on flint and quartz respectively. It is suggested that reduction took place away from the contexts excavated, given the almost total lack of debitage smaller than $10 \mathrm{~mm}$. The lack of small debitage is a common indicator for early Neolithic working on the east coast of Scotland (Warren forthcoming a)). The mixing of burnt and unburnt pieces in certain contexts shows that burning of the lithics did not occur in situ and that the material was therefore redeposited. This would explain the lack of debitage, as smaller pieces may not have been transported when redeposited.

All the utilised pieces are regular and irregular flakes, the retouched pieces have been semiabruptly modified along one lateral edge, the classic 'nibbling' noted by Warren (forthcoming b)), and probably used mainly for cutting, although some scraping would also have been undertaken (possible side-scraper present). The use of all types of flake shows that there was apparently little concern for the form, and they would have been quickly made and used, again this trait has been detected from early Neolithic assemblages on the east coast of the mainland (ibid), although the opportunistic nature 
of this assemblage is common throughout the Neolithic (Edmonds 1995).

A further parallel with early Neolithic working is the frequency of utilised pieces without retouch, overall the assemblage would fit into either early or later Neolithic typologies. The assemblage lacks a number of early Neolithic tool types however, such as fabricators, formal convex scrapers and plano-convex knives (see Edmonds for full discussion on these tool types), although the quartz flakes are longer than the flint flakes, and many have edge damage along one side. There is evidence of the quartz being knapped in a more controlled fashion, with a softmedium hammer using direct percussion.

Leaf-shaped arrowheads are typical Early Neolithic indicators for Scotland and Britain (Green 1980), with examples from Scotland dating to the earliest part of the fourth millennium (associated with contexts which have been radiocarbon dated; Warren forthcoming a)), although 'kiteshaped' arrowheads, are usually associated with the later part of the early Neolithic (ibid), and a Later Neolithic date cannot be ruled out. Many of these arrowheads have been found in funerary or ritual contexts, although also used for hunting and warfare. The form of these arrowheads suggests that they would have been effective tools for both hunting and warfare, but their beautiful shape and tactile form, along with their rarity (especially in Lewis) also implies they would have been given a strong social importance (Edmonds 1995, 46). This importance would go beyond the physical appearance of the piece, as it would take on symbolic properties relating to where it came from and how it was used, carrying with it associations of specific people or places.

Ongoing survey work in the Ness area has recovered further burnt flint and quartz lithic scatters in the immediate local, a few hundred metres to the south of this site on a similar natural promontory, although these are still to be analysed (Barrowman, CS forthcoming a) and b)). There are also known quartz assemblages and knapping floors to the north of the area on the eroding coastal machair at Cross, Swainbost and Habost (Cowie 1995; Barrowman, C S in prep), and also in areas where the peat moor is eroding at Skigersta and Cross (ibid). Flint and quartz industries utilising bipolar and platform techniques are known from Olcote, Breasclete (Warren forthcoming b)) and Barra (Wickham-Jones 1995), and quartz assemblages are found on numerous sites in Lewis, such as Dalmore (Sharples in prep), Northton (Simpson 1976), Barvas (Cowie in prep), Calanais (Ashmore in prep) and Berie (Lacaille 1937), all dating to the Neolithic and Bronze Age.

There is no doubt that the lithics from Dunasbroc are an invaluable addition to a small yet growing body of prehistoric flint and quartz assemblages in Lewis from datable contexts.

\subsection{Flaked lithics from STAC 2004, surface finds (see table 9 for details)}

A total of five flaked lithics were recovered from surface finds on two stack sites. Three flakes of quartz were recorded from Dunasbroc. Two flakes of flint and one flake of quartz were recovered from Dun Arnistean.

The Dunasbroc surface finds correspond with the excavated assemblage. Two of the flakes are long and have a similar form, with one sharp lateral edge. One of the pieces (SF4B) has been utilised, although there is no modification visible.

The lithics from Dun Arnistean are also prehistoric: one of the flint flakes appears to be a rejuvenation piece, and has two blade scars on the dorsal face. This face is fairly messy, which may be the reason for a thicker removal using the same platform, to create a fresh working face. The piece of quartz from the same site may have been modified along one lateral edge, and there are signs of edge damage at this point. 


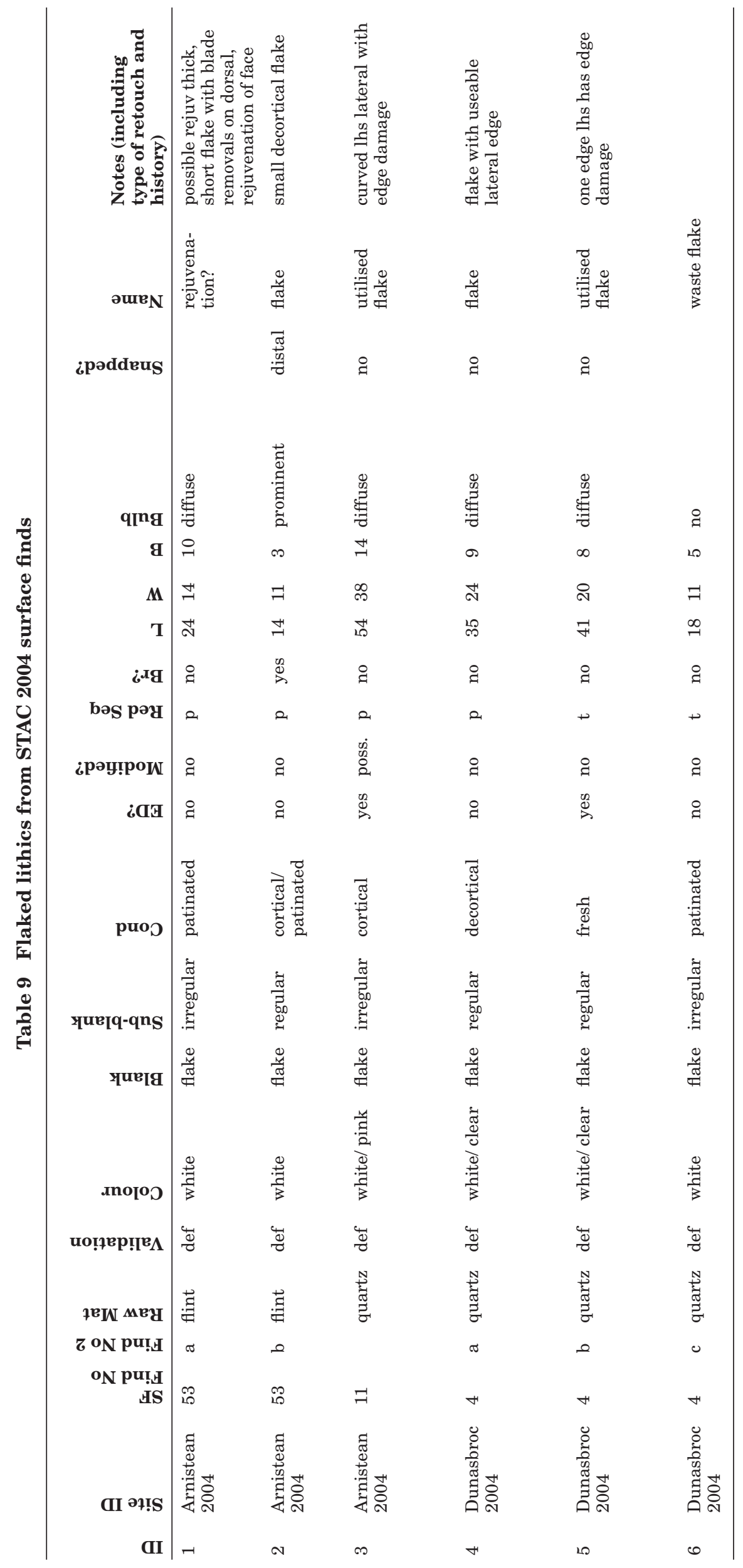




\section{APPENDIX 5: DUNASBROC 2005: STONE ARTEFACTS REPORT by Chris Barrowman}

\subsection{Discussion}

A total of 28 stones were recovered from the excavation at Dunasbroc, and all are pebbles from local stone types (Lewisian gneiss, sandstone, quartz and quartzite; table 10). These types are all available from the immediate vicinity.

Although the majority of the stones show no alteration or damage, there are four stones which show signs of edge damage (SFs 039, 081, 140 and 155). This consists of small peck marks, the result of using the stones for light hammering, such as knapping lithics. This damage varies from slight pecking along the edges of an oval-shaped stone (SF155), through to light pecking on one end of an elongated stone (SF039), and pecking on both ends of a similar elongated stone (SF081). Stone SF140 shows the most alteration, with both ends heavily pecked and worn through longer term use. This quartzite stone is unlike the other three in that it has an irregular morphology (shaped like an hourglass), and the waist shows signs of polish, possibly through handling rather than rubbing.

Polished surfaces are present on two examples

Table 10 Dunasbroc 2005 stone artefacts catalogue

\begin{tabular}{|c|c|c|c|c|c|}
\hline Trench & Context & Find No. & $\mathbf{L} \times \mathbf{W} \times \mathbf{B}(\mathbf{m m})$ & Stone type & Description \\
\hline 1 & 004 & 117 & $70 \times 43 \times 33$ & Gneiss & Heat-cracked pebble \\
\hline 1 & 012 & 155 & $102 \times 79 \times 54$ & Sandstone & Pebble, slight edge damage \\
\hline 1 & 008 & 161 & $32 \times 25 \times 18$ & Sandstone & Pebble, no damage \\
\hline 1 & 008 & 163 & $110 \times 79 \times 49$ & Sandstone & Pebble, no damage \\
\hline 1 & 004 & 039 & $94 \times 59 \times 27$ & Sandstone & Pebble, slight pecking on one end \\
\hline 1 & 004 & 040 & $97 \times 82 \times 36$ & Sandstone & Pebble, no damage \\
\hline 1 & 004 & 120 & $73 \times 55 \times 25$ & Quartz & Pebble, no damage \\
\hline 2 & 006 & 140 & $45 \times 36 \times 32$ & Quartzite & $\begin{array}{l}\text { Irregular shaped pebble with uniform } \\
\text { pecked damage at both ends. Smooth } \\
\text { waist possibly through handling. }\end{array}$ \\
\hline 2 & 006 & 136 & $67 \times 63 \times 24$ & Gneiss & Pebble, no damage \\
\hline 2 & 006 & $136 b$ & $34 \times 20 \times 11$ & Gneiss & Pebble with flake removal, no damage \\
\hline 2 & 006 & 065 & $42 \times 37 \times 16$ & Gneiss & Pebble, polished on one surface \\
\hline 1 & 004 & 123 & $55 \times 40 \times 28$ & Quartz & Pebble, no damage \\
\hline 2 & 006 & 064 & $46 \times 34 \times 20$ & Quartz & Pebble, no damage \\
\hline 2 & 006 & 124 & $54 \times 52 \times 53$ & Gneiss & Heat cracked pebble \\
\hline 2 & 006 & 063 & $35 \times 35 \times 15$ & Gneiss & Pebble, polished one surface \\
\hline 2 & 006 & 077 & $59 \times 36 \times 20$ & Gneiss & Pebble, no damage \\
\hline 2 & 006 & 153 & $41 \times 29 \times 18$ & Gneiss & Pebble, no damage \\
\hline 1 & 004 & 159 & $34 \times 32 \times 19$ & Quartz & Pebble, no damage \\
\hline 2 & 006 & 081 & $37 \times 32 \times 28$ & Quartzite & Pebble, pecked damage on both ends \\
\hline 2 & 006 & 105 & $19 \times 19 \times 3$ & Sandstone & Flake, no edge damage \\
\hline 2 & 006 & 085 & $32 \times 30 \times 16$ & Gneiss & Pebble, water worn, no damage \\
\hline 1 & 004 & 118 & $37 \times 34 \times 30$ & Gneiss & Heat cracked stone \\
\hline 1 & 004 & $118 b$ & $26 \times 21 \times 20$ & Quartz & Heat cracked stone \\
\hline 1 & 004 & 116 & $51 \times 50 \times 43$ & Gneiss & Heat cracked stone \\
\hline 1 & 002 & 041 & $56 \times 37 \times 24$ & Sandstone & Pebble, no damage \\
\hline 2 & 006 & 062 & $30 \times 22 \times 14$ & Gneiss & Pebble, water worn, no damage \\
\hline 2 & 006 & 076 & $45 \times 40 \times 17$ & Quartzite & Pebble, no damage \\
\hline 1 & 002 & 031 & $29 \times 21 \times 12$ & Gneiss & Heat cracked stone \\
\hline
\end{tabular}


Table 11 Stone from STAC 2003/ 2004, surface finds

\begin{tabular}{|c|c|c|c|c|}
\hline Site & Find No. & $\begin{array}{l}\mathbf{L} \times \mathbf{W} \times \mathbf{B} \\
(\mathbf{m m})\end{array}$ & Stone type & Description \\
\hline Dun Arnistean 2004 & 10 & $113 \times 52 \times 37$ & $\begin{array}{l}\text { Gneiss, high feldspar } \\
\text { content }\end{array}$ & $\begin{array}{l}\text { Elongated hammer stone with uniform } \\
\text { pecked damage at both ends }\end{array}$ \\
\hline Dun Arnistean 2004 & 12 & $97 \times 50 \times 29$ & Gneiss & Smooth beach pebble, no obvious damage \\
\hline Dun Arnistean 2004 & 15 & $41 \times 31 \times 27$ & Gneiss & $\begin{array}{l}\text { Small round beach pebble with possible } \\
\text { polish on one end }\end{array}$ \\
\hline Dun Arnistean 2004 & 20 & $28 \times 24 \times 20$ & $\begin{array}{l}\text { Sandstone, coarse } \\
\text { grained }\end{array}$ & Natural pebble, no damage visible \\
\hline Dun Arnistean 2004 & 55 & $88 \times 73 \times 32$ & Gneiss & $\begin{array}{l}\text { Heart-shaped beach pebble. No obvious } \\
\text { damage or polish. }\end{array}$ \\
\hline Dun Arnistean 2004 & 57 & $125 \times 49 \times 32$ & $\begin{array}{l}\text { Gneiss, mostly feldspar } \\
\text { with white bands } \\
\text { running lengthways }\end{array}$ & $\begin{array}{l}\text { Elongated hammer stone, with uniform } \\
\text { pecking both ends. Flake scar on widest end. }\end{array}$ \\
\hline Dun Arnistean 2004 & 59 & $44 \times 35 \times 18$ & Sandstone, fine grained & Natural pebble \\
\hline Dun Arnistean 2004 & 62 & $179 \times 120 \times 24$ & Sandstone & $\begin{array}{l}\text { Large flaked pebble, with edge damage } \\
\text { distal end and a third of either side at same } \\
\text { end }\end{array}$ \\
\hline Dun Arnistean 2004 & 63 & $137 \times 88 \times 48$ & Gneiss & Natural irregular shaped pebble, no damage \\
\hline Dun Arnistean 2004 & 67 & $101 \times 80 \times 29$ & Gneiss & Natural pebble, no damage \\
\hline Dun Arnistean & 70 & $142 \times 91 \times 20$ & Gneiss & $\begin{array}{l}\text { Natural pebble, large break at one end, } \\
\text { probably natural damage }\end{array}$ \\
\hline Dun Arnistean 2004 & 75 & $111 \times 80 \times 58$ & Gneiss & Natural pebble, no damage \\
\hline Dun Arnistean 2004 & 78 & $46 \times 25 \times 11$ & Gneiss & Small fragment, natural \\
\hline Dun Arnistean 2004 & 81 & $49 \times 39 \times 24$ & Gneiss & Small pebble, high polish on one face \\
\hline Dun Arnistean 2004 & 82 & $77 \times 32 \times 17$ & Gneiss & Elongated pebble, slight abrasion on one end \\
\hline Luchruban 2003 & $\begin{array}{l}\text { WE1068/ } \\
\text { SMR } 457\end{array}$ & $99 \times 73 \times 68$ & Gneiss & $\begin{array}{l}\text { Coarse rubbing stone. Irregular shaped } \\
\text { pebble, heavy abrasion from rubbing/ } \\
\text { pecking on both ends and around whole } \\
\text { circumference. }\end{array}$ \\
\hline Stac a Chasteil 2004 & 1 & $114 \times 85 \times 53$ & Gneiss & $\begin{array}{l}\text { Irregular shaped pebble, heavy abrasion on } \\
\text { both ends. Faces flaking off through onion- } \\
\text { skin weathering }\end{array}$ \\
\hline Dunasbroc 2004 & 11 & $113 \times 48 \times 36$ & Sandstone & $\begin{array}{l}\text { Elongated pebble with slight abrasion on } \\
\text { either end }\end{array}$ \\
\hline Dunasbroc 2004 & 13 & $282 \times 222 \times 50$ & Gneiss, green & $\begin{array}{l}\text { Large oval beach stone, with one perfectly } \\
\text { flat surface which has been ground flat. } \\
\text { Opposite face has slight depression through } \\
\text { grinding and polish. Natural abrasion } \\
\text { present along edges, flakes have been split } \\
\text { off one end from flat surface. }\end{array}$ \\
\hline
\end{tabular}

(SF063 and SF065), this is visible on only one surface of both stones, and may be the result of burnishing unfired pottery, leather or wood. The stones were recovered from the same context (006).

There are six fragments of stone which have undergone fire-cracking (SFs 117, 124, 118, 118b, 116 and 031). Four of these are from Context 004, one from 002 and the other from 006.

\subsection{Contextual analysis}

The natural, undamaged pebbles were recovered from Context 004 in Trench 1 and Context 006 in Trench 2. Three of the used pebbles were also recovered from these contexts, SF081 and SF140 which show damage on both ends were from Context 006 in Trench 2, and SF039 which has damage on one end was from Context 004 in Trench 1. The pebble with slight edge damage along its sides (SF155) was recovered from Context 012 in Trench 1 . It is interesting to note that the two pebbles showing signs of most wear come from Context 006, where the majority of the other artefacts were recovered. The two stones which have evidence of polish (SF063 and SF065) were also found in this context.

Four of the fire-cracked stones came from Context 004 in Trench 1, supporting the hypothesis that this 
context is the result of 'indirect or secondary consequences of burning' (McHardy 2005b), 17). The remaining two were recovered from Contexts 002 and 006 .

Two coarse stone tool surface finds were recovered in 2004; these are discussed below.

\subsection{Stone from STAC $2003 / 2004$}

The stone surface finds from the STAC sites surveyed in 2003 and 2004 are similar in nature and form to the assemblage from the Dunasbroc 2005 excavations (table 11). They are all based on either Lewisian gneiss or sandstone, and are mainly natural beach pebbles.
The utilised stones consist of a small range of types The examples from Dun Arnistean consist of three elongated hammer stones, two of which (SF10 and SF57) have been used for end-on hammering of a hard material, possibly quartz. The pecking and resultant damage on either end of both stones has left an almost flat end. The third stone has slight abrasion but has not been used to the same extent (SF82).

There are two smaller, round pebbles (SF15 and SF81), both of which have one surface polished, the result of burnishing leather-hard pottery, leather or similar material. Finally, a large flake of sandstone, akin to a crude knife or simple chopping tool, has heavy edge damage along its end and lateral edges.

A heavily abraded, irregularly shaped pebble of

Table 12

Coarse mineral material $(<10 \mu \mathrm{m})$

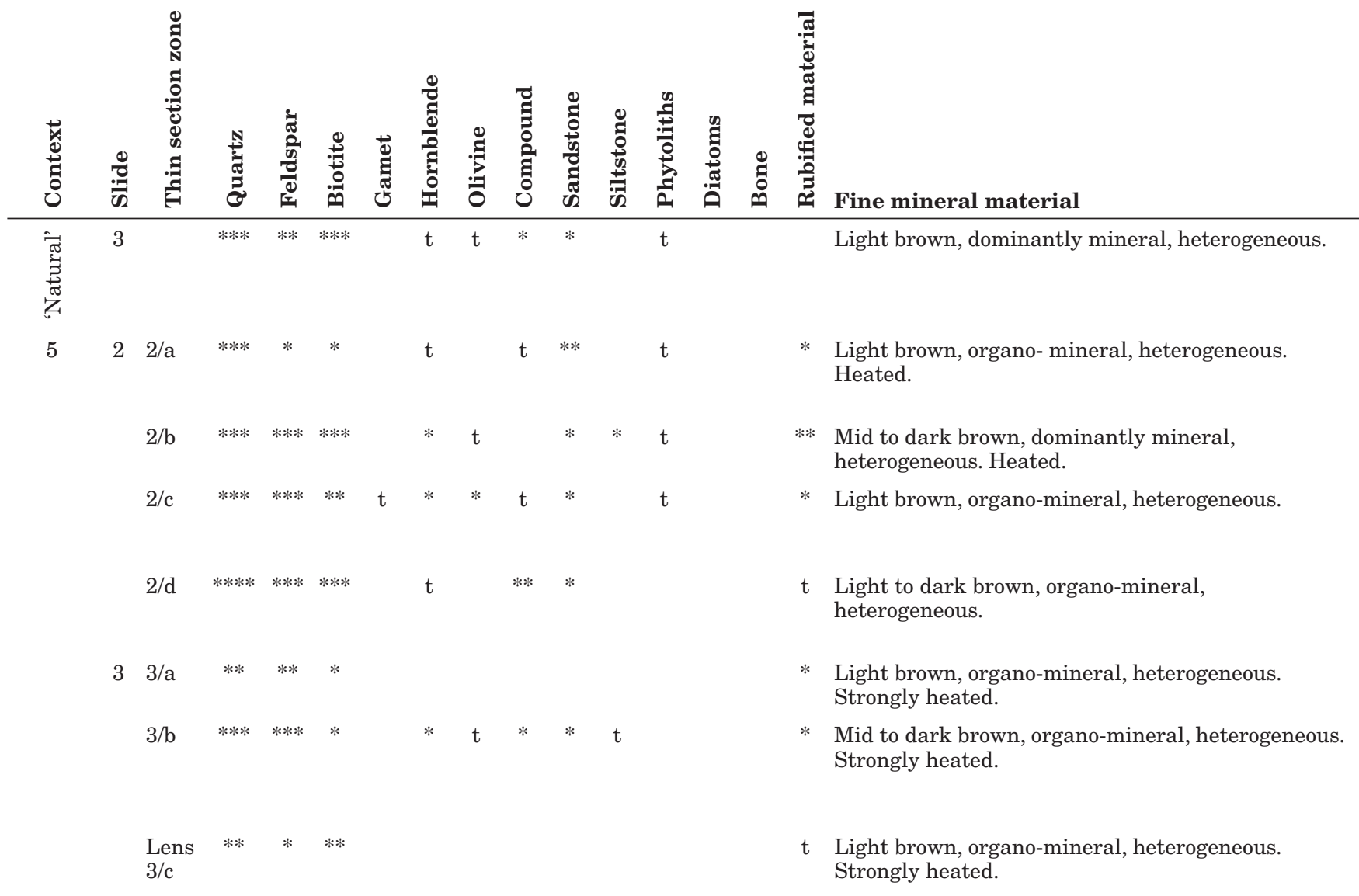

Frequency class refers to the appropriate area of section (Bullock et al 1985): t Trace; * Very few; ** Few; *** Frequent/common; ****Dominant/Very dominant

Frequency class for textural pedofeatures (Bullock et al 1985): t Trace; * Rare; ** Occasional; *** Many 
Lewisian gneiss was recovered from Luchruban (WE1068/SMR457). This has been subject to rubbing and pounding, the resultant wear and abrasion forms a band approximately $20 \mathrm{~mm}$ wide along its entire circumference. A similar stone tool was recovered from Stac a' Chaisteal, although the heavy abrasion is restricted to either end in this case.

Two coarse stone tool surface finds were recovered from Dunasbroc in 2004. The first is an elongated pebble (SF11) with slight edge damage on either end, although this has not been utilised for heavy work. The second find is very unusual and no known parallel has been found in the archaeological record. It is a very large beach pebble of gneiss with one completely flat surface. The degree of working and grinding involved to form such an even and flat surface would have been comparable to that shown through stone axe-polishing. It is difficult to imagine the function of this piece, some form of working platform for the preparation of skins or leather, or wood-working may be a possibility. A baking stone cannot be ruled out, although there are no signs of burning. It may be that the end function of the piece is irrelevant, and it is the working and forming of the stone itself which was significant. The amount of work involved to shape it would certainly give it a high value, and imbue the artefact with strong symbolic references.

Micromorphology of Slide 2 from Dunasbroc

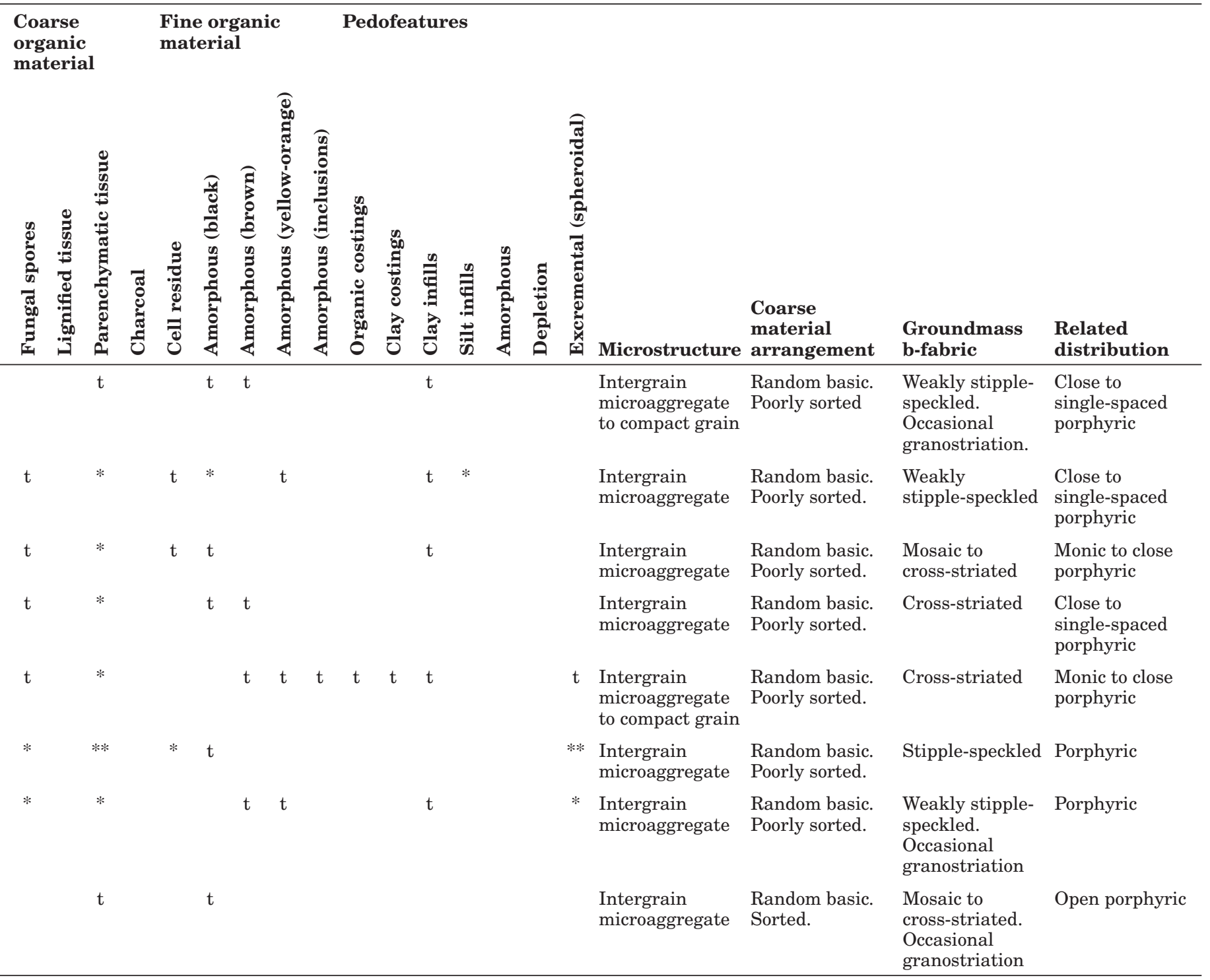




\section{APPENDIX 6: BOTANICAL REPORT FROM DUNASBROC by Susan Ramsay}

\subsection{Summary}

Excavation of a number of archaeological features on Dunasbroc, a steep-sided stack in the parish of Barvas, Isle of Lewis, provided 17 bulk samples and 11 small finds of charcoal for analysis. Evidence was recovered for the utilisation of a diverse range of wood fuel types on the stack, although it is probable that none of these wood types was growing on the stack itself. The wood could have been collected from woodland on the mainland or in the form of driftwood from nearby shores. The spruce/larch charcoal from the site must have been collected as driftwood as these trees are not native to Scotland. Evidence was also found for the utilisation of cereals, particularly six-row barley, either for food or as some form of ritual deposit. There is also some indication that a wicker structure or object may have been burned within the area defined by Trench 2 .

\subsection{Introduction}

The following archaeobotanical report details the processing, analysis and interpretation of environmental samples recovered during the excavation of archaeological features recorded at Dunasbroc, a steep-sided stack in the parish of Barvas, Isle of Lewis (McHardy 2005a). This excavation was part of the ongoing STAC research project, which is funded by Historic Scotland, Comhairle nan Eilean Siar and The Russell Trust. The excavations comprised two trenches: Trench 1 was laid out across the top of the plateau and down the landward side of the stack, whilst Trench 2 was opened across an eroding section, with pottery visible within the eroded face.

Two main objectives were set for the outcomes of this archaeobotanical investigation:

- To identify and interpret botanical evidence in terms of the utilisation of local environmental resources for food, fuel, construction or other purposes.

- To recover carbonised macroplant material for AMS radiocarbon dating.

It was anticipated that analysis of the archaeobotanical assemblages recovered during the excavations on Dunasbroc, Isle of Lewis, would add to the information gained from the archaeological excavation and other specialist analyses, and would aid in the understanding of human activity in this remote location.

\subsection{Methodology}

Samples were all from free-draining contexts that were highly unlikely to have retained any waterlogged remains contemporaneous with the occupation of the site. Consequently, the larger samples were floted for the recovery of carbonised remains, although the small finds were not processed prior to identification taking place. The dried flots and retents from the bulk samples were sorted using low-power microscopy, and all seeds, plant macrofossils (both carbonised and uncarbonised) and charcoal fragments greater than $c 5 \mathrm{~mm}$ were identified from the samples examined in order to give a good representation of the range of taxa present. For each sample, estimation was made of the total volume of carbonised material present and modern contaminants were scored using a scale of 1-3 'plus' marks. Charcoal was initially studied at variable magnifications of between $\times 4$ and $\times 40$ to observe the anatomy of the transverse section. Subsequently the internal wood anatomy in radial longitudinal and transverse longitudinal section was observed at $\times 200$ magnification using the reflected light of a Zenith Metam-P1 metallurgical microscope. Identification was by comparison with the text and photographs in Schweingruber (1990).

Cereal grains and other seeds were identified at variable magnifications of between $\times 4$ and $\times 40$. Identification was by reference to the extensive modern reference collection at Glasgow University and to Beijerinck (1947), Jacomet (1987) and Zohary \& Hopf (2000). Higher plant nomenclature follows Stace (1997) apart from cereals, which conform to the genetic classifications of Zohary \& Hopf (2000).

\subsection{Results}

The results are shown in table 13 (for bulk sample results) and table 14 (for small finds). Where a context had more than one bulk sample taken, these results were added together and presented as a single data column in the results table, for ease of interpretation. The samples included within each context are recorded in the table. No modern seeds were recovered from any of the samples analysed.

\section{Trench 1}

Context 001 was topsoil and contained no identifiable carbonised remains, ie was essentially sterile when considering archaeobotanical evidence. Under Context 002, which lay directly beneath the turf and covered most of the plateau, lay 004, a sandy clay 
layer that extended over the width of the trench and was thought to be rich in ash during excavation. The carbonised assemblage recovered was very diverse, with charcoal of birch, hazel, heather type, spruce/ larch and willow all present, along with cereal grains, including hulled six-row barley. In addition, there was evidence for the burning of turf in the form of grass/sedge stems, underground rhizomes and weed seeds of dock and chickweed/mouse-ear. The carbonised remains from 004 suggest detritus from a hearth, with some indication of food preparation or ritual deposition of grain. The turf remains may have come from turves burnt on the fire or from the original turf surface of the stack itself. Below Context 004 lay a sandy clay layer 014, which showed evidence of burning and may have been a floor surface. This context contained charcoal of birch, heather and spruce/larch, together with several cereal grains that were all well enough preserved to be identifiable as six-row hulled barley. This charcoal assemblage could have come from a fire built directly on the floor surface, with the cereal grains perhaps only having been exposed to moderate heat on the floor near the fire, rather than having been in the heart of the fire itself. This could explain why the cereal grains are all well preserved. Context 005 lay under 004 and was thought to represent natural subsoil with evidence for burning. Significant numbers of charcoal fragments were recovered from this Context, with birch and spruce/larch both present. A few cereal grains were recorded, with six-row barley and also a single grain of $\mathrm{cf}$ emmer/spelt wheat also identified. Again, this suggests hearth waste and possibly the preparation or deposition of food on the site. Contexts 008 013 and 022 , associated with the remains of Walls A and B, together with Context 012 (the fill of linear feature 011), contained broadly similar carbonised assemblages with heather type and spruce/larch type or indeterminate conifer charcoal present. Occasional grains of six-row barley and rhizomes were also recorded. The only other addition to the carbonised assemblage was found in 008, which also contained rowan-type charcoal; the only occurrence of this type on the site. The lack of charcoal from deciduous trees is notable in these contexts and may suggest that the charcoal present in association with the walls had a different origin from that found elsewhere on the site, either in terms of the original reason for the burning or through representing a different episode of burning.

\section{Trench 2}

The five contexts $(003,006,009,010,020)$ analysed from Trench 2 contained very similar assemblages of carbonised remains. Charcoal was generally of birch, heather type and willow with occasional pieces of hazel in Contexts 006 and 009. The small finds of charcoal (table 14) all came from Context 006 and were overwhelmingly of birch, with lesser quantities of willow and a single occurrence of hazel.
The only cereals from Trench 2 came from Context 006 and were identifiable mainly to six-row hulled barley, with a few further identifiable to the hulled variety. This is in keeping with the other finds of cereal from the site. In addition, a single fragment of hazel nutshell was also recorded from Context 006. During excavation, Context 006 also produced numerous artefactual finds, including pottery, flint, bone and a leaf-shaped arrowhead.

\subsection{Discussion}

The carbonised assemblage from Dunasbroc was much more diverse than would have been expected considering the exposed and barren nature of the present-day stack. It seems unlikely that even in the past the stack could have supported trees of any size. Any trees that did manage to survive would have been extremely stunted and unlikely to have provided much in the way of fuel or timber for construction. Therefore, it is considered likely that most, if not all, of the tree charcoal recovered from the site was brought there, either from the mainland or collected as driftwood from mainland shores near the stack or from the base of the stack itself. The charcoal from broadleaved taxa is representative of native species that could have grown on land close to the stack, although the diversity of types may suggest that at least some of this material was collected as driftwood that had arrived from further afield. More definitive evidence for the utilisation of driftwood comes in the form of the evidence for non-native spruce/larch charcoal in Trench 1 . Neither spruce nor larch would have grown in Scotland prior to the planting of these species within the last 200 years or so, initially as specimen trees on large estates and subsequently as commercial forestry plantations. Therefore, as this site is thought to be prehistoric in date, the spruce/larch charcoal must have come from collected driftwood. The practice of utilising driftwood for fuel and even construction purposes seems to have been widespread in the Western and Northern Isles throughout recorded human occupation of these areas (Dickson 1992). It is impossible to determine exactly where the driftwood came from but the most likely sources are North America or northern Europe. It was notable that no evidence for spruce/larch or any other coniferous type was present in Trench 2 . This is in stark contrast to Trench 1, where spruce/larch or indeterminate conifer charcoal occurs in almost every context examined and suggests that different activities were taking place between the areas of Trench 1 and Trench 2 . This contrast between the carbonised remains recovered from each trench is also highlighted by the fact that all but one of the contexts from Trench 2 contained willow charcoal, whereas only one context from Trench 1 contained this charcoal type. This could indicate that dwarf willow once grew on the stack and was used for fuel 


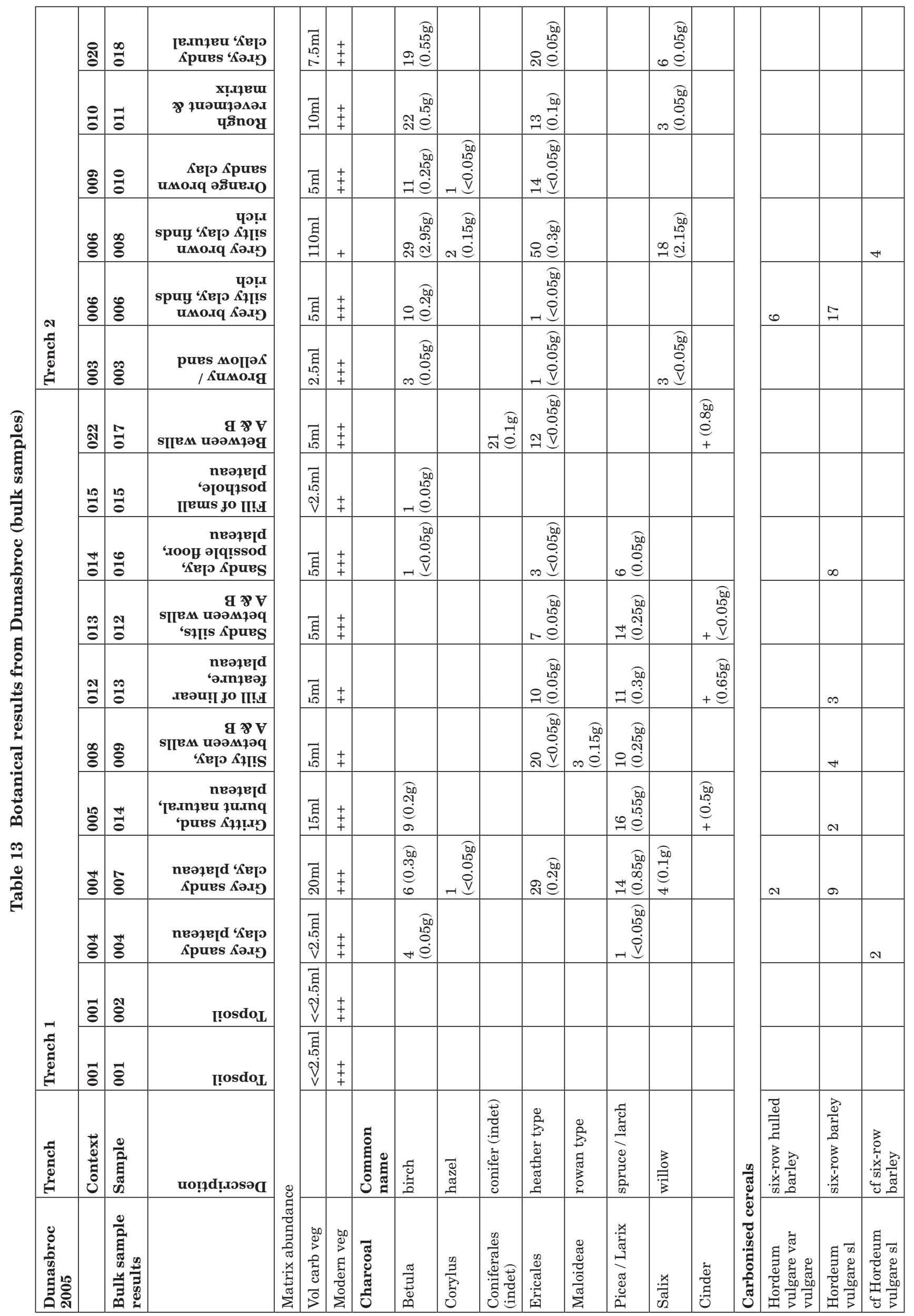




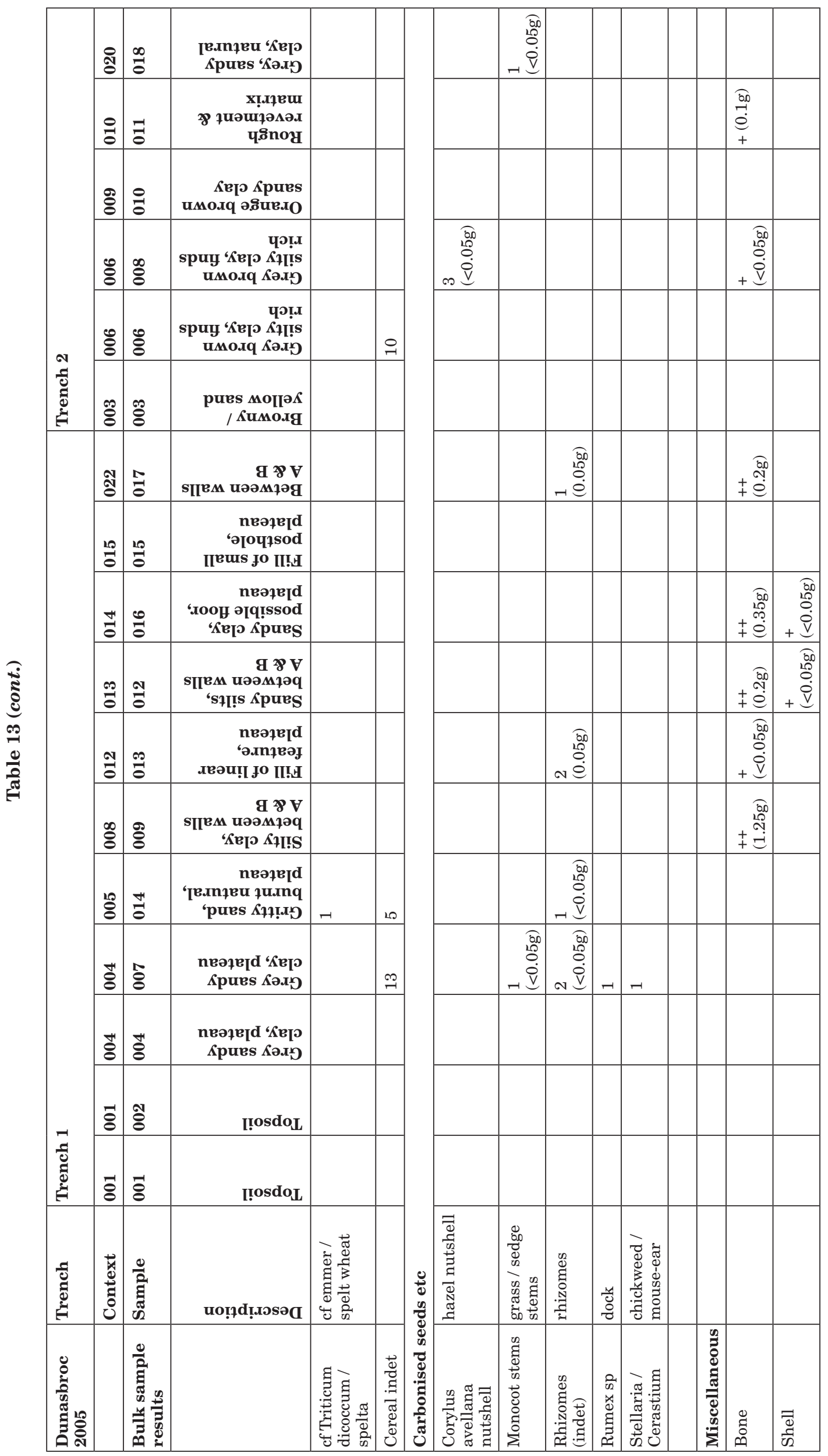


Table 14 Dunasbroc small find results and charcoal taxa

\begin{tabular}{cccccc}
\hline \multicolumn{2}{c}{ Dunasbroc Small Find Results } & \multicolumn{3}{c}{ Charcoal Taxa } \\
Small Find & Context & Trench & Betula & Corylus & Salix \\
\hline 45 & 006 & $\operatorname{Tr} 2$ & $3(0.3 \mathrm{~g})$ & & \\
49 & 006 & $\operatorname{Tr} 2$ & $1(0.05 \mathrm{~g})$ & & $4(0.6 \mathrm{~g})$ \\
51 & 006 & $\operatorname{Tr} 2$ & $3(0.35 \mathrm{~g})$ & \\
59 & 006 & $\operatorname{Tr} 2$ & $2(0.35 \mathrm{~g})$ & $1(0.1 \mathrm{~g})$ & $1(0.15 \mathrm{~g})$ \\
78 & 006 & $\operatorname{Tr} 2$ & $3(0.7 \mathrm{~g})$ & \\
131 & 006 & $\operatorname{Tr} 2$ & $3(1.45 \mathrm{~g})$ & & $1(0.1 \mathrm{~g})$ \\
137 & 006 & $\operatorname{Tr} 2$ & $3(1.0 \mathrm{~g})$ & $3(0.15 \mathrm{~g})$ \\
148 & $\operatorname{Tr} 2$ & $7(1.5 \mathrm{~g})$ & & $5(0.35 \mathrm{~g})$ \\
\hline$?$
\end{tabular}

within the area of Trench 2. However, it could be an indication that some kind of wicker structure or object was burnt in the area of Trench 2 , as willow is the commonest wood type used for wickerwork and would explain why willow is only rarely present in Trench 1.

Heather-type charcoal was common in many of the samples analysed from Dunasbroc. Heather may have grown on the stack itself or could have been collected from the mainland, most probably to be used as fuel, but it can have a multitude of uses including packing, bedding, thatching etc, although there was no evidence for any of these other uses here. Some of the heather may have come from heathy turves, used for fuel or even construction purposes. When wood was in short supply, minerogenic heather turf was often the fuel of necessity in the Highlands and Islands of Scotland, and also formed the main component of walls or wall cores in many marginal environment dwellings (Dickson \& Dickson 2000). There was evidence within the carbonised assemblage from Dunasbroc for the burning of grassy turf, but it was not possible to determine whether this was deliberate burning of collected turves or simply reflected the vegetation colonising the ground surface on which a fire had been built.

Although cereal grains were not commonly found during this study, small numbers of grains were present in at least half of the samples analysed. These were generally six-row barley, with the hulled variety (Hordeum vulgare var vulgare) of this type further identifiable on occasion. Barley has been the commonest cereal type grown in Scotland from the Neolithic to the medieval period, when oats began to dominate. Naked barley (Hordeum vulgare var nudum) was generally grown in the Neolithic period, but was superseded by the hulled variety from the Bronze Age onwards in Scotland. This is thought to be a response by Bronze Age farmers to climatic deterioration because hulled barley was better protected from damp and fungal attack as a result of the grain being enclosed in papery fused glumes whereas the naked, free-threshing variety was prone to fungal infestations. A single grain of $\mathrm{cf}$ emmer/spelt wheat was also recovered but this does not necessarily mean that wheat was being grown as a crop in the area. The wheat may simply have been growing as a weed within the main barley crop. What is certain is that the soil conditions present on the stack would not have been suitable for the growing of crops and therefore the grain must have been transported onto the stack. The lack of crop weed seeds and chaff could suggest that the grain was fully cleaned prior to being brought onto the stack.

\subsection{Conclusions}

The archaeobotanical analyses of the samples taken during the excavation on Dunasbroc stack have shown that much of the plant material, including wood, cereal grains and hazelnuts, must have been transported onto the stack from elsewhere. The presence of cereal grains suggests that either food was being prepared on the stack or cereal grains were being deposited in fires built on the stack, perhaps for ritual purposes. Subsequent AMS radiocarbon dating of material from the excavations at Dunasbroc has produced dates that cluster within two distinct periods. Dating of six-row barley grains from Contexts 004, 005, 006 and 014 indicates that these were all probably deposited during the last four centuries BC. However, AMS radiocarbon dating of charcoal from Contexts 004, 006, 010 and 015 produced dates that cluster around the mid fourth millennium BC, 4,000 years earlier than the cereal grains. This discrepancy between the radiocarbon dating results of cereals and charcoal is difficult to explain. The cereals are obviously later but seem 
to have become mixed with much earlier material, either through accidental percolation down into lower deposits, or through accidental or deliberate mixing of material during the utilisation of the site. It does seem clear that the site underwent two distinct periods of use, four thousand years apart, and that only the latter period of use, in the Iron Age, provides evidence for cereal deposition. 


\section{APPENDIX 7: ANIMAL BONE REPORT FROM DUNASBROC 2005 by Catherine Smith}

\subsection{Introduction}

The excavations at Stac, Lewis, carried out by GUARD in July 2005 recovered a small animal bone assemblage. The bone fragments were generally very small, of the order of a few millimetres in length, while the largest fragment was a cattle molar tooth of approximately $50 \mathrm{~mm}$ length. The majority of the fragments were affected by burning and many were completely calcined to a whitish-grey colour, indicating that they had been exposed to temperatures of at least $645^{\circ} \mathrm{C}$ (Mays 1998, 216). The small fragment size is in part due to exposure to high temperatures, which has caused splitting and shrinkage of both bones and teeth. Despite this damage, the calcined fragments are relatively free of abrasion. However, the unburnt bones from the site are markedly eroded.

\subsection{Method}

Where possible, fragments have been identified as far as species level by direct comparison with modern defleshed material. However, many of the fragments showed no diagnostic characteristics and have been described as 'indeterminate mammal'. Fragments are listed by context in the catalogue.

\subsection{Results (for details see table 15)}

Identified species were cattle and sheep/goat. Particular bones identified were limited to small carpals or tarsals, which, being small and densely structured tend to have a higher recognition rate than fragments of larger long bones. Teeth were also found in a recognisable condition, although some had disintegrated into their component parts, the central pillars or infundibula, and the outer enamel casing. Such deterioration is common when teeth are subjected to high temperatures.

Evidence regarding the age at death of the animals was limited. However, a sheep/goat metapodial fragment consisting only of an unfused distal epiphyses was assumed to have come from a juvenile or immature animal (Context 1, Trench 1, SF3). Similarly, an epiphysis from a cattle calcaneum (tarsal) must also have come from a juvenile or immature beast (Context 5, Trench 1, SF183). A cattle lower third molar assessed at Grant's (1982) stage b in which the fifth cusp (third pillar) was as yet unworn probably came from an animal below the age of five years in modern terms (Context 12, Trench 1, SF156).

An unburnt mammalian bone, probably from a long bone shaft, showed evidence of human modification (Context 2, Trench 1). Although much abraded, knife cuts were apparent on each long edge of the fragment near one of the extremities, which may have been modified to form a rough point or gouge. The knife cuts were orientated in a medio-lateral (side-to-side) direction, at right angles to the longitudinal axis of the bone shaft. Such bone 'scoops' are not unknown at Scottish sites dating to the Iron Age and have been found at sites on Tiree, Orkney and Shetland (Ballin Smith 1994, 174-6).

\subsection{Discussion}

Although the bone assemblage is small and very fragmentary, it provides a few indicators as to the nature of the site. The burning on many of the bones indicates human activity. The simplest explanation is cookery or some other type of food preparation, although disposal of rubbish in a domestic fire is also a possibility. Since sheep/goat and cattle bones were present, it can be assumed that a pastoral economy was practised in the vicinity of the site. There was evidence that individual sheep or goats were killed when juvenile or immature, although this does not necessarily mean that no sheep reached maturity: simply that the evidence did not survive. Cattle may also have been killed or died when immature. This is not surprising given the nature of the site. In subsistence economies, it is often difficult to husband cattle over several winters and selective culling may be necessary in order to eke out scarce winter fodder.

The animal bones from Dunasbroc therefore, provide supporting evidence for human occupation at the site. 


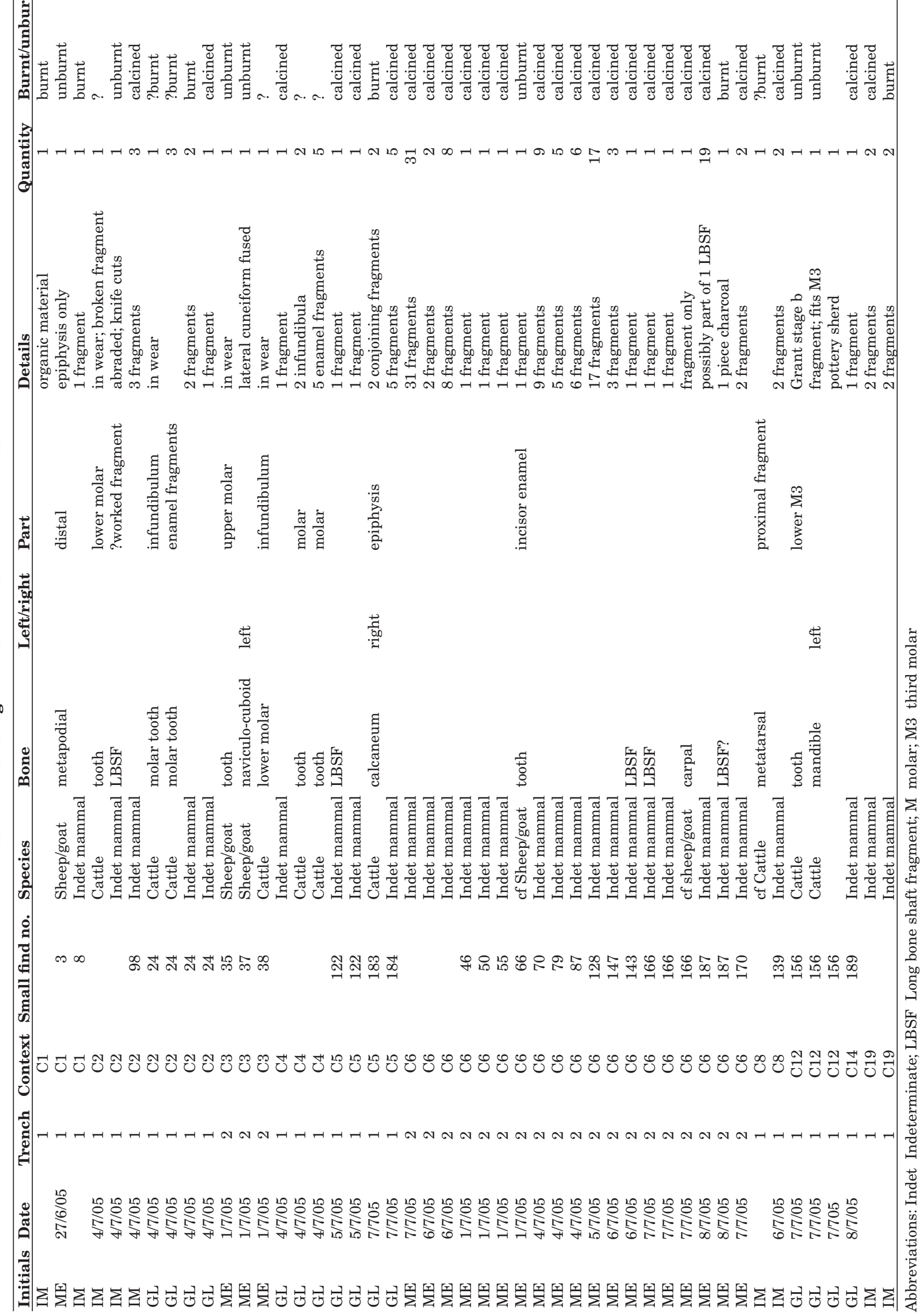




\section{APPENDIX 8: SOIL MICROMORPHOLOGY REPORT FROM DUNASBROC by Jo McKenzie}

\subsection{Introduction}

Analysis of micromorphological soil features is an established technique in archaeology which is not only able to identify anthropogenic features which may not be recognised through excavation, but can also allow these features to be set in context with the natural pedogenetic and disturbance-related processes to which an archaeological site is subject, both during and after its occupation. When coupled with more traditional spatial and stratigraphic archaeological analyses, soil micromorphology can therefore address key archaeological questions on, especially, the mechanics of site formation and the nature of the soils and sediments - and therefore the cultural environment - of the site in question (Davidson \& Simpson 2001).

Dunasbroc is a steep-sided conical stack located at NGR: NB 47136215 off the north-west coast of Lewis, within a generally eroding coastal erosion cell of low rock platform and till cliffs (Barrowman, McHardy \& MacLeod 2004, 28). Archaeological investigation upon the stack identified a range of vestigial structural features including a small plateau formed by natural bedrock and apparently artificially enhanced soil deposits. Excavation indicated that these deposits may have undergone significant heating; however, no directly anthropogenic indicators were recovered from this platform feature. The presence of pottery, stone tools, burnt bone and carbonised materials within other parts of the excavated area attest to a significant anthropogenic presence upon the stack, and offer a range of potential interpretations for the apparent heating activity seen at the platform. Micromorphological analysis of the platform deposits was therefore selected as the most appropriate means of investigating further the nature of this feature, and that of its potential past anthropogenic activity.

Three undisturbed sediment samples were collected in Kubiena tins $(70 \times 50 \times 40 \mathrm{~mm})$ during excavation as follows (McHardy pers comm):

- Sample 1: the 'natural' subsoil adjacent to the platform feature

- Sample 2: the lower area of the platform feature (Context 005 Lower), apparently consisting of slightly reddened natural subsoil

- Sample 3: the near-surface platform deposit (Context 005 Upper), consisting of a highly reddened soil deposit with a more 'clayey' appearance than that seen in Context 005 Lower

The objective of this report is threefold:

- To confirm or disprove that the reddened soil matrix noted during excavation of the platform deposits indicates heating activity
- To assess the extent and nature of anthropogenic inclusions present in the sample set, and thus to comment on possible uses for the platform

- To use the natural subsoil sample provided in Sample 1 to assess the likely origin of the potentially human-influenced soils of Samples 2 and 3, and thus comment on the role of soil redeposition and enhancement in the creation of the platform feature

\subsection{Methodology}

Thin sections were prepared at the Thin Section Micromorphology Laboratory, University of Stirling. All water was removed from the samples by acetone exchange and confirmed by specific gravity measurement. The samples were then impregnated using polyester 'crystic resin type 17449' and the catalyst Q17447 (methyl ketone peroxide, 50\% solution in phthalate). The mixture was thinned with acetone and a standard composition of $180 \mathrm{ml}$ resin, $1.8 \mathrm{ml}$ catalyst and $25 \mathrm{ml}$ acetone used for each Kubiena tin. No accelerator was used but the samples were impregnated under vacuum to ensure complete outgassing of the soil. The impregnated soils were cured for three to four weeks, culminating with four days in a $40^{\circ} \mathrm{C}$ oven. Resin impregnated soils were sliced, bonded to a glass slide and precision lapped to $30 \mu \mathrm{m}$ thickness, then cover-slipped to complete the manufacture of the thin section.

The manufactured thin sections were described using an Olympus BX-50 petrological microscope and by following the procedures of the International Handbook for Thin Section Description (Bullock et al 1985) and the most recent procedures of Stoops (2003). This allows systematic description of soil microstructure, basic mineral components, basic organic components, groundmass and pedofeatures. A range of magnifications $(\times 10-\times 400)$ and light sources (plane polarised, crossed polars and oblique incident) were used to obtain detailed descriptions and these were recorded on a standard table (table 12). Interpretation of the observed features rests on the accumulated evidence of a number of workers, notably Courty et al (1989) and FitzPatrick (1993).

\subsection{Results and discussion}

\subsubsection{Slide 1 - 'Natural'}

This thin section, taken from apparently natural material adjacent to the platform feature, shows a predominantly mineral deposit with a mineralogy 
typical of Lewisian gneiss. Quartz, feldspars and especially biotite predominate, allowing the deposit to be identified as 'biotite-gneiss' (MacDonald et al 2003, 216). This coarse mineral fraction is highly degraded, with quartz and especially biotite generally fragmented. A light brown fine material fraction is seen throughout the deposit, but especially in areas of significant mineral degradation. Although this is dominantly mineral, a small organic fraction is present, with a small amount of degraded plant material and very occasional phytoliths. Towards the base of the slide, some small traces of limpid clay infills are seen. These are a clear orangered with no sign of the organic punctuations which would indicate anthropogenic disturbance, and are probably the result of illuviation. Diagnostic anthropogenic material, such as charcoal, is absent from the deposit, with only very occasional small rounded pieces of black amorphous organic material present. Although these may represent anthropogenic additions, their size and rarity do not indicate human activity as an influence upon this deposit, and the deposit is not heated.

\subsubsection{Slide 2: Context 005}

This thin section, taken from the lower half of the platform feature, clearly separates into four distinct zones within the slide. These are recorded separately in table 11 and are described below.

\section{Zone $2 / \mathrm{a}$}

Zone $2 / \mathrm{a}$ is seen only in the top centimetre of the slide, and could therefore represent a larger area within the platform stratigraphy than suggested in the sample. The coarse mineral fraction is dominated by generally rounded and weathered medium to fine sand-sized quartz grains with frequent small sandstone fragments and little biotite, in clear contrast to the natural material seen in Slide 1. The fine material fraction is denser and more organic than that seen in Slide 1 and shows frequent small organic punctuations, frequent small fragments of parenchymatic tissue and very occasional phytoliths. Although there is little direct evidence for potential anthropogenic activity, with only one small patch of disaggregated black amorphous organic material, the overall matrix of this deposit indicates a degree of material mixing which may represent disturbance, dumping or even construction activity. Towards the centre of the zone, a large discrete patch of almost exclusively fine material - clay to silt-sized mineral with some organic material - stands out within the fine sand matrix. This clayey lump could represent a fragment of construction material and may be related to the building of the platform. Additional small infills of fine, silt-sized material are seen filling void spaces throughout the zone. These are indicative of physical disturbance which again could relate to the construction of the platform.
The clearest evidence for anthropogenic influence within or near to Zone 2/a is, however, seen under oblique incident light, which reveals that the whole of this deposit has seen significant heating. Individual mineral grains, and the whole of the fine material fraction, are reddened to a degree consistent with heating at temperatures around $400^{\circ} \mathrm{C}$ (Simpson et al 2003, 1408). The absence of fuel residue material within both Zone 2/a and the lower zones in this slide suggests that burning activities above the deposit - presumably at the surface of the platform - are the cause of this.

However, the most significant feature of Zone 2/a is its lower boundary, and the contrast between this and the stratigraphy of the zones below it. Zones $2 / \mathrm{b}, 2 / \mathrm{c}$, and $2 / \mathrm{d}$ show sloping, diffuse boundaries whose angles echo the lamination seen within each zone, and are reminiscent of the sloping, laminated, dominantly mineral matrix seen in natural deposit Slide 1. By contrast, Zone 2/a shows a clear, horizontal boundary which cuts across the parallel slopes of Zones $2 / \mathrm{b}$ and $2 / \mathrm{d}$. It would seem that the lower boundary of Zone 2/a represents a truncation of these lower zones, and that deposit 2/a itself therefore represents a clear redeposition episode. As discussed below and in the Conclusion, thin section evidence points to this as the clearest point of primary construction activity within the platform stratigraphy.

\section{Zone $2 / \mathrm{b}$}

Sealed by Zone 2/a, Zone 2/b extends from just inside the right-hand edge of Slide 2 to beyond its left-hand extent, sloping to this left to a maximum depth of $3.5 \mathrm{~cm}$. The coarse mineral fraction is much coarser than at Zone 2/a, and consists of coarse sand-sized quartz, feldspar and biotite arranged in repeated laminations which follow the slope of the deposit. These show frequent weathering. The fine fraction is mixed: largely mineral, but with some areas of denser, darker organomineral material which show some iron accumulation. There are some parenchyma and phytoliths. There is no direct evidence for anthropogenic activity, apart from possibly the two small, grey, crypto-crystalline features similar in appearance to those seen in Slide 3 (see Zone $3 / \mathrm{b})$. Like Zone $2 / \mathrm{a}$, the soil matrix shows heating, possibly to a slightly lesser extent than that seen above.

The mineralogy and material arrangement of Zone $2 / \mathrm{b}$ suggests that this deposit is, unlike the zone above, very similar to that seen in Slide 1 and represents degraded and probably disturbed biotitegneiss bedrock.

\section{Zone $2 / \mathrm{c}$}

Zone $2 / \mathrm{c}$ is a small lens of material present in the lower left-hand side of the slide and sealed by Zone $2 / \mathrm{b}$. The coarse mineral fraction is finer, shows less biotite, and is paler and less iron-rich than Zone 
$2 / \mathrm{b}$, however, the angle of slope of the deposit and its (less pronounced) internal lamination are more or less parallel with that seen in Zone $2 / \mathrm{b}$, suggesting that, like $2 / \mathrm{b}$, this is potentially a degraded gneiss bedrock deposit. Areas of fine organomineral material are larger and more frequent, and there are more degraded plant fragments than seen above, and occasional phytoliths. Anthropogenic material is absent, and, like the lower area of Zone 2/d (below), the soil matrix of Zone 2/c does not appear to have been heated. It would seem that the effect of heating from activities on the top of the platform extends only into the upper half of Slide 2.

\section{Zone $2 / \mathrm{d}$}

This is the largest of the three lower zones in Slide 2 , sealed at the top right-hand of the slide by Zone 2/a and sloping downward to fill the lower area of the slide. The coarse mineral fraction is dominated by very coarse sand-sized quartz grains and biotite accumulations which are strongly laminated and packed together to form a compact, largely singlegrain structure very similar to the degraded bedrock of Slide 1 . Although there is once again very little evidence for anthropogenic activity, with only very occasional small amorphous carbonised fragments, there is stronger evidence for some physical disturbance. Within areas of more degraded coarse mineral material, accumulations of fine organomineral material show some signs of faunal activity, with occasional spheroidal excrements. These are associated with some small organic coatings on single quartz grains. Several small and fractured limpid clay coatings and infills are seen within areas of degraded biotite. Towards the base of the zone, organomineral material becomes slightly more frequent, with small patches of dark brown colloidal material, and the deposit has a darker, more iron-rich appearance. Several large parenchyma fragments are seen near the top of the zone. In oblique incident light, the upper half of the zone is strongly heated, but this quickly lessens down-slide, and the base of Zone 2/d appears unheated. Like Zones 2/b and 2/c, Zone $2 / \mathrm{d}$ appears to be directly derived from the natural gneiss bedrock seen in Slide 1, showing disturbance and some mixing with finer organomineral material but little actual anthropogenic influence.

\subsubsection{Slide 3: Context 005}

Slide 3 is taken through the upper half of platform Context 005. Unlike Slide 2, in thin section this sample appears largely homogeneous with, however, a small discrete lens (Zone 3/a) at the top of the slide, and one towards the base (Zone $3 / \mathrm{c}$ ).

\section{Zone 3/a}

This is a thin (max. 2mm depth) lens of light-brown, silty organomineral material which is seen at the very top of Slide 3. Zone 3/a shows frequent disaggregated cell residue material, fungal spores, and frequent parenchyma, some of which show some horizontal lamination. Much of the groundmass consists of small, spherical faunal excrements, indicating considerable biological reworking. Anthropogenic indicators are absent; however, oblique incident light shows this area, like the rest of Slide 3, to have been subject to considerable heating (see below).

It is likely that this material, with its frequent plant residues, is related to the present-day surface, perhaps brought into the soil profile by worms or other soil fauna.

\section{Zone $3 / \mathrm{b}$}

Zone $3 / \mathrm{b}$ is the most extensive single deposit in the sample sequence, taking up (with the exception of the two small lenses 3/a and 3/c) the whole of Slide 3 . The coarse mineral fraction is composed mainly of fine to medium sand-sized and weathered quartz and feldspars, and frequent small sandstone fragments. Biotite is relatively rare, and thus there is a contrast between this deposit and both the natural material in Slide 1 and what has been interpreted as natural-derived material seen in the lower three deposits in Slide 2. The mineralogy of Zone 3/a is more similar to that seen in the topmost section of Slide 2 , above that point at which the more natural material is truncated. Zone $3 / \mathrm{b}$ appears to represent deliberately introduced material which is not directly related to the surrounding natural, and has undergone considerable weathering.

The appearance of the fine fraction of the groundmass is also consistent with a dumped deposit. This is mixed and turbated, consisting of a mix of mineral and organomineral material ranging from light to dark brown to grey, with the lighter areas showing a slightly higher incidence of degraded plant fragments with occasional fungal spores. However, no phytoliths are recorded, although this could be related to the denser organomineral fraction present in this deposit. Textural pedofeatures consistent with physical movement and disturbance are also present, with fine silt material infilling several larger voids and some small clay infills present.

However, as in the more 'natural' deposits recorded in Slides 1 and 2, clear evidence for anthropogenic activity is still minimal. There are very occasional small amorphous fragments of carbonised material, and some small fragments of brown organic material that could be degraded peat (illus 69a). The most significant evidence for anthropogenic influence on the deposit is seen under oblique incident light, where the whole of the slide is seen to have been strongly heated. The strong red colouration seen here indicates a slightly higher heating temperature than that seen in Slide 2, probably above $400^{\circ} \mathrm{C}$, but not above $800^{\circ} \mathrm{C}$ (at which point the deposit would take on a yellow-white colour; Simpson et al 2003, 1408). The absence of fuel residue deposits such as charcoal or burnt peat in this slide to complement 

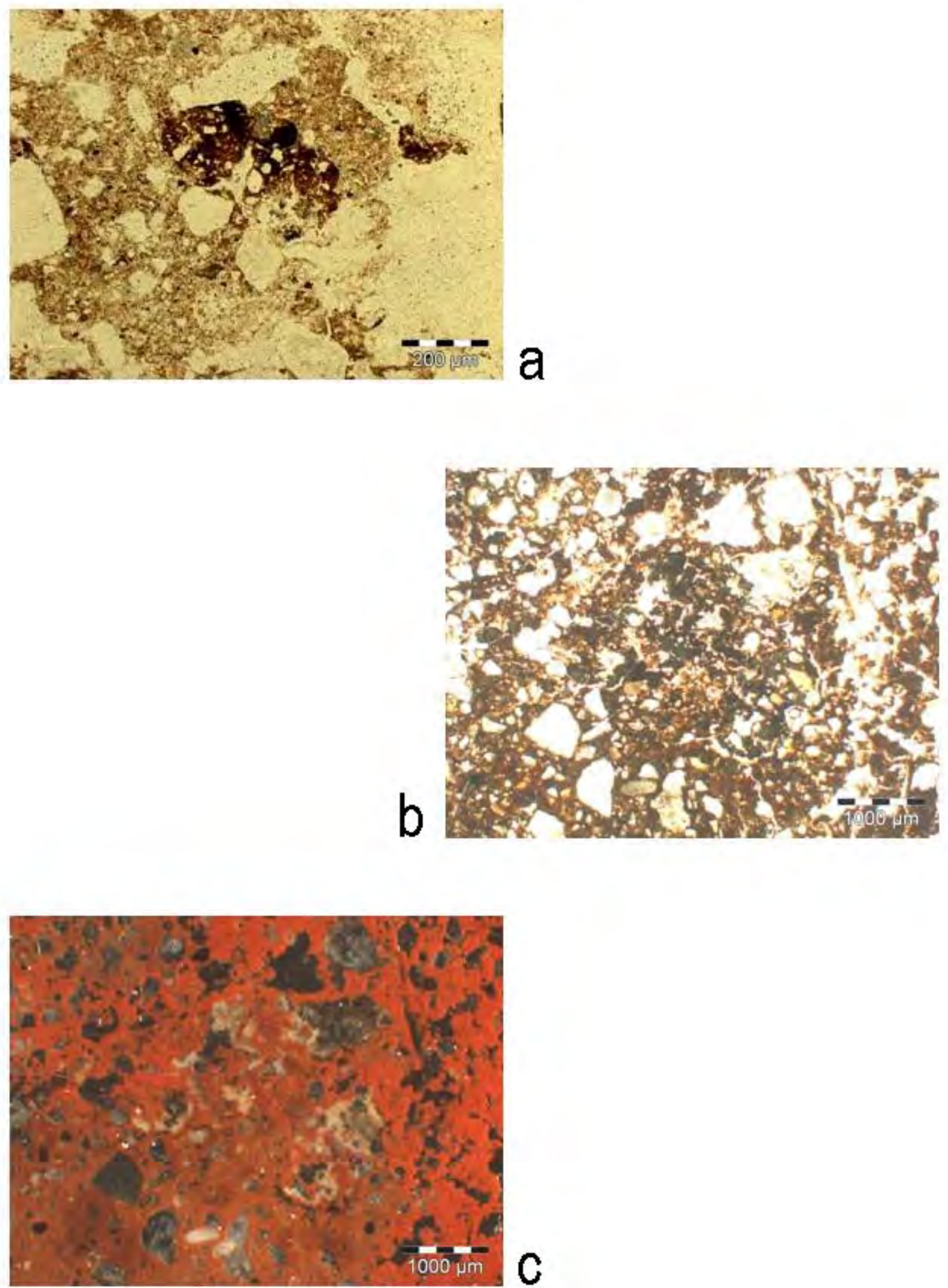

Illus 69a Zone 3/b: brown amorphous material, possibly an unburnt peat fragment. Plane polarised light. Illus $69 \mathrm{~b}$ Zone $3 / \mathrm{b}$ : grey crypto-crystalline features possibly representing fuel residue materials. Plane polarised light.

Illus 69c Zone 3/b: as above, in oblique incident light. Bright yellow-white colour of possible fuel residue indicates high temperature heating. Note extensive reddening of surrounding soil matrix, indicative of comprehensive heating at c $400-500^{\circ} \mathrm{C}$. 
such evidence for intensive heating is unusual. Bone, burnt or otherwise, is also absent.

The most interesting feature of Zone $3 / \mathrm{b}$ is seen midway down the slide at the centre of the deposit. This is a patch of several small, rounded pieces of crypto-crystalline material which are pale grey in plane polarised light (illus 69b) and have a slight 'glow' in crossed polars. Under oblique incident light, these features are a bright yellow-white, and are clearly more highly heated than the surrounding soil matrix (illus 69c). These are similar in appearance to distinctive suites of features noted in urban and semi-rural anthropogenic soil contexts, where they appear closely related to fuel residues connected with industrial and domestic heating processes, such as clinker (McKenzie 2006). Their presence in this context is intriguing, and further investigation of, for example, their elemental composition, would be a worthwhile addition to further research into the nature of the platform deposits.

\section{Zone 3/c}

This is a small, elliptical-shaped lens of fragmented clay/silt material extending for about two centimetres within the lower half of Slide 3. It is therefore contained within Zone $3 / \mathrm{b}$ and is essentially an inclusion within that deposit, albeit one large enough to merit separate recording. Although occasional (mainly quartz) individual mineral grains are present, this area mainly consists of fine silt and clay which appears to have been introduced as a discrete 'clod' of densely packed material. Several large cracks running through this zone only indicate some drying and shrinkage, which presumably occurred prior to deposition. There are no anthropogenic indicators present. It is possible that this lens represents a lump of construction material similar to that seen in Zone 2/a.

\subsection{Conclusions}

The three thin section samples from the Dunasbroc site provide an interesting and somewhat unexpected insight into both the construction of the platform feature and the possible circumstances of its use.

The first of the three questions posed in the Introduction - have the platform deposits been heated? - is clearly answered by the appearance of Slides 2 and 3 under oblique incident light. Their highly reddened appearance under this light source is consistent with heating at temperatures around $400^{\circ} \mathrm{C}$ (eg illus 69c). Furthermore, the nature of these colour changes - more intensely red at the top of the sequence and gradually lessening into Slide 2 - indicates that the source of this heating was at the platform surface.

This leads to the second question - what evidence can micromorphological investigation provide for human activity on the platform? With such strong evidence for significant heating at the top of the platform, frequent inclusions of fuel residue materials, such as charcoal or burnt peat alongside numerous more amorphous carbonised fragments, would be expected. However, these features are almost entirely absent from the sample set. In addition, unburnt inclusions indicative of human activity - such as the bone in evidence elsewhere on the site, or unburnt fuel and construction materials such as peat or turf - are also almost absent. This suggests that the platform area was not one in which 'everyday' activities were undertaken, and is likely to have been separate from any activity area at the Dunasbroc site. Furthermore, any residues of the burning activities that were undoubtedly undertaken on the platform appear to have been comprehensively removed quite quickly after the event, certainly before they could be incorporated into the material of Context 005 by, for example, faunal or weathering processes. Such removal could either have been deliberate or as a result of windblow on this exposed stack.

The only potential indicators for specific human activity on the platform are the small inclusions of possible fuel residue material seen in Zone $3 / \mathrm{b}$. Although small and fragmentary, these strongly resemble a type of material inclusion noted in anthropogenic soils associated with fuel residues from highly heated contexts such as industrial furnaces. Previously seen only in urban-influenced, postmedieval contexts, the appearance of such features at a site of this type is interesting, and further characterisation of these features could provide an interesting addition to the site interpretation.

The final objective of this analysis was to investigate the nature of the soil material making up the platform structure, and the relationship of this to the 'natural' soil sample provided by Slide1. Here, some interesting observations can be made. Firstly, clear differences between the mineralogy and internal structure of the Lewisian gneiss deposit seen in Slide 1 and the platform deposits of Slides 2 and 3 indicate that the platform itself is indeed artificially constructed. However, it would appear that the extent of the platform sampled in Slides 2 and 3 represents two distinct phases of construction, within which different soil materials from different areas of the stack were used to build up the platform area. The boundary between these two phases is clearly marked in the upper area of lower Slide 2. Below this boundary, three broadly similar deposits of material which appear to be disturbed and probably redeposited natural are seen. They show the lowest incidence of anthropogenic inclusions and are similar in mineralogy to the natural material sampled at Slide 1. The uppermost of these sloping, laminated deposits is abruptly and horizontally truncated by a distinctly different dump of material whose mineralogy indicates that it is not redeposited natural material from the immediate vicinity. Similar dumped material is seen throughout upper Slide 3 . In both slides, the mineralogy of this upper 
material shows intensive weathering, dominated by small rounded quartz grains and with biotite largely absent. While still showing only minimal evidence for fuel residue material, in both slides, this dumped material contains large inclusions of dense, clayey material, possibly constructional. To interpret: it would appear that the lower part of the platform was constructed by redeposition of local soil and degraded gneiss bedrock. There is evidence that this may have been levelled before the introduction of finer, weathered, surface soil material, possibly from elsewhere on the stack, to further build up the platform. This upper element may have been strengthened, shaped or consolidated through the use of daub-like clay and silt material packed into and possibly around the platform structure. 